\title{
Characterization and Monitoring
} of $\mathbf{3 0 0}$ Area Facility Liquid Waste Streams: 1994 Annual Report
R. G. Riley
K. B. Olsen
M. Y. Ballinger
R. M. Ozanich
E. G. Damberg
C. J. Thompson
J. C. Evans
H. R. Vogel
J. L. Julya

April 1995

Prepared for the U.S. Department of Energy under Contract DE-AC06-76RLO 1830

Pacific Northwest Laboratory Operated for the U.S. Department of Energy by Battelle Memorial Institute 


\title{
DISCLAIMER
}

This report was prepared as an account of work sponsored by an agency of the United States Government. Neither the United States Government nor any agency thereof, nor Battelle Memorial Institute, nor any of their employees, makes any warranty, expressed or implied, or assumes any legal liability or responsibility for the accuracy, completeness, or usefulness of any information, apparatus, product, or process disclosed, or represents that its use would not infringe privately owned rights. Reference herein to any specific commercial product, process, or service by trade name, trademark, manufacturer, or otherwise does not necessarily constitute or imply its endorsement, recommendation, or favoring by the United States Government or any agency thereof, or Battelle Memorial Institute. The views and opinions of authors expressed herein do not necessarily state or reflect those of the United States Government or any agency thereof.

\author{
PACIFIC NORTHWEST LABORATORY \\ operated by \\ BATTELLE MEMORIAL INSTITUTE \\ for the \\ UNITED STATES DEPARTMENT OF ENERGY \\ under Contract DE-AC06-76RLO 1830
}

Printed in the United States of America

Available to DOE and DOE contractors from the

Office of Scientific and Technical Information, P.O. Box 62, Oak Ridge, TN 37831; prices available from (615) 576-8401. FTS 626-8401.

Available to the public from the National Technical Information Service, U.S. Department of Commerce, 5285 Port Royal Rd., Springfield, VA 22161. 


\section{Characterization and Monitoring of 300 Area Facility Liquid Waste Streams: 1994 Annual Report}
R. G. Riley
M. Y. Ballinger
E. G. Damberg
J. C. Evans
J. L. Julya
K. B. Olsen
R. M. Ozanich
C. J. Thompson
H. R. Vogel
Technical Editor
K. L. Manke

April 1995

Prepared for

the U.S. Department of Energy

under Contract DE-AC06-76RLO 1830 


\section{Abstract}

The Effluent Monitoring Program characterizes and monitors liquid waste streams from 300 Area buildings owned by the U.S. Department of Energy and managed by the Pacific Northwest Laboratory. ${ }^{\text {(a) }}$ This program is managed by the Pacific Northwest Laboratory. This report summarizes the results of characterizing and monitoring the following sources during calendar year 1994 (the first year of the program): liquid waste streams from Buildings 306, 320, 324, 326, 331, and 3720; treated and untreated Columbia River water (influent); and water at the confluence of the waste streams (that is, end-of-pipe). Data were collected from March to December before the sampling system installation was completed. Data from this initial part of the program are considered tentative.

Samples collected were analyzed for chemicals, radioactivity, and general parameters. In general, the concentrations of chemical and radiological constituents and parameters in building wastewaters which were sampled and analyzed during CY 1994 were similar to historical data. Exceptions were the occasional observances of high concentrations of chloride, nitrate, and sodium that are believed to be associated with excursions that were occurring when the samples were collected. Occasional observances of high concentrations of a few solvents also appeared to be associated with infrequent building releases.

During calendar year 1994, nitrate, aluminum, copper, lead, zinc, bis(2-ethylhexyl)phthalate, and gross beta exceeded U.S. Environmental Protection Agency maximum contaminant levels or the Treated Effluent Disposal Facility's National Pollution Discharge Elimination System permit limits on a frequent or occasional bases at end-of-pipe. Phthalates are suspected to be artifacts of sampling. The metals are also suspected to be a result of artifacts introduced during the sample collection and analysis process and/or leaching of residuals associated with the aged building and sewer piping systems.

Concentrations and clearance times for contaminants at end-of-pipe depended strongly on the source concentration at the building release point, waste stream flow rates, dispersion, and the mechanical action of sumps. When present, the action of sumps had the greatest impact on contaminant clearance times. In the absence of sump activity, dispersion and flow rate were the controlling factors.

Initial field evaluations of a transportable gas chromatograph/mass spectrometer, adsorptive stripping voltametry, solid phase extraction, and continuous monitoring of $\mathrm{pH}$, flow, and conductivity were favorable. Future plans call for integrating the gas chromatographic capabilities with continuous monitoring of $\mathrm{pH}$, conductivity, and flow to allow greater clarification of building waste stream chemistry during excursions.

(a) The Pacific Northwest Laboratory is operated by the Battelle Memorial Institute under Contract DE-AC06-76RLO 1830. 
. 


\section{Executive Summary}

Liquid effluent streams from six U.S. Department of Energy-owned and Pacific Northwest Laboratory-operated buildings (306, 320, 324, 326, 331, and 3720), end-ofpipe, and influent in the 300 Area of the Hanford Site were monitored for six general classes of parameters. Conclusions were drawn from the data generated from the analysis of mostly 24-hr composite samples collected one to two times a month from waste streams. However, at the most, this sampling practice leads to monitoring less than 3 to $6 \%$ of the effluent discharged from a building over the course of 1 month. Also, this was the initial sampling performed on sampling systems that were being installed in the facilities. Sampling system installations were not completed until 1995 and the data presented in this report are considered tentative.

Elevated concentrations of general chemical parameters, ammonia and anions, and. volatile organic compounds appeared more frequently in the waste streams of Buildings 326,331 , and 3720 than in the waste streams of other buildings (i.e., 306, 320, and 324). Occasional elevated levels of sodium, chloride, phosphate, and pH were observed at end-of-pipe.

Chlorination of influent (Columbia River water) introduces volatile byproducts (i.e., chloroform, bromoform, bromodichloromethane, and dibromochloromethane) into building source water at levels slightly higher than those observed in the building effluents. Observed concentrations ranged from 0.5 to $40 \mu \mathrm{g} / \mathrm{L}$ in building waste streams and 0.9 to $20 \mu \mathrm{g} / \mathrm{L}$ at end-of-pipe. The observed concentration range for all four trihalomethanes at end-of-pipe was below the U.S. Environmental Protection Agency (EPA) maximum contaminant level (MCL) of $100 \mu \mathrm{g} / \mathrm{L}$.

Six other volatile halogenated hydrocarbons (i.e., 1,1,1-trichloroethane, 1,1,2-trichloroethane, 1,2-dichloroethylene, trichloroethene, tetrachloroethene, and trichlorofluoromethane) were detected infrequently in building waste streams and end-of-pipe at trace levels $(0.6$ to $2 \mu \mathrm{g} / \mathrm{L})$. None of the observed levels of these compounds exceeded EPA MCLs or National Pollutant Discharge Elimination System (NPDES) permit limits for the Treated Effluent Disposal Facility.

Elevated levels (24 to $40,800 \mu \mathrm{g} / \mathrm{L}$ ) of volatile organic solvents (i.e., acetone, acetonitrile, tetrahydrofuran, toluene, 2-butanone, hexone, ethanol, and isopropanol) were occasionally observed in waste streams from Buildings $320,326,331$, and 3720 and at end-of-pipe. It is postulated that these observances are associated with infrequent building releases.

In general, metals were detected at trace levels (generally from 0.1 to $10 \mu \mathrm{g} / \mathrm{L}$ ). Their presence is suspected to be the result of artifacts introduced during the sample collection and analysis process and/or leaching of residuals associated with the aged buildings and sewer piping systems. 
Pesticides were found in the effluents of Buildings 326 and 331 but for the most part were detected at extremely trace levels (i.e., $<20 \mathrm{ng} / \mathrm{L}$ ). Phthalates were also detected in several building effluents (i.e., 326, 331, 3720). Bis(2-ethylhexyl)phthalate was detected at end-of-pipe at levels above the EPA MCL of $6 \mu \mathrm{g} / \mathrm{L}$. Phthalates are suspected to be a largely unavoidable artifact of sampling.

Building 3720 effluent had gross alpha radiation levels consistently in the range of 4 to $45 \mathrm{pCi} / \mathrm{L}$ while other buildings and end-of-pipe had much lower levels (1 to $4 \mathrm{pCi} / \mathrm{L}$ ). For all locations, the average gross beta activity was in the range of 3.5 to $7.4 \mathrm{pCi} / \mathrm{L}$. Tritium was frequently detected in the effluent from Buildings 306, 324 (process and retention process sewer), 326 , and 331 in the range of 118 to $687 \mathrm{pCi} / \mathrm{L}$. Tritium was also detected once at end-of-pipe at an activity level of $227 \mathrm{pCi} / \mathrm{L}$.

On occasion, gross alpha and/or gross beta radiological activity in samples slightly exceeded EPA MCL at Buildings 306, 324, 331, and 3720.

In general, concentrations of chemical and radiological constituents and parameters in wastewaters sampled and analyzed during calendar year (CY) 1994 were similar to historical data. Exceptions were the occasional observances of high concentrations of chloride, nitrate, and sodium that are believed to be associated with excursions that were occurring at the time that samples were being collected.

During CY 1994, nitrate, aluminum, copper, lead, zinc, bis(2-ethylhexyl)phthalate, and gross beta exceeded EPA MCLs or Treated Effluent Disposal Facility NPDES permit limits on a frequent or occasional basis at end-of-pipe.

Concentrations and clearance times at end-of-pipe were highly dependent on waste stream flow rates, dispersion, and the mechanical action of sumps. When present, the sumps had the greatest impact on clearance times. In the absence of sump activity, dispersion and flow rate were the controlling factors.

Initial evaluations of field transportable gas chromatography/mass spectrometry, adsorptive stripping voltametry, solid phase extraction, and continuous monitoring of flow, $\mathrm{pH}$, and conductivity were favorable. These technologies illustrated the highly variable nature of the effluent streams and the potential to improve current characterization practices. 


\section{Contents}

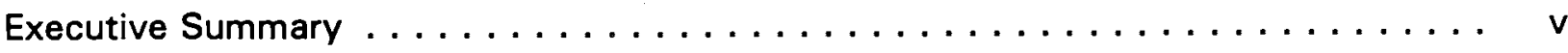

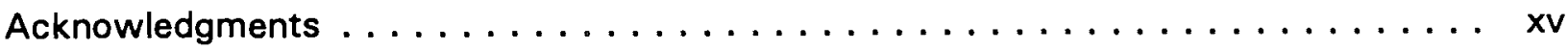

Acronym and Abbreviation List $\ldots \ldots \ldots \ldots \ldots \ldots \ldots \ldots \ldots \ldots \ldots \ldots \ldots \ldots \ldots \ldots$

Trademarks Used $\ldots \ldots \ldots \ldots \ldots \ldots \ldots \ldots \ldots \ldots \ldots \ldots \ldots \ldots \ldots \ldots \ldots$ xiii

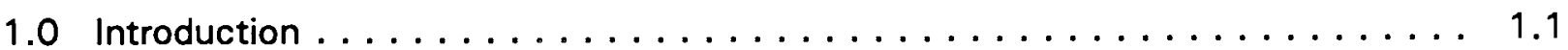

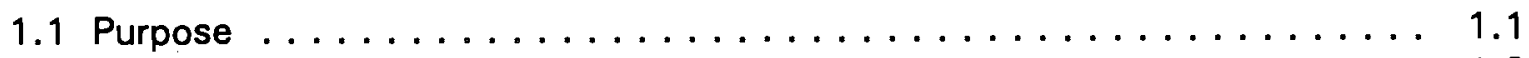

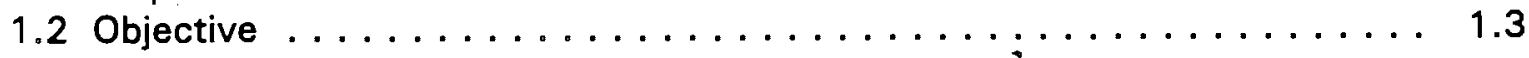

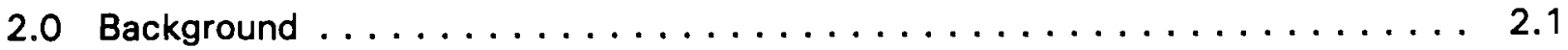

3.01994 Liquid Waste Stream Characterization and Monitoring . . . . . . . . . . . 3.1

3.1 Sample Types and Dates of Collection . . . . . . . . . . . . . 3.1

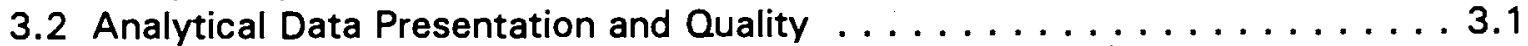

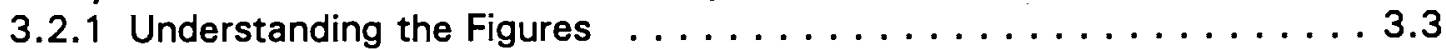

3.2 .2 Quality Assurance and Quality Control . . . . . . . . . . 3.3

3.2 .3 Quality Control Data . . . . . . . . . . . . . . . 3.4

3.2.4 Influent Chemistry (Untreated, Treated, Alternate) . . . . . . . . 3.6

3.2.5 Data Limitations . . . . . . . . . . . . . . . . . . 3.7

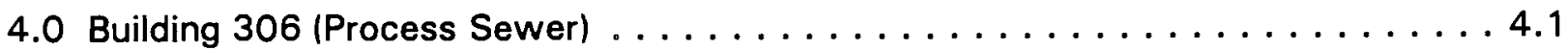

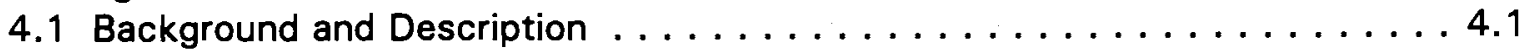

4.2 Routine Sampling . . . . . . . . . . . . . . . . 4.1

4.2.1 General Chemical Parameters . . . . . . . . . . . . 4.1

4.2 .2 Ammonia and Anions . . . . . . . . . . . . . 4.1

4.2 .3 Metals ......................... 4.2

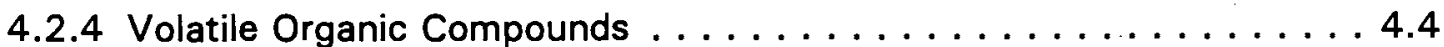

4.2.5 Semivolatile Organic Compounds . . . . . . . . . . . . . . 4.4

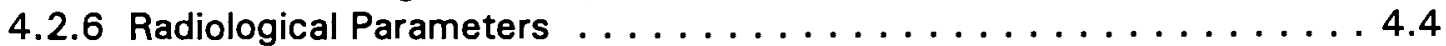

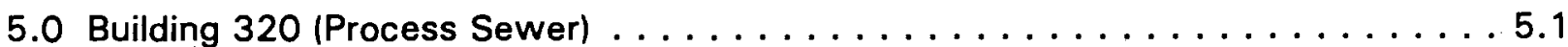

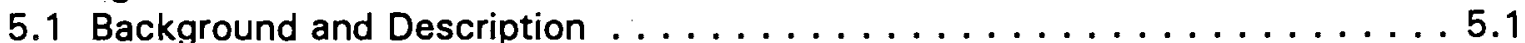

5.2 Routine and Nonbusiness Day Sampling . . . . . . . . . . . . . . . 5.1

5.2.1 General Chemical Parameters . . . . . . . . . . . . . . . 5.1

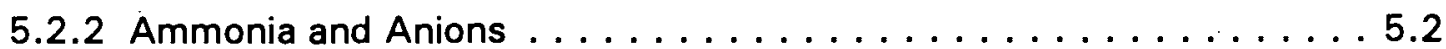

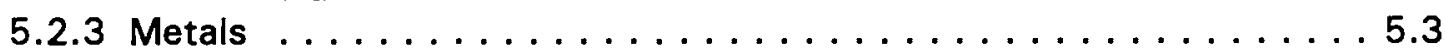

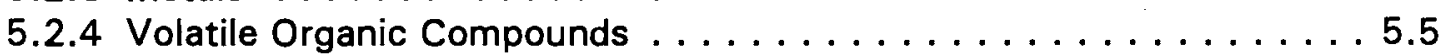

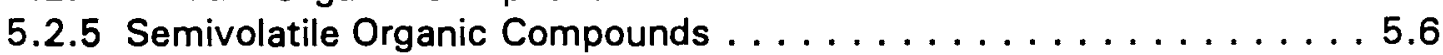

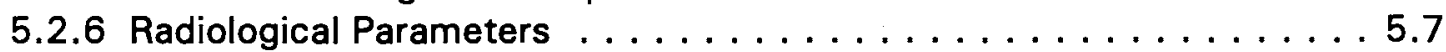


6.0 Building 324 (Process Sewer and Retention Process Sewer) . . . . . . . . . . 6.1

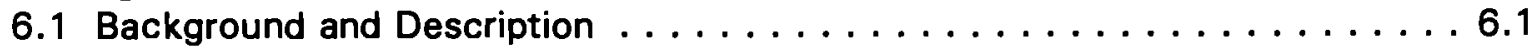

6.2 Routine Sampling . . . . . . . . . . . . . . . . . 6.1

6.2.1 General Chemical Parameters . . . . . . . . . . . . . 6.1

6.2 .2 Ammonia and Anions . . . . . . . . . . . . . . 6.2

6.2 .3 Metals ......................... 6.3

6.2 .4 Volatile Organic Compounds . . . . . . . . . . . 6.4

6.2 .5 Semivolatile Organic Compounds . . . . . . . . . . . . 6.4

6.2 .6 Radiological Parameters . . . . . . . . . . . . . 6.4

7.0 Building 326 (Process Sewer) . . . . . . . . . . . . . . . . 7.1

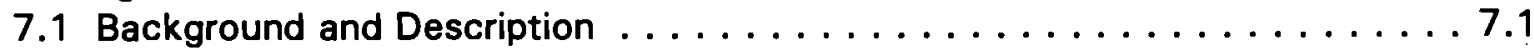

7.2 Routine Sampling . . . . . . . . . . . . . . . . . 7.1

7.2.1 General Chemical Parameters . . . . . . . . . . . . . . 7.1

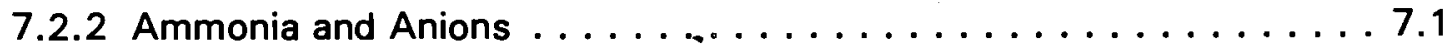

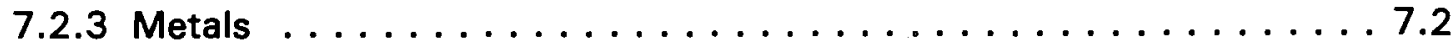

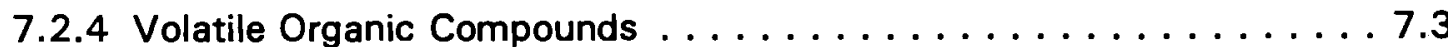

7.2 .5 Semivolatile Organic Compounds . . . . . . . . . . . . . . 7.4

7.2.6 Radiological Parameters . . . . . . . . . . . . . 7.4

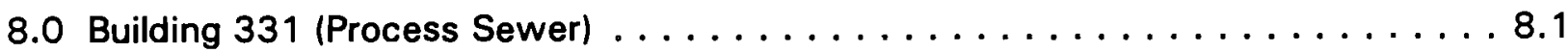

8.1 Background and Description . . . . . . . . . . . . . . 8.1

8.2 Routine and Nonbusiness Day Sampling . . . . . . . . . . . . 8.1

8.2.1 General Chemical Parameters . . . . . . . . . . . . 8.1

8.2.2 Ammonia and Anions . . . . . . . . . . . . . 8.2

8.2 .3 Metals . . . . . . . . . . . . . . . . . . 8.4

8.2.4 Volatile Organic Compounds . . . . . . . . . . . . 8.6

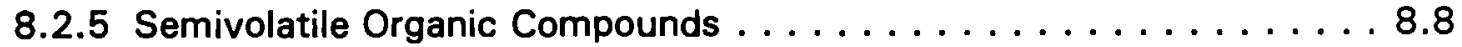

8.2.6 Radiological Parameters . . . . . . . . . . . . . . 8.9

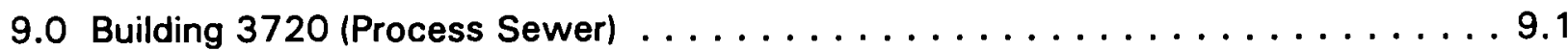

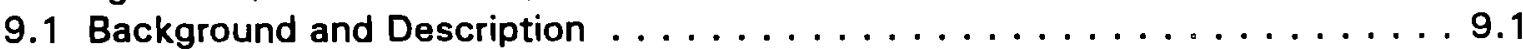

9.2 Routine and Nonbusiness Day Sampling . . . . . . . . . . . . . . . 9.1

9.2.1 General Chemical Parameters . . . . . . . . . . . . . . . . . . 9.1

9.2 .2 Ammonia and Anions . . . . . . . . . . . . . 9.2

9.2 .3 Metals . . . . . . . . . . . . . . . . . . 9.3

9.2 .4 Volatile Organic Compounds . . . . . . . . . . . . . 9.5

9.2 .5 Semivolatile Organic Compounds . . . . . . . . . . . . . 9.7

9.2.6 Radiological Parameters . . . . . . . . . . . . . 9.8

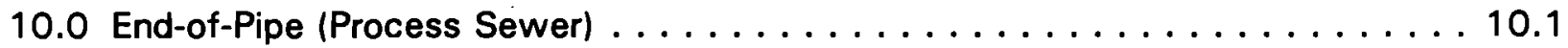

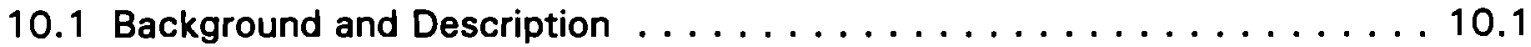

10.2 Routine and Nonbusiness Day Sampling . . . . . . . . . . . . 10.1

10.2.1 General Chemical Parameters . . . . . . . . . . . . . . 10.1

10.2.2 Ammonia and Anions . . . . . . . . . . . . . 10.2 


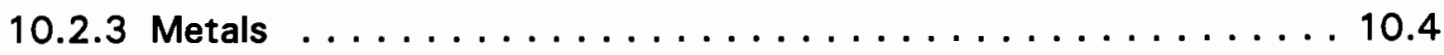

10.2.4 Volatile Organic Compounds . . . . . . . . . . . . . 10.5

10.2.5 Semivolatile Organic Compounds . . . . . . . . . . . . . . 10.7

10.2.6 Radiological Parameters . . . . . . . . . . . . . 10.8

10.3 Comparison of CY 1994 End-of-Oioe Data to Historical Information $\quad 10.9$

10.4 Comparison of CY 1994 End-of Pipe Data to Regulatory . . . . . . . . 10.9

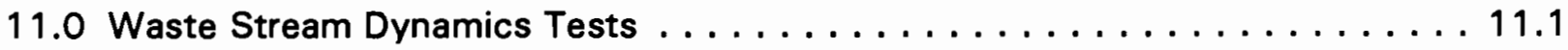

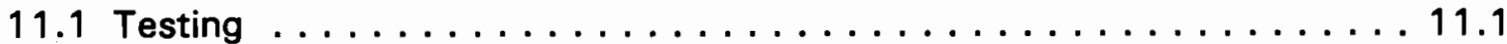

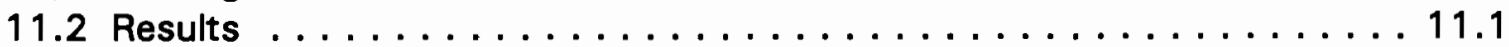

11.2.1 Arrival Times and End-of-Pipe Transit Times . . . . . . . . . 11.2

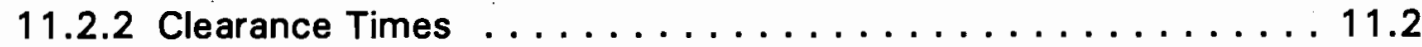

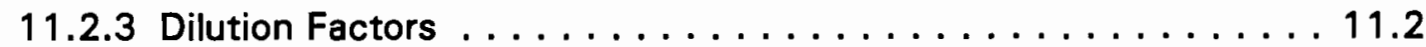

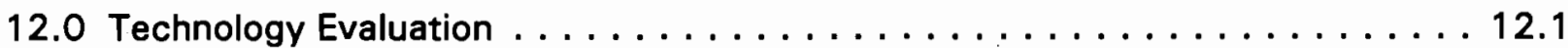

12.1 Gas Chromatograph/Mass Spectrometer . . . . . . . . . . . . 12.1

12.1.1 Methods Development and Analysis of Water Samples . . . . . 12.1

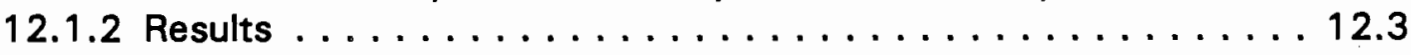

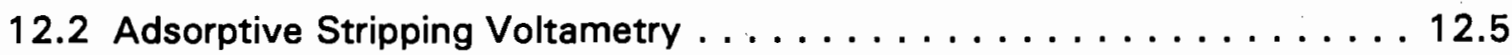

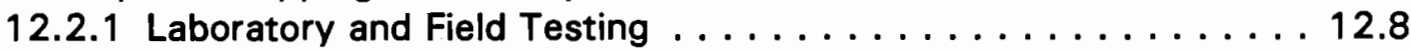

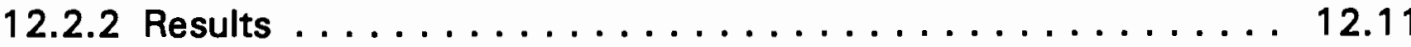

12.3 Solid Phase Extraction . . . . . . . . . . . . . . . . . 12.11

12.3.1 Methods Development . . . . . . . . . . . . . . 12.11

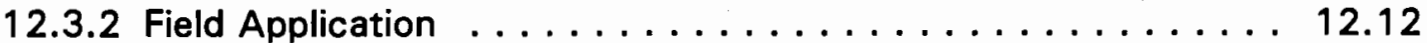

12.4 Continuous Monitoring Systems . . . . . . . . . . . . . . . . 12.13

12.4.1 Stand-Alone Data Logging System . . . . . . . . . . . . . . . 12.13

12.4.2 Preliminary Results . . . . . . . . . . . . . . . . . . 12.13

12.4.3 Future Plans . . . . . . . . . . . . . . . . . 12.14

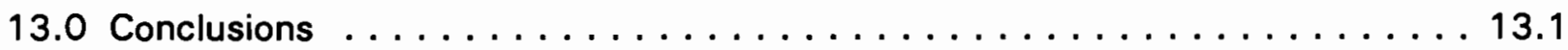

13.1 General Chemical Parameters . . . . . . . . . . . . . . 13.1

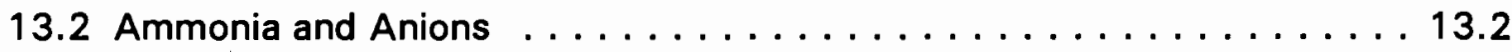

13.3 Metals . . . . . . . . . . . . . . . . . . . . 13.3

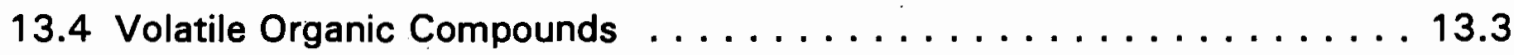

13.5 Semivolatile Organic Compounds . . . . . . . . . . . . . 13.4

13.6 Radiological Parameters . . . . . . . . . . . . . . . . . . . . 13.4

13.7 Comparison of CY 1994 End-of-Pipe Data to Historical Information

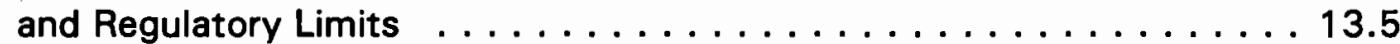

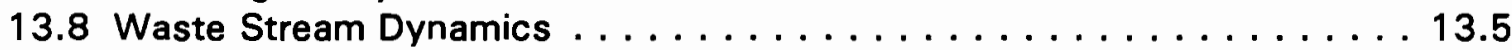

13.9 Program Development . . . . . . . . . . . . . . . . . . 13.5

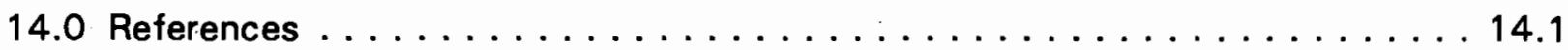

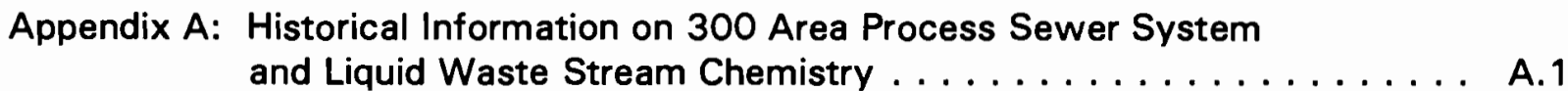

Appendix B: Parameter and Constituent Selection and Monitoring Process . . . . . . B.1 
Appendix C: Description of Sampling and Analysis Processes and Capabilities _. . . C.1

Appendix D: Quality Control Data: Sample Blanks and Duplicate Samples . . . . . D.1

Appendix E: Data on Influent Water Chemistry . . . . . . . . . . . . E.1

Appendix F: Detailed Tabular Information on the Parameters and Constituents

Detected in Buildings 306, 320, 324, 326, 331, 3720 and End-of-Pipe F.1

Appendix G: Glossary . . . . . . . . . . . . . . . . . G.1 


\section{Figures}

1.1 Location of Pacific Northwest Laboratory-Operated Buildings

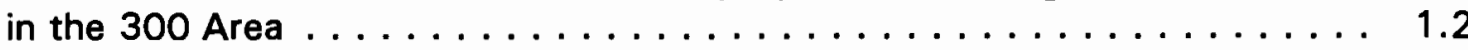

3.1 Location of Facility Sampling Stations, Source Water, and End-of-Pipe $\ldots . .3 .2$

3.2 Example Figure Showing the Frequencies of Detection and the Average, Minimum, and Maximum Concentrations of Detected

Parameters and Constituents $\ldots \ldots \ldots \ldots \ldots \ldots \ldots \ldots \ldots$

4.1 Building 306 General Chemical Parameters . . . . . . . . . . . . 4.1

4.2 Building 306 Ammonia and Anions . . . . . . . . . . . . . 4.2

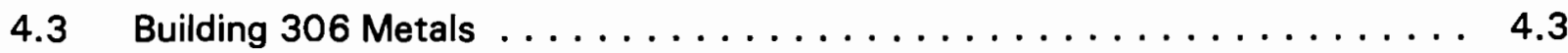

4.4 Building 306 Volatile Organic Compounds . . . . . . . . . . . . . 4.4

4.5 Building 306 Radiological Parameters $\ldots \ldots \ldots \ldots \ldots \ldots$

5.1 Building 320 General Chemical Parameters . . . . . . . . . . . 5.1

5.2 Building 320 Ammonia and Anions $\ldots \ldots \ldots \ldots \ldots \ldots \ldots \ldots \ldots \ldots \ldots \ldots \ldots$

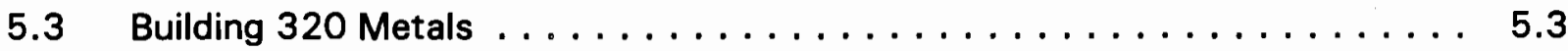

5.4 Building 320 Volatile Organic Compounds $\ldots \ldots \ldots \ldots . \ldots \ldots$

5.5 Building 320 Radiological Parameters for Routine Sampling . . . . . . . . 5.7

6.1 Building 324 General Chemical Parameters . . . . . . . . . . . . 6.1

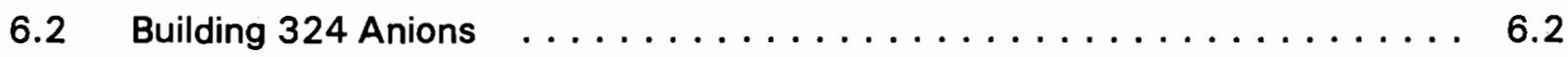

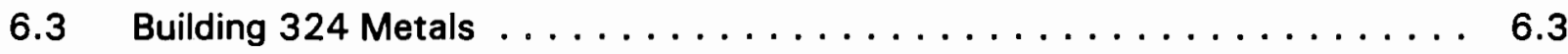

6.4 Building 324 Volatile Organic Compounds $\ldots \ldots \ldots \ldots \ldots \ldots$

6.5 Building 324 Radiological Parameters $\ldots \ldots \ldots \ldots \ldots \ldots$

7.1 Building 326 General Chemical Parameters $\ldots \ldots \ldots \ldots \ldots \ldots$

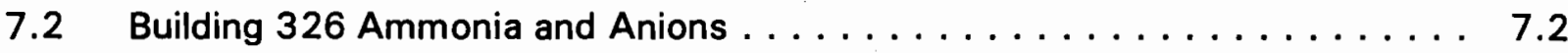


$7.3 \quad$ Building 326 Metals $\ldots \ldots \ldots \ldots \ldots \ldots \ldots \ldots \ldots \ldots \ldots$

7.4 Building 326 Volatile Organic Compounds $\ldots \ldots \ldots \ldots \ldots \ldots \ldots$

7.5 Building 326 Semivolatile Organic Compounds $\ldots \ldots \ldots \ldots \ldots \ldots .4$

7.6 Building 326 Radiological Parameters $\ldots \ldots \ldots \ldots \ldots \ldots \ldots \ldots .7 .5$

8.1 Building 331 General Chemical Parameters $\ldots \ldots \ldots \ldots \ldots \ldots \ldots .2$

8.2 Building 331 Ammonia and Anions $\ldots \ldots \ldots \ldots \ldots \ldots \ldots \ldots .3$

8.3 Building 331 Metals $\ldots \ldots \ldots \ldots \ldots \ldots \ldots \ldots \ldots \ldots \ldots .4$

8.4 Building 331 Volatile Organic Compounds $\ldots \ldots \ldots \ldots \ldots \ldots \ldots .6$

8.5 Building 331 Semivolatile Organic Compounds $\ldots \ldots \ldots \ldots \ldots \ldots .8$

8.6 Building 331 Radiological Parameters $\ldots \ldots \ldots \ldots \ldots \ldots \ldots \ldots .9$

9.1 Building 3720 General Chemical Parameters $\ldots \ldots \ldots \ldots \ldots \ldots . . \ldots 9$

9.2 Building 3720 Ammonia and Anions . . . . $\ldots \ldots \ldots \ldots \ldots \ldots .2$

9.3 Building 3720 Metals $\ldots \ldots \ldots \ldots \ldots \ldots \ldots \ldots \ldots \ldots \ldots .3$

9.4 Building 3720 Volatile Organic Compounds $\ldots \ldots \ldots \ldots \ldots \ldots .7$

9.5 Building 3720 Semivolatile Organic Compounds $\ldots \ldots \ldots \ldots \ldots . .$.

9.6 Building 3720 Radiological Parameters $\ldots \ldots \ldots \ldots \ldots \ldots \ldots \ldots . .8$

10.1 End-of-Pipe General Chemical Parameters $\ldots \ldots \ldots \ldots \ldots \ldots \ldots \ldots \ldots \ldots \ldots \ldots \ldots$

10.2 End-of-Pipe Ammonia and Anions $\ldots \ldots \ldots \ldots \ldots \ldots \ldots \ldots \ldots \ldots \ldots \ldots \ldots$

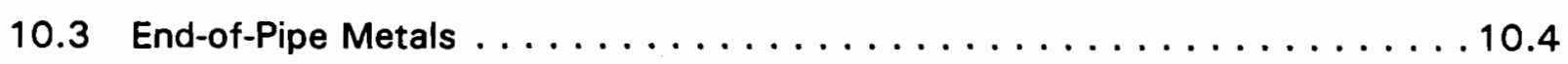

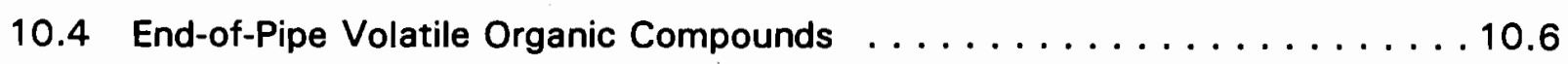

10.5 End-of-Pipe Semivolatile Organic Compounds $\ldots \ldots \ldots \ldots \ldots \ldots \ldots$

10.6 End-of-Pipe Radiological Parameter $\ldots \ldots \ldots \ldots \ldots \ldots \ldots \ldots \ldots \ldots \ldots \ldots \ldots \ldots \ldots$

11.1 End-of-Pipe Fluorescence From Two Dye Releases at Building $3720 \ldots \ldots 11.3$

11.2 End-of-Pipe Fluorescence at Building $331 \ldots \ldots \ldots \ldots \ldots \ldots \ldots \ldots \ldots$ 
11.3 Time Measurement from Fluorescence Data $\ldots \ldots \ldots \ldots \ldots \ldots \ldots$

12.1 Building 3720 Volatile Organic Compound Tracer Tests . . . . . . . . . . 12.4

12.2 Chloroform Concentrations in Building 331 Effluent $\ldots \ldots \ldots \ldots \ldots$

12.3 Uranium Monitoring Flow System $\ldots \ldots \ldots \ldots \ldots$

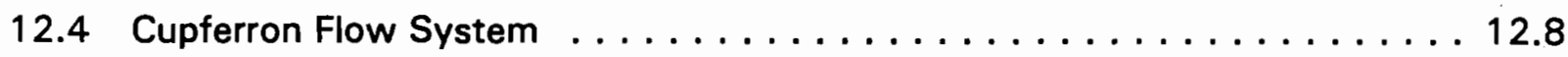

12.5 Uranium-Cupferron Flow System $\ldots \ldots \ldots \ldots \ldots \ldots \ldots \ldots$

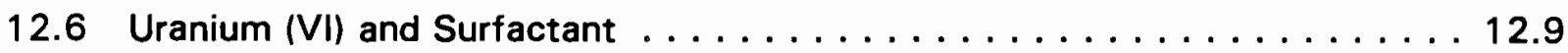

12.7 Continuous Effluent Monitoring Systems $\ldots \ldots \ldots \ldots \ldots \ldots \ldots \ldots$

12.8 Example of Data Collected on a Stand-Alone Data Logging System . . . . . 12.12 


\section{Tables}

$3.1 \quad$ Quality Control Sample Summary $\ldots \ldots \ldots \ldots \ldots \ldots \ldots$

10.1 Comparison of Observed Concentration Ranges ( $\mu \mathrm{g} / \mathrm{L})$ of Parameters and Constituents at End-of-Pipe During CY 1994 to

Historical Data . . . . . . . . . . . . . . . . . . . . . 10.10

11.1 Stream Dynamics: July Test Dates and Number of Dye Releases . . . 11.5

$11.2 \quad$ Building 3720 Arrival and Transit Times $\ldots \ldots \ldots \ldots \ldots$

11.3 Building 331 Arrival and Transit Times $\ldots \ldots \ldots \ldots \ldots$

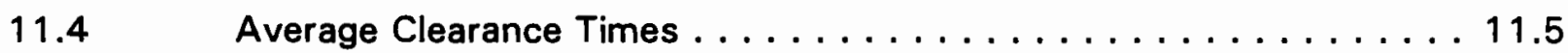

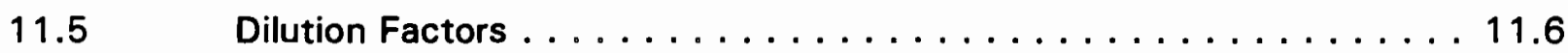




\section{Acknowledgments}

The authors gratefully acknowledge those who made this report possible. The U.S. Department of Energy provided guidance and direction for this report. Alice Ikenberry and Rodger Woodruff managed the Effluent Monitoring Program. Brian Opitz, manager of the Field Sampling and Analysis group, provided management support and review. Paul Thorne reviewed the document. Jeff Leeper and the staff of Facilities Engineering designed and built the sampling and monitoring stations. David Douglas and Laurie True provided logistical support in sampler operations. Elizabeth Westergard coordinated sampling of effluents. Janelly Alejandro extensively worked on the waste stream dynamic tests and solid phase extraction studies. Denise Sauers developed and managed the analytical measurement database. Denice Carrothers and Teresa Riley assisted in publishing the report, ETB text processing team (with special thanks to Toni Jewell) designed this document, and Sigma I Graphics assisted with the artwork. 



\section{Acronym and Abbreviation List}

\begin{tabular}{ll} 
ASV & adsorptive stripping voltametry \\
CY & calendar year \\
DOE & U.S. Department of Energy \\
EPA & U.S. Environmental Protection Agency \\
FEMP & Facility Effluent Monitoring Program \\
FMCS & Facilities Management Control System \\
GC/MS & gas chromatograph/mass spectrometer \\
MCL & maximum contaminant level \\
NPDES & National Pollutant Discharge Elimination System \\
PCB & polychlorinated biphenyl \\
PNL & Pacific Northwest Laboratory \\
OA & quality assurance \\
SPE & solid phase extraction \\
SVOC & semivolatile organic compound \\
TEDF & Treated Effluent Disposal Facility \\
WHC & volatile organic compound \\
\hline
\end{tabular}




\section{Trademarks Used}

Carbitol is a registered trademark of Union Carbide Chemicals \& Plastics Technology Corporation, Wilmington, Delaware.

Freon 11 is a registered trademark of E. I. duPont DeNemours and Company, Wilmington, Delaware.

Isco is a registered trademark of Isco, Inc., Lincoln, Nebraska.

Hewlett-Packard is a registered trademark of the Hewlett-Packard Company, Palo Alto, California.

Teflon is a registered trademark of E. I. duPont DeNemours and Company, Wilmington, Delaware.

Tygon is a registered trademark of Norton Company, Worcester, Massachusetts. 


\subsection{Introduction}

Physical, chemical, and radiological data are being gathered by the Pacific Northwest Laboratory (PNL) on the liquid waste streams (i.e., process and retention process sewer effluents) from 300 Area U.S. Department of Energy (DOE)-owned and PNL-operated buildings where radioactive and/or hazardous materials are used (Figure 1.1). Samples were collected and analyzed to meet the requirements of DOE Order 5400.1 (DOE 1988). The 300 Area is located on the Hanford Site, a National Environmental Research Park, in southeastern Washington State. Activities within these buildings involve basic and applied research and the evaluation and deployment of technology in support of environmental restoration and waste management activities across the DOE complex.

For calendar year (CY) 1994, liquid samples were collected from the following six buildings:

- Building 306

- Building 320

- Building 324

- Building 326

- Building 331

- Building 3720.

PNL is also monitoring end-of-pipe, which is where effluents from all of the 300 Area buildings come together before discharging to process trenches (previous to December 29, 1994) or the Treated Effluent Disposal Facility (TEDF)

(Figure 1.1) (after December 29, 1994). The effluents at end-of-pipe include building process sewer and retention process sewer effluents. Before the streams are combined, the retention process sewer effluents are sent to 307 Basins where the streams are monitored by WHC for gross alpha and beta radioactivity. After screening, waste water with acceptably low radiation levels is discharged to the process sewer which is routed to the TEDF. This facility, which is managed by Westinghouse Hanford Company (WHC), is fulfilling a milestone in the Hanford Federal Facility Agreement and Consent Order (Ecology et al. 1989). Building effluents routed to TEDF are treated and discharged to the Columbia River according to the requirements of a National Pollutant Discharge Elimination System (NPDES) permit WA-0025917 (EPA 1994a).

Columbia River water is the source water for the buildings. This water is treated by filtration and chlorination at Building 315 before being routed as influent to the buildings. Treated and untreated influent is also being monitored as part of this program to provide background information on water coming into the buildings. Building 315 is operated by WHC.

Three more buildings are scheduled for baseline characterization and monitoring as sampling stations come online during CY 1995. The three additional buildings are

- Building 325

- Building 327

- Building 329.

\subsection{Purpose}

This report summarizes the results from 1) characterization and monitoring of effluent and influent performed during CY 1994 (March to December), 2) waste stream dynamics tests, and 3) technology 


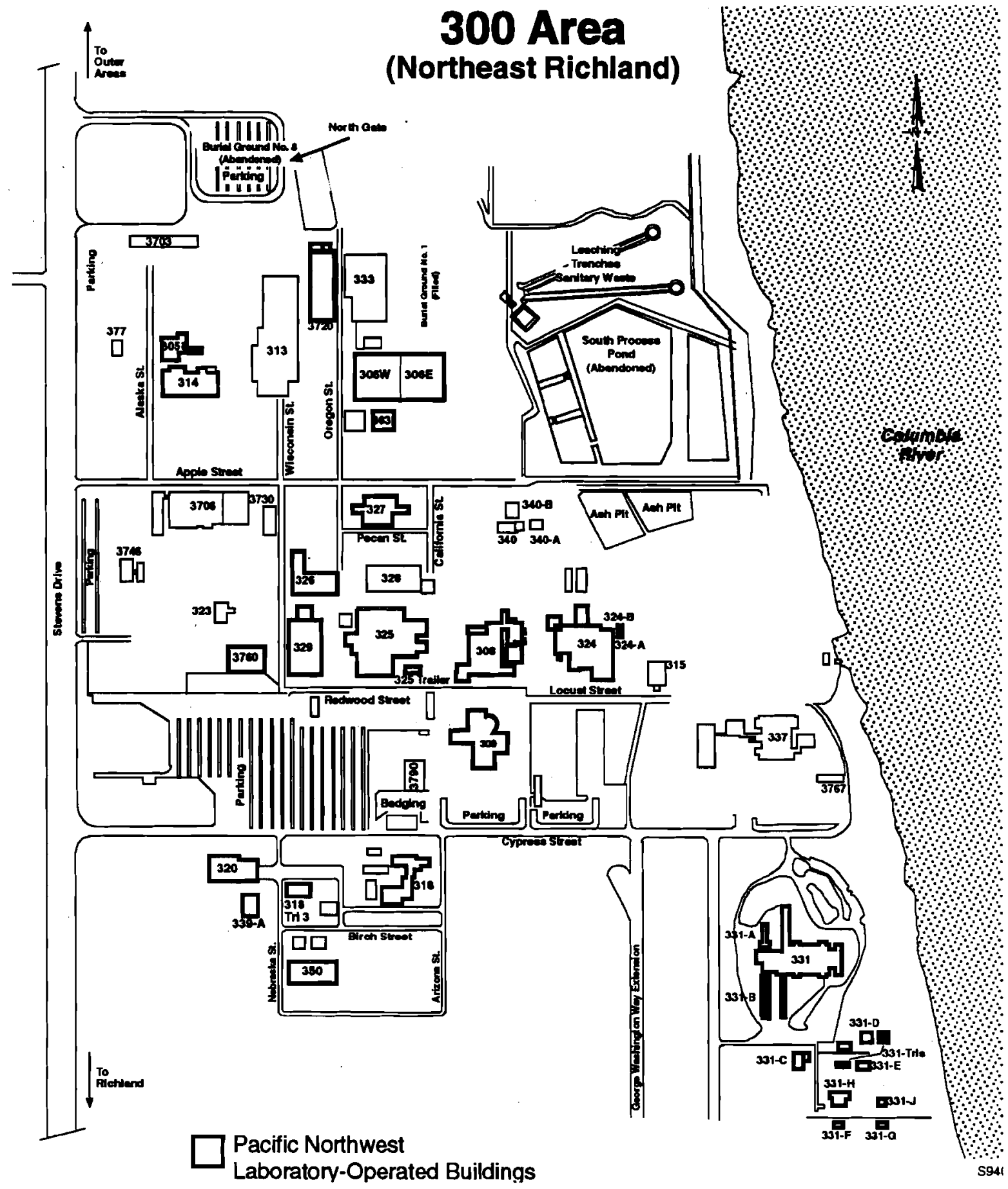

Figure 1.1. Location of Pacific Northwest Laboratory-Operated Buildings in the 300 Area

evaluation. The appendixes contain historical information on the 300 Area process sewer system and chemistry
(Appendix A), information on the processes used for identifying the target parameters (Appendix B), information on 
sampling and analyses processes and capabilities (Appendix $\mathrm{C}$ ), quality control information for sample blanks and duplicate samples (Appendix D), detailed information on the chemical composition of influent (Appendix $E$ ), and tables with detailed information on the parameters and constituents detected at the buildings and end-of-pipe (Appendix F), and the glossary (Appendix G).

\subsection{Objective}

The objective of this report is to provide technical information for the purpose of responsible management of building effluents. This includes controlling effluents to support TEDF in meeting regulatory requirements and regularly assessing PNL administrative controls used to manage discharges to end-of-pipe from 300 Area PNL-operated buildings. 


\subsection{Background}

Operation of facilities in the 300 Area began in February 1943 when the Hanford Site was created to produce plutonium for the first atomic bombs. Activities in the 300 Area have included fabricating reactor fuel and evaluating pilot-scale separations processes and the conduct of basic and applied research for industrial and governmental agencies.

For over five decades, chemically and radiologically contaminated waste waters from these activities were discharged to ponds, trenches, and cribs in the 300 Area (Riley and Zachara 1992). The waste waters were discharged using an intricate system of sewer lines linking facilities to waste disposal areas. The sewer system consisted of independently functioning sanitary and process components. Detailed information describing the sewer system (past, present, and future) and 300 Area liquid waste disposal practices can be found in Past Practices Technical Characterization Study-300 Area-Hanford Site (Gerber 1992). Information from that report is summarized in Appendix A with an emphasis on the process and retention process sewer systems because the sanitary sewer and radioactive liquid waste systems are not monitored by the effluent program. Preliminary information on the characterization and monitoring of 300 Area facility waste streams conducted by the Effluent Monitoring Program can be found in Riley et al. (1994). 



\subsection{Liquid Waste Stream Characterization and Monitoring}

This section summarizes information about the samples collected during $C Y$ 1994 (such as types, location, and dates). The sampling process is described in Appendix C. Also, this section summarizes quality control and background information that is used to clarify the interpretation of waste stream data presented in Sections 4.0 through 10.0. Guidance on how to interpret the figures is provided. Sampling and analytical data limitations are also discussed.

\subsection{Sample Types and Dates of Collection}

Effluents in the 300 Area were routinely collected and analyzed from six PNL-operated buildings equipped with automated, refrigerated samplers, and periodic sampling was done at two buildings using portable samplers. A total of 11 locations were sampled in CY 1994; 6 process (chemical) sewers, 1 retention (radiological) process sewer, end-of-pipe, and 3 influent sites (Figure 3.1). The influent was sampled and analyzed to provide a baseline from which the chemical and radiological composition of building effluents could be assessed. Source water locations that were sampled included untreated influent (originating from the Columbia River), treated influent (after Columbia River water was treated at Building 315), and an alternate influent originating from the city of Richland. Alternate influent was used on occasions when the primary treated influent was not available.

Samples for CY 1994 were collected from March 22, 1994, through December 20, 1994. Buildings were sampled during business hours on a weekly basis from March through September and on a biweekly basis from October through December. Untreated and treated influent samples were collected from May 1.1, 1994, through July 8, 1994. Alternate influent was sampled on August 4, 1994. Grab samples of influent and effluent were collected from May 11, 1994, through September 27, 1994, for volatile organic compound (VOC) analysis using a U.S. Environmental Protection Agency (EPA) standard protocol. In addition, liquid effluent from buildings was sampled biweekly during nonbusiness days (e.g., weekends and holidays) from May 23, 1994, through August 15, 1994. No restriction was placed on building activities during these latter sampling activities. Therefore, the analytical data obtained from the analyses of nonbusiness day samples could be nonrepresentative of the actual building background composition. See Appendix $C$ for detailed information on all samples collected (i.e., descriptions of sample type, analyses requested, and deviations from the sample collection and analyses process).

\subsection{Analytical Data Presentation and Quality}

This section describes information that will assist the reader in understanding the data presented in Sections 4.0 through 10.0. Interpretation of figures is discussed. Normalization of analytical data, taking into account quality control (i.e., data from blanks and duplicate samples) and background data (i.e., data on influents), is presented. Limitations of the sampling and analytical data are also discussed. 


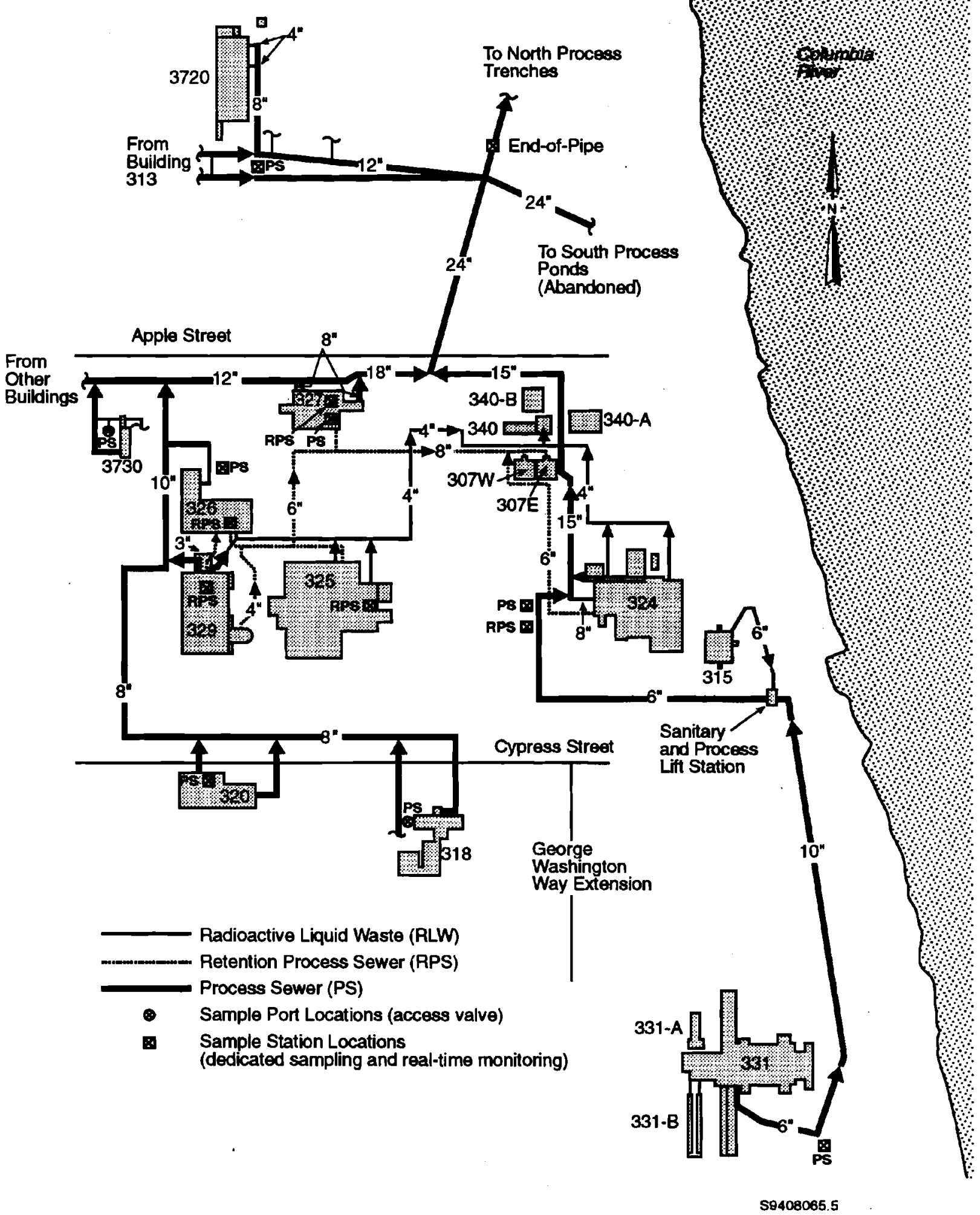

Figure 3.1. Location of Facility Sampling Stations, Source Water, and End-of-Pipe 


\subsubsection{Understanding the Figures}

The format for presenting analytical data is shown in Figure 3.2. This format was chosen to enable rapid interpretation of monitoring results. Detected analytes are listed along the abscissa ( $\mathrm{x}$-axis or horizontal axis) in order of increasing concentration (from left to right). The primary ordinate (left $y$-axis or left vertical axis) corresponds to concentration. The height of each column depicts an analyte's average concentration, and the superimposed range bars represent the corresponding minimum and maximum detected concentrations. For example, in Figure 3.2, the average concentration of compound $X$ is $25 \mu \mathrm{g} / \mathrm{L}$, and the associated range is approximately 10 to $50 \mu \mathrm{g} / \mathrm{L}$. When concentrations are too low to discern from the graph, the results are listed in the figure caption. The secondary ordinate (right $y$-axis or right vertical axis) displays the frequency of detection, which is defined as the number of times a constituent was detected divided by the number of samples that were analyzed. For an individual analyte, the frequency of detection is indicated by the height of a small circle positioned above the analyte's name. In Figure 3.2, compound $X$ was detected only $10 \%$ of the time, while compound $Y$ was detected in every sample analyzed.

A few caveats should be kept in mind when viewing the figures. A high frequency of detection could be the result of a small number of sample analyses, as is the case with some of the nonbusiness day results. The absence or apparent absence of a range bar on some figures could indicate that an analyte was detected only once, or that an analyte had a very narrow concentration range. In addition, the figures only list analytes that were detected. For a complete listing of the analyses which were performed, see Appendix C. Additional

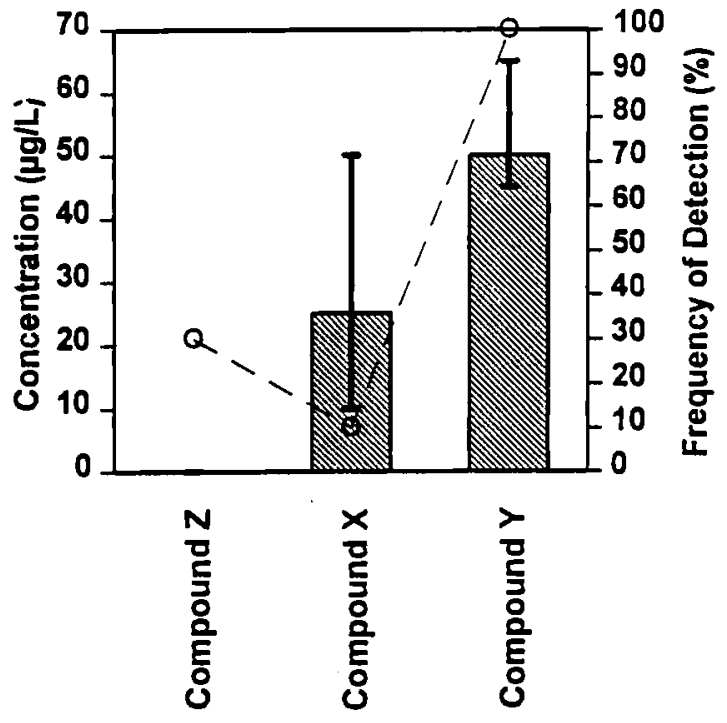

Figure 3.2. Example Figure Showing the Frequencies of Detection and the Average, Minimum, and Maximum Concentrations of Detected Parameters and Constituents

information (i.e., numerical averages, ranges, standard deviations, and the number of analyses performed) can be found in Appendix F.

Conclusions drawn from analytical data must be made with care because of the potential for qualitative and quantitative errors. Both the sampling and analysis processes can introduce bias, errors, and contamination. Thus, sometimes, several interpretations of the data are possible. Interpretations made in the text note these concerns when appropriate.

\subsubsection{Quality Assurance and Quality Control}

The Quality Assurance (QA) program for the 300 Area Effluent Monitoring Program is based on the following documentation:

- 10 CFR 830.120, "Quality Assurance for DOE Nuclear Facilities" 
- DOE Order 5400.1, "General Environmental Protection Program"

- DOE Order 5700.6C, "Quality Assurance"

- EPA QAMS-005/80, "Interim Guidelines for Preparing Quality Assurance Project Plans"

- PNL QA manual and associated implementing procedures

- SW-846, "USEPA Methods for Evaluating Solids Waste, Physical/ Chemical Methods" (EPA 1986).

The program has a draft QA plan which addresses the applicable requirements delineated in the above documents. Future project work activity (liquid effluent sampling and monitoring system operations, associated analytical services, and data validation and reduction) will be conducted in accordance with this QA plan. Although the QA plan is still under development, many of its components have been addressed during CY 1994 characterization and monitoring activities.

- Sampling procedures were developed and implemented.

- Appropriate training was given and documented.

- Sample chain-of-custody was maintained and documented.

- Analyses were performed in accordance with PNL-approved statements of work and procedures.

- Quality control sampling and analyses were performed as described in Section 3.2.3

\subsubsection{Quality Control Data}

Quality control consisted of making analytical measurements on five types of sample blanks (bottle blanks, equipment blanks, field-transfer blanks, full-trip blanks, and daily-trip blanks) which were prepared and submitted to the laboratories for analysis. In addition, 1 laboratory reagent blank was analyzed for every 20 samples. Definitions of the various blank types can be found in the glossary.

Duplicate samples were prepared and analyzed to determine analytical laboratory reproducibility. A detailed summary of data generated from duplicate samples and sample blanks can be found in Appendixes $D$ and $F$. A brief summary is provided in Sections 3.2.3.1 and 3.2.3.2.

\subsubsection{Blanks}

Table 3.1 summarizes the analysis results of the various blanks for the parameters and constituents of interest. This table lists only those analytes which were detected in the various blank analyses. A total of 21 parameters and constituents were identified with varying frequencies in one or more of the blank types. Aluminum, chromium, iron, lead, acetone, chloroform, methylene chloride, and tetrahydrofuran were the constituents observed in most (i.e., in three or more) of the blank types. Of these constituents, chromium, lead, and methylene chloride were observed at levels similar to the concentrations observed in actual samples of building effluent. Alkalinity, chemical oxygen demand, total carbon, nitrate, sodium, zinc, toluene, and trichloroethane were observed in only one to two blank types and at concentrations below levels observed in effluents. Sulfides, manganese, nickel, thallium, and vanadium were observed in only one to 
Table 3.1. Quality Control Sample Summary

\begin{tabular}{|c|c|c|c|c|c|}
\hline Parameter & $\begin{array}{c}\text { Laboratory } \\
\text { Reagent } \\
\text { Blanks }\end{array}$ & $\begin{array}{l}\text { Bottle } \\
\text { Blanks }\end{array}$ & $\begin{array}{l}\text { Equipment } \\
\text { Blanks }\end{array}$ & $\begin{array}{c}\text { Field } \\
\text { Transfer } \\
\text { Blanks }\end{array}$ & $\begin{array}{c}\text { Trip } \\
\text { Blanks }\end{array}$ \\
\hline \multicolumn{6}{|c|}{ General Chemical Parameters } \\
\hline Alkalinity & $\star$ & & & & \\
\hline Chemical Oxygen Demand & & & $\nabla$ & & \\
\hline Total carbon & $\star$ & & & & \\
\hline \multicolumn{6}{|c|}{ Common Anions } \\
\hline Nitrate & & & $\nabla$ & & \\
\hline Sulfides & & $\bullet$ & & & $\nabla$ \\
\hline \multicolumn{6}{|c|}{ Metals } \\
\hline Aluminum & $\star$ & $\boldsymbol{\nabla}$ & & & $\bullet$ \\
\hline Chromium & & $\bullet$ & $\bullet$ & & $\bullet$ \\
\hline Iron & $\star$ & $\nabla$ & & & $\bullet$ \\
\hline Lead & $\star$ & $\bullet$ & $\bullet$ & & $\bullet$ \\
\hline Manganese & & & $\bullet$ & & \\
\hline Nickel & & & & & $\bullet$ \\
\hline Sodium & $\star$ & & & & \\
\hline \multicolumn{6}{|l|}{ Thallium } \\
\hline Vanadium & & . & $\bullet$ & & \\
\hline Zinc & $\star$ & $\nabla$ & & & \\
\hline \multicolumn{6}{|c|}{ Volatile Organic Compounds } \\
\hline Acetone & & $\nabla$ & & $\bullet$ & $\boldsymbol{\nabla}$ \\
\hline Chloroform & & $\boldsymbol{\nabla}$ & $\boldsymbol{\nabla}$ & & $\boldsymbol{\nabla}$ \\
\hline Methylene chloride & $\star$ & $\bullet$ & $\bullet$ & $\bullet$ & $\boldsymbol{\nabla}$ \\
\hline Tetrahydrofuran & & $\nabla$ & $\bullet$ & & $\boldsymbol{\nabla}$ \\
\hline Toluene & & $\boldsymbol{\nabla}$ & & $\boldsymbol{\nabla}$ & \\
\hline Trichloroethene & & $\nabla$ & & & \\
\hline \multicolumn{6}{|c|}{$\begin{aligned} \star= & \text { Detected in } 10 \% \text { or more of the laboratory reagent blanks. } \\
\nabla= & \text { Concentrations observed at levels below levels detected in effluent samples. } \\
\bullet= & \text { Concentrations observed at levels similar to levels detected in one or more } \\
& \text { effluent samples. }\end{aligned}$} \\
\hline
\end{tabular}


two blank types; however, they were observed at least once at levels similar to concentrations in building effluent samples.

Blank data were compared against building effluent and influent sample data; the impact of contamination resulting from the sampling and analysis process was noted. A more detailed discussion of the analysis of the blanks along with figures and tables is presented in Appendix D.

\subsubsection{Duplicate Samples}

Matching results for a total of 42 constituents were compared in up to six duplicate sample pairs. For most of these analytes, the analytical precision was fairly high (i.e., the results were within $25 \%$ of each other). A few metals, organic compounds, and radiological parameters exhibited poorer agreement. However, among these latter constituents, only iron, potassium, manganese, and carbon disulfide had average concentrations which were significantly above their method detection limits. Thus, for most constituents, these results illustrate that the measurement precision is lower for constituents measured at levels near the detection limit. Overall, these results suggest that the level of precision associated with CY 1994 analytical measurements on effluent samples should not have a significant impact on the data's interpretation. Additional caution should be applied when drawing conclusions from trace-level concentrations, which were typically reported for many metals, pesticides, and radiological parameters. Detailed information on the duplicate samples' results can be found in Appendix D.
3.2.4 Influent Chemistry (Untreated, Treated, Alternate)

Influent was sampled periodically before and after treatment (i.e., filtration and chlorination) at Building 315. Alternate influent (which was treated) was used in the buildings when the primary influent was not available. Because alternate influent sampling was performed only once, the results are considered tentative. Also, only limited data (five samples) on influent before and after treatment at Building 315 are available. Samples were taken from May to July 1994, and thus provide information for only one season. This data set has much less variability than most of the building data sets which were generated. from a much larger number of samples.

Primary influent is pumped into the 300 Area directly from the Columbia River at the 312 Intake Pumphouse and treated at Building 315 . Alternate influent is supplied at Building $382 \mathrm{~B}$ and was used for a few weeks in CY 1994. All of these buildings are maintained and operated by WHC. Periodic, 24-hr time-proportional sampling was done at all three locations using a portable sampler. Concentrations of constituents in untreated, treated, and alternate influent were compared. Results are summarized in the following text. Detailed quantitative data (figures and tables) for the influent can be found in Appendix $\mathrm{E}$.

\section{General Chemical Parameters.} Treated influent contained 10 to $20 \%$ less total carbon and total organic carbon compared to untreated influent. Values for chemical oxygen demand, alkalinity, and total dissolved solids were similar for untreated and treated influents. Alternate 
influent contained approximately $50 \%$ less total organic carbon, slightly less total carbon, and no detectable chemical oxygen demand. Alkalinity and total dissolved solids were slightly higher in the alternate influent compared to untreated and treated influent.

Ammonia and Anions. Concentrations of selected anions were significantly higher in the treated influent than in the untreated influent. Chloride was approximately four times higher; fluoride and sulfate were approximately twice as high. Ammonia was detected in the alternate influent but not in the untreated or treated influent.

Metals. Aluminum, arsenic, chromium, iron, manganese, and tin were detected in untreated and treated influent but not in the alternate influent. The concentrations of the alkali and alkaline earth metals (sodium, potassium, calcium, and magnesium) were similar among all the influents.

Volatile Organic Compounds. Although 10 to $20 \%$ of total carbon and total organic carbon appear to be removed from untreated influent during the chlorination process, trihalomethanes (e.g., chloroform and bromodichloromethane) are introduced, increasing their concentrations above background levels. Chloroform, the most common chlorination byproduct, was always found at concentrations 2 to 7 times higher in the treated influent when compared to the untreated influent. The highest value was greater than 1.5 times the TEDF waste acceptance criteria of $26 \mu \mathrm{g} / \mathrm{L}$, but the concentration was below the trihalomethane drinking water standard of $100 \mu \mathrm{g} / \mathrm{L}$. Bromodichloromethane was also frequently detected in the treated influent.
A number of the VOCs identified in the three influents are probably artifacts of the sampling and analysis process. For example, methylene chloride and tetrahydrofuran were also detected in sample blanks, and benzene and toluene were reported at near method detection limit concentrations. Chlorobenzene's low frequency of detection requires that its presence be considered suspect.

Semivolatile Organic Compounds. Trace levels of di-n-butylphthalate $(-2 \mu \mathrm{g} / \mathrm{L})$ and low nanogram per liter concentrations of delta-BHC (a pesticide) were also found in the treated influent.

Radiological Parameters. No radiological analyses were performed on influent samples.

\subsubsection{Data Limitations}

Ideally, building effluents should be monitored continuously, providing information on the concentrations of parameters and constituents in a real-time mode. In this way, decisions can be made on the control of effluent discharges from the building and end-of-pipe. However, limitations on task financial resources and on characterization technologies restricted the frequency in which building effluents were monitored. During CY 1994, sampling of building effluents consisted of collecting a 24-hr composite sample one to four times a month for chemical and radiological analyses. A simple calculation shows that such a sampling practice at the most is sampling 3 to $13 \%$ of the effluent discharged from a building over the course of 1 month. Some limited information on continuous monitoring of $\mathrm{pH}$, conductivity, and flow suggest that discharge events do occur in building 
effluents and that these events, in most cases, do not correspond to the limited time in which composite sampling is performed. Thus, with finite composite sampling, the uncertainty of understanding the effluent composition at any given time during the year is high.

When considering the influent, the small number of samples collected at the source water locations results in an uncertainty associated with this data that is higher than that calculated for effluent samples.

In most cases, more samples were taken of the effluent than the influent.
Also, effluent sampling covered a much larger time frame than influent sampling. Thus, some of the differences noted between the effluent and influent may simply be the cause of better effluent characterization. These uncertainties should be taken into account when reading the information and conclusions provided in Sections 4.0 through 10.0 on building effluent chemistry. A plan is under development to deploy over time new characterization tools to reduce characterization and monitoring uncertainty of 300 Area building effluents. 


\subsection{Building 306 (Process Sewer)}

\subsection{Background and Description}

Building 306 is located in the northeast corner of the 300 Area. Here, PNL and WHC staff conduct metallurgical research and development. The facility is equipped for metal working, heat treating, and finishing equipment activities.

General activities include the development, demonstration, and testing of pilotphase fabrication processes and new material concepts.

\subsection{Routine Sampling}

At Building 306, seven 24-hr composite sampling events occurred. However, seven analyses do not necessarily exist for each constituent because additional grab samples may have been taken, additional analyses may have been requested for specific constituents, or inadequate samples may have been collected for the analyses desired. Table C. 2 lists the analyses performed on the samples from Building 306. Samples were collected with a portable 24-hour, time-proportional sampler. Summary data supporting the constituent class discussions in Sections 4.2.1 through 4.2.6 are shown in the accompanying figures. Comparisons to influent chemistry are based on the data in Appendix E. Tables with detailed building effluent information can be found in Appendix $F$.

\subsubsection{General Chemical Parameters}

Except for chemical oxygen demand and total organic carbon, the concentrations of general chemical parameters were slightly elevated over treated influent levels. Both alkalinity and total dissolved solids were approximately $70 \%$ higher; total carbon was nearly $50 \%$ higher. Chemical oxygen demand and total organic carbon levels were slightly less than (i.e., 10 to $20 \%$ lower than) treated influent concentrations (Figure 4.1). None of the general chemical parameters that were investigated have regulatory standards of comparison except total dissolved solids. The maximum total dissolved solid value observed for Building 306 was $180 \mathrm{mg} / \mathrm{L}$, which is much less than the National Secondary Drinking Water Standard of $500 \mathrm{mg} / \mathrm{L}$.

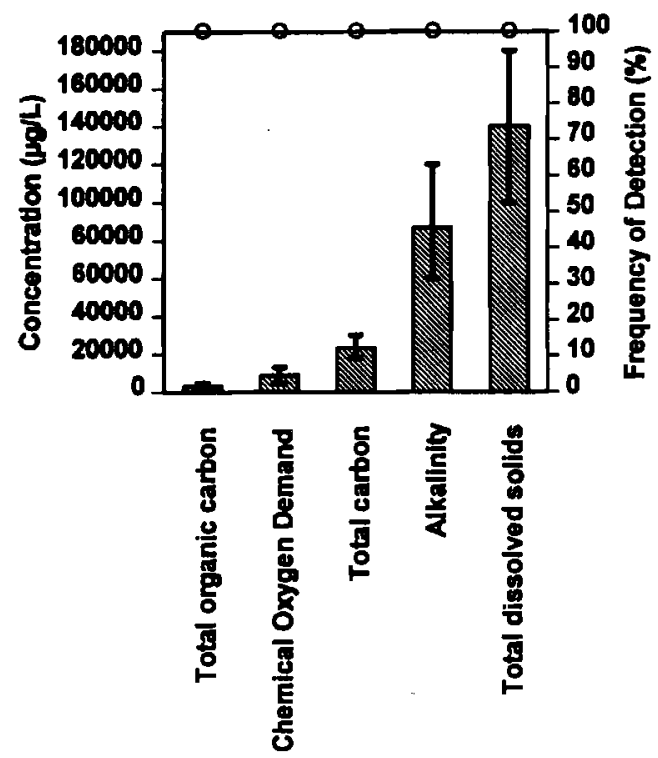

Figure 4.1. Building 306 General Chemical Parameters

\subsubsection{Ammonia and Anions}

Ammonia and sulfides were detected in $50 \%$ of the samples. Although the ammonia concentrations were low, they were likely valid because ammonia was not detected in any blank samples (bottle, 
trip, or reagent). However, the effluent's sulfide concentration and detection frequency were comparable to those found in the bottle blanks. In addition, the sulfides concentration was near the method detection limit $(210 \mu \mathrm{g} / \mathrm{L})$. Concentrations of fluoride in the Building 306 effluent were $40 \%$ lower than in the treated influent. Nitrate concentrations fluctuated substantially and were approximately 15 times greater than treated influent levels. Chloride concentrations were nearly $60 \%$ higher than levels found in treated influent. Sulfate concentrations were $10 \%$ higher than treated influent levels but varied over a larger range $(13,400$ to $22,600 \mu \mathrm{g} / \mathrm{L}$ ) (Figure 4.2$)$.

For reference only (building effluent is not meant to be drinking water and is treated by the TEDF before being discharged to the river), concentrations of ammonia and anions were compared to the National Drinking Water Standards, which exist for four of the constituents detected (chloride, fluoride, nitrate, and sulfate). Only the nitrate standard of $10 \mathrm{mg} / \mathrm{L}$ was exceeded with a maximum observed concentration of $13.5 \mathrm{mg} / \mathrm{L}$ in the effluent (this was true of almost all of the building waste streams). The TEDF waste acceptance criteria exist for only one of the constituents detected; ammonia was measured at a small fraction $(<6 \%)$ of the waste acceptance criteria.

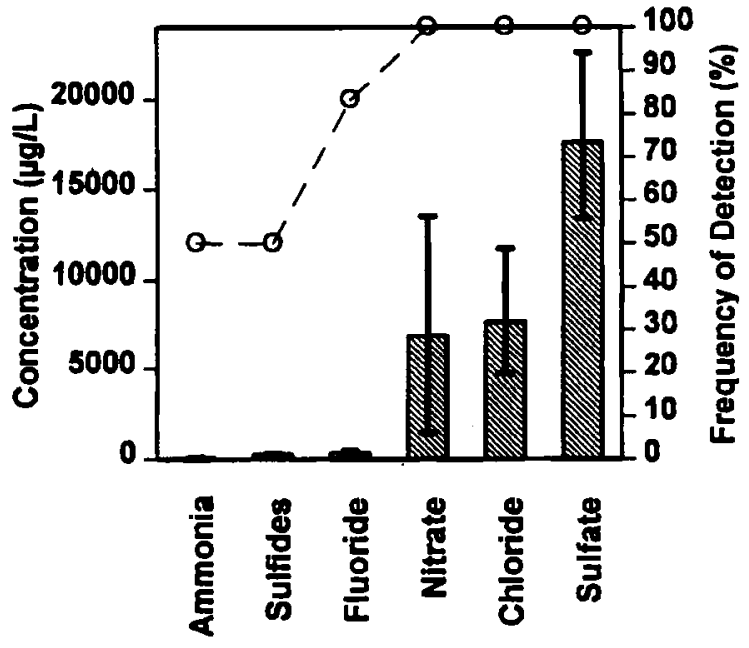

Figure 4.2. Building 306 Ammonia and Anions (Ammonia Average $60 \mu \mathrm{g} / \mathrm{L}$, Range 40 to $100 \mu \mathrm{g} / \mathrm{L}$; Sulfides $273 \mu \mathrm{g} / \mathrm{L}$, Range 220 to $300 \mu \mathrm{g} / \mathrm{L}$ )

\subsubsection{Metals}

The validity of the metals results detected below $10 \mu \mathrm{g} / \mathrm{L}$ is questionable because of their low frequencies of occurrence and because their concentrations are comparable to the method detection limits (Figure 4.3a and b). The detection of many of the heavy metals in the blanks and the treated influent samples demonstrates the high potential for finding these constituents when monitoring at trace levels. The concentration of manganese was twice as high in the effluent $(14 \mu \mathrm{g} / \mathrm{L})$ compared to the untreated influent, while levels of aluminum, barium, and copper were similar to those found at influent sampling points. The source of aluminum and copper at these locations may be attributable to leaching of these constituents from a corroded local water delivery system (piping and plumbing), given the low levels of copper found in the treated influent and previously reported river values (Dirkes et al. 1993). Zinc $(105 \mu \mathrm{g} / \mathrm{L})$ and iron $(285 \mu \mathrm{g} / \mathrm{L})$ concentrations were several times higher than the 
influent (9 to $44 \mu \mathrm{g} / \mathrm{L}$ zinc; 46 to $160 \mu \mathrm{g} / \mathrm{L}$ iron), but their presence may also be a result of leaching of corroded facility plumbing and sewer systems. Other metals were found at higher concentrations that ranged from $40 \%$ (sodium) to $65 \%$ (potassium, magnesium, calcium) above treated influent levels (Figure 4.3c).

The TEDF has waste acceptance criteria for 10 of the metals detected:

aluminum, arsenic, copper, iron, lead, manganese, mercury, selenium, silver, and zinc. One of the seven zinc measurements at Building 306 was above the waste acceptance criteria of $210 \mu \mathrm{g} / \mathrm{L}$; zinc is believed to be present in steam condensate. None of the other waste acceptance criteria were exceeded. Note that even though the waste acceptance criteria for zinc ( $210 \mu \mathrm{g} / \mathrm{L})$ was exceeded, the National Drinking Water Standards for zinc $(5,000 \mu \mathrm{g} / \mathrm{L})$ was not.
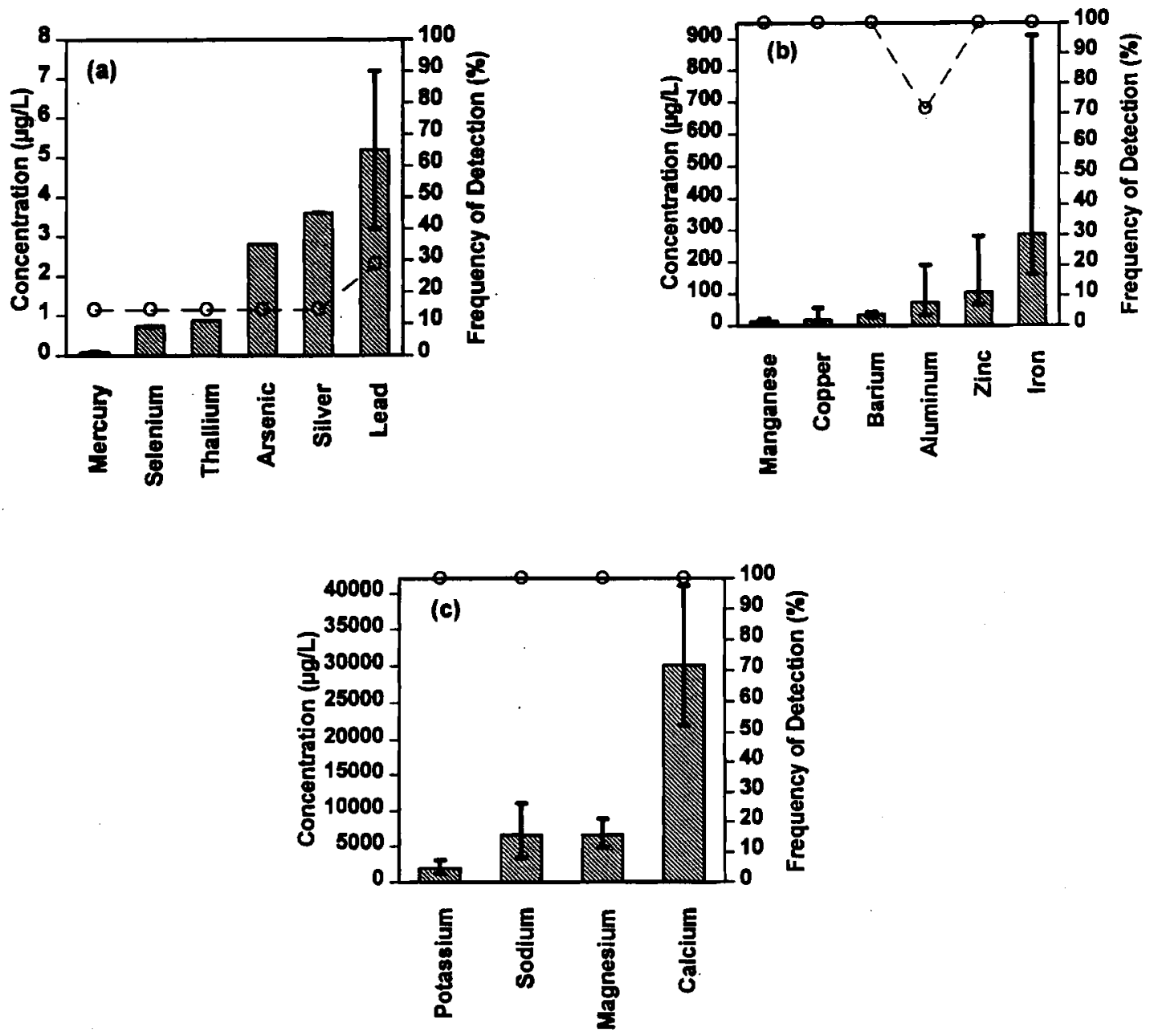

Figure 4.3. Building 306 Metals (a) Concentrations Less than $8 \mu \mathrm{g} / \mathrm{L}$, (Mercury Average $0.08 \mu \mathrm{g} / \mathrm{L}$, Range N/A) (b) Concentrations Between 10 and $900 \mu \mathrm{g} / \mathrm{L}$, (c) Concentrations Greater than $900 \mu \mathrm{g} / \mathrm{L}$ 


\subsubsection{Volatile Organic Compounds}

Two trihalomethanes, chloroform and bromoform, were detected at low concentrations. The average for chloroform $(1.4 \mu \mathrm{g} / \mathrm{L})$ was approximately 16 times lower than the treated influent level $(22.4 \mu \mathrm{g} / \mathrm{L})$. Both compounds are common byproducts of water disinfection. Acetone and methylene chloride were also detected at low concentrations (i.e., $15 \mu \mathrm{g} / \mathrm{L}$ or less) (Figure 4.4), but the blank results suggest that methylene chloride probably resulted from sample contamination. None of the TEDF waste acceptance criteria or National Drinking Water Standards were exceeded for these constituents.

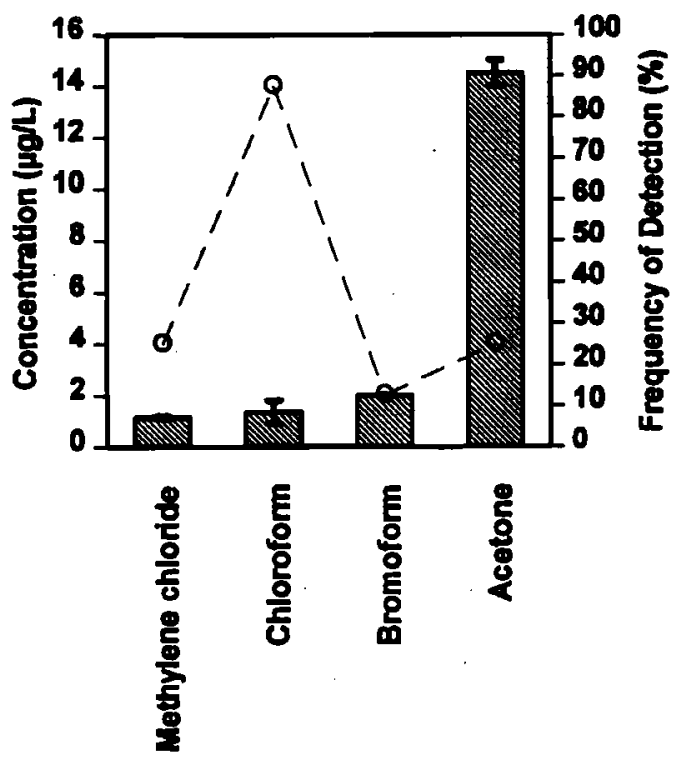

Figure 4.4. Building 306 Volatile Organic Compounds

\subsubsection{Semivolatile Organic Compounds}

No target semivolatile organic compounds (SVOCs) were detected in the Building 306 effluent.

\subsubsection{Radiological Parameters}

Low levels of gross alpha $(3.7 \mathrm{pCi} / \mathrm{L})$, gross beta $(7.4 \mathrm{pCi} / \mathrm{L})$, and tritium $(326.2 \mathrm{pCi} / \mathrm{L})$ were detected in most samples (Figure 4.5). All three parameters exhibited a wide range of concentrations; the average gross beta concentration was the highest found at any monitoring location, but was still less than half the TEDF waste acceptance criteria of $50 \mathrm{pCi} / \mathrm{L}$. None of the TEDF waste acceptance criteria were exceeded.

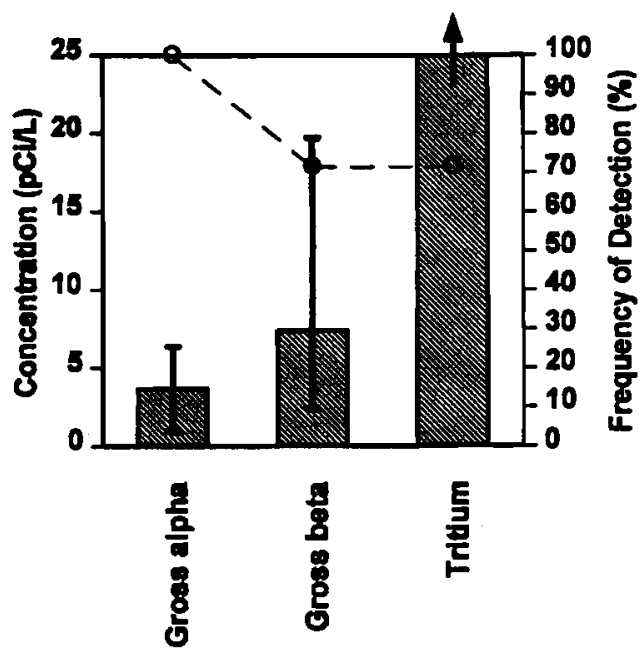

Figure 4.5. Building 306 Radiological Parameters (Tritium Average $326.2 \mathrm{pCi} / \mathrm{L}$, Range 155.0 to $687.0 \mathrm{pCi} / \mathrm{L}$ ) 


\subsection{Building 320 (Process Sewer)}

\subsection{Background and Description}

Building 320 is located in the southwest end of the 300 Area and supports a variety of trace analysis research.

\subsection{Routine and Nonbusiness Day Sampling}

At Building 320, 32 routine and 7 nonbusiness day 24-hr composite sampling events and 21 routine and 6 nonbusiness day grab sampling events occurred. However, the full number of analyses do not necessarily exist for each constituent because additional grab samples may have been taken, additional analyses may have been requested for specific constituents, or inadequate samples may have been collected for the analyses desired. Table C. 2 lists the analyses performed for the sampling events from Building 320 . Summary data supporting the constituent class discussions in Sections 5.2.1 through 5.2.6 are shown in the accompanying figures. Comparisons to influent chemistry are based on the data in Appendix E. Tables with detailed building effluent information can be found in Appendix $\mathrm{F}$.

\subsubsection{General Chemical Parameters}

The concentrations of general chemical parameters in Building 320 effluent reveal a mixture of trends when compared to treated influent levels. Routine monitoring of alkalinity and total dissolved solids showed approximately 20 to $25 \%$ higher concentrations than treated influent, while chemical oxygen demand was nearly $25 \%$ lower, and total organic carbon was about $55 \%$ lower (Figure 5.1 $a$ and b). Total carbon was observed at concentrations similar to (i.e., within $3 \%$ ) treated influent levels.
The maximum concentrations of alkalinity, total carbon, and total dissolved solids in routine samples were almost twice as high as the maximum concentrations in nonbusiness day samples. However, this disparity may be caused, in part, by the relatively small number of nonbusiness day samples collected (Figure 5.1b). Both routine and nonbusiness day samples showed average concentrations for total organic carbon of approximately $1,700 \mu \mathrm{g} / \mathrm{L}$.

None of the general chemical parameters that were investigated have standards of comparison except total dissolved solids. The maximum total dissolved solid value observed for Building 320 was $210 \mathrm{mg} / \mathrm{L}$, which is much less than the National Secondary Drinking Water Standard of $500 \mathrm{mg} / \mathrm{L}$.

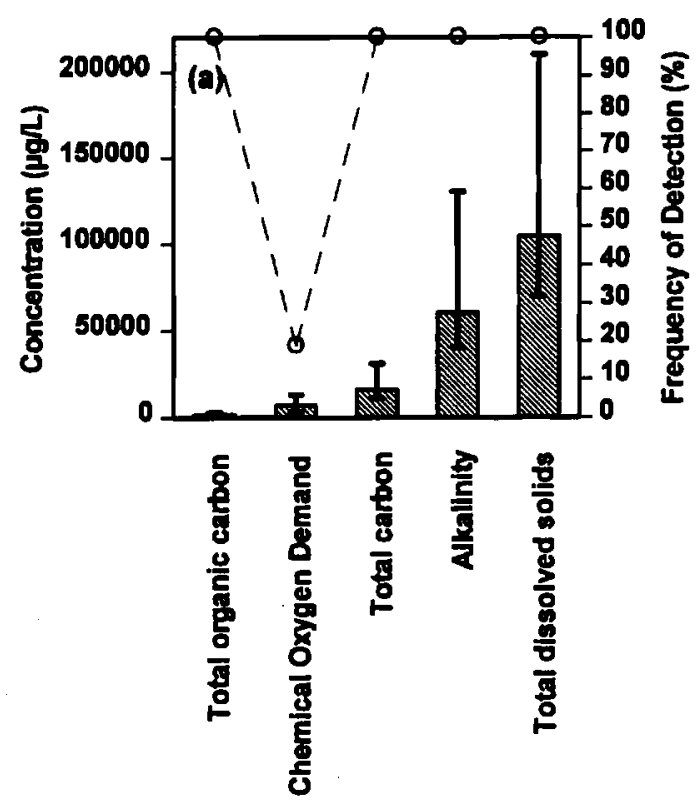

Figure 5.1. Building 320 General Chemical Parameters: (a) Routine Sampling (Total Organic Carbon Average 1,781 $\mu \mathrm{g} / \mathrm{L}$, Range $1,000$ to $3,000 \mu \mathrm{g} / \mathrm{L})$ 


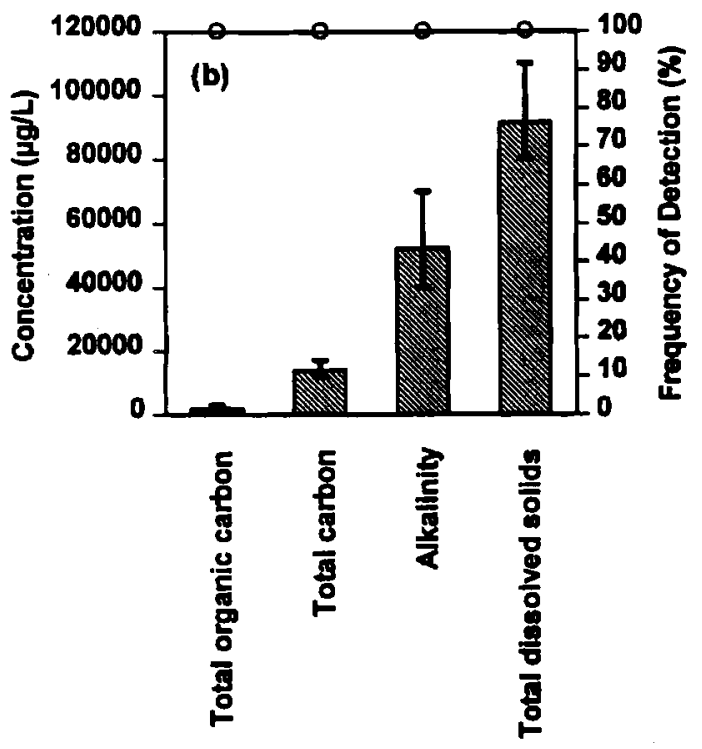

Figure 5.1 (contd). Building 320 General Chemical Parameters: (b) Nonbusiness Day Sampling

\subsubsection{Ammonia and Anions}

Ammonia was detected three times at very low levels in routine and nonbusiness day samples from Building 320 effluent, but the low concentrations and low frequency of detection suggest its actual presence is questionable (Figures 5.2a and b). Sulfide concentrations and frequency of detection were comparable to those found in the bottle blanks. Moreover, the concentration of sulfides was near the method detection limit $(210 \mu \mathrm{g} / \mathrm{L})$. Fluoride concentrations (average $=571 \mu \mathrm{g} / \mathrm{L}$ ) were comparable to influent levels and were similar for both sample types. The concentration of nitrate (100 to $15,600 \mu \mathrm{g} / \mathrm{L}$ ) fluctuated considerably in the routine samples (from levels comparable to influent to 30 times greater than influent concentrations); nitrate levels were much more constant in the nonbusiness day samples (200 to $1,700 \mu \mathrm{g} / \mathrm{L})$ and averaged less than twice influent levels. Chloride $(1,800$ to $11,800 \mu \mathrm{g} / \mathrm{L})$ and sulfate 18,500 to $23,500 \mu \mathrm{g} / \mathrm{L}$ ) concentrations were comparable among both sample types and were similar to the influent levels. However, routine samples had 50 to $100 \%$ greater levels of chloride and sulfate than nonbusiness day samples (Figures $5.2 \mathrm{~b}$ and $\mathrm{c}$ ).

For reference only /building effluent is not meant to be drinking water and is treated by the TEDF before being discharged to the river), concentrations of ammonia and anions were compared to the National Drinking Water Standards, which exist for four of the constituents detected (chloride, fluoride, nitrate, and sulfate). Only the nitrate standard of $10 \mathrm{mg} / \mathrm{L}$ was exceeded with a maximum observed concentration of $15.6 \mathrm{mg} / \mathrm{L}$ in the effluent. The TEDF waste acceptance criteria exist for only one of the constituents detected; ammonia was measured at a small fraction $(<3 \%)$ of the waste acceptance criteria.

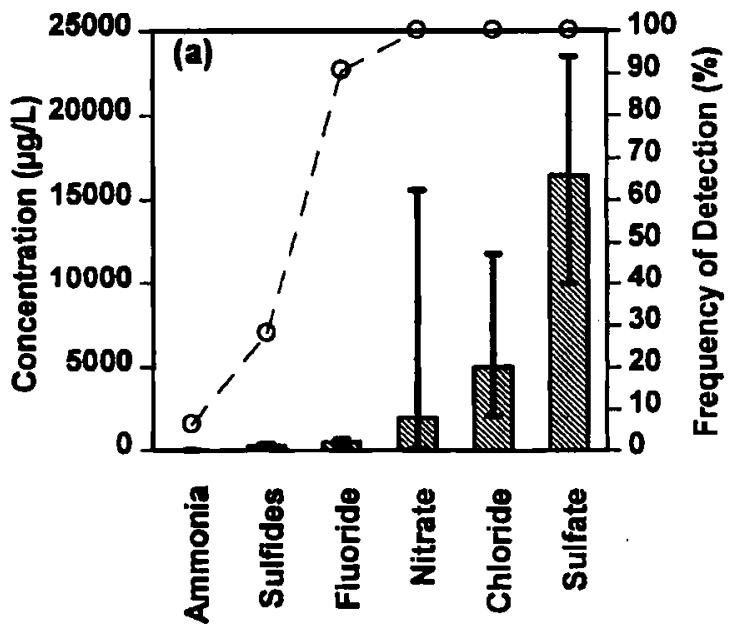

Figure 5.2. Building 320 Ammonia and Anions: (a) Routine Sampling (Ammonia Average $30 \mu \mathrm{g} / \mathrm{L}$, Range N/A; Sulfides Average $296 \mu \mathrm{g} / \mathrm{L}$, Range 220 to $400 \mu \mathrm{g} / \mathrm{L}$ ) 

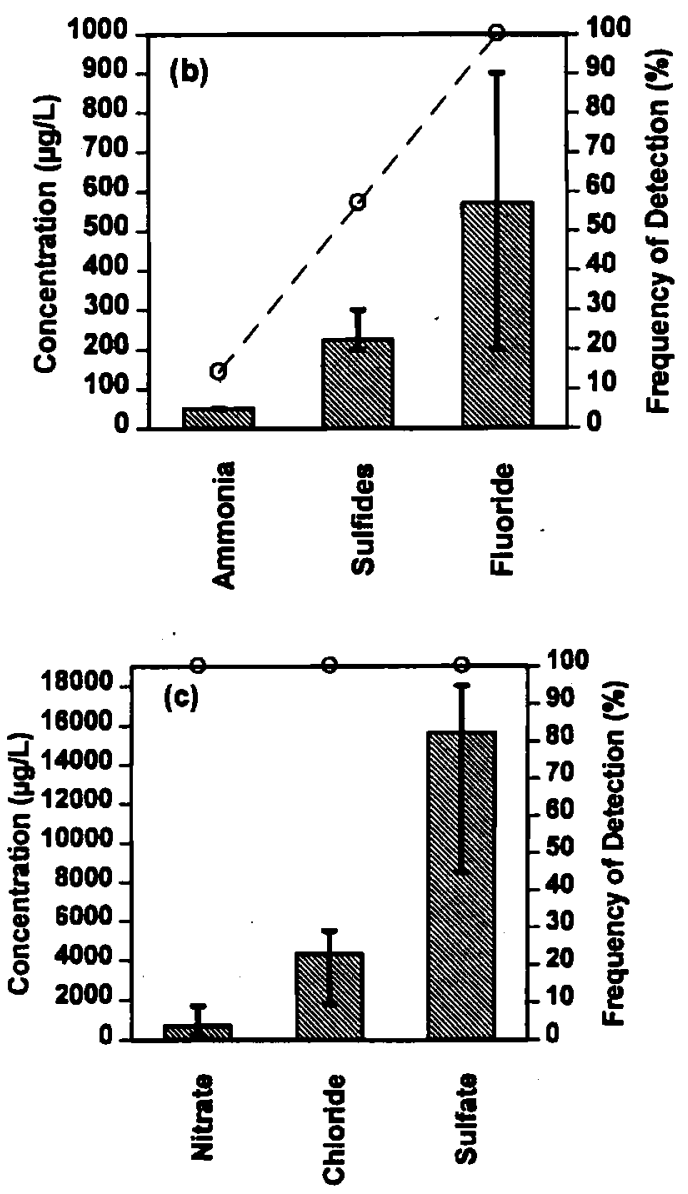

Figure 5.2 (contd). Building 320 Ammonia and Anions: (b) Nonbusiness Day Sampling Concentrations Less than 1,000 $\mu \mathrm{g} / \mathrm{L}$, (c) Nonbusiness Day Sampling Concentrations Greater than $1,000 \mu \mathrm{g} / \mathrm{L}$

\subsubsection{Metals}

The concentrations of heavy metals found in Building 320 effluent were generally similar to levels found in the blank and influent samples. A few exceptions should be noted. Low levels of mercury were detected with similar frequencies $(20 \%)$ in the routine and nonbusiness day samples; 50 to $100 \%$ higher concentrations of mercury and lead

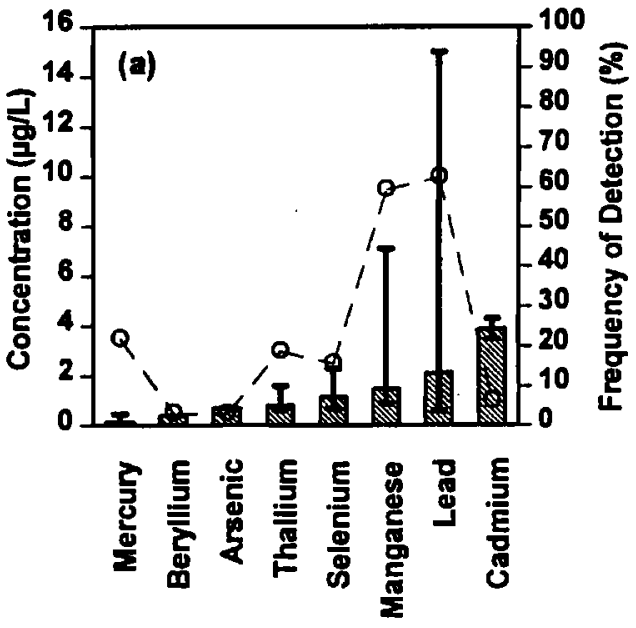

Figure 5.3. Building 320 Metals: (a) Routine Sampling Concentrations Less than $16 \mu \mathrm{g} / \mathrm{L}$ (Mercury Average $0.15 \mu \mathrm{g} / \mathrm{L}$, Range 0.05 to $0.46 \mu \mathrm{g} / \mathrm{L})$ 

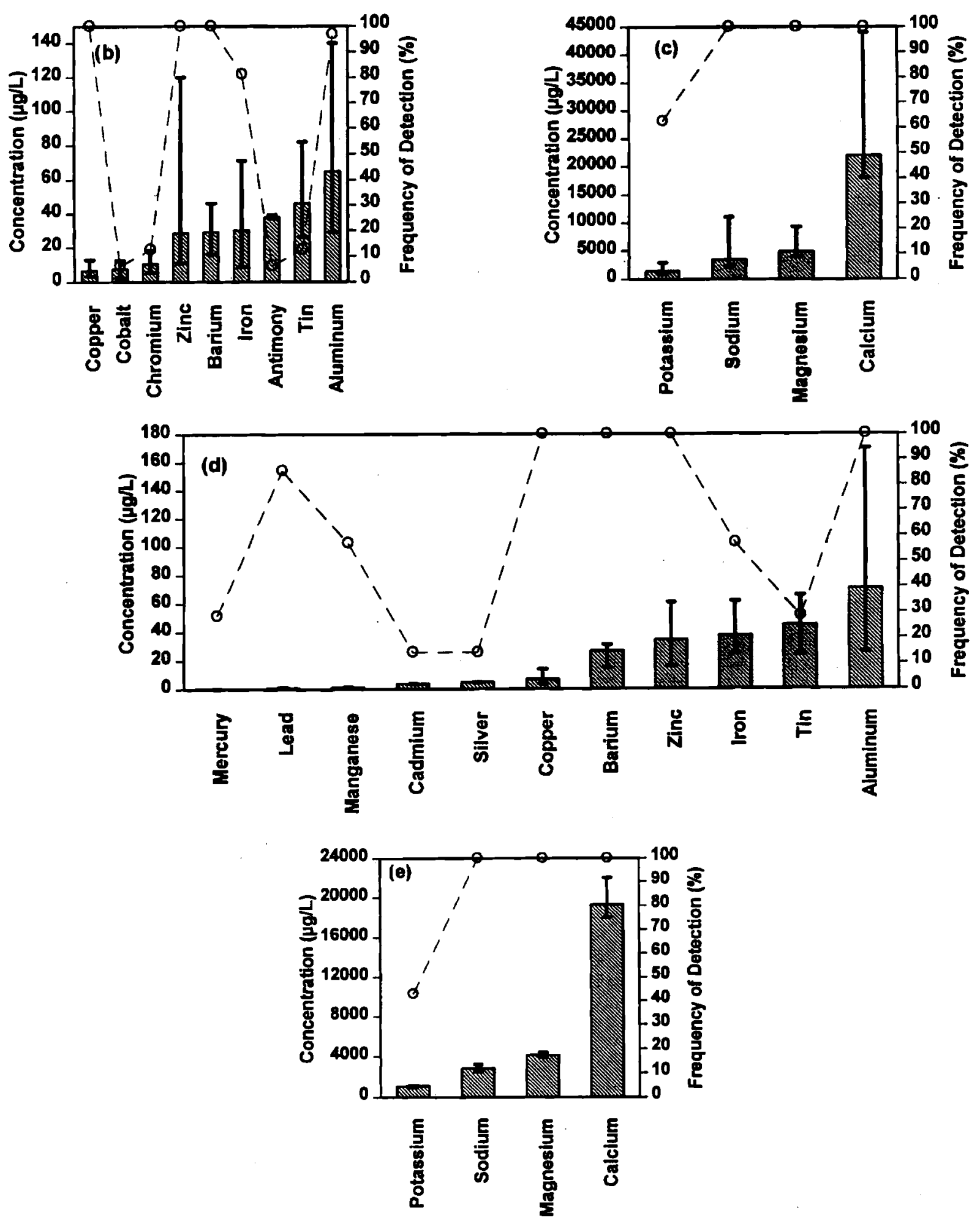

Figure 5.3 (contd). Building 320 Metals: (b) Routine Sampling Concentrations Between 16 and $140 \mu \mathrm{g} / \mathrm{L}$, (c) Routine Sampling Concentrations Greater than $140 \mu \mathrm{g} / \mathrm{L}$, (d) Nonbusiness Day Sampling Concentrations Less than $180 \mu \mathrm{g} / \mathrm{L}$ (Mercury Average $0.15 \mu \mathrm{g} / \mathrm{L}$, Range N/A; Lead Average $0.9 \mu \mathrm{g} / \mathrm{L}$, Range 0.6 to $1.2 \mu \mathrm{g} / \mathrm{L}$; Manganese Average $1.3 \mu \mathrm{g} / \mathrm{L}$, Range 1.2 to $1.6 \mu \mathrm{g} / \mathrm{L}$ ), (e) Nonbusiness Day Sampling Concentrations Greater than $180 \mu \mathrm{g} / \mathrm{L}$ 


\subsubsection{Volatile Organic Compounds}

A variety of VOCs were detected in routine and nonbusiness day samples (Figures 5.4a and b). 1,1,1-trichloroethane and toluene were detected at or just slightly above the method detection limits. Therefore, the presence of these compounds in the effluent is somewhat questionable. Similarly, the frequent detection of methylene chloride should be considered suspect based on the high detection frequency of this compound in the reagent blanks.

Trihalomethanes were detected in routine and nonbusiness day samples (Figure 5.4a through c); the average concentrations of bromodichloromethane and chloroform were similar to the treated influent concentrations. Bromoform and dibromochloromethane were also detected infrequently at low concentrations(i.e., less than $2 \mu \mathrm{g} / \mathrm{L}$ ) in the routine samples.

Several common solvents, including acetone, acetonitrile, 2-butanone (methyl ethyl ketone), hexone (methyl isobutyl ketonel, and tetrahydrofuran, were detected in $15 \%$ or less of the routine samples. The average concentrations of these constituents ranged from $26 \mu \mathrm{g} / \mathrm{L}$ (acetone and 2-butanone) to $170 \mu \mathrm{g} / \mathrm{L}$ (acetonitrile). Similar concentrations of acetone and approximately $50 \%$ lower concentrations of hexone were detected in nonbusiness day samples (Figure 5.4c).

Ethylbenzene and total xylenes were sporadically detected at low concentrations (12 $\mu \mathrm{g} / \mathrm{L}$ or less) in routine and nonbusiness day samples. The average concentrations of both constituents were about twice as high in the routine samples as in the nonbusiness day samples (Figures 5.4a and $\mathrm{c}$ ).

Specific waste acceptance criteria from the TEDF exist for five of the constituents detected: bromodichloromethane, chloroform, methylene chloride, toluene, and 1,1,1-trichloroethane. Of these, only chloroform measurements (up to $32 \mu \mathrm{g} / \mathrm{L}$ ) exceeded the waste acceptance criteria. Chloroform is produced from chlorination of influent in the treatment facility (Building 315) and was measured at Building 315 in concentrations up to $41 \mu \mathrm{g} / \mathrm{L}$. The two other constituents (ethylbenzene and xylenes) that were measured did not exceed the National Drinking Water Standards.

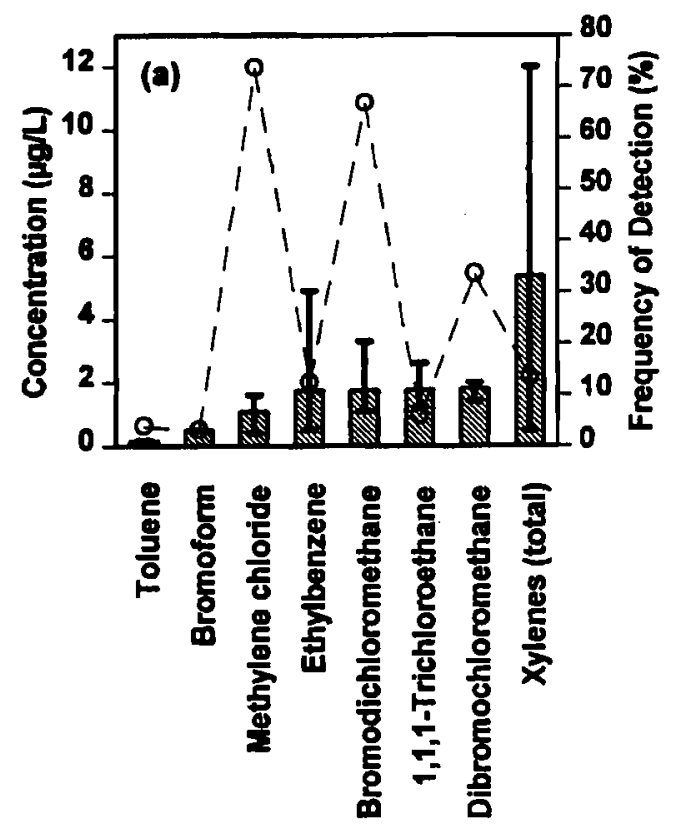

Figure 5.4. Building 320 Volatile Organic Compounds: (a) Routine Sampling Concentrations Less than $12 \mu \mathrm{g} / \mathrm{L}$ (Toluene Average $0.16 \mu \mathrm{g} / \mathrm{L}$, Range 0.14 to $0.18 \mu \mathrm{g} / \mathrm{L}$ ) 

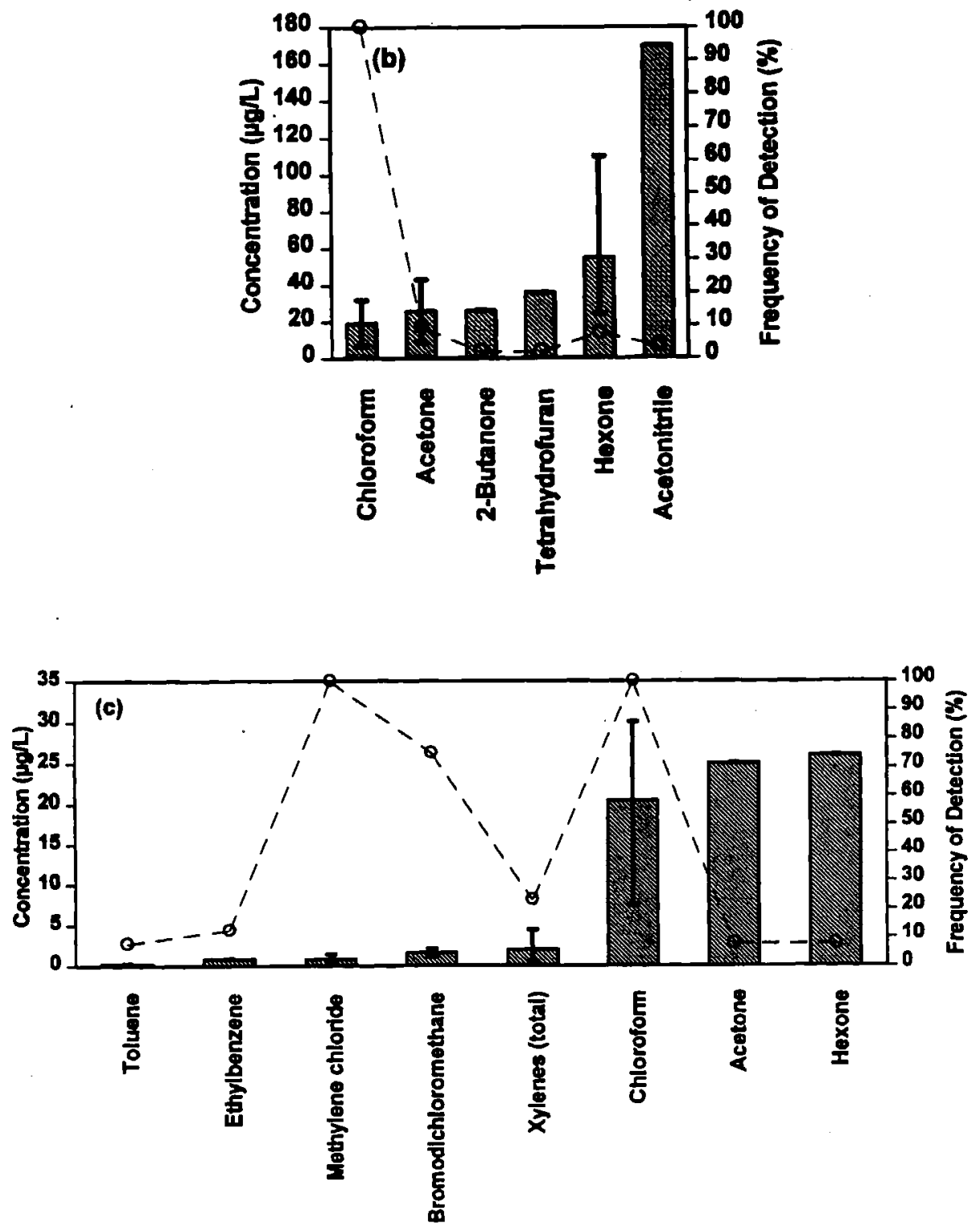

Figure 5.4 (contd). Building 320 Volatile Organic Compounds: (b) Routine Sampling Concentrations Greater than $12 \mu \mathrm{g} / \mathrm{L}$, (c) Nonbusiness Day Sampling (Toluene Average $0.2 \mu \mathrm{g} / \mathrm{L}$, Range N/A)

\subsubsection{Semivolatile Organic Compounds}

Di-n-butylphthalate was found at trace levels in about $10 \%$ of the routine samples. Phthalates are commonly found at trace levels in liquids that have contacted plastic materials. Thus, this constituent is likely an artifact of the sampling and analysis process and not a constituent being discharged as a result of building activities. 


\subsubsection{Radiological Parameters}

No gross alpha or gross beta radiation was detected in the nonbusiness day samples. Although very low levels (i.e., less than $5 \mathrm{pCi} / \mathrm{L}$ ) of both were measured in approximately $33 \%$ of the routine samples (Figure 5.5), the positive detects are suspect, because none of the results were greater than twice the background counting error. Tritium analyses were not performed on Building 320 samples. All measurements were less than the TEDF waste acceptance criteria.
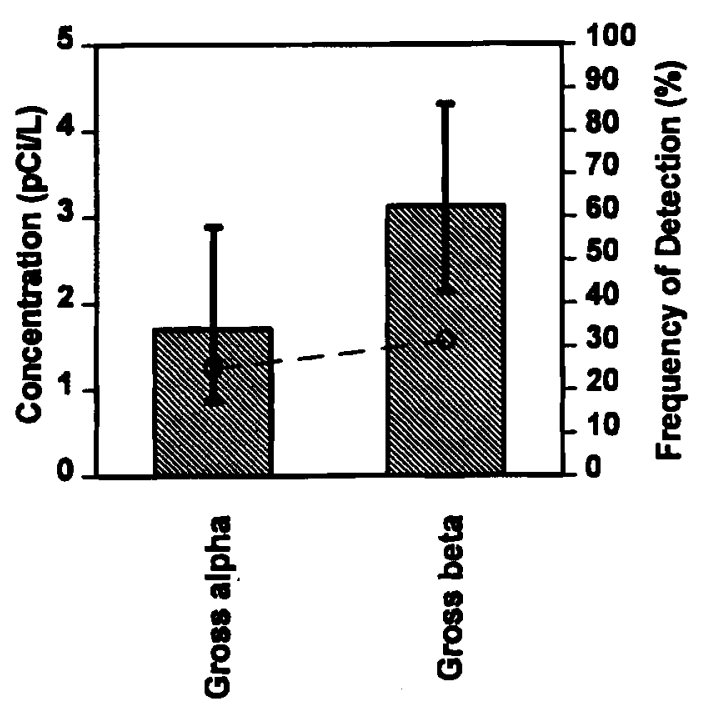

Figure 5.5. Building 320 Radiological Parameters for Routine Sampling 



\subsection{Building 324 (Process Sewer and Retention Process Sewer)}

\subsection{Background and Description}

Building 324 is located in approximately the middle of the 300 Area, just off of Locust Street. Staff in this building conduct research in the areas of waste characterization and immobilization, waste remediation and clean-up development, biomass research, spent fuel characterization, tritium development, and cesium chloride encapsulation.

\subsection{Routine Sampling}

At Building 324, two process sewer and three retention process sewer sampling events occurred. All the samples were $24-\mathrm{hr}$ composites. Table C. 2 shows the analyses performed for each sampling event. The small number of sampling events make the results for Building 324 tentative. Summary data supporting the constituent class discussions in Sections 6.2.1 through 6.2.6 are shown in the accompanying figures. Comparisons to influent chemistry are based on the data in Appendix E. Tables with detailed building effluent information can be found in Appendix F.

\subsubsection{General Chemical Parameters}

Most of the general chemical parameters were lower in the process sewer (Figure 6.1a) than in the retention process sewer (Figure 6.1b), but the levels in both were distinct from the influent. Chemical oxygen demand concentrations were approximately $30 \%$ (retention process sewer) to $50 \%$ (process sewer) lower than the concentration observed in the treated influent. Total organic carbon concentrations were $20 \%$ (retention process sewer) to $25 \%$ (process sewer) as high as influent levels. Concentrations of alkalinity, total carbon, and total dissolved solids were approximately 35 to $45 \%$ higher in the retention process sewer than in the process sewer. Retention process sewer values for these three parameters were also roughly 25 to $55 \%$ greater than treated influent values.

None of the general chemical parameters that were investigated have regulatory standards of comparison except total dissolved solids. The maximum total dissolved solids value observed for Building 324 was $200 \mathrm{mg} / \mathrm{L}$, which is much less than the National Secondary Drinking Water Standard of $500 \mathrm{mg} / \mathrm{L}$.

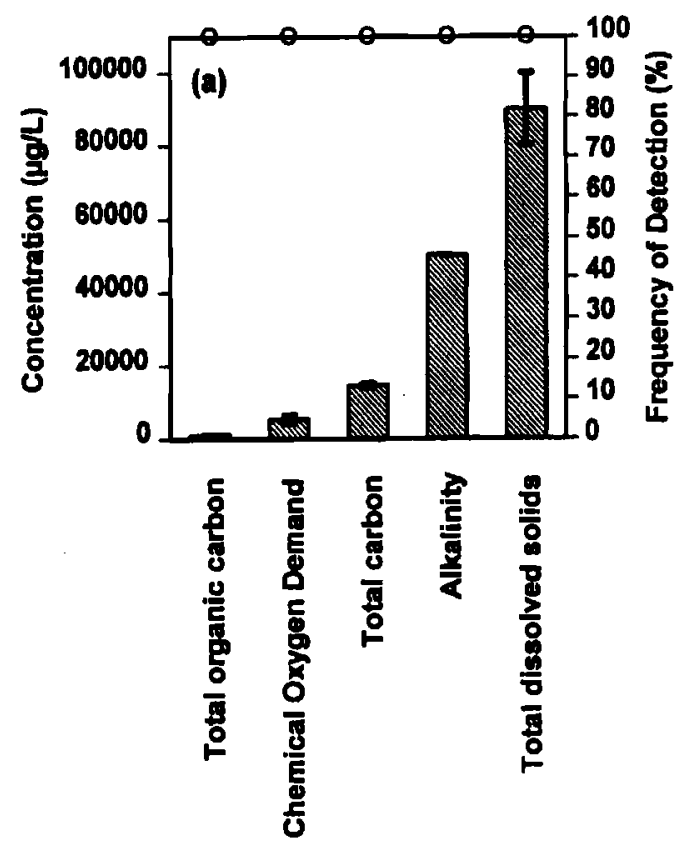

Figure 6.1. Building 324 General Chemical Parameters: (a) Process Sewer (Total Organic Carbon Average 1,000 $\mu \mathrm{g} / \mathrm{L}$, Range N/A) 


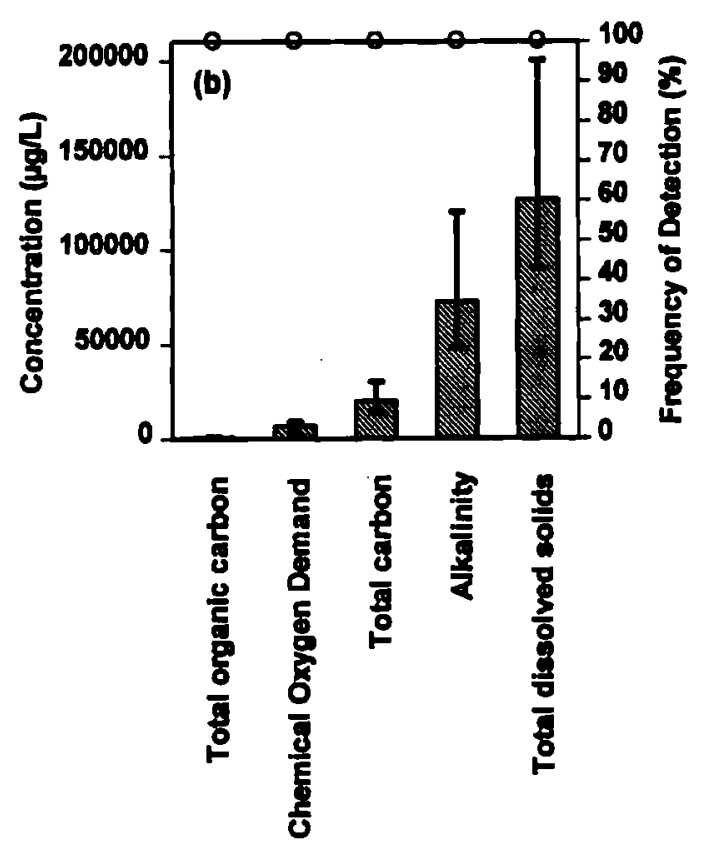

Figure 6.1 (contd). Building 324 General Chemical Parameters: (b) Retention Process Sewer (Total Organic Carbon Average $767 \mu \mathrm{g} / \mathrm{L}$, Range 600 to $1,000 \mu \mathrm{g} / \mathrm{L}$ )

\subsubsection{Ammonia and Anions}

Ammonia was detected once in the retention process sewer, and sulfides were detected in both the process sewer (300 $\mu \mathrm{g} / \mathrm{L})$ and retention process sewer $(350 \mu \mathrm{g} / \mathrm{L}$ ) (Figures $6.2 \mathrm{a}$ and $\mathrm{b})$. The average concentration of nitrate in. the retention process sewer $(5,748 \mu \mathrm{g} / \mathrm{L})$ was 17 times higher than the concentration observed in the treated influent and nearly 7 times higher than the process sewer level. The concentration of chloride was twice as high in the retention process sewer $(6,427 \mu \mathrm{g} / \mathrm{L})$ compared to the process sewer, while sulfate $(17,467 \mu \mathrm{g} / \mathrm{L})$ was only $20 \%$ higher.

For reference only (building effluent is not meant to be drinking water and is treated by the TEDF before being discharged to the river), concentrations of ammonia and anions were compared to the National Drinking Water Standards which exist for four of the constituents detected (chloride, fluoride, nitrate, and sulfate). Only the nitrate standard of $10 \mathrm{mg} / \mathrm{L}$ was exceeded with a maximum observed concentration of $15.4 \mathrm{mg} / \mathrm{L}$ in the effluent (this was true of almost all of the building waste streams). The TEDF waste acceptance criteria exist for only one of the constituents detected; ammonia was measured only in the retention process sewer stream at a small fraction $(<3 \%)$ of the waste acceptance criteria.
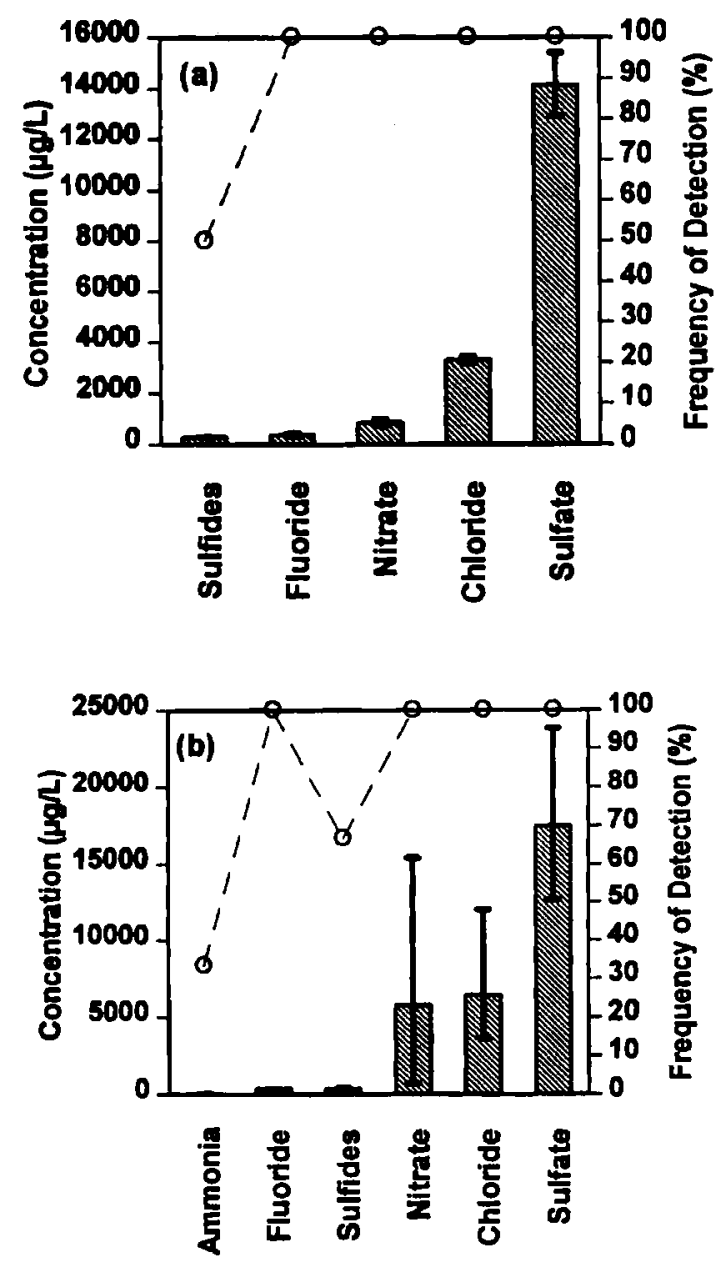

Figure 6.2. Building 324 Anions: (a) Process Sewer (b) Retention Process Sewer (Ammonia Average $50 \mu \mathrm{g} / \mathrm{L}$, Range N/A) 


\subsubsection{Metals}

Heavy metals were detected at concentrations comparable to various blank and influent results, although retention process sewer cations (potassium, sodium, magnesium, and calcium) were found at elevated levels. The average sodium $(5,433 \mu \mathrm{g} / \mathrm{L})$ and potassium $(2,150 \mu \mathrm{g} / \mathrm{L})$ concentrations were
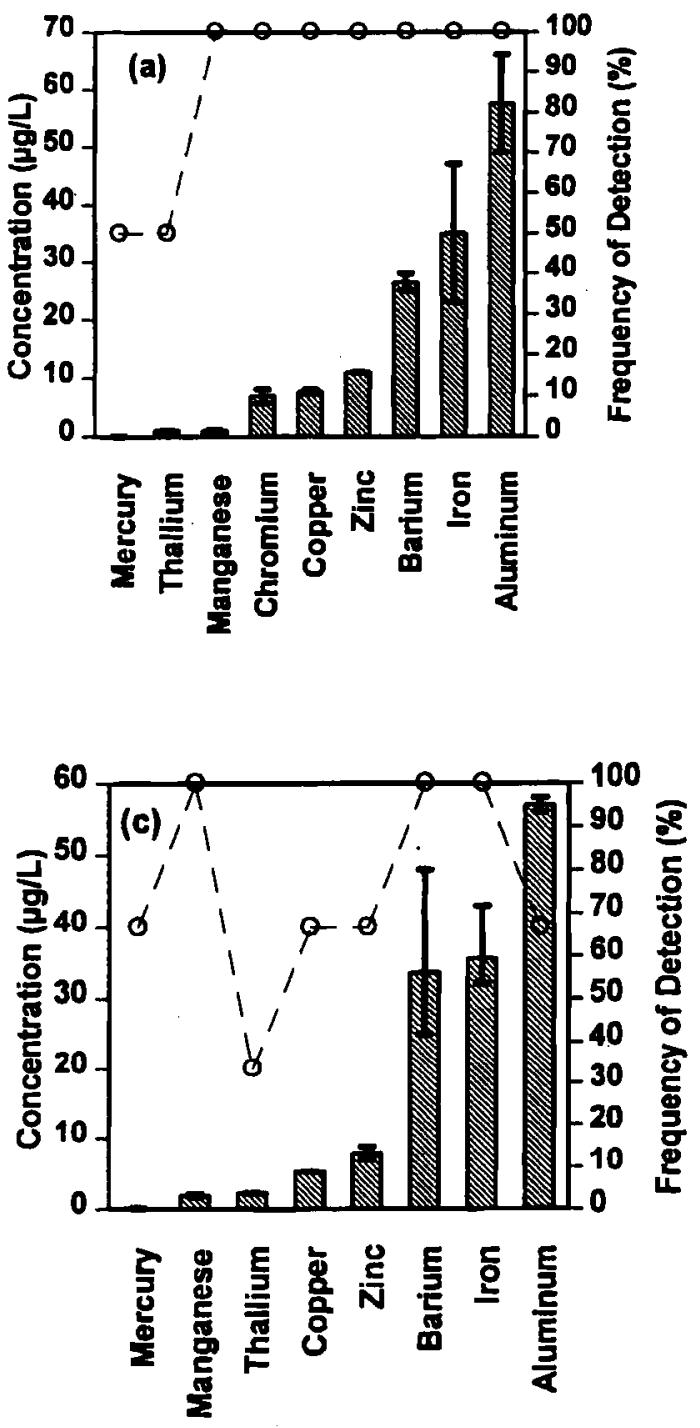

twice as high in the retention process sewer relative to the process sewer, while calcium and magnesium were $50 \%$ higher (Figure 6.3a through d).

The TEDF has waste acceptance criteria for seven of the metals detected: aluminum, chromium, copper, iron, manganese, mercury, and zinc. None of the metals exceeded the criteria.
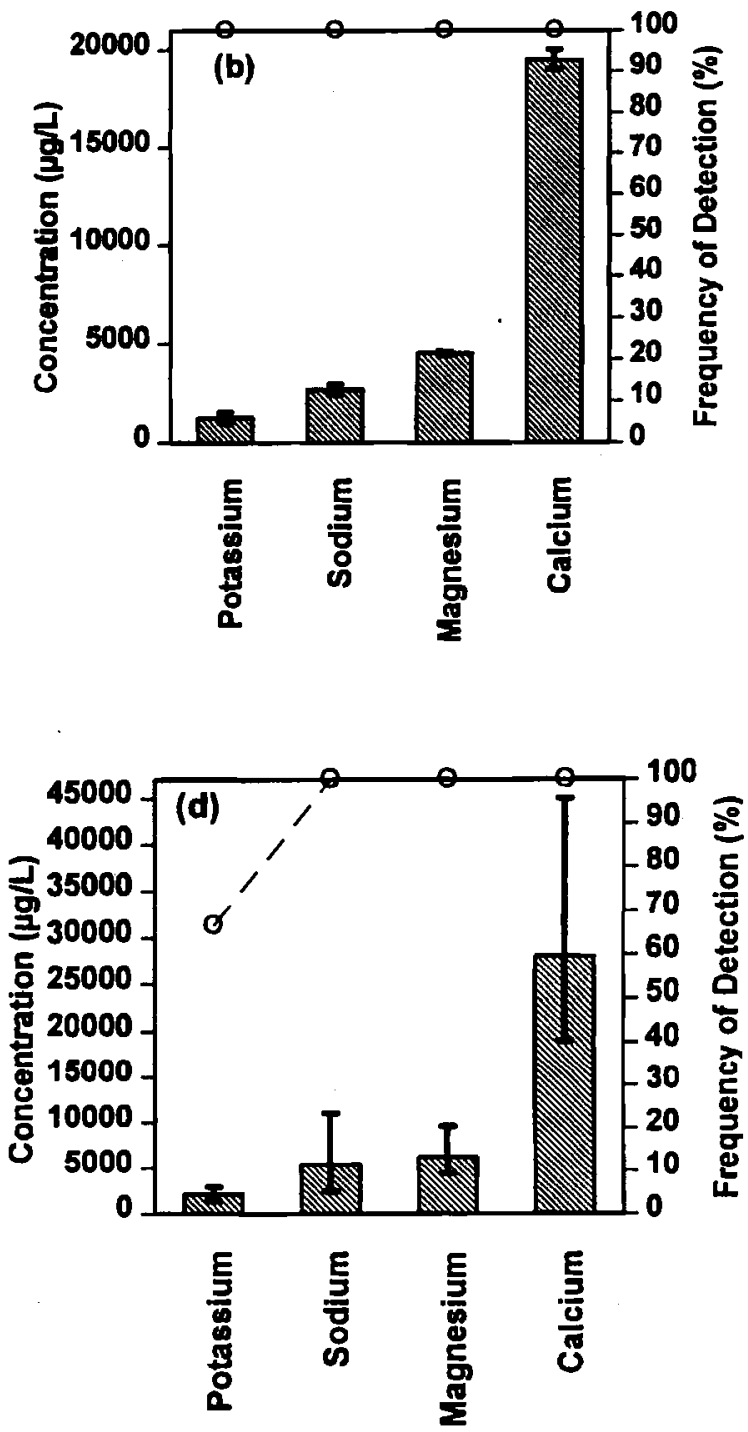

Figure 6.3. Building 324 Metals: Concentrations Greater than $70 \mu \mathrm{g} / \mathrm{L}$, (a) Process Sewer with Concentrations Less than $70 \mu \mathrm{g} / \mathrm{L}$ (Mercury Average $0.12 \mu \mathrm{g} / \mathrm{L}$, Range N/A) (b) Process Sewer with Concentrations Greater than $70 \mu \mathrm{g} / \mathrm{L}$, (c) Retention Process Sewer with Concentrations Less than $60 \mu \mathrm{g} / \mathrm{L}$ (Mercury Average $0.07 \mu \mathrm{g} / \mathrm{L}$, Range 0.05 to $0.09 \mu \mathrm{g} / \mathrm{L}$ ), (d) Retention Process Sewer with Concentrations Greater than $60 \mu \mathrm{g} / \mathrm{L}$ 


\subsubsection{Volatile Organic Compounds}

Three VOCs, bromodichloromethane, dibromochloromethane, and chloroform, were detected in both the process sewer and retention process sewer (Figures 6.4a and b). All three compounds are trihalomethanes and are common byproducts of water disinfection. Of the VOCs, chloroform was measured at the highest concentrations in both waste streams 4 to $9 \mu \mathrm{g} / \mathrm{L})$, but the average concentrations were roughly 70 to $80 \%$ lower compared to the treated influent. Dibromochloromethane and bromodichloromethane were measured at approximately $1 \mu \mathrm{g} / \mathrm{L}$ in both the process sewer and retention process sewer; concentrations of bromodichloromethane were roughly 15 to $40 \%$ lower than treated influent levels. The TEDF waste acceptance criteria were not exceeded for these constituents.

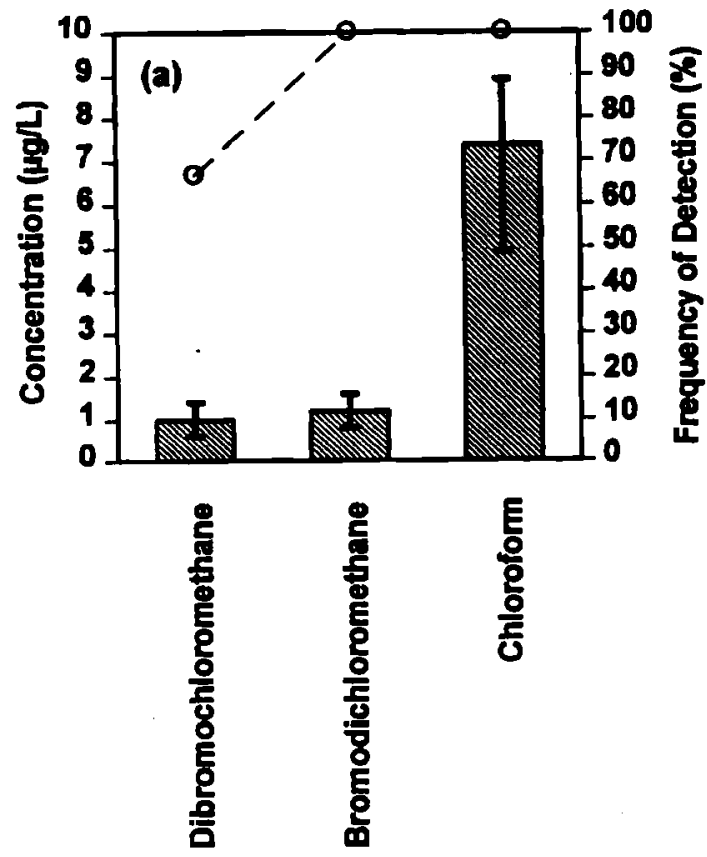

Figure 6.4. Building 324 Volatile Organic Compounds: (a) Process Sewer
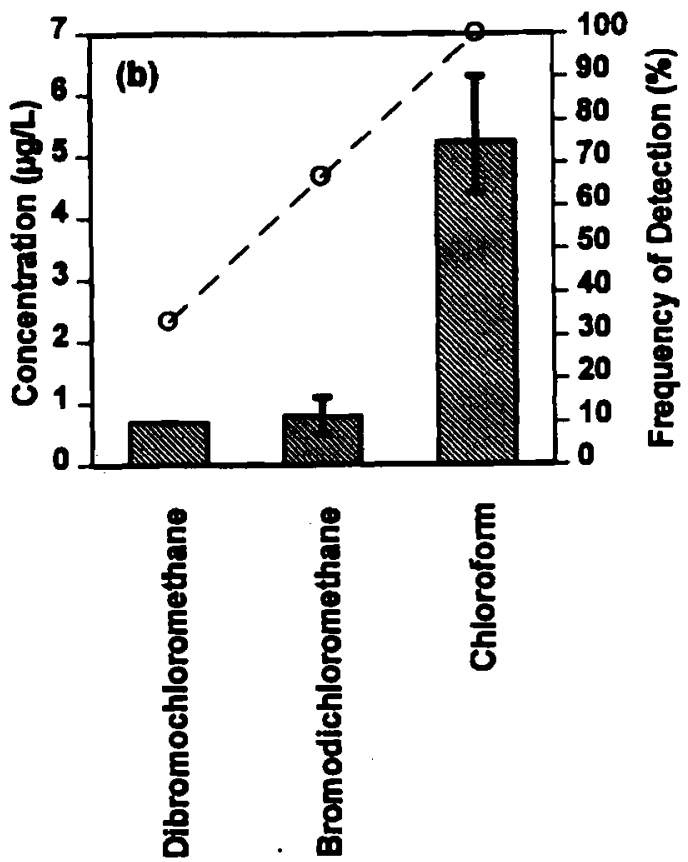

Figure 6.4. (contd) Building 324 Volatile Organic Compounds: (b) Retention Process Sewer

\subsubsection{Semivolatile Organic Compounds}

No target SVOCs were detected in the process sewer or retention process sewer samples.

\subsubsection{Radiological Parameters}

Gross alpha, gross beta, and tritium were detected at very low levels in samples from both the process sewer and retention process sewer (Figures $6.5 \mathrm{a}$ and b). The average concentrations of tritium and gross alpha were approximately 20 to $25 \%$ higher in the retention process sewer, while gross beta was nearly twice as high in the process sewer. Because of the low levels of radiation encountered and the relatively small number of samples analyzed, these results should be considered tentative. The TEDF waste acceptance criteria were not exceeded for these constituents. 

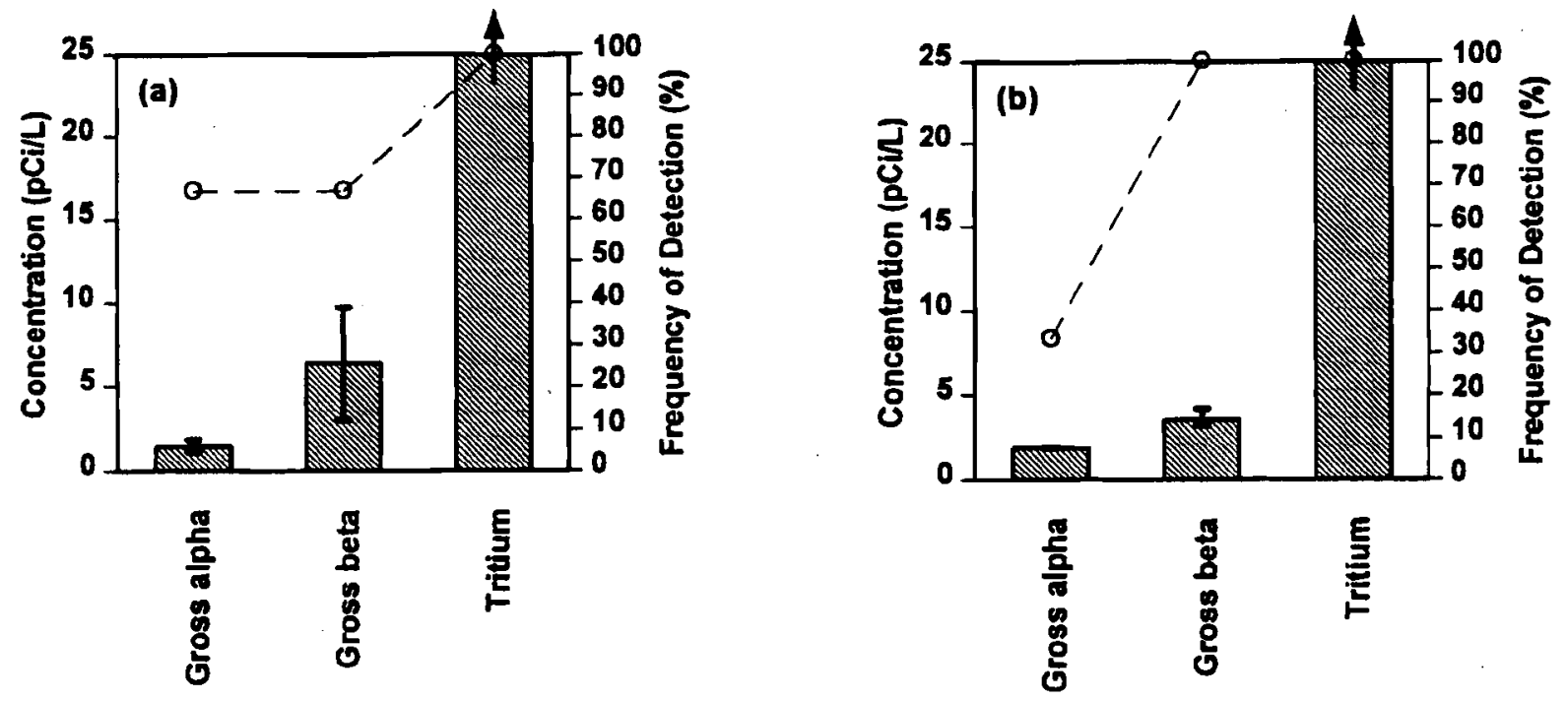

Figure 6.5. Building 324 Radiological Parameters: (a) Process Sewer (Tritium Average $358.5 \mathrm{pCi} / \mathrm{L}$, Range 172.0 to $545.0 \mathrm{pCi} / \mathrm{L}$ ), (b) Retention Process Sewer (Tritium Average $421.7 \mathrm{pCi} / \mathrm{L}$, Range 136.0 to $627.0 \mathrm{pCi} / \mathrm{L})$ 



\subsection{Building 326 (Process Sewer)}

\subsection{Background and Description}

Building 326 is located in the northwest part of the 300 Area along Wisconsin Street. Staff conduct studies of metallurgical, chemical, and physical properties of materials.

\subsection{Routine Sampling}

At Building 326, seven 24-hr composite and one grab sampling events occurred. However, eight analyses were not performed for all constituents. Table C.2 lists the analyses performed for the sampling events from Building 326 . Summary data supporting the constituent class discussions in Sections 7.2.1 through 7.2.6 are shown in the accompanying figures. Comparisons to influent chemistry are based on the data in Appendix E. Tables with detailed building effluent information are in Appendix $F$.

\subsubsection{General Chemical Parameters}

Concentrations of all of the general chemical parameters in the effluent showed large fluctuations and elevated average concentrations when compared to the treated influent. Alkalinity, total carbon, and total dissolved solid concentrations were each approximately $85 \%$ higher, total organic carbon concentrations were about twice as high, and chemical oxygen demand concentrations were more than three times greater (Figure 7.1).

None of the general chemical parameters that were investigated have regulatory standards of comparison except total dissolved solids. The

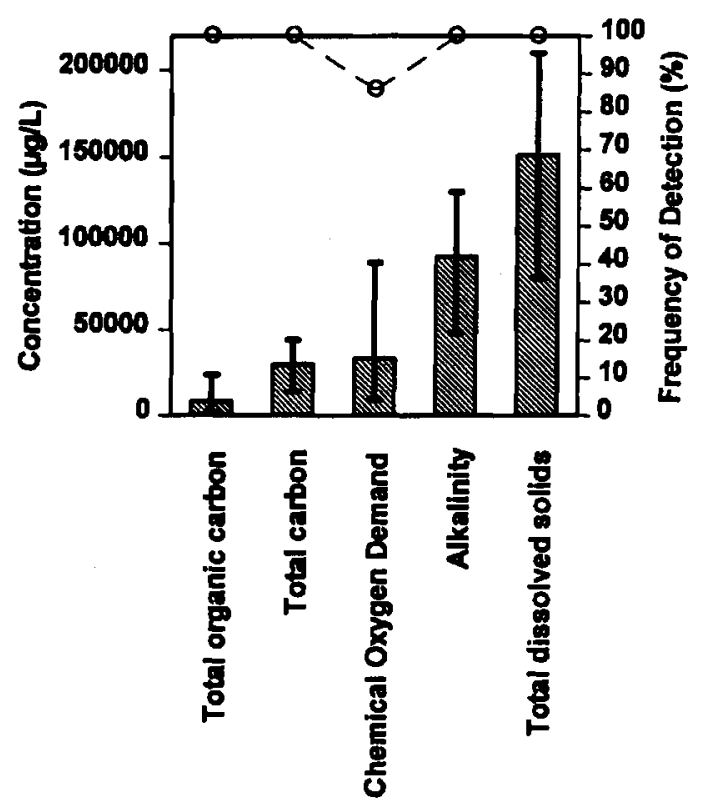

Figure 7.1. Building 326 General Chemical Parameters

maximum total dissolved solids value observed for Building 326 was $210 \mathrm{mg} / \mathrm{L}$, which is much less than the National Secondary Drinking Water Standard of $500 \mathrm{mg} / \mathrm{L}$.

\subsubsection{Ammonia and Anions}

Ammonia (225 $\mu \mathrm{g} / \mathrm{L}$ ) and sulfides $(307 \mu \mathrm{g} / \mathrm{L})$ were found in several samples, while an easily measurable phosphate concentration was found in one sample $(1,060 \mu \mathrm{g} / \mathrm{L})$. Nitrate concentrations fluctuated considerably $(1,200$ to $12,400 \mu \mathrm{g} / \mathrm{L}$ ) and were 15 to 20 times greater than influent levels; chloride concentrations $(8,686 \mu \mathrm{g} / \mathrm{L})$ were $70 \%$ greater than influent levels. Sulfate levels $(29,771 \mu \mathrm{g} / \mathrm{L})$ were nearly twice as high as the influent levels (Figure 7.2a and b). 
For reference only (building effluent is not meant to be drinking water and is treated by the TEDF before being discharged to the river), concentrations of ammonia and anions are compared to the National Drinking Water Standards, which exist for four of the constituents detected (chloride, fluoride, nitrate, and sulfate). Only the nitrate standard of $10 \mathrm{mg} / \mathrm{L}$ was exceeded with a maximum observed concentration of $12.4 \mathrm{mg} / \mathrm{L}$ in the effluent (this was true of almost all of the building waste streams). The TEDF waste acceptance criteria exist for ammonia only; ammonia was measured at a small fraction $(<17 \%)$ of the waste acceptance criteria.
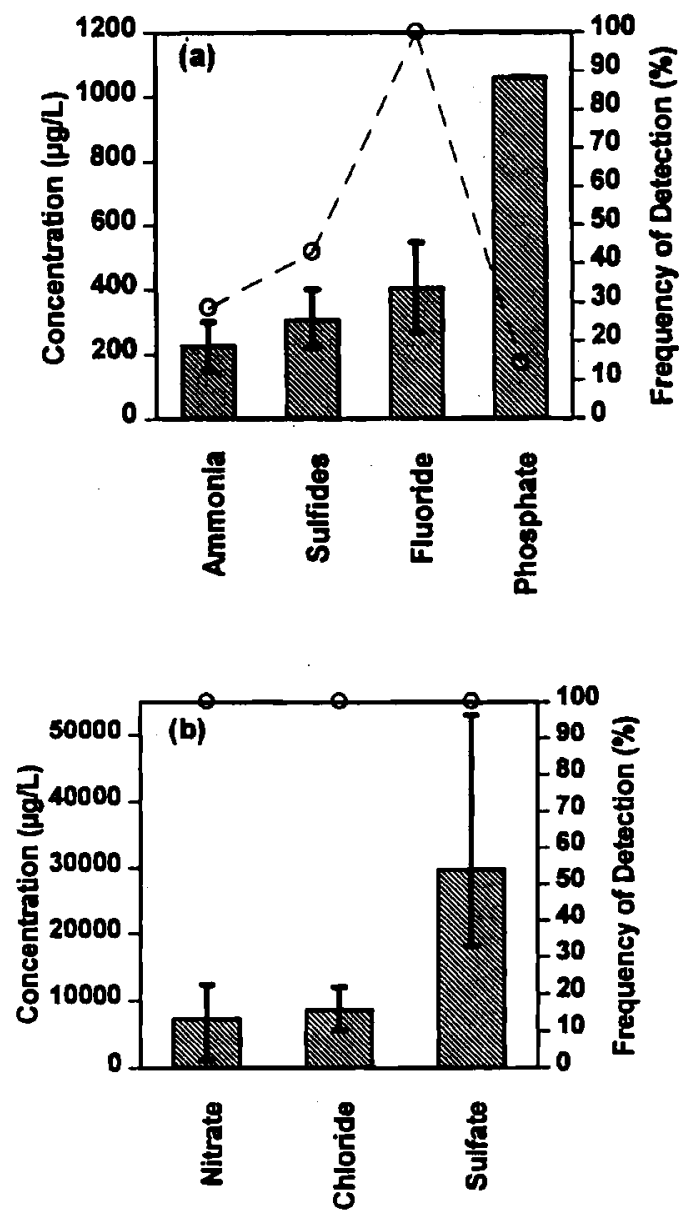

Figure 7.2. Building 326 Ammonia and Anions: (a) Concentrations Less than $1,200 \mu \mathrm{g} / \mathrm{L}$, (b) Concentrations Greater than $1,200 \mu \mathrm{g} / \mathrm{L}$

\subsubsection{Metals}

Heavy metals were found in most samples, although the low levels and frequencies of detection were comparable with those found in blanks and influent samples. One exception was mercury, which did not appear in the blank or influent samples, but was found in two samples $(0.11$ to $0.23 \mu \mathrm{g} / \mathrm{L})$ at 2 to 3 times the method detection limit. Lead and chromium were detected in liquid effluents at levels commonly found in various blank and influent samples (i.e., below $10 \mu \mathrm{g} / \mathrm{L}$ ). Iron, manganese, and copper were measured at 5,20 , and 25 times higher than the influent, respectively. Zinc was 15 times the level observed in the influent and exhibited large concentration variations $(48$ to $520 \mu \mathrm{g} / \mathrm{L})$. Magnesium and calcium were observed at 60 to $80 \%$ higher levels than influent, while potassium and sodium were 2 and 4 times higher, respectively (Figure 7.3a through $\mathrm{c}$ ).

The TEDF has waste acceptance criteria for 11 of the metals detected: aluminum, beryllium, chromium, copper, iron, lead, manganese; mercury, nickel, selenium, and zinc. Three of the seven copper measurements and two of the seven zinc measurements exceeded the criteria. These metals are believed to be from steam condensate. Also note that even though the waste acceptance criteria are exceeded, the National Drinking Water Standards are not: the waste acceptance criteria for copper and zinc are less than an order of magnitude of drinking water standards. 

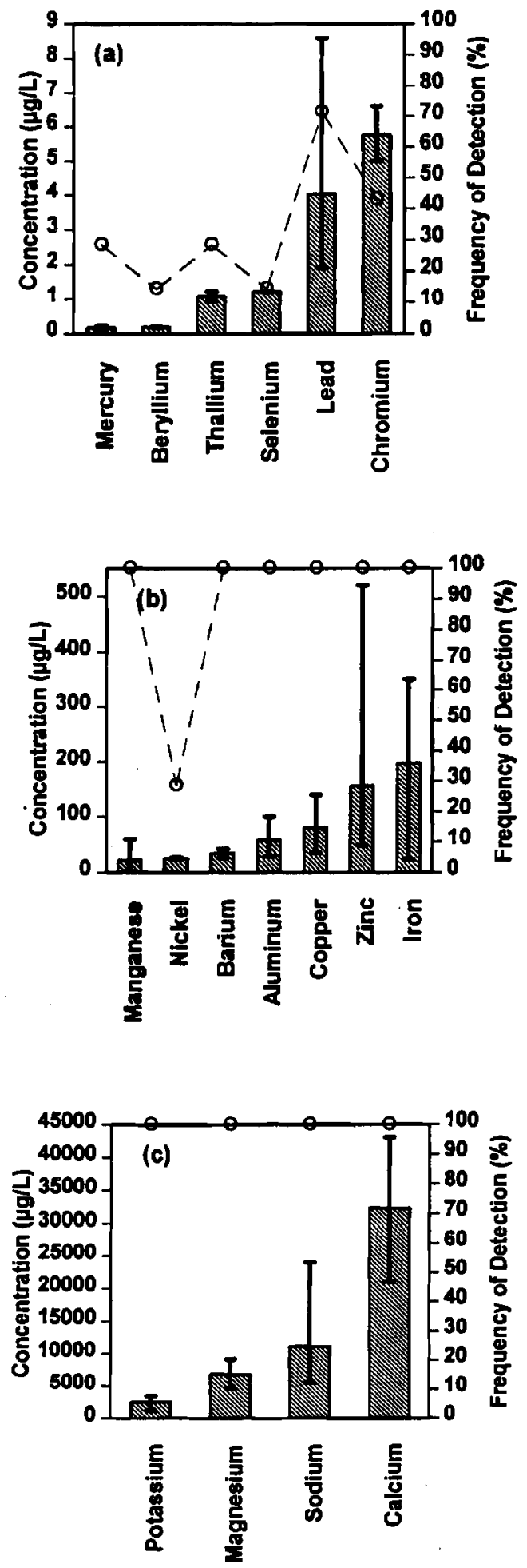

Figure 7.3. Building 326 Metals:

(a) Concentrations Less than $9 \mu \mathrm{g} / \mathrm{L}$,

(b) Concentrations Between 9 and $500 \mu \mathrm{g} / \mathrm{L}$,

(c) Concentrations Greater than $500 \mu \mathrm{g} / \mathrm{L}$

\subsubsection{Volatile Organic Compounds}

Three VOCs were detected with varying frequencies (Figure 7.4a). Concentrations of tetrahydrofuran and methylene chloride were within $10 \%$ of the concentrations found in the treated influent, but the actual presence of both compounds is suspect based on frequent blank contamination. The average chloroform level $(1.2 \mu \mathrm{g} / \mathrm{L})$ was almost 20 times lower than the concentration observed in the treated influent. The TEDF waste acceptance criteria for chloroform and methylene chloride were not exceeded.

Significant concentrations of isopropyl alcohol and acetone were measured in the effluent from Building 326 (Figure 7.4b). Isopropyl alcohol was only detected once, but its high concentration of $40,800 \mu \mathrm{g} / \mathrm{L}$ appears to account for the large range and elevated concentrations of total carbon and total organic carbon observed in the building effluent. Acetone was frequently detected and exhibited large concentration fluctuations $(450$ to $2,540 \mu \mathrm{g} / \mathrm{L}$ ).

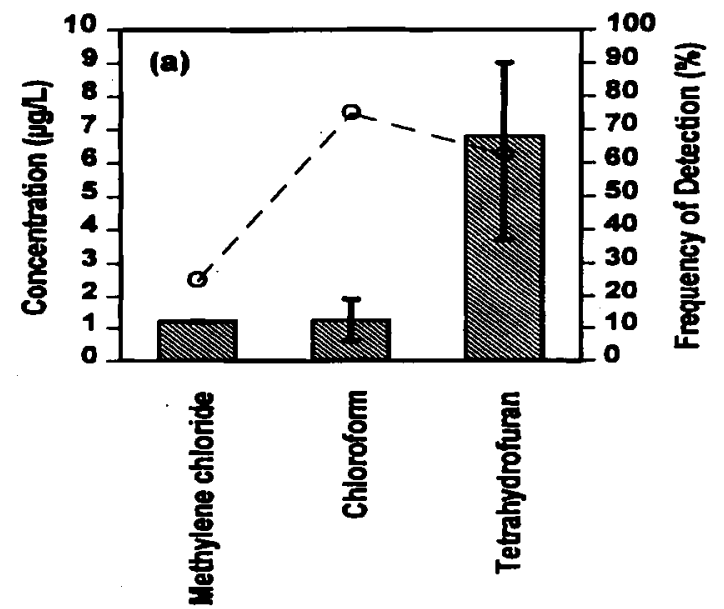

Figure 7.4. Building 326 Volatile Organic Compounds: (a) Concentrations Less than $10 \mu \mathrm{g} / \mathrm{L}$ 


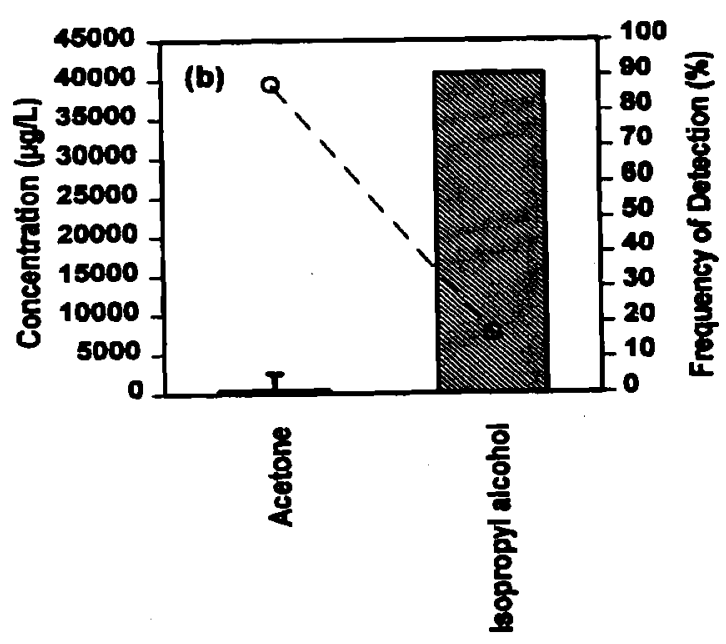

Figure 7.4 (contd). Building 326 Volatile Organic Compounds: (b) Concentrations Greater than $10 \mu \mathrm{g} / \mathrm{L}$ (Acetone Average $505 \mu \mathrm{g} / \mathrm{L}$, Range 45 to $2,535 \mu \mathrm{g} / \mathrm{L}$ )

\subsubsection{Semivolatile Organic Compounds}

Di-n-octylphthalate and diethylphthalate were found at low concentrations and frequency in the process sewer samples (Figure 7.5a). Phthalates are commonly found at trace levels in liquids that have contacted plastic materials. Low parts-per-trillion levels of two pesticides, alpha-BHC and aldrin, were found in three samples (Figure 7.5b). Influent samples had similar constituents (both phthalates and pesticides) which were found at comparable concentrations and frequencies. The TEDF waste acceptance criteria were not exceeded.
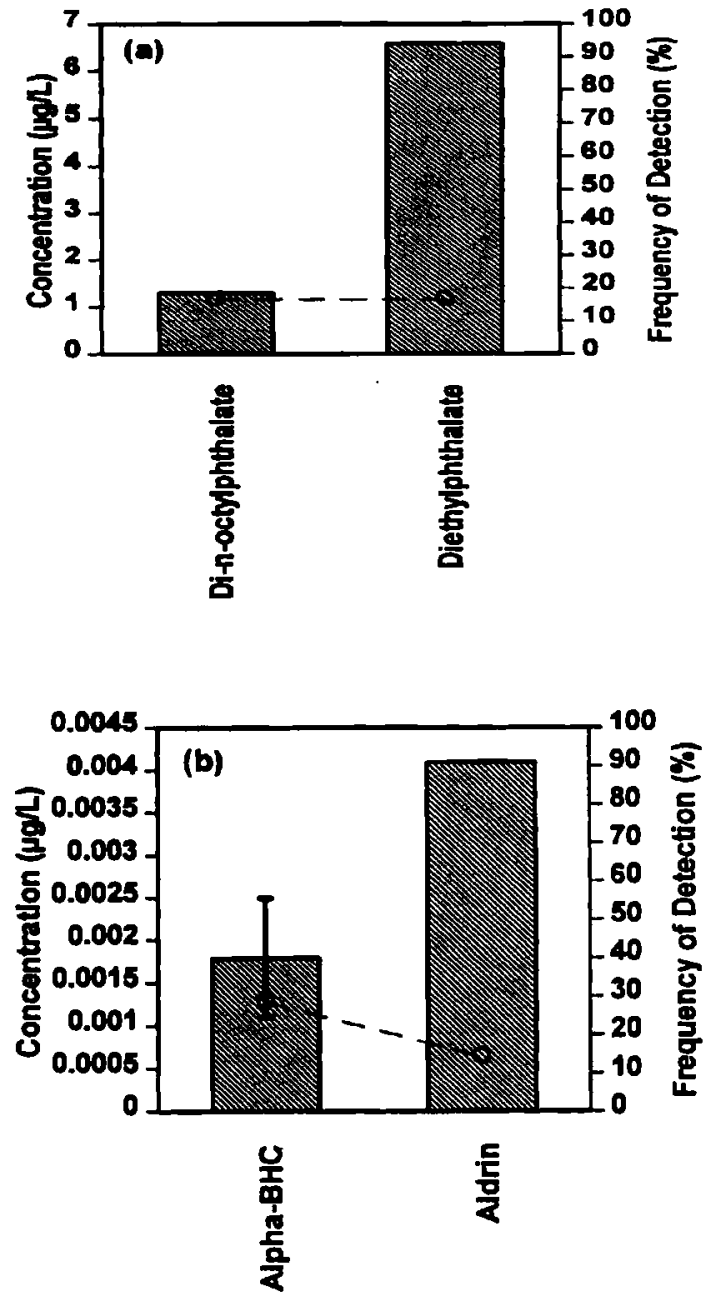

Figure 7.5. Building 326 Semivolatile Organic Compounds: (a) Di-n-octylphthalate and Diethylphthalate, (b) Pesticides

\subsubsection{Radiological Parameters}

Gross alpha, gross beta, and tritium were observed at low levels (Figure 7.6). Gross beta was detected most often, with counts above the background in approximately $85 \%$ of the samples. Tritium and gross alpha had detection frequencies of 30 and $60 \%$, respectively. However, for all three parameters, most of the sample measurements were less than 2 times the associated background counting error; no measurements were greater than 3 times 
measurements were greater than 3 times the counting error. Thus, the average concentrations and frequencies of detection probably include some falsepositive results. All measurements were less than the TEDF waste acceptance criteria $(15 \mathrm{pCi} / \mathrm{L}$ alpha, $50 \mathrm{pCi} / \mathrm{L}$ beta, and $20,000 \mathrm{pCi} / \mathrm{L}$ tritium).

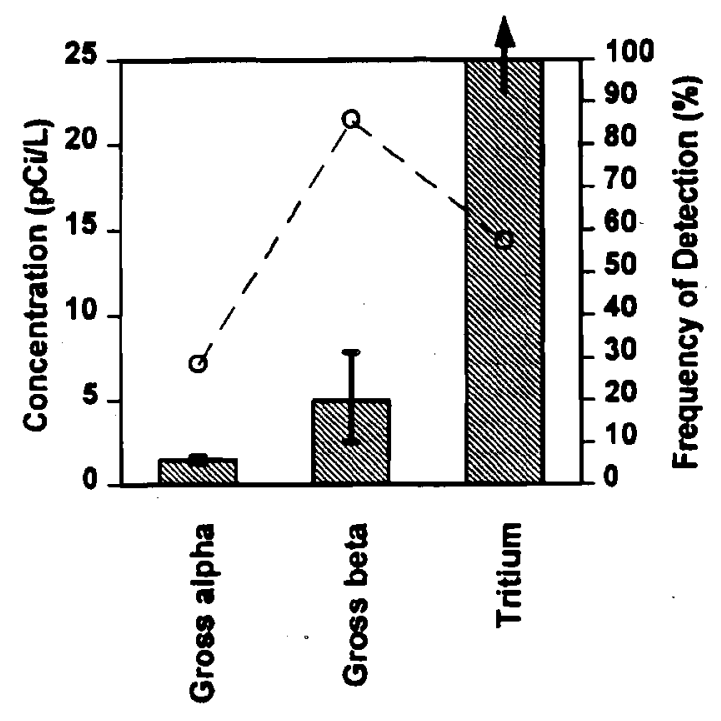

Figure 7.6. Building 326 Radiological Parameters (Tritium Average $275.3 \mathrm{pCi} / \mathrm{L}$, Range 118.0 to $420.0 \mathrm{pCi} / \mathrm{L}$ ) 



\subsection{Building 331 (Process Sewer)}

\subsection{Background and Description}

Building .331 is in the southeast corner of the 300 Area near the Columbia River. Staff conduct mechanism-based biochemistry research at the cellular and molecular levels to understand the effects of environmental influences, toxicology and risk assessment, aquatic and terrestrial ecology, environmental microbiology, and macromolecular structure and dynamics.

\subsection{Routine and Nonbusiness Day Sampling}

At Building 331, 35 routine and 5 nonbusiness day 24-hr composite sampling events and 20 routine and 5 nonbusiness day grab sampling events occurred. However, the full range of analyses do not necessarily exist for each constituent because additional analyses may have been requested for specific constituents, or inadequate samples may have been collected for the analyses desired. Table C. 2 lists the analyses performed on the samples from Building 331 . Summary data supporting the constituent class discussions in Sections 8.2.1 through 8.2.6 are shown in the accompanying figures. Comparisons to influent chemistry are based on the data in Appendix E. Tables with detailed building effluent information can be found in Appendix F.

\subsubsection{General Chemical Parameters}

Relative to the treated influent, elevated values for all of the general chemical parameters were observed in the routine samples. Alkalinity and total carbon results were approximately $40 \%$ higher than the treated influent concentrations, total dissolved solids and total organic carbon were about $70 \%$ greater, and chemical oxygen demand was approximately twice as high. Relatively large fluctuations were apparent in all five parameters (Figure 8.1a).

Concentrations of general chemical parameters in nonbusiness day samples were consistently lower than the routine sampling values. Alkalinity and total dissolved solids were approximately $30 \%$ less, chemical oxygen demand and total organic carbon were about $60 \%$ less, and total carbon was reduced nearly $40 \%$ (Figure 8.1b).

None of the general chemical parameters that were investigated have regulatory standards of comparison except total dissolved solids. The maximum total dissolved solid value observed for Building 331 was $480 \mathrm{mg} / \mathrm{L}$ which is under the National Secondary Drinking Water Standard of $500 \mathrm{mg} / \mathrm{L}$. 

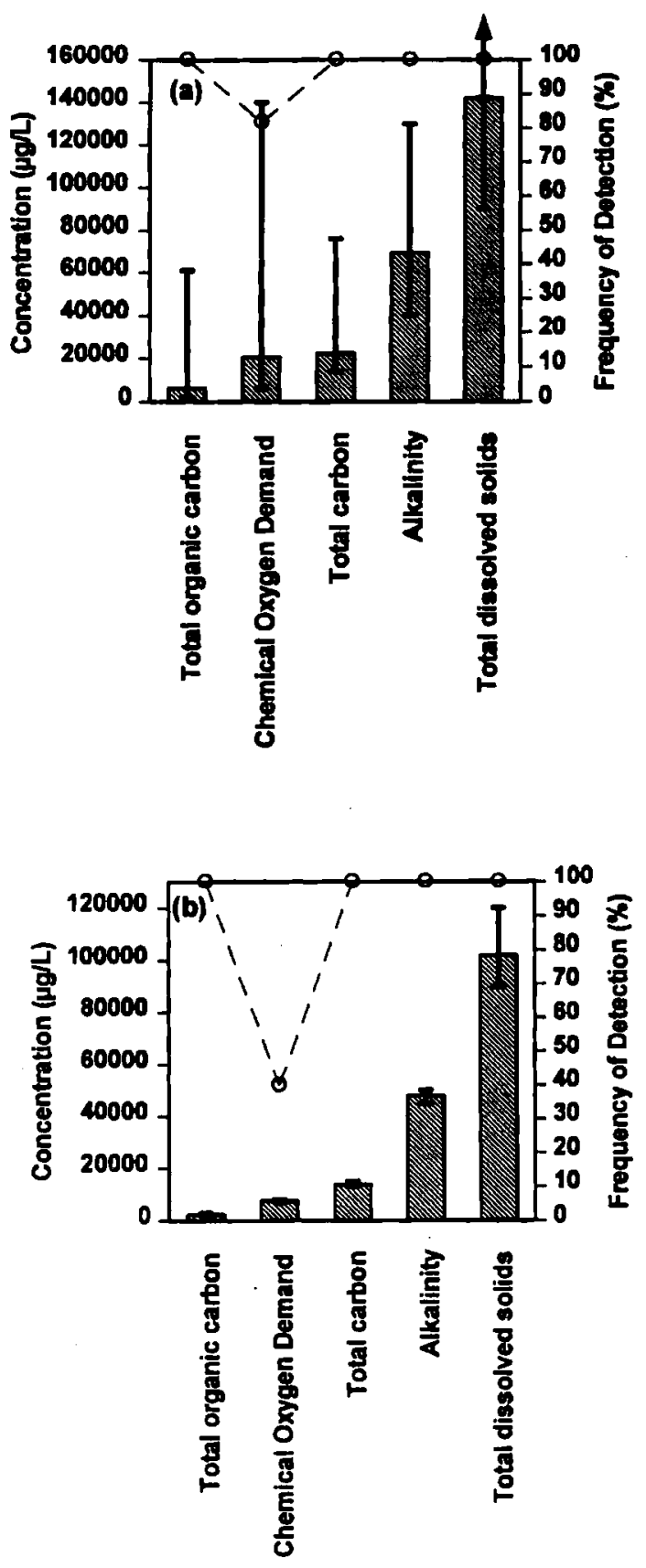

Figure 8.1. Building 331 General Chemical Parameters: (a) Routine Sampling (Total Dissolved Solids Average 142,188 $\mu \mathrm{g} / \mathrm{L}$, Range 90,000 to $480,000 \mu \mathrm{g} / \mathrm{L}$ ),

(b) Nonbusiness Day Sampling

\subsubsection{Ammonia and Anions}

Cyanide was detected in 25 out of 32 routine samples ( 1 to $70 \mu \mathrm{g} / \mathrm{L}$ ) at levels well above the method detection limit, while nitrite was found in only two samples (110 to $130 \mu \mathrm{g} / \mathrm{L})$. Nonbusiness day samples had average cyanide concentrations which were 3 to 4 times lower than routine samples. Ammonia was also frequently detected in nonbusiness day samples ( 3 of 5 samples) with concentrations averaging less than $20 \%$ of the routine sample levels $(28 \mu \mathrm{g} / \mathrm{L})$. High ammonia concentrations 130 to $1,000 \mu \mathrm{g} / \mathrm{L}$ ) were found in some routine samples. Bromide was measured at 1 to 2 times the method detection limit in two routine samples and one nonbusiness day sample. Phosphate (212 to $19,800 \mu \mathrm{g} / \mathrm{L})$, nitrate (300 to $33,000 \mu \mathrm{g} / \mathrm{L})$, chloride $(3,600$ to $167,000 \mu \mathrm{g} / \mathrm{L})$, and sulfate $(10,000$ to $47,900 \mu \mathrm{g} / \mathrm{L})$ were frequently found in routine samples and displayed large concentration excursions. These same anions were detected in nonbusiness day samples at significantly lower and more consistent concentrations (phosphate was $50 \%$ lower, nitrate was 4 times lower, chloride was 2 times lower), with the exception of sulfate $(19,000 \mu \mathrm{g} / \mathrm{L})$ which was present at levels similar to those found in routine samples. Relative to treated influent levels, concentrations of nitrate were 3 times higher in nonbusiness day samples $(1,200 \mu \mathrm{g} / \mathrm{L})$ and 15 times higher in routine samples $(5,803 \mu \mathrm{g} / \mathrm{L})$. Chloride concentrations for nonbusiness day samples $(6,060 \mu \mathrm{g} / \mathrm{L})$ were comparable with the treated influent values, but routine samples had twice the chloride levels $(12,031 \mu \mathrm{g} / \mathrm{L}$ ) (Figures 8.2a through d).

For reference only (building effluent is not meant to be drinking water and is treated by the TEDF before being discharged to the river), concentrations of 
ammonia and anions were compared to the National Drinking Water Standards which exist for four of the constituents detected (chloride, fluoride, nitrate, and sulfate). Only the nitrate standard of $10 \mathrm{mg} / \mathrm{L}$ was exceeded with a maximum observed concentration of $33 \mathrm{mg} / \mathrm{L}$ in the effluent. Although all of the buildings exceeded the nitrate standard, effluent from Building 331 had the highest nitrate
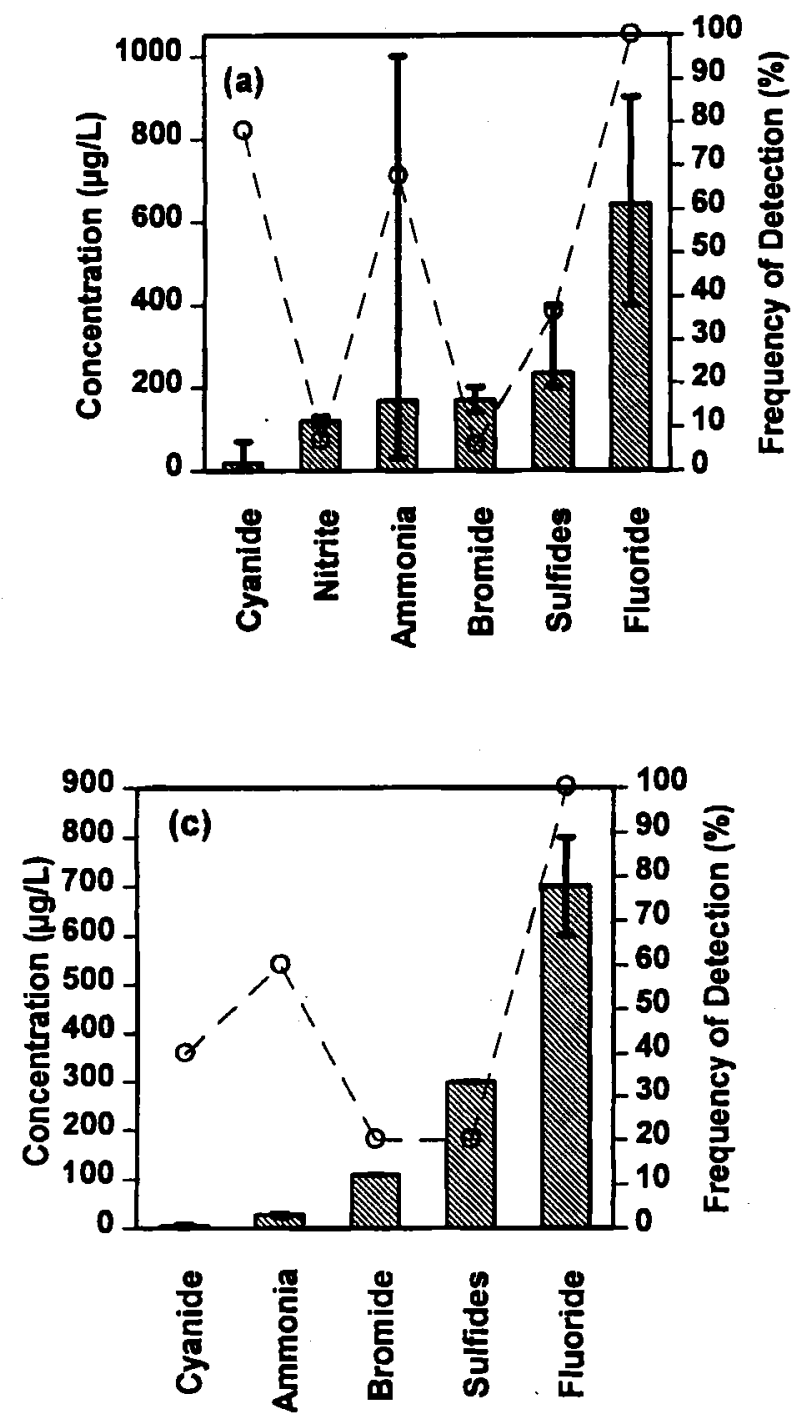

concentrations. The TEDF waste acceptance criteria exist for three of the constituents detected (ammonia, cyanide, and nitrite). Ammonia and nitrate were only observed at concentrations less than the waste acceptance criteria, but cyanide was observed twice at $70 \mu \mathrm{g} / \mathrm{L}$ which is above the waste acceptance criteria of $50 \mu \mathrm{g} / \mathrm{L}$.
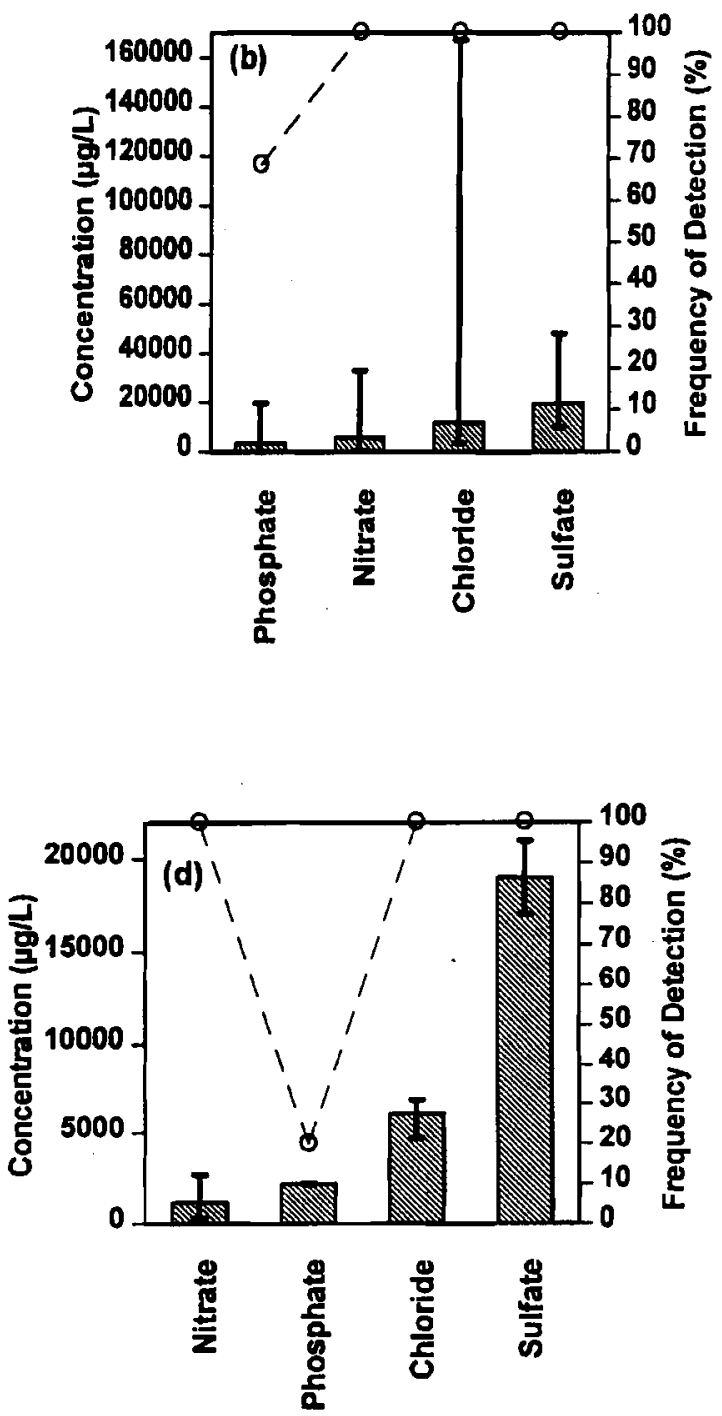

Figure 8.2. Building 331 Ammonia and Anions: (a) Routine Sampling Concentrations Less than $1,000 \mu \mathrm{g} / \mathrm{L}$, (b) Routine Sampling Concentrations Greater than 1,000 $\mu \mathrm{g} / \mathrm{L}$, (c) Nonbusiness Day Sampling Concentrations Less than $900 \mu \mathrm{g} / \mathrm{L}$ (Cyanide Average $5 \mu \mathrm{g} / \mathrm{L}$, Range 2 to $8 \mu \mathrm{g} / \mathrm{L}$ ), (d) Nonbusiness Day Sampling Concentrations Greater than $900 \mu \mathrm{g} / \mathrm{L}$ 


\subsubsection{Metals}

Heavy metals were found in most samples, although the trace levels $(<10 \mu \mathrm{g} / \mathrm{L})$ and low frequencies of detection $(<10 \%)$ were comparable with those found in blanks and influent samples. The concentrations for many metals (e.g., arsenic) were reported at or very close to the method detection limit, where a higher probability exists for false positive results. Mercury was detected in seven routine samples $(0.06$ to $0.17 \mu \mathrm{g} / \mathrm{L})$ at 1 to 3 times the method detection limit. Levels of lead ( 1 to $3 \mu \mathrm{g} / \mathrm{L}$ ) and manganese $(3 \mu \mathrm{g} / \mathrm{L})$ were similar to the treated influent for both sample types; a small number of routine samples had slightly elevated concentrations of manganese and lead $(15 \mu \mathrm{g} / \mathrm{L}$ and $17 \mu \mathrm{g} / \mathrm{L}$, respectively). Chromium was found in four routine samples 17 to $22 \mu \mathrm{g} / \mathrm{L})$ at levels 2 to 4 times greater than the method detection limit. Elevated levels of copper were found in all samples (10 to $110 \mu \mathrm{g} / \mathrm{L}$ ); the greatest concentrations were found in routine samples. Tin, iron, and aluminum had average concentrations twice as high in routine versus nonbusiness day samples, which largely was a result of a few individual samples with high concentrations. Potassium and sodium were twice as high in the routine samples compared to nonbusiness day samples; magnesium and calcium were $20 \%$ higher. All four of these metals were 1 to 2 times higher in the nonbusiness day samples relative to treated influent (Figures 8.3a through e).

The TEDF has waste acceptance criteria for 14 of the metals detected: aluminum, arsenic, beryllium, cadmium, chromium, copper, iron, lead, manganese, mercury, nickel, selenium, silver, and zinc. Five of the 32 aluminum measurements and one of the 33 copper measurements exceeded the waste acceptance criteria. These metals are believed to be from piping corrosion. Compared to the National Drinking Water Standards, aluminum concentrations (maximum $630 \mu \mathrm{g} / \mathrm{L}$ ) exceed the National Secondary Drinking Water Standard of $200 \mu \mathrm{g} / \mathrm{L}$ while the maximum copper measurement $(110 \mu \mathrm{g} / \mathrm{L})$ is less than a tenth of the primary drinking water standard of $1,300 \mu \mathrm{g} / \mathrm{L}$.
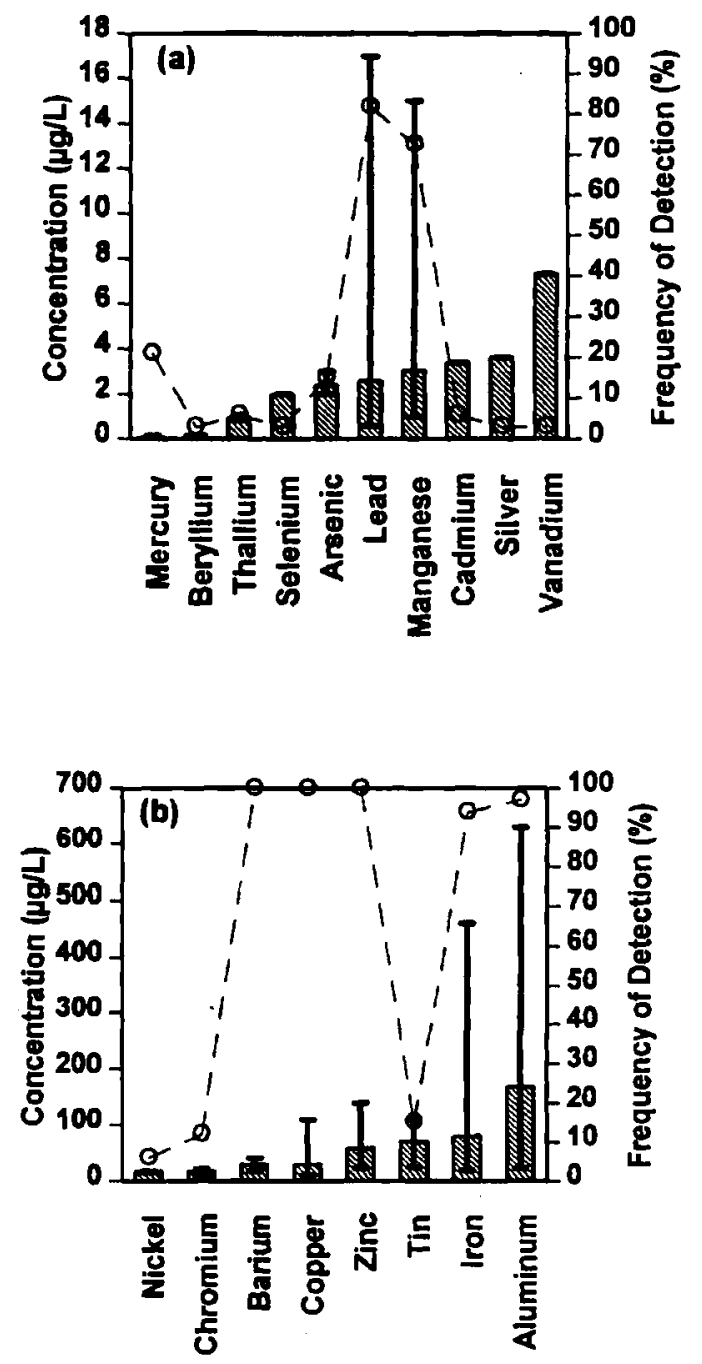

Figure 8.3. Building 331 Metals: (a) Routine Sampling Concentrations Less than $18 \mu \mathrm{g} / \mathrm{L}$ (Mercury Average $0.11 \mu \mathrm{g} / \mathrm{L}$, Range 0.05 to $0.17 \mu \mathrm{g} / \mathrm{L}$; Beryllium Average $0.19 \mu \mathrm{g} / \mathrm{L}$, Range N/A), (b) Routine Sampling Concentrations Between 18 and $700 \mu \mathrm{g} / \mathrm{L}$ 

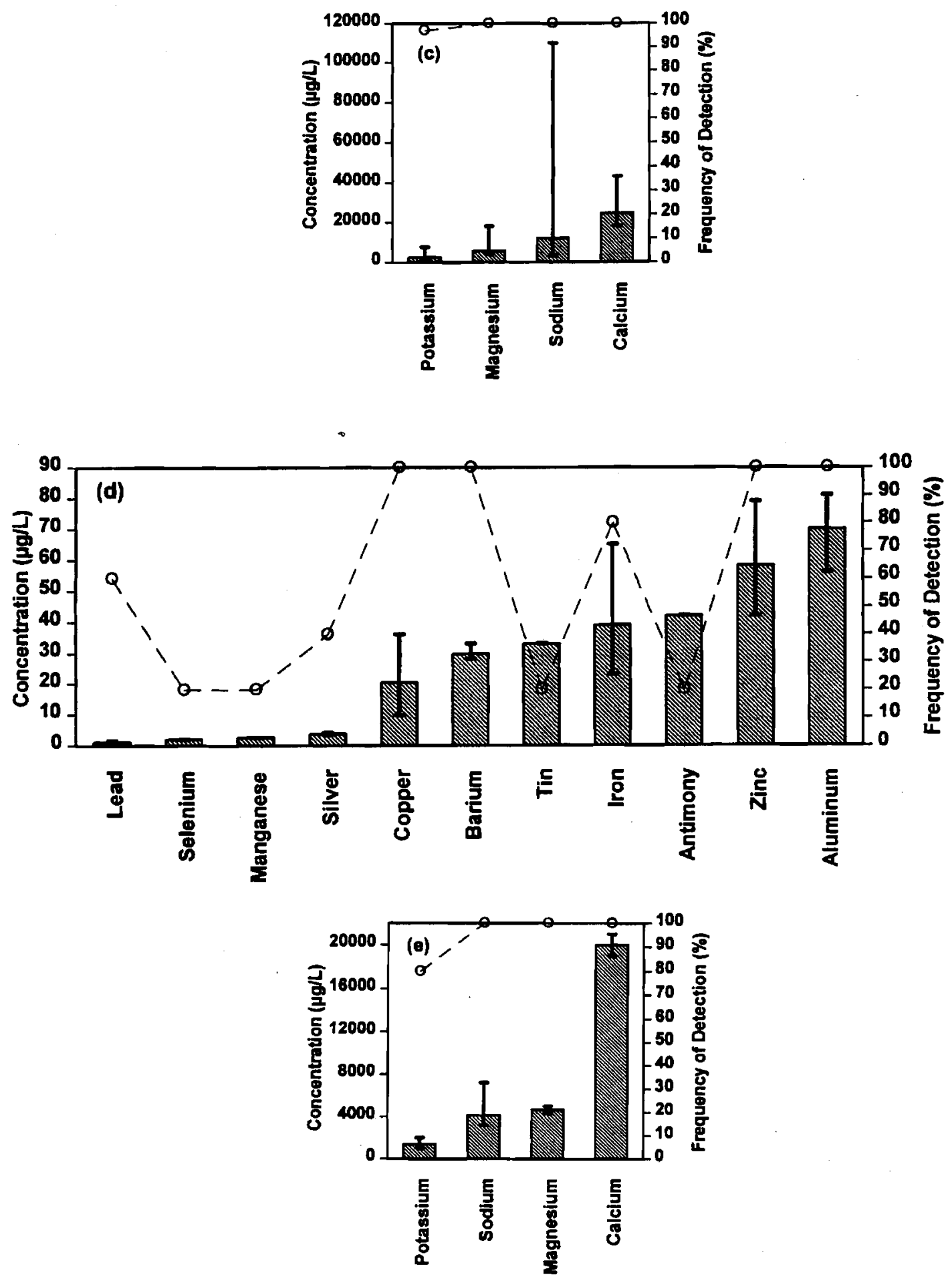

Figure 8.3 (contd). Building 331 Metals: (c) Routine Sampling Concentrations Greater than $700 \mu \mathrm{g} / \mathrm{L}$, (d) Nonbusiness Day Sampling Concentrations Less than $90 \mu \mathrm{g} / \mathrm{L}$ (Lead Average $1.0 \mu \mathrm{g} / \mathrm{L}$, Range 0.6 to $1.5 \mu \mathrm{g} / \mathrm{L}$ ), (e) Nonbusiness Concentrations Greater than $90 \mu \mathrm{g} / \mathrm{L}$ 


\subsubsection{Volatile Organic Compounds}

A total of 15 VOCs were detected in routine samples; 9 were also detected in the nonbusiness day samples (Figures $\mathbf{8 . 4}$ a through $\mathrm{c}$ ). Several compounds, including 1,1,1-trichloroethane, trichloroethene, xylenes, toluene, and chlorobenzene, were detected infrequently, and the concentrations were always at or just slightly above the method detection limit. Thus, the results for these constituents are tentative. Likewise, the presence of methylene chloride in Building 331 effluent is doubtful, because methylene chloride was also measured at similar concentrations in the majority of the blank samples.

Among the four trihalomethanes detected, chloroform and bromoform had the highest average concentrations. Chloroform was always detected, and the average routine and nonbusiness day sample concentrations were 25 to $50 \%$ lower than the treated influent levels. Bromoform was only rarely detected, with approximately $70 \%$ higher concentrations in the routine samples. Bromodichloromethane and dibromochloromethane showed large fluctuations and approximately 40 to $135 \%$ higher concentrations in the nonbusiness day samples. Bromodichloromethane levels were approximately 1.5 to 2 times higher in effluent samples than in the treated influent samples.

A few organic solvents (i.e., acetonitrile, acetone, 2-butanone, hexone, and tetrahydrofuran) were sporadically observed in the routine samples. Acetonitrile was only detected once in the effluent, but its concentration of $430 \mu \mathrm{g} / \mathrm{L}$ was greater than most of the other VOCs. Acetone showed large fluctuations in effluent concentrations including one high result of $1,800 \mu \mathrm{g} / \mathrm{L}$. Hexone and acetone were also detected once in the nonbusiness day samples; their concentrations were roughly 2 times greater (hexone) to 4 times less (acetone) than the average levels found in routine samples.

Specific waste acceptance criteria from the TEDF exist for six of the constituents detected: bromodichloromethane, chloroform, methylene chloride, toluene, 1,1,1-trichloroethane, and trichloroethylene. Of these, only chloroform (up to $33 \mu \mathrm{g} / \mathrm{L}$ ) and bromodichloromethane (up to $9.8 \mu \mathrm{g} / \mathrm{L}$ ) exceeded their waste acceptance criteria $126 \mu \mathrm{g} / \mathrm{L}$ for chloroform; $4 \mu \mathrm{g} / \mathrm{L}$ for bromodichloromethane). Both compounds are produced from chlorination of influent in the treatment facility (Building 315). The National Drinking Water Standards for two other constituents (chlorobenzene and xylenes) were not exceeded.

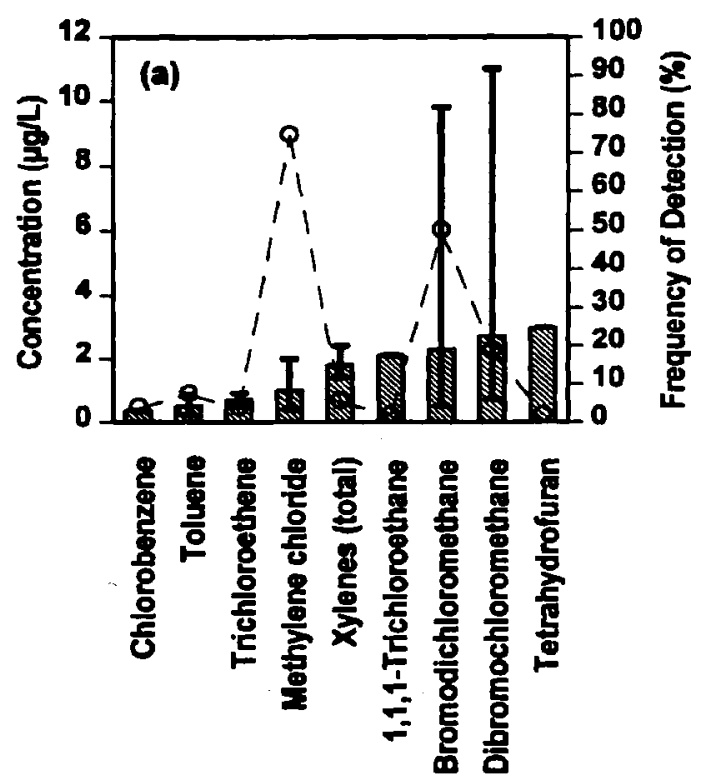

Figure 8.4. Building 331 Volatile Organic Compounds: (a) Routine Sampling Concentrations Less than $12 \mu \mathrm{g} / \mathrm{L}$ 

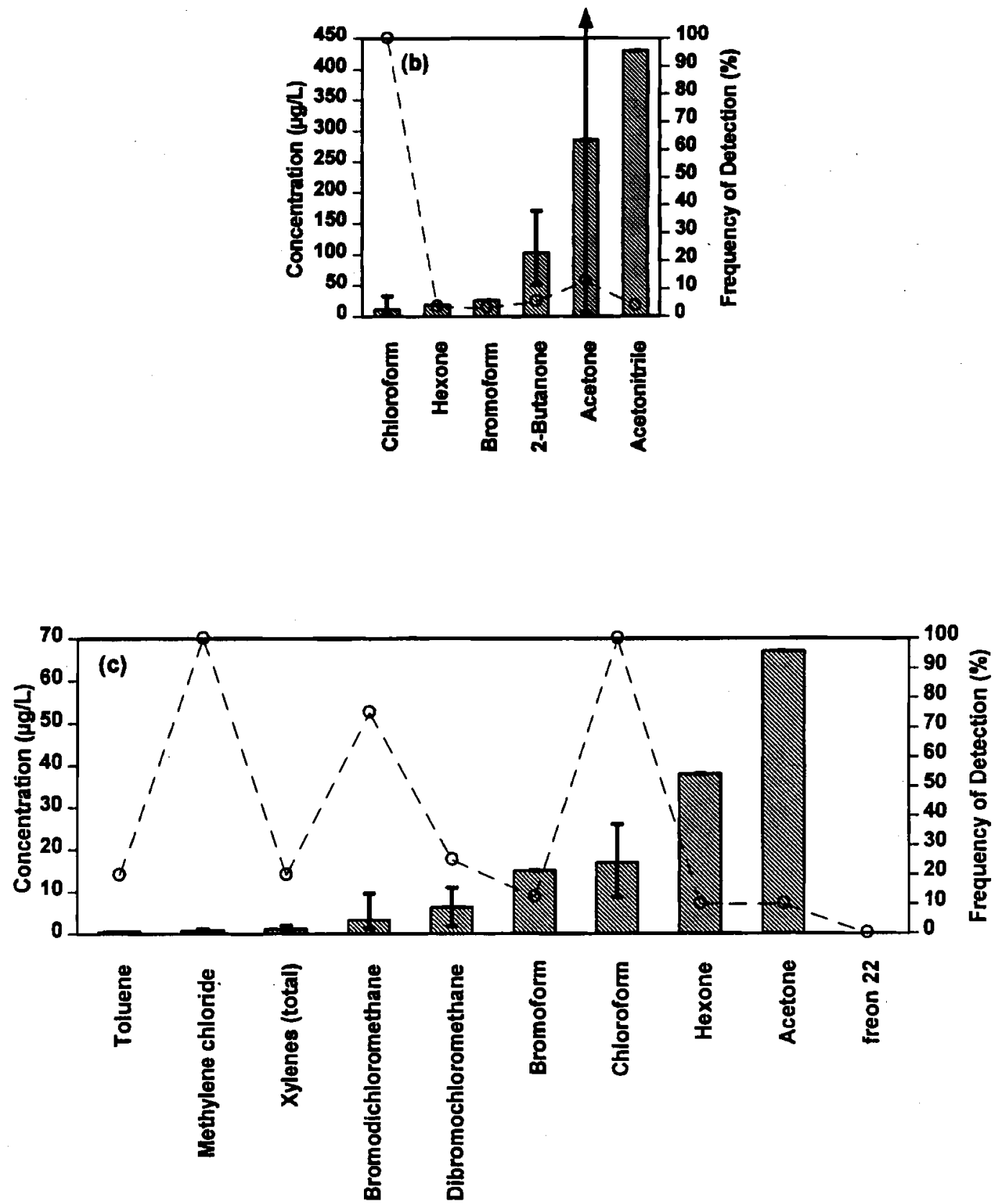

Figure 8.4 (contd). Building 331 Volatile Organic Compounds: (b) Routine Sampling Concentrations Greater than $12 \mu \mathrm{g} / \mathrm{L}$ (Acetone Average $284.9 \mu \mathrm{g} / \mathrm{L}$, Range 7.4 to $1,800.0 \mu \mathrm{g} / \mathrm{L}$ ), (c) Nonbusiness Day Sampling 


\subsubsection{Semivolatile Organic Compounds}

Several SVOCs were detected in the effluent samples from Building 331 (Figures 8.5a through c). Di-n-butylphthalate and bis(2-ethylhexyl)phthalate were found at less than $5 \mu \mathrm{g} / \mathrm{L}$ in 4 out of 18 and 7 out of 40 routine samples, respectively (Figure 8.5a). Bis(2-ethylhexyllphthalate was also found at similar concentrations in nonbusiness day samples (Figure 8.5c). Benzyl alcohol (5 to $27 \mu \mathrm{g} / \mathrm{L}$ ) and decane (35 $\mu \mathrm{g} / \mathrm{L}$ ) were found in 2 out of 18 and 1 out of 22 routine samples, respectively.

Ten pesticides were found at low partper-trillion levels in several routine samples, while two pesticides were also found at these levels in one nonbusiness day sample. Delta-BHC was the most frequently detected pesticide in routine samples $(25 \%)$, nonbusiness day samples $(20 \%)$, and influent samples $(20 \%)$, although its concentration averaged only 20 parts-per-trillion. Other BHC isomers were also detected in 10 to $15 \%$ of the routine samples at similar or lower concentrations. The pesticide with the highest concentration, 4,4'-DDE, was found in 3 out of 34 routine samples with results ranging from 0.002 to $0.72 \mu \mathrm{g} / \mathrm{L}$. None of the TEDF waste acceptance criteria for SVOCs was exceeded.
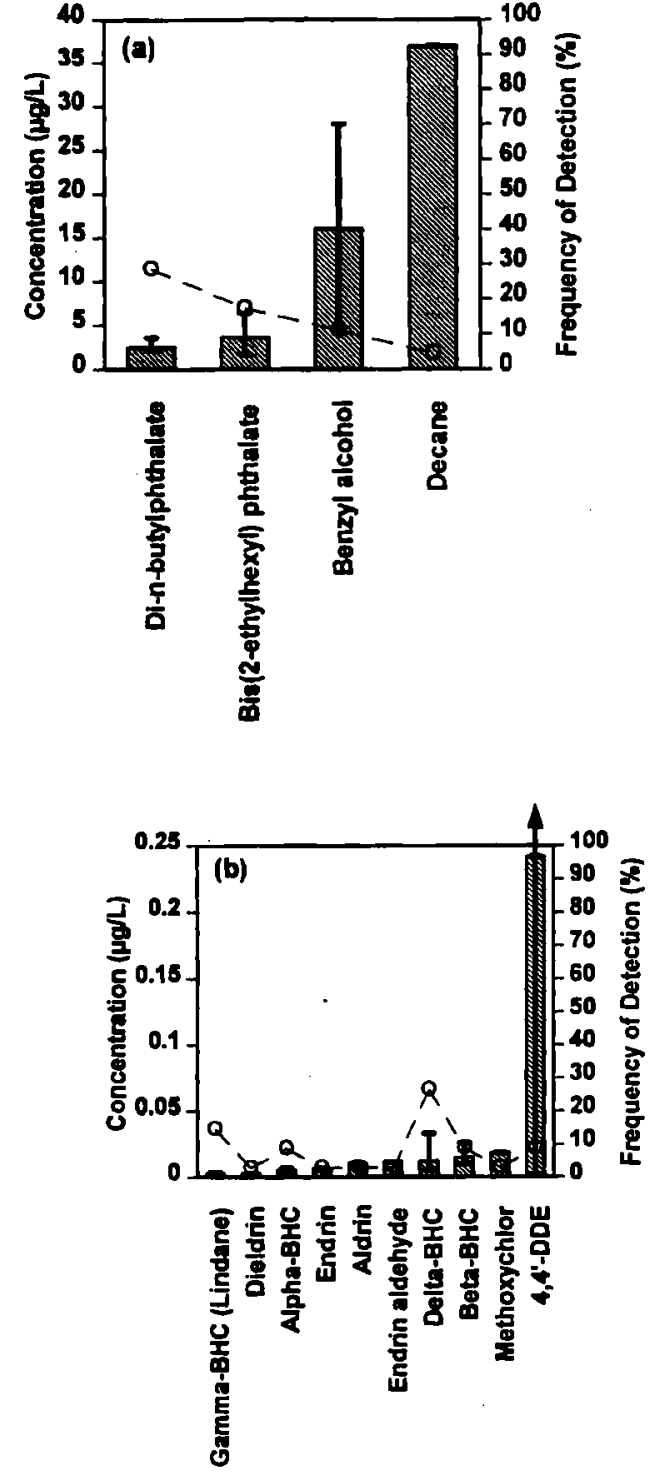

Figure 8.5. Building 331 Semivolatile Organic Compounds: (a) Routine Sampling, (b) Routine Sampling Pesticides (Gamma-BHC Average $0.003 \mu \mathrm{g} / \mathrm{L}$, Range 0.002 to 0.004 $\mu \mathrm{g} / \mathrm{L}$; Dieldrin Average $0.003 \mu \mathrm{g} / \mathrm{L}$, Range $\mathrm{N} / \mathrm{A}$; Alpha-BHC Average $0.006 \mu \mathrm{g} / \mathrm{L}$, Range 0.004 to $0.007 \mu \mathrm{g} / \mathrm{L} ; 4,4^{\prime}$-DDE Average $0.242 \mu \mathrm{g} / \mathrm{L}$, Range 0.002 to $0.720 \mu \mathrm{g} / \mathrm{L}$ ) 


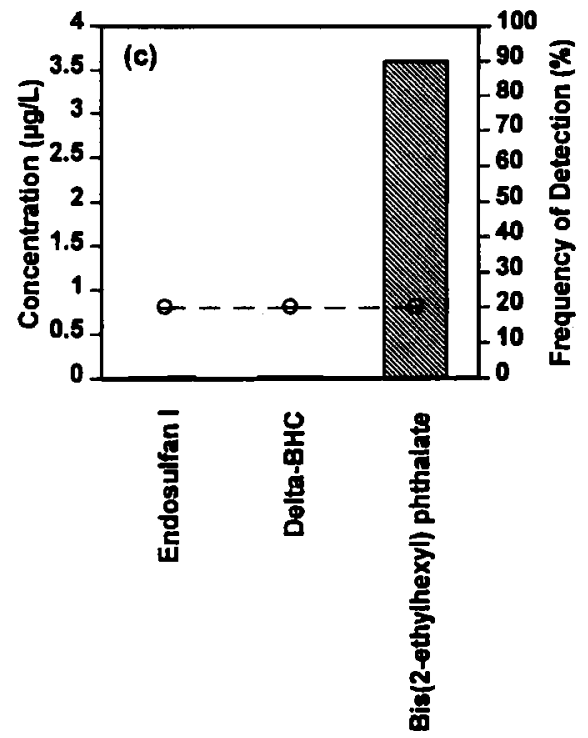

Figure 8.5. (contd). Building 331

Semivolatile Organic Compounds: (c) Nonbusiness Day Sampling (Endosulfan Average $0.01 \mu \mathrm{g} / \mathrm{L}$, Range N/A; Delta-BHC Average $0.02 \mu \mathrm{g} / \mathrm{L}$, Range N/A)

\subsubsection{Radiological Parameters}

Low levels of gross alpha and gross beta radiation were detected in routine and nonbusiness day samples

(Figures $8.6 a$ and b). Gross alpha activity was measured over a relatively large activity range in both sample sets, but most of the sample measurements were less than 2 times the background counting error. The average activity of the nonbusiness day samples was approximately $65 \%$ higher than the routine samples' average. Gross beta was only detected once in the nonbusiness day samples; the concentration $(2.7 \mathrm{pCi} / \mathrm{L}$ ) was nearly $40 \%$ lower than the average activity in the routine samples. Most of the gross beta results were less than 2 times the background counting error.

Two tritium analyses were performed on routine samples; both results may be false positive readings because the sample counts were only slightly higher (i.e., about twice as high) as the background.
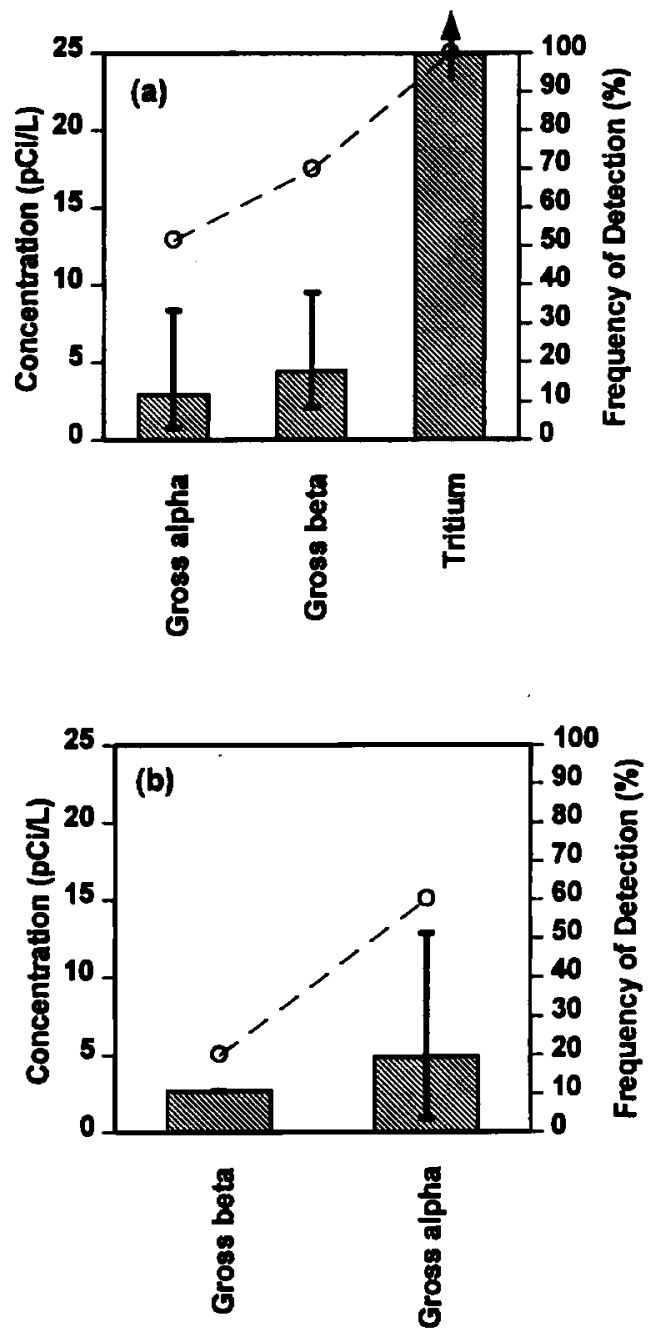

Figure 8.6. Building 331 Radiological Parameters: (a) Routine Sampling (Tritium Average $305 \mu \mathrm{g} / \mathrm{L}$, Range 280 to $330 \mu \mathrm{g} / \mathrm{L}$ ), (b) Nonbusiness Day Sampling 


\subsection{Building 3720 (Process Sewer)}

\subsection{Background and Description}

Building 3720 is located in the northcentral corner of the 300 Area along Oregon Street. Staff conduct research in the areas of materials characterization and testing and waste management. Research activities include the use of radioactive and hazardous materials.

\subsection{Routine and Nonbusiness Day Sampling}

At Building 3720, 29 routine and 6 nonbusiness day 24-hr composite and 19 routine and 5 nonbusiness day grab sampling events occurred. However, the full range of analyses do not necessarily exist for each constituent because additional analyses may have been requested for specific constituents, or inadequate samples may have been collected for the analyses desired. Table C. 2 lists the analyses performed for the events from Building 3720 . Summary data supporting the constituent class discussions in Sections 9.2.1 through 9.2.6 are shown in the accompanying figures. Comparisons to influent chemistry are based on the data in Appendix E. Tables with detailed building effluent information can be found in Appendix F.

\subsubsection{General Chemical Parameters}

Except for total organic carbon, the values of general chemical parameters were slightly elevated over treated influent levels. Results from routine sampling indicate the concentrations of alkalinity and total carbon were elevated by approximately $15 \%$, and chemical oxygen demand and total dissolved solids were roughly $30 \%$ greater. The average concentration of total organic carbon in routine samples was approximately $15 \%$ less than the corresponding treated influent value.

Values of general chemical parameters for nonbusiness day samples were generally 10 to $25 \%$ lower than routine samples levels, although the one positive, nonbusiness day result for chemical oxygen demand was nearly $10 \%$ higher than the average value for routine samples. All five parameters showed larger fluctuations in the routine samples (Figures 9.1 $\mathrm{a}$ and b).

None of the general chemical parameters that were investigated have regulatory standards of comparison except total dissolved solids. The maximum total dissolved solid value observed for Building 3720 was 190 $\mathrm{mg} / \mathrm{L}$ which is much less than the National Secondary Drinking Water Standard of $500 \mathrm{mg} / \mathrm{L}$.

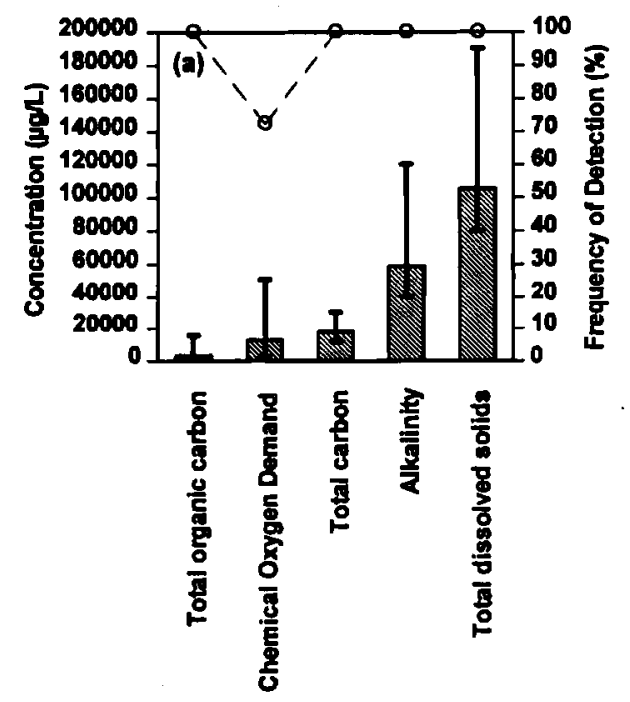

Figure 9.1. Building 3720 General Chemical Parameters: (a) Routine Sampling 


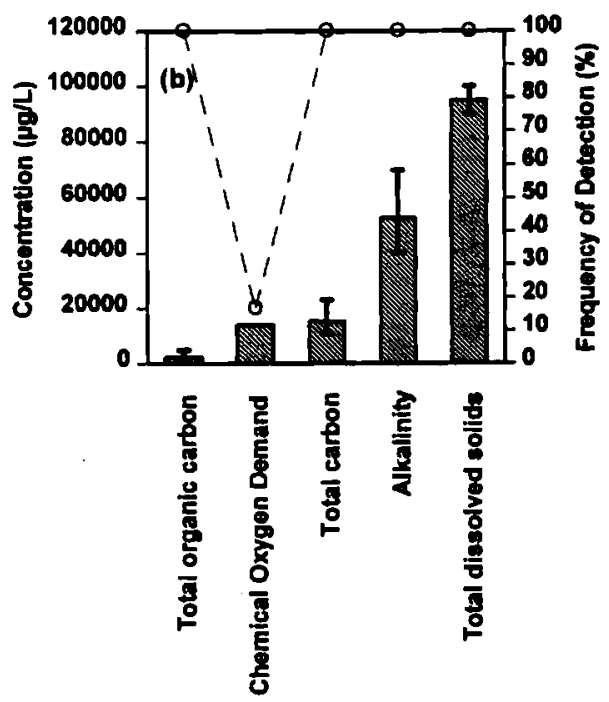

Figure 9.1. (contd). Building 3720 General Chemical Parameters: (b) Nonbusiness Day Sampling

\subsubsection{Ammonia and Anions}

Ammonia and sulfides were detected in low concentrations and with similar frequencies in routine and nonbusiness day samples lammonia's detection frequency was $15 \%$; sulfides' detection frequency was 40 to $50 \%$ ). Cyanide was detected in four routine samples at an average concentration of $5 \mu \mathrm{g} / \mathrm{L}$.

Compared to the concentrations in treated influent samples, average nitrate levels were twice as high in nonbusiness day samples $(867 \mu \mathrm{g} / \mathrm{L})$ and eight times higher in routine samples $(3,234 \mu \mathrm{g} / \mathrm{L})$. In addition, large fluctuations in nitrate concentration (600 to $16,000 \mu \mathrm{g} / \mathrm{L}$ ) were observed for the routine samples (Figures 9.2a through d).

For reference only (building effluent is not meant to be drinking water and is treated by the TEDF before being discharged to the river), concentrations of ammonia and anions were compared to the National Drinking Water Standards which exist for four of the constituents detected (chloride, fluoride, nitrate, and sulfate). Only the nitrate standard of 10 $\mathrm{mg} / \mathrm{L}$ was exceeded with a maximum observed concentration of $16 \mathrm{mg} / \mathrm{L}$ in the effluent (this was true of almost all of the building waste streams). The TEDF waste acceptance criteria exist for two of the constituents detected (ammonia and cyanide). Both of these constituents were measured at a small fraction $1<$ $20 \%$ l of the waste acceptance criteria.

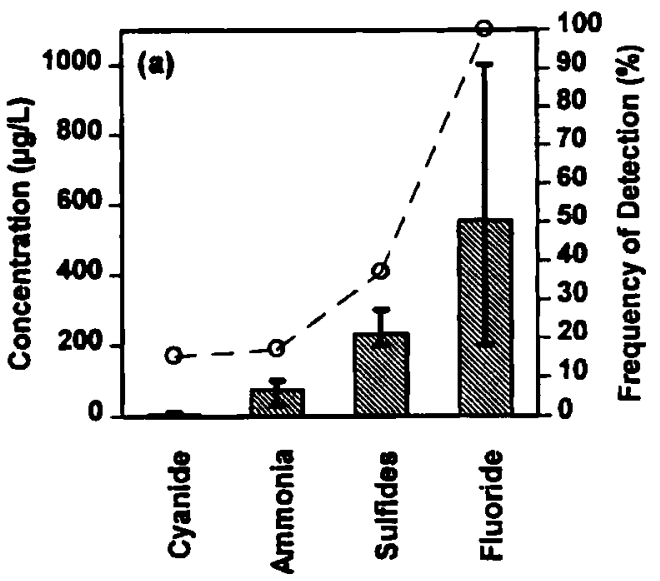

Figure 9.2. Building 3720 Ammonia and Anions: (a) Routine Sampling Concentrations Less than $900 \mu \mathrm{g} / \mathrm{L}$ (Cyanide Average $5.3 \mu \mathrm{g} / \mathrm{L}$, Range 2 to $10 \mu \mathrm{g} / \mathrm{L}$ ) 

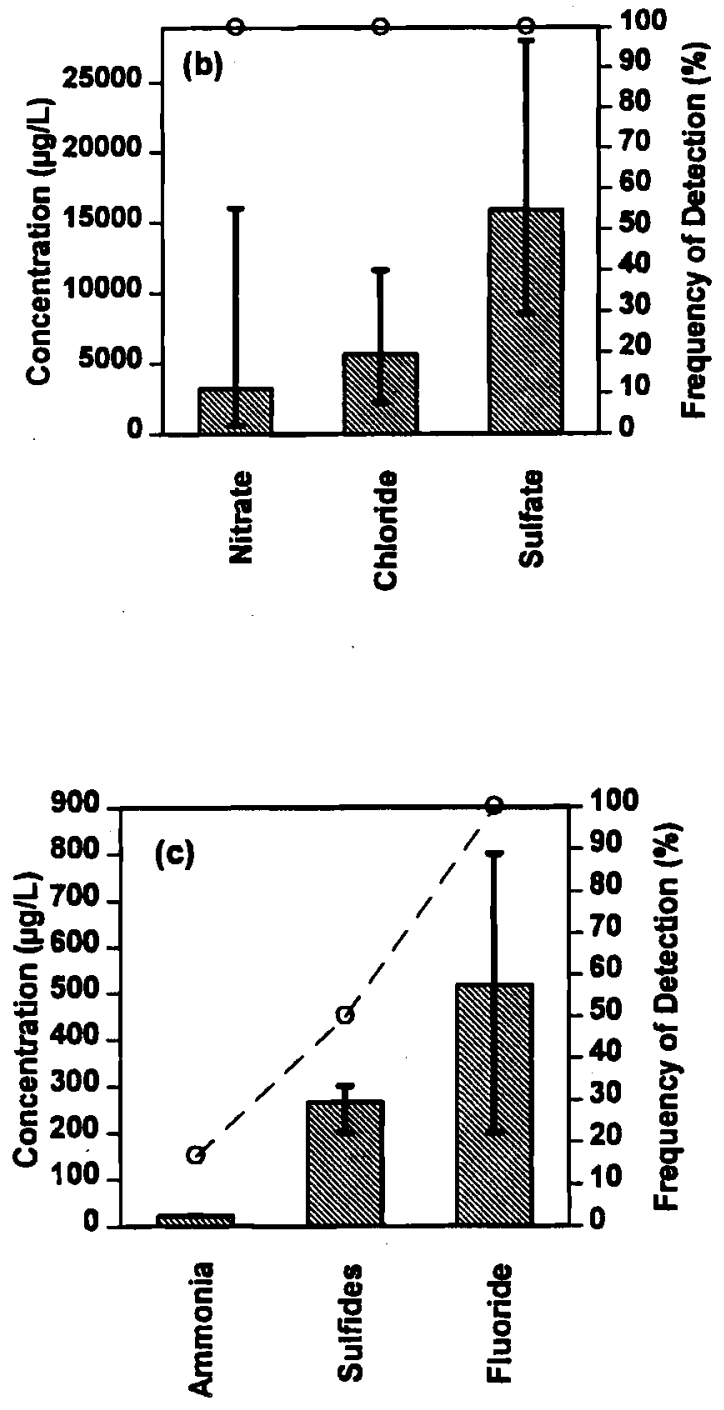

Figure 9.2. (contd). Building 3720 Ammonia and Anions: (b) Routine Sampling Concentrations Greater than $900 \mu \mathrm{g} / \mathrm{L}$, (c) Nonbusiness Day Sampling Concentrations Less than $900 \mu \mathrm{g} / \mathrm{L}$

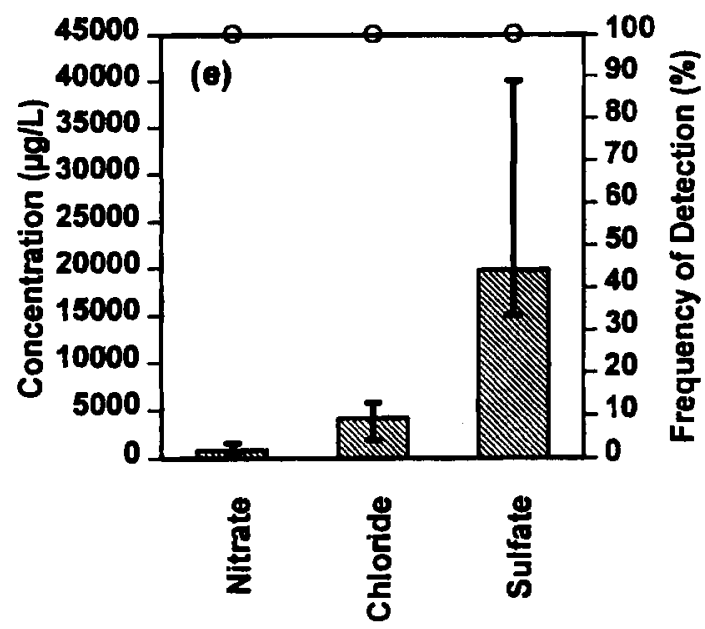

Figure 9.2. (contd). Building 3720 Ammonia and Anions: (d) Nonbusiness Day Sampling Concentrations Greater than $900 \mu \mathrm{g} / \mathrm{L}$

\subsubsection{Metals}

Heavy metals were found in most routine and nonbusiness day samples (Figures 9.3a through e), although the trace levels and modest frequencies of detection for most were comparable with those found in the blanks and treated influent samples. Mercury was detected in greater than $70 \%$ of both sample types at concentrations below $1 \mu \mathrm{g} / \mathrm{L}$.

Chromium was detected in five routine samples $(4.7$ to $27 \mu \mathrm{g} / \mathrm{L})$ at an average concentration which was only 3 times greater than the method detection limit. Copper and barium levels (19 and $29 \mu \mathrm{g} / \mathrm{L}$, respectively) were elevated in routine samples relative to both nonbusiness day samples (copper $10.2 \mu \mathrm{g} / \mathrm{L}$; barium $25 \mu \mathrm{g} / \mathrm{L}$ ) and treated influent (copper $3 \mu \mathrm{g} / \mathrm{L}$; barium $28 \mu \mathrm{g} / \mathrm{L}$ ). Zinc, aluminum, and iron were higher in routine samples $(60 \mu \mathrm{g} / \mathrm{L}, 69 \mu \mathrm{g} / \mathrm{L}$, $89 \mu \mathrm{g} / \mathrm{L}$, respectively) than in nonbusiness day samples (zinc $34 \mu \mathrm{g} / \mathrm{L}$; aluminum $77 \mu \mathrm{g} / \mathrm{L}$; iron $65 \mu \mathrm{g} / \mathrm{L})$; zinc 
was also detected at levels 3 to 5 times greater than those observed in the treated influent. Cations above $1,000 \mu \mathrm{g} / \mathrm{L}$ (potassium, calcium, magnesium, and sodium) showed larger fluctuations and somewhat higher levels in routine $11,537 \mu \mathrm{g} / \mathrm{L}, 21,897 \mu \mathrm{g} / \mathrm{L}, 4,803 \mu \mathrm{g} / \mathrm{L}$, $5,766 \mu \mathrm{g} / \mathrm{L})$ than in nonbusiness day samples $(1,100 \mu \mathrm{g} / \mathrm{L}, 19,833 \mu \mathrm{g} / \mathrm{L}$, $4283 \mu \mathrm{g} / \mathrm{L}, 2,983 \mu \mathrm{g} / \mathrm{L}$, respectively) (Figure $9.3 \mathrm{c}$ through $\mathrm{e}$ ).

The TEDF has waste acceptance criteria for 12 of the metals detected: aluminum, arsenic, cadmium, chromium, copper, iron, lead, manganese, mercury, nickel, selenium, and zinc. One of the 29 copper measurements and one of the 29 zinc measurements exceeded the waste acceptance criteria. These metals are believed to be from steam condensate. Also, note that even though the waste acceptance criteria were exceeded, the National Drinking Water Standards were not: the waste acceptance criteria for copper and zinc are more than an order of magnitude less than the drinking water standards.

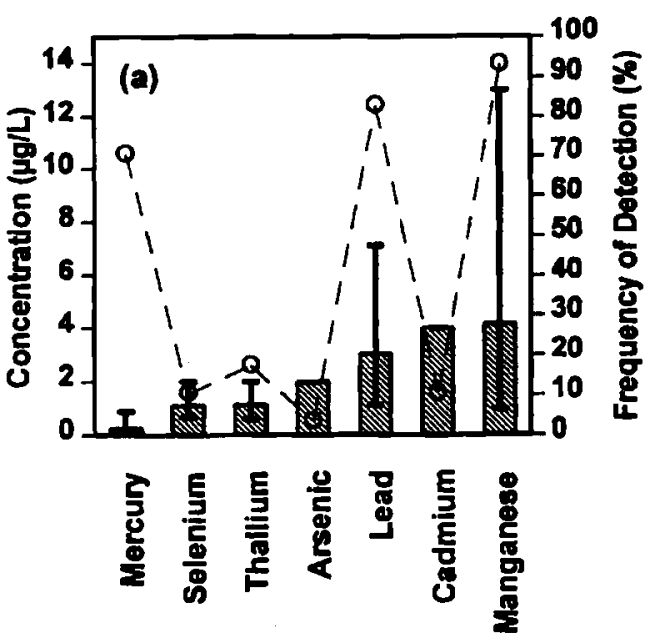

Figure 9.3. Building 3720 Metals:

(a) Routine Sampling Concentrations Less
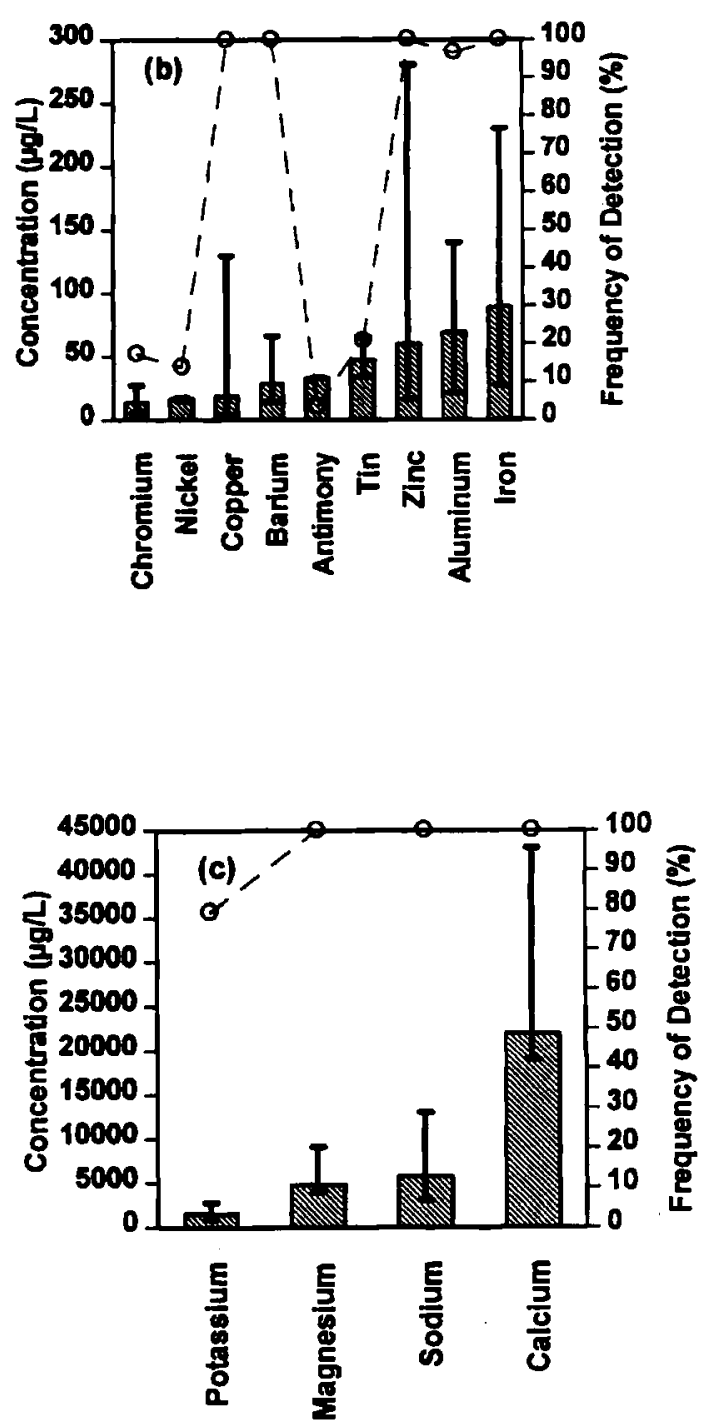

Figure 9.3. (contd). Building 3720 Metals: (b) Routine Sampling Concentrations Between 14 and $300 \mu \mathrm{g} / \mathrm{L}$, (c) Routine Sampling Concentrations Greater than $300 \mu \mathrm{g} / \mathrm{L}$ 


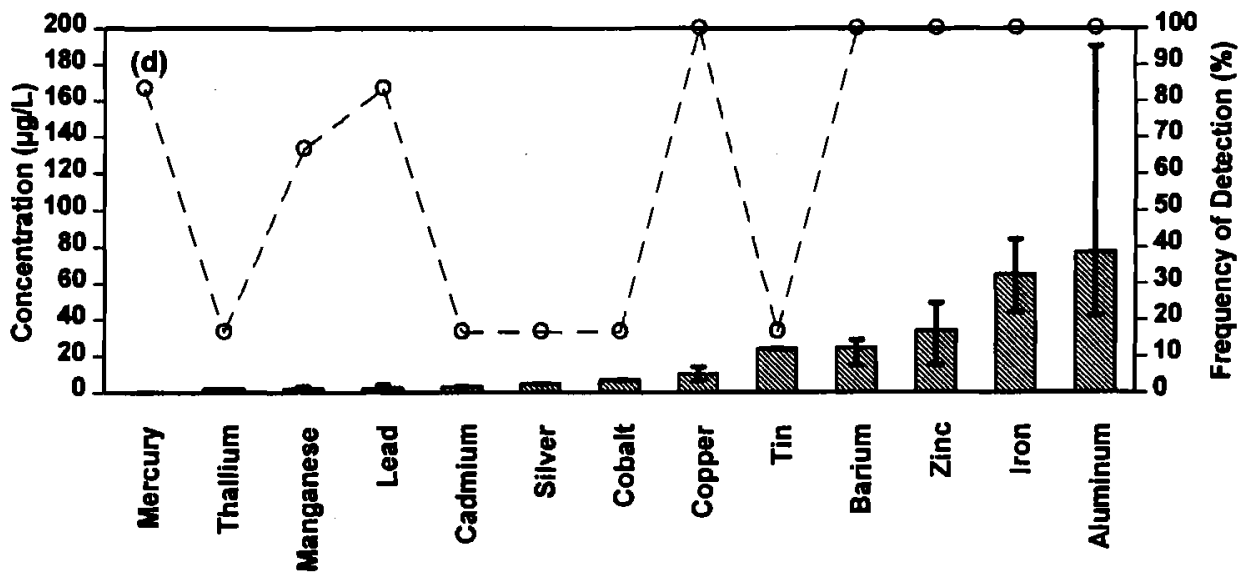

Figure 9.3. (contd). Building 3720 Metals: (d) Nonbusiness Day Sampling Concentrations Less than $200 \mu \mathrm{g} / \mathrm{L}$ (Mercury Average $0.18 \mu \mathrm{g} / \mathrm{L}$, Range 0.1 to $0.26 \mu \mathrm{g} / \mathrm{L}$ )

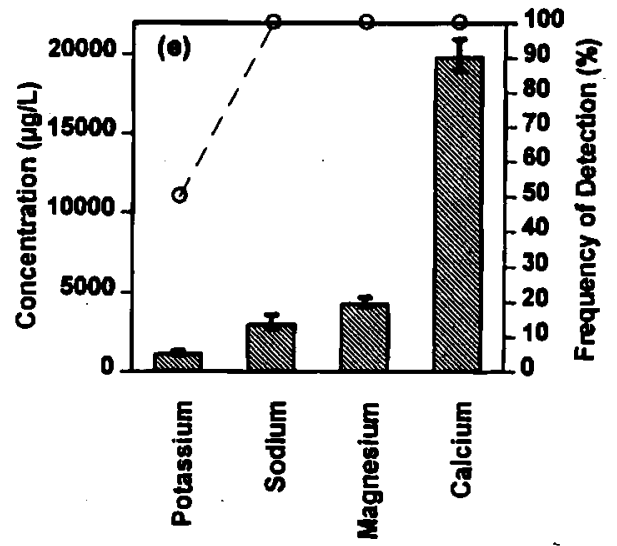

Figure 9.3. Building 3720 Metals: (e) Nonbusiness Day Sampling Concentrations Greater than $200 \mu \mathrm{g} / \mathrm{L}$

\subsubsection{Volatile Organic Compounds}

VOCs constitute the bulk of the organic compounds detected in both the routine and nonbusiness day samples. In most cases, the concentrations of VOCs were significantly above the method detection limits, and the chances for false positive detection should have been fairly low. However, the two compounds with the lowest average concentrations, 1,2-dichloroethylene and ethylbenzene, were always measured at levels near the method detection limits. Consequently, the presence of these compounds in the effluent should be considered tentative. The recurrence of methylene chloride is also questionable, because it was frequently observed in the sample and reagent blanks. Nonetheless, one methylene chloride result (approximately $10 \mu \mathrm{g} / \mathrm{L}$ ) is considered significant because it was higher than the concentrations reported in all of the blanks (Figure 9.4a).

Three trihalomethanes were detected in routine samples; two of these compounds were also measured in nonbusiness day samples. Chloroform 
was always detected; routine monitoring and nonbusiness day concentrations were within $20 \%$ of each other but were approximately $40 \%$ lower compared to the treated influent (Figures $9.4 \mathrm{~b}$ and $\mathrm{c}$ ). Bromodichloromethane and dibromochloromethane were observed sporadically in the range of 1 to $2 \mu \mathrm{g} / \mathrm{L}$ in the routine samples.

Bromodichloromethane was also measured between 0.9 and $2.5 \mu \mathrm{g} / \mathrm{L}$ in the treated influent and nonbusiness day samples (Figures 9.4a and $\mathrm{c}$ ).

Several common solvents were occasionally observed in the routine samples. Acetone, which was measured over a wide concentration range $(8$ to $530 \mu \mathrm{g} / \mathrm{Ll}$, was detected in almost $50 \%$ of the samples. Roughly $65 \%$ lower concentrations of acetone were also observed in the nonbusiness day samples. Acetonitrile, toluene, and tetrahydrofuran each had one high result (i.e., in the range from 400 to $800 \mu \mathrm{g} / \mathrm{L}$ ) but were also measured at much lower concentrations. Low levels (i.e., less than $25 \mu \mathrm{g} / \mathrm{L}$ ) of hexone (methyl isobutyl ketone), diethyl ether, and xylenes were also infrequently detected in the routine samples (Figure 9.4b).

Ethanol and isopropanol were identified in a few of the routine samples. Because both compounds are nontarget analytes with low detection efficiencies, their results require some additional explanation. In the analysis method employed (i.e., purge-and-trap gas chromatography), the concentrations of nontarget compounds may be inaccurately estimated because a rigorous calibration is not performed for such compounds. In the case of highly watermiscible compounds such as ethanol and isopropanol, detection efficiencies are very low, resulting in relatively high method detection limits. Thus, the ethanol and isopropanol concentrations shown in Figure 9.4b lapproximately $14 \mu \mathrm{g} / \mathrm{L}$ ) are probably 100 to 1,000 times lower than the actual values. Isopropanol was also observed in one nonbusiness day sample; its concentration was approximately $50 \%$ lower compared to the routine monitoring average.

Three other VOCs were detected with varying frequencies. Trichloroethene was measured at low concentrations in all of the routine and nonbusiness day samples. Low levels of carbon disulfide and 1,1,2trichloroethane were also observed in the routine samples.

Specific waste acceptance criteria from TEDF exist for five of the VOCs detected: bromodichloromethane, chloroform, methylene chloride, trichloroethylene, and toluene. Of these, chloroform (up to $40 \mu \mathrm{g} / \mathrm{L}$ ) exceeded the waste acceptance criteria and is believed to be produced from chlorination of influent in the treatment facility (Building 315). One out of 39 methylene chloride measurements and four out of seven toluene measurements also exceeded the waste acceptance criteria. National Drinking Water Standards exist for five other constituents (1,1,2-trichloroethane, 1,2-dichloroethylene, chlorobenzene, ethylbenzene, and xylenes); the standards were not exceeded for any of these constituents. 

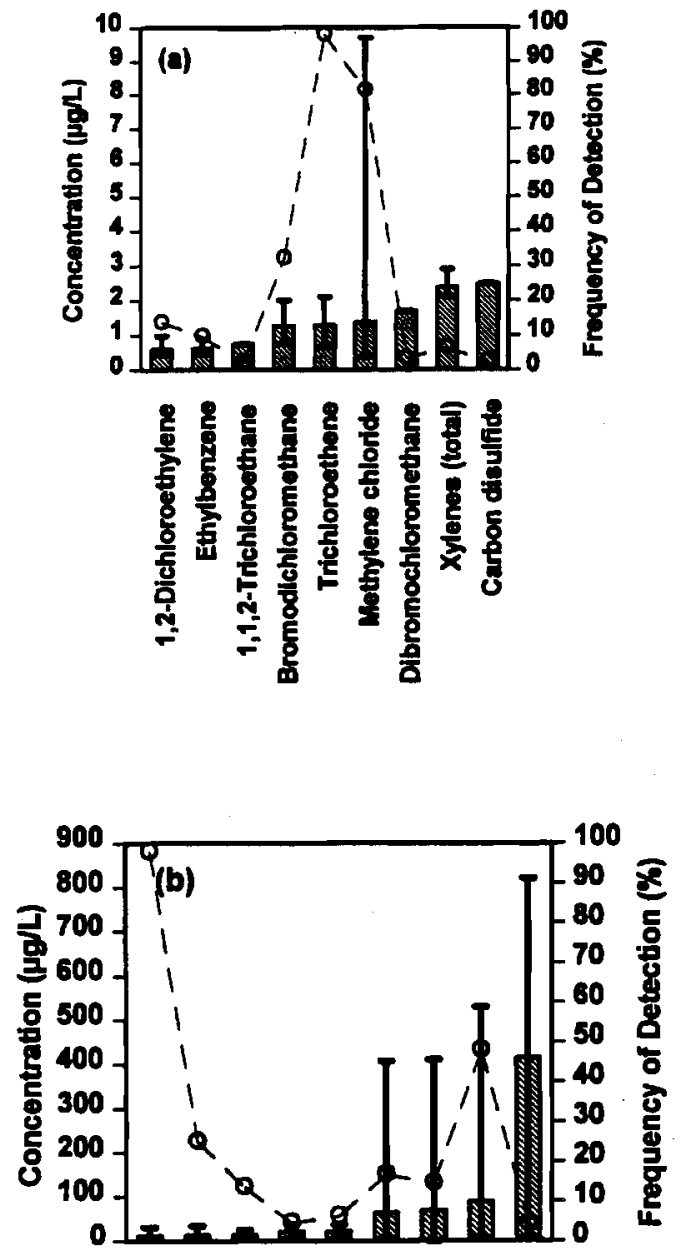

Figure 9.4. Building 3720 Volatile Organic Compounds: (a) Routine Sampling Concentrations Less than $10 \mu \mathrm{g} / \mathrm{L}$, (b) Routine Sampling Concentrations Greater than $10 \mu \mathrm{g} / \mathrm{L}$ (Chloroform Average $12.4 \mu \mathrm{g} / \mathrm{L}$, Range 2.5 to $32.0 \mu \mathrm{g} / \mathrm{L}$; Isopropanol Average $13.1 \mu \mathrm{g} / \mathrm{L}$, Range 5.2 to $34.0 \mu \mathrm{g} / \mathrm{L}$; Ethanol Average $14.1 \mu \mathrm{g} / \mathrm{L}$, Range 5.5 to $26.0 \mu \mathrm{g} / \mathrm{L}$ )

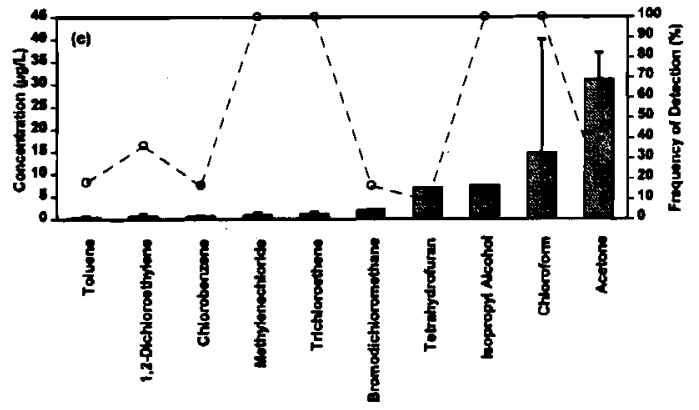

Figure 9.4. Building 3720 Volatile Organic Compounds: (c) Nonbusiness Day Sampling (Toluene Average $0.4 \mu \mathrm{g} / \mathrm{L}$, Range 0.2 to $0.6 \mu \mathrm{g} / \mathrm{L})$

\subsubsection{Semivolatile Organic Compounds}

Di-n-butylphthalate and bis (2ethylhexyl)phthalate were found in 20 to $30 \%$ of both routine and nonbusiness day samples. Bis(2-ethylhexyl)phthalate was detected at levels ranging from 1 to $10 \mu \mathrm{g} / \mathrm{L}$. An exception was diethylphthalate, which was found in 4 out of 18 routine samples at levels ranging from 35 to $170 \mu \mathrm{g} / \mathrm{L}$. The constituent is regulated as a toxic material and thus is included in the TEDF waste acceptance criteria at $100 \mu \mathrm{g} / \mathrm{L}$. This value was exceeded in one measurement at Building 3720 . Tributyl phosphate was found in 2 out of 33 routine samples at an average concentration of $8 \mu \mathrm{g} / \mathrm{L}$ (Figures $9.5 \mathrm{a}$ ). 


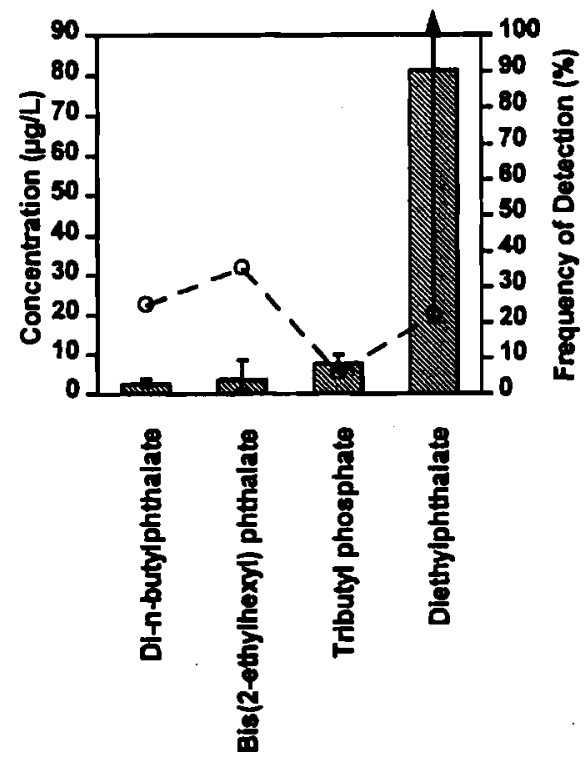

Figure 9.5. Building 3720 Semivolatile Organic Compounds (Diethylphthalate Average $81.3 \mu \mathrm{g} / \mathrm{L}$, Range 35.0 to $170.0 \mu \mathrm{g} / \mathrm{L})$

\subsubsection{Radiological Parameters}

Gross alpha and gross beta radiation were generally observed at low levels in $85 \%$ or more of the routine and nonbusiness day samples (Figures 9.6a and $b)$. The average gross beta concentration was approximately $20 \%$ higher in the routine samples, while the average gross alpha activity was roughly $25 \%$ higher in the nonbusiness day samples. Compared to the other monitoring locations with detectable gross alpha, the average concentration in routine samples was 3 to 9 times higher.

Because of the relatively high gross alpha and gross beta results as well as past practices and inventories at Building 3720 , one routine sample was analyzed for several potential alpha and beta emitters, including ${ }^{241} \mathrm{Am},{ }^{60} \mathrm{Co},{ }^{137} \mathrm{Cs}$, ${ }^{238} \mathrm{Pu},{ }^{239},{ }^{240} \mathrm{Pu},{ }^{106} \mathrm{Ru},{ }^{125} \mathrm{Sb},{ }^{90} \mathrm{Sr},{ }^{234} \mathrm{U}$, ${ }^{235} \mathrm{U}$, and ${ }^{238} \mathrm{U}$. The only radionuclides detected were the three uranium isotopes, and the activity of the enriched form $\left({ }^{235} \mathrm{U}\right)$ was negligible compared to the other two. Thus, the gross alpha radiation was primarily attributed to ${ }^{234} \mathrm{U}$ and ${ }^{238} \mathrm{U}$.

The gross alpha measurements at Building 3720 exceeded the TEDF waste acceptance criteria (15 pCi/L) 13 out of 34 times including almost all of the nonbusiness day samples. The activity is believed to be caused by residual uranium in the building piping.

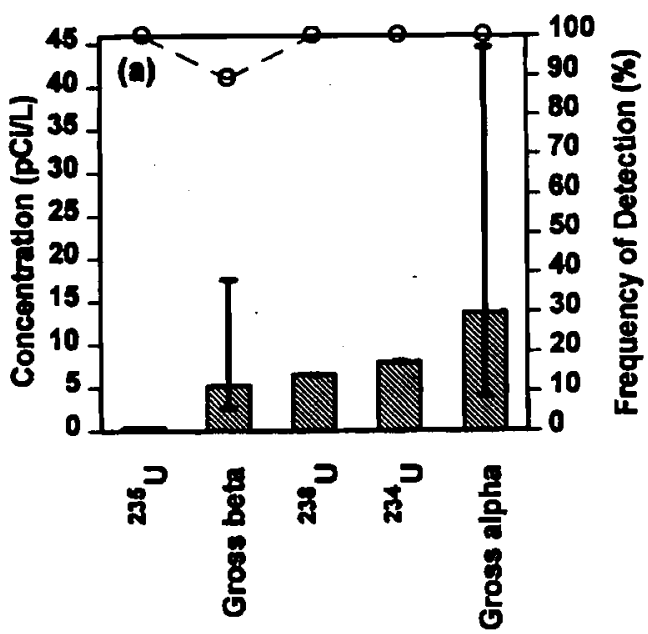

Figure 9.6. Building 3720 Radiological Parameters: (a) Routine Sampling $\left.\right|^{235} \mathrm{U}$ Average $0.4 \mathrm{pCi} / \mathrm{L}$, Range N/A) 


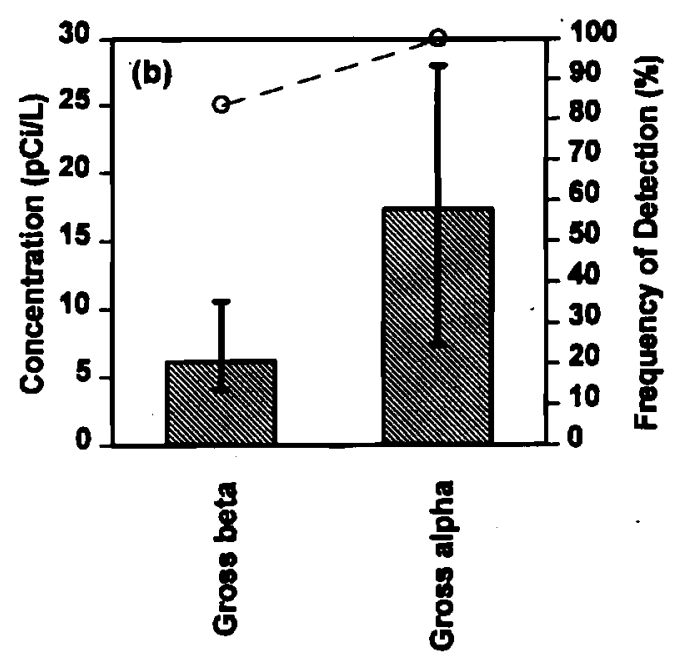

Figure 9.6. (contd). Building $\mathbf{3 7 2 0}$

Radiological Parameters: (b) Nonbusiness

Day Sampling 


\subsection{End-of-Pipe (Process Sewer)}

\subsection{Background and Description}

The end-of-pipe sample collection station is located just south of the TEDF Collection Sump. This location is downstream of the point of confluence for all 300 Area process sewer streams and includes effluent from WHC and ICF-Kaiser Hanford facilities in addition to PNL facilities. At this location, the stream also contains any retention process sewer effluent that has not been diverted to the Radioactive Liquid Waste Sewer. Diversions are rare, and this location normally contains all of the process sewer and retention process sewer effluent. Samples collected at this point are representative of the waste water which enters TEDF:

\subsection{Routine and Nonbusiness Day Sampling}

At end-of-pipe, 29 routine and 7 nonbusiness day 24-hr composite and 17 routine and 6 nonbusiness day grab sampling events occurred. However, the full range of analyses do not necessarily exist for each constituent because additional analyses may have been requested for specific constituents, or inadequate samples may have been collected for the analyses desired. Table C. 2 lists the analyses performed on the samples from end-of-pipe. Summary data supporting the constituent class discussions in Sections 10.2.1 through 10.2.6 are shown in the accompanying figures. Comparisons to influent chemistry are based on the data in Appendix E. Tables with detailed information can be found in Appendix $F$.

\subsubsection{General Chemical Parameters}

Overall, general chemical parameter levels were higher in the routine samples than in the treated influent. The effluent samples showed approximately $15 \%$ higher alkalinity and total carbon concentrations, while chemical oxygen demand and total dissolved solids concentrations were about $30 \%$ higher. Large fluctuations were apparent in the total organic carbon data, but the average concentration $(3,800 \mu \mathrm{g} / \mathrm{L})$ was approximately the same as the treated influent value (Figure 10.1a).

General chemical parameter concentrations in nonbusiness day samples were consistently lower than routine sample levels. Concentrations of alkalinity averaged $10 \%$ lower, total carbon and total dissolved solids averaged nearly $20 \%$ lower, and total organic carbon was approximately $45 \%$ lower. Chemical oxygen demand was only detected in one nonbusiness day sample (Figure 10.1b); the concentration was about $30 \%$ lower than the average routine monitoring concentration. 

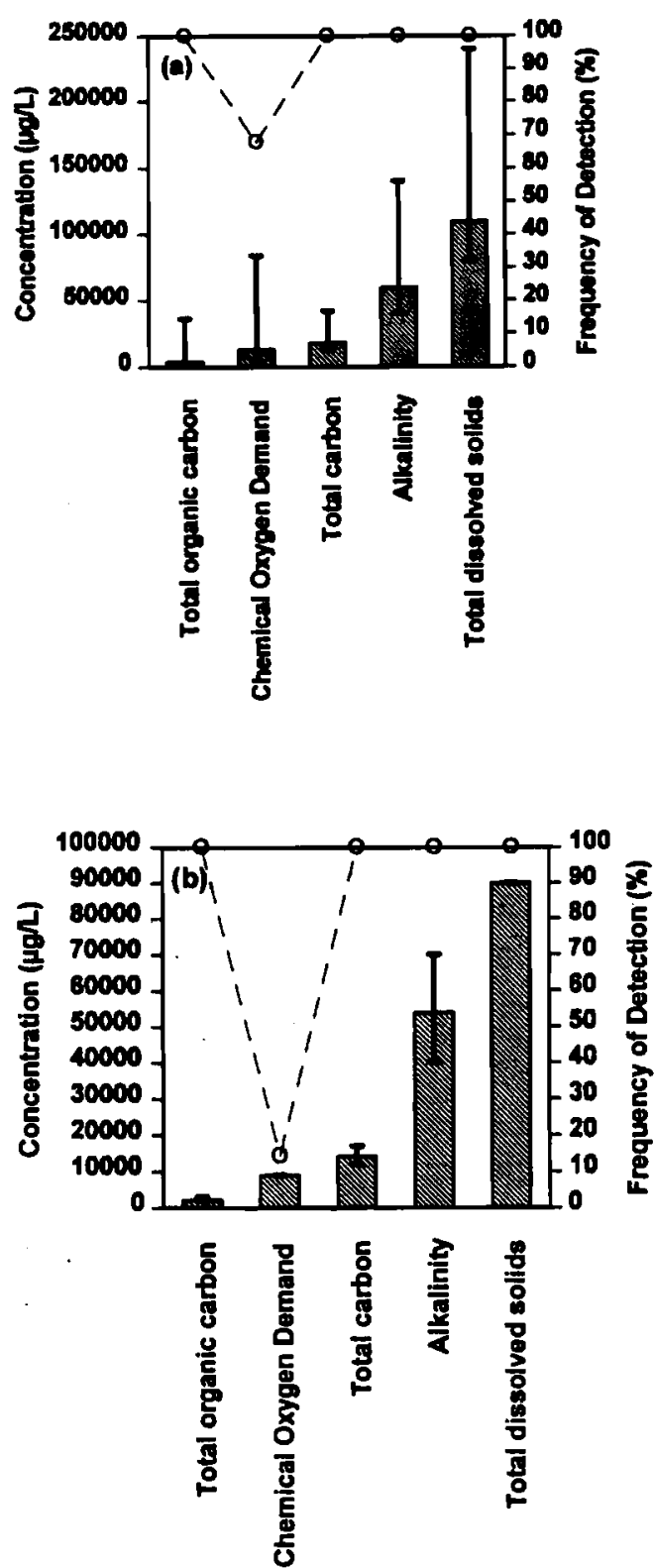

Figure 10.1. End-of-Pipe General Chemical Parameters: (a) Routine Sampling, (b) Nonbusiness Day Sampling
None of the general chemical parameters that were investigated have regulatory standards of comparison except total dissolved solids. The maximum total dissolved solids value observed for end-of-pipe was $240 \mathrm{mg} / \mathrm{L}$, which is much less than the National Secondary Drinking Water Standard of $500 \mathrm{mg} / \mathrm{L}$.

\subsubsection{Ammonia and Anions}

Cyanide was detected in 4 out of 28 routine samples at 1 to 5 times the method detection limit of $1 \mu \mathrm{g} / \mathrm{L}$, while ammonia was detected at an average concentration of $48 \mu \mathrm{g} / \mathrm{L}$ in 8 out of 26 samples. Nonbusiness day samples had a frequency of detection for ammonia (approximately $15 \%$ ) that was half that of the routine samples, although the concentrations in both sample sets were similar. Bromide was measured at two times the method detection limit in one routine sample, but the result could be the result of laboratory error. Sulfides were detected with similar frequencies in both sample types; the routine samples had somewhat elevated concentrations, although these levels are not significantly different from those observed in some blank and treated influent samples.

Phosphate was found $25 \%$ of the time in routine samples at readily detectable levels. Phosphate was not found in any blank or treated influent samples.

Fluoride concentrations and frequencies of detection were equivalent for both sample types and were very similar to treated influent values. Nitrate was always found in both sample types; routine samples had an average concentration approximately 4 times higher than nonbusiness day samples and 8 to 10 times higher than treated influent samples. Chloride and sulfate levels (chloride was $4,740 \mu \mathrm{g} / \mathrm{L}$; sulfate was $16,200 \mu \mathrm{g} / \mathrm{L}$ ) for nonbusiness day samples were similar to treated influent; 
sulfate concentrations in routine samples were also comparable to treated influent. Large concentration excursions of chloride were found in the routine samples (Figures 10.2a through d).

For reference only (the combined building effluent is not meant to be drinking water and is treated by the TEDF before being discharged to the river), concentrations of ammonia and anions were compared to the National Drinking Water Standards, which exist for four of the constituents detected (chloride, fluoride, nitrate, and sulfate). Only the nitrate standard of $10 \mathrm{mg} / \mathrm{L}$ was exceeded with a maximum observed concentration of $20 \mathrm{mg} / \mathrm{L}$ in the effluent. The TEDF waste acceptance criteria exist for two of the constituents detected (ammonia and cyanide). Both of these constituents were measured at a small fraction $(<10 \%)$ of the waste acceptance criteria.

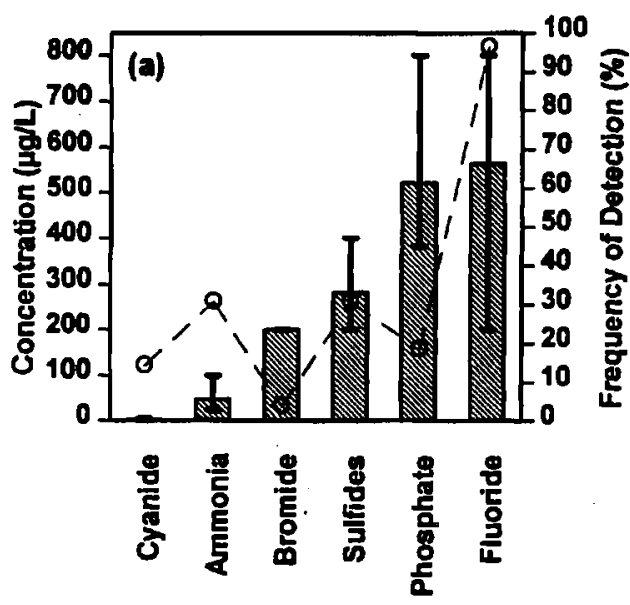

Figure 10.2. End-of-Pipe Ammonia and Anions: (a) Routine Sampling Concentrations Less than $800 \mu \mathrm{g} / \mathrm{L}$ (Cyanide Average $2.5 \mu \mathrm{g} / \mathrm{L}$, Range 1 to $5 \mu \mathrm{g} / \mathrm{L}$ )
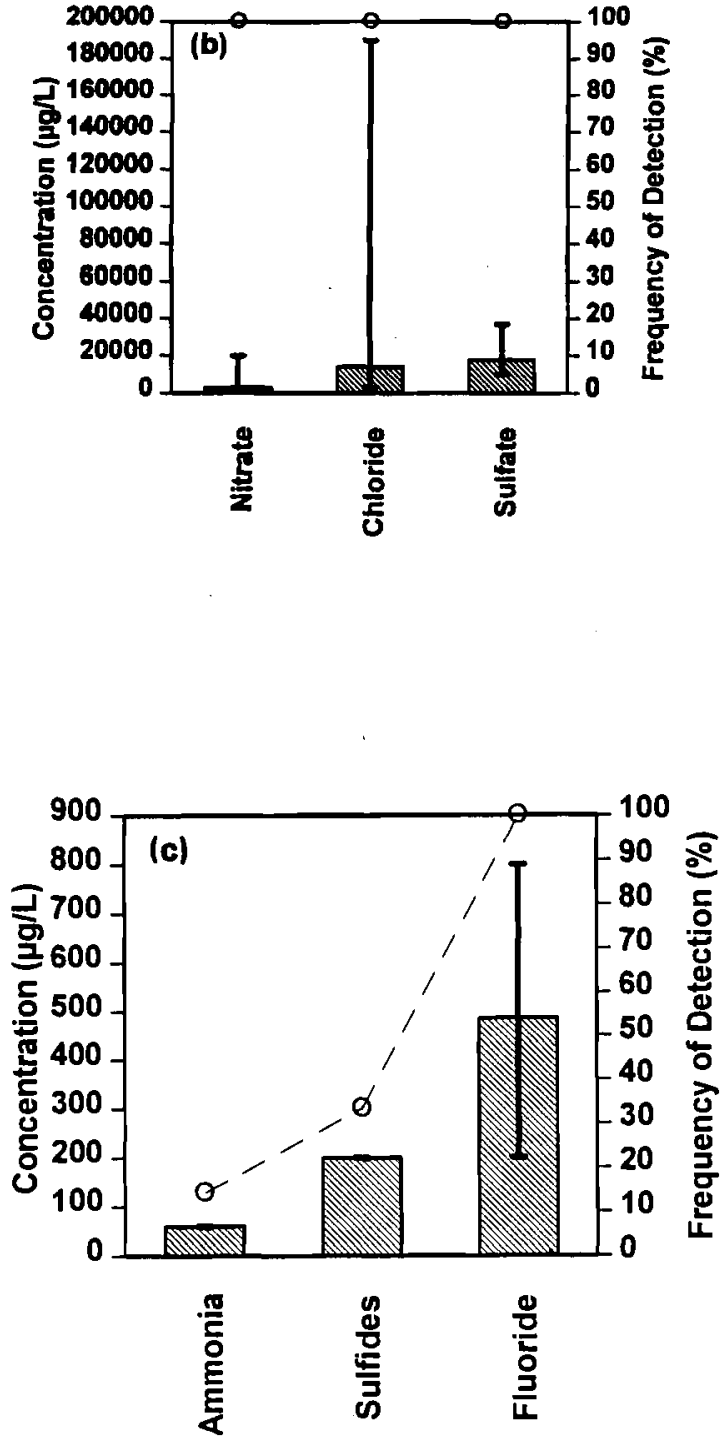

Figure 10.2. (contd). End-of-Pipe Ammonia and Anions: (b) Routine Sampling Concentrations Greater than $800 \mu \mathrm{g} / \mathrm{L}$, (c) Nonbusiness Day Sampling Concentrations Less than $900 \mu \mathrm{g} / \mathrm{L}$ 


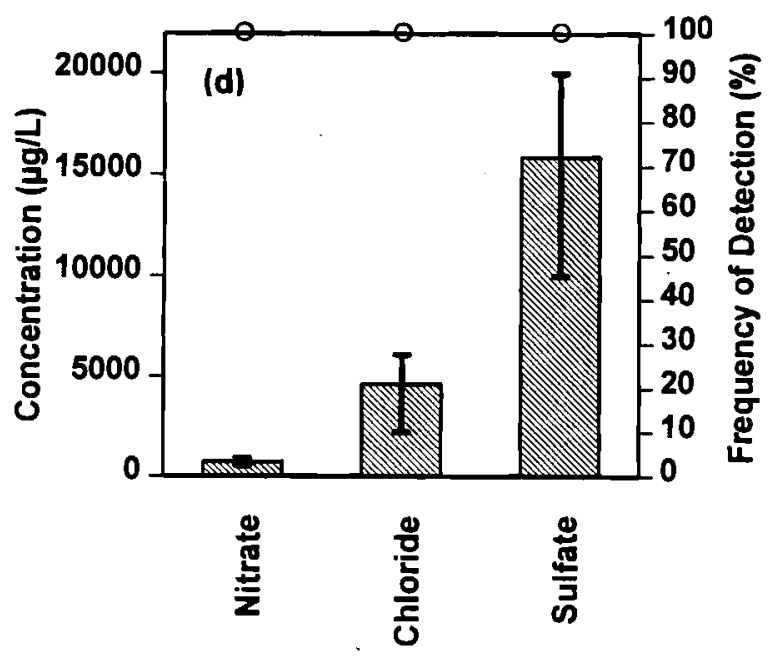

Figure 10.2. (contd). End-of-Pipe Ammonia and Anions: (d) Nonbusiness Sampling Concentrations Greater than $900 \mu \mathrm{g} / \mathrm{L}$

\subsubsection{Metals}

Mercury was detected in only routine samples at a frequency of nearly $50 \%$; the concentration ranged from 1 to 8 times the method detection limit. Other heavy metals found at concentrations below $20 \mu \mathrm{g} / \mathrm{L}$ were also found in blank and treated influent samples with similar concentrations and detection frequencies. Some analytes (e.g., arsenic and cadmium) had average concentrations at or slightly below their method detection limits (some concentrations were below the method detection limits because the limits changed later in the year). In addition, many species detected near their method detection limits in some endof-pipe samples le.g., tin, beryllium, selenium, thallium, and lead) were also found with similar frequencies in the reagent blanks (Appendix D). Chromium was found in three routine samples at slightly elevated levels relative to treated influent and blank samples. Barium had a twofold greater concentration range in routine samples, but the average was similar to treated influent and nonbusiness day samples. Aluminum, iron, and zinc were observed at similar average concentrations for both sample types, but higher concentration excursions were observed for routine samples. Average aluminum and iron levels were comparable to influent; aluminum was also found at similar levels in blanks. The concentration of zinc in routine samples (39 $\mu \mathrm{g} / \mathrm{L})$ was about 3 times higher than the influent concentration. The alkali and alkaline earth metals (potassium, magnesium, sodium, and calcium) had average concentrations which were 15 to $20 \%$ higher in routine than nonbusiness day samples. A large excursion of sodium was also detected in one routine sample. Levels of these metals were slightly elevated over concentrations observed in treated influent samples (Figures 10.3a through e).

The TEDF has waste acceptance criteria for 12 of the metals detected: aluminum, arsenic, beryllium, chromium, copper, iron, lead, manganese, mercury, nickel, selenium, and zinc. None of the metals exceeded the waste acceptance criteria.

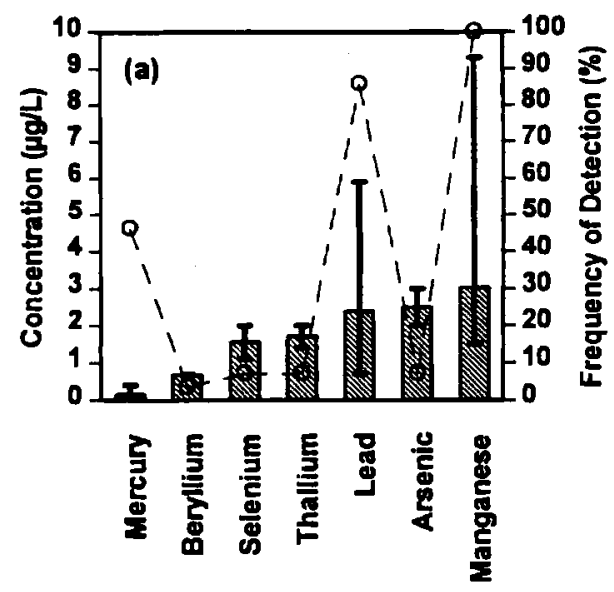

Figure 10.3. End-of-Pipe Metals: (a) Routine Sampling Concentrations Less than $10 \mu \mathrm{g} / \mathrm{L}$ 

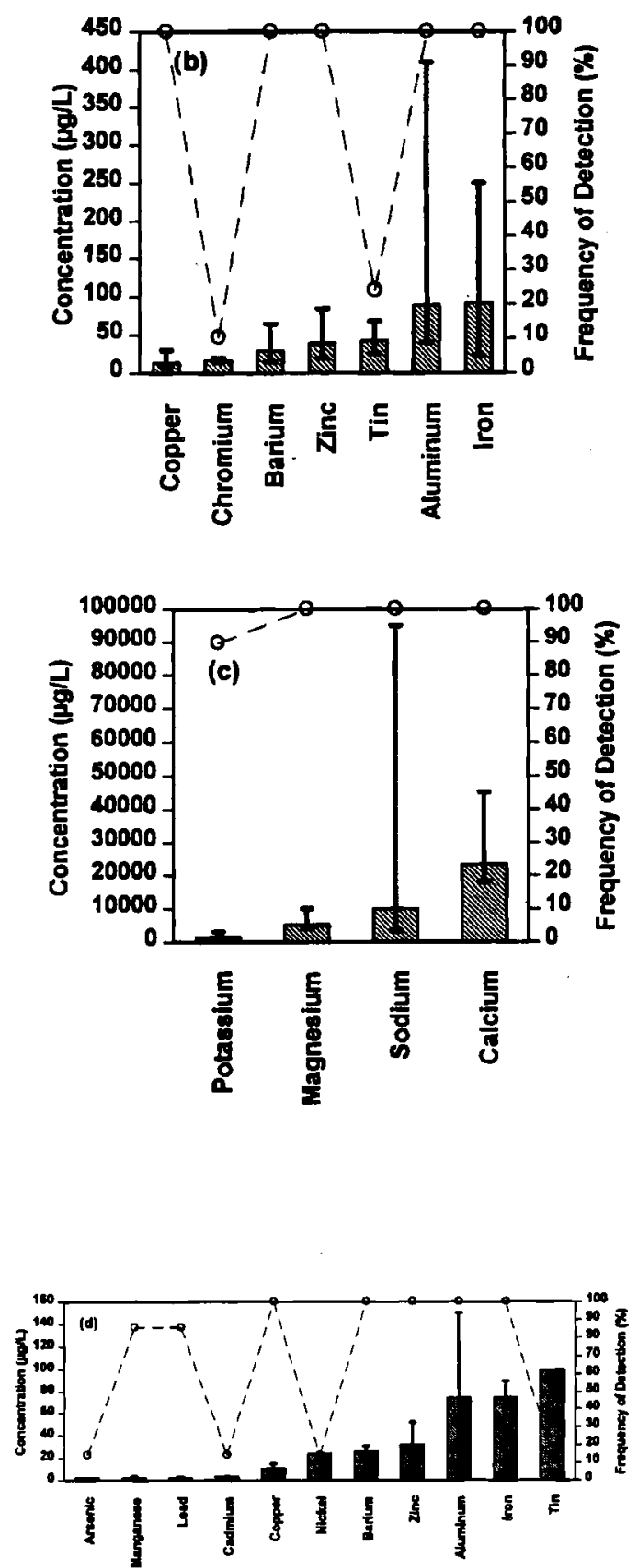

Figure 10.3. (contd). End-of-Pipe Metals: (b) Routine Sampling Concentrations Between 10 and $450 \mu g / L$, (c) Routine Sampling Concentrations Greater than $450 \mu \mathrm{g} / \mathrm{L}$, (d) Nonbusiness Day Sampling Concentrations Less than $160 \mu \mathrm{g} / \mathrm{L}$

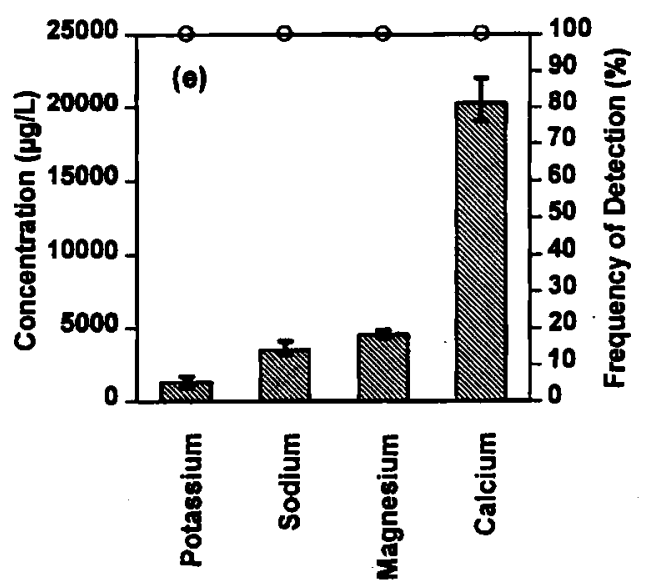

Figure 10.3. (contd). (e) Nonbusiness Day Sampling Concentrations Greater than $160 \mu \mathrm{g} / \mathrm{L}$

\subsubsection{Volatile Organic Compounds}

Several VOCs were detected in routine and nonbusiness day samples (Figures 10.4a through c). Methylene chloride and four trihalomethanes were observed most frequently, although the actual presence of methylene chloride is uncertain because of suspected laboratory contamination. Among the trihalomethanes, chloroform was detected most often and had the highest concentrations (up to $20 \mu \mathrm{g} / \mathrm{L}$ ). The average chloroform concentration in routine samples $(11.2 \mu \mathrm{g} / \mathrm{L})$ was approximately $50 \%$ lower than the level observed in the treated influent samples and was $20 \%$ higher relative to nonbusiness day samples. Bromodichloromethane was observed in approximately $50 \%$ of the routine and nonbusiness day samples; the average concentrations were roughly 1.5 times higher than treated influent levels. The remaining trihalomethanes, dibromochloromethane and bromoform, were detected less often (i.e., in $33 \%$ or fewer of the samples), and their 
concentrations were approximately 20 to $140 \%$ higher in the nonbusiness day samples.

Four other chlorinated hydrocarbons were detected in a small fraction of the effluent samples. Trichloroethene and tetrachloroethene were observed at trace levels ( $2 \mu \mathrm{g} / \mathrm{L}$ or lower) in both the routine and nonbusiness day samples. However, the presence of trichloroethene is questionable, because trichloroethene was also found in some of the blanks. Trichlorofluoromethane, a common refrigerant also known as Freon $11^{\circ}$, was measured at approximately the same concentration range in both routine and nonbusiness day samples. Notably, this compound was not detected in any of the samples from other monitoring locations. 1,1,1-trichloroethane was detected at a low concentration $(1.4 \mu \mathrm{g} / \mathrm{L})$ in one routine sample.

A variety of volatile organic solvents were infrequently detected in the routine samples; two of these compounds were also observed in nonbusiness day samples. Isopropyl alcohol was detected once with a relatively high concentration of approximately $600 \mu \mathrm{g} / \mathrm{L}$. This value should be more accurate than the alcohol data at Building 3720, because the endof-pipe sample measurement was made at a later date when a more thorough calibration was applied. Acetone and hexone (methyl isobutyl ketone) were detected in both routine and nonbusiness day samples. While the average acetone concentration was approximately the same for both sample sets, the average hexone concentration was slightly more than 2 times higher in the nonbusiness day samples. Acetonitrile was measured at a concentration of $76 \mu \mathrm{g} / \mathrm{L}$ in one routine sample. Low levels (i.e., less than $10 \mu \mathrm{g} / \mathrm{L})$ of two other solvents, tetrahydrofuran and toluene, were also detected in the routine samples.
Ethylbenzene and xylenes were detected in a few samples, but these data are tentative because the compounds were measured near their method detection limits. Xylenes were measured at $2 \mu \mathrm{g} / \mathrm{L}$ or lower in both routine and nonbusiness samples; the concentrations were approximately twice as high in the nonbusiness day samples.
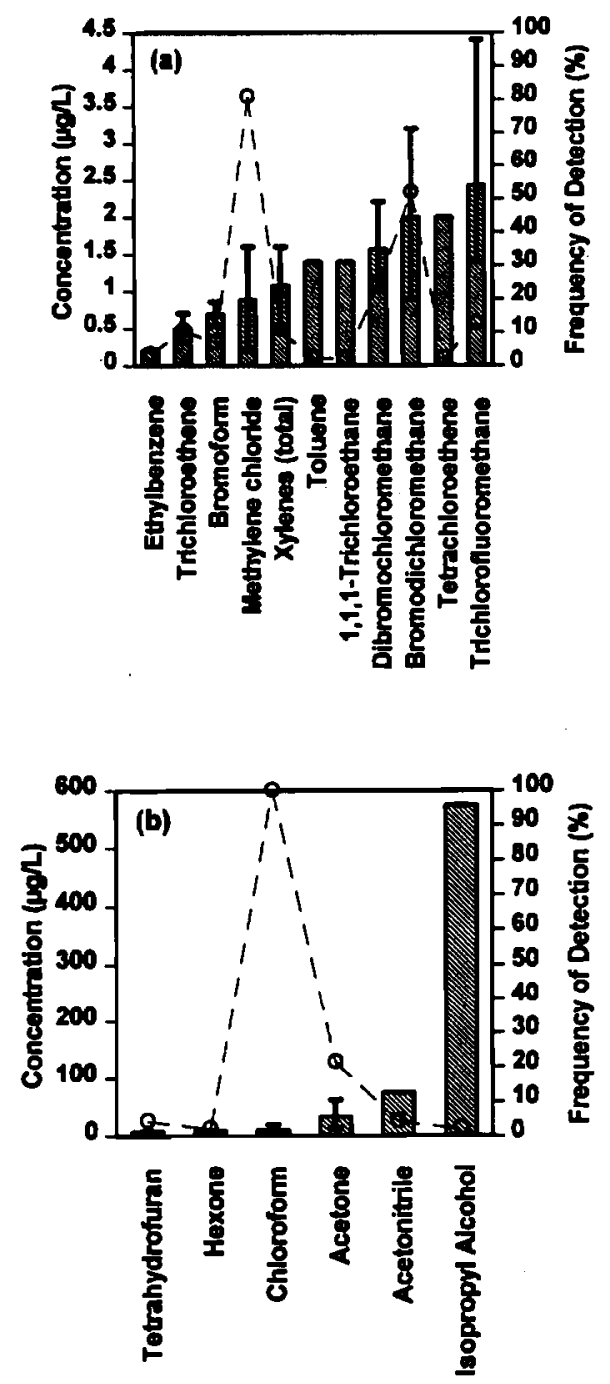

Figure 10.4. End-of-Pipe Volatile Organic Compounds: (a) Routine Sampling Concentrations Less than $4.5 \mu \mathrm{g} / \mathrm{Lm}$, (b) Routine Sampling Concentrations Greater than $4.5 \mu \mathrm{g} / \mathrm{L}$ 


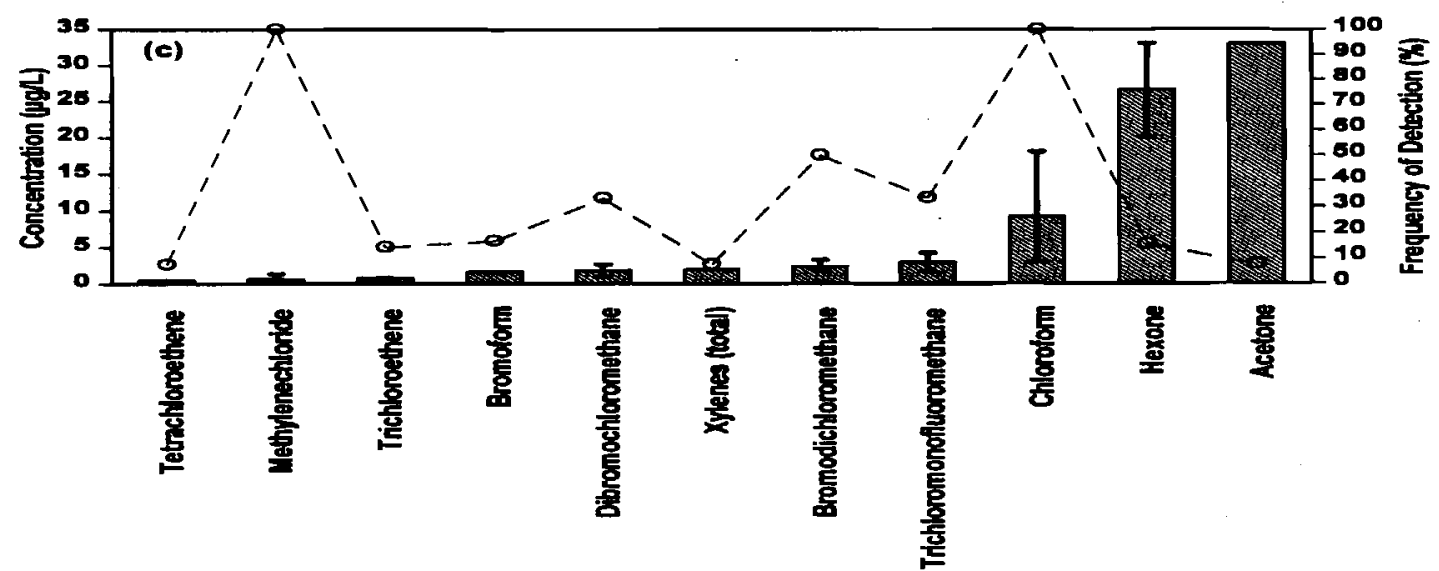

Figure 10.4. (contd). End-of-Pipe Volatile Organic Compounds: (c) Nonbusiness Day Sampling

\subsubsection{Semivolatile Organic Compounds}

Three phthalate compounds ( 5 to $37 \mu \mathrm{g} / \mathrm{L})$, tributyl phosphate $(6 \mu \mathrm{g} / \mathrm{L})$, and seven pesticides ( 2 to $35 \mathrm{ng} / \mathrm{L}$ ) were found in 5 to $40 \%$ of the routine samples (Figures 10.5a and b). Delta-BHC,

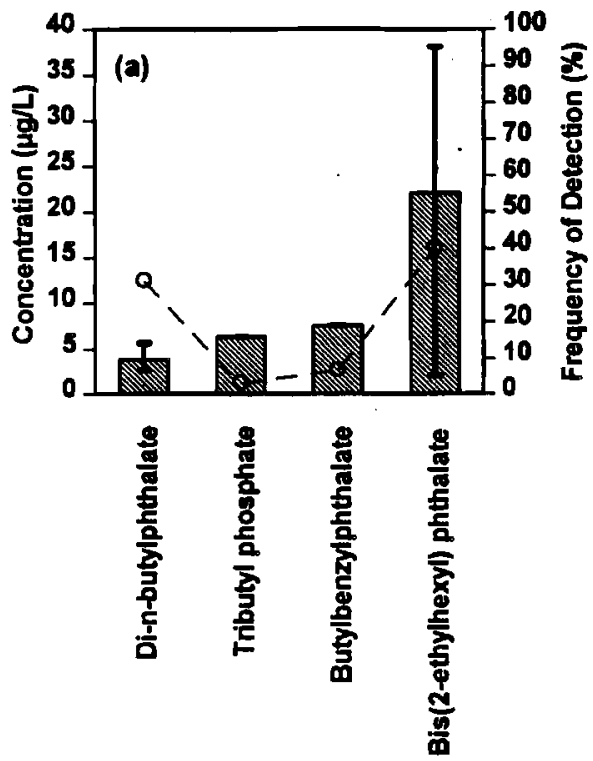

heptachlor, and bis(2-ethylhexyl)phthalate were found in several nonbusiness day samples (Figure 10.5c). One routine sample had the highest concentration (36 $\mathrm{ng} / \mathrm{L}$ ) of endosulfan sulfate, a pesticide. The TEDF waste acceptance criteria were not exceeded.

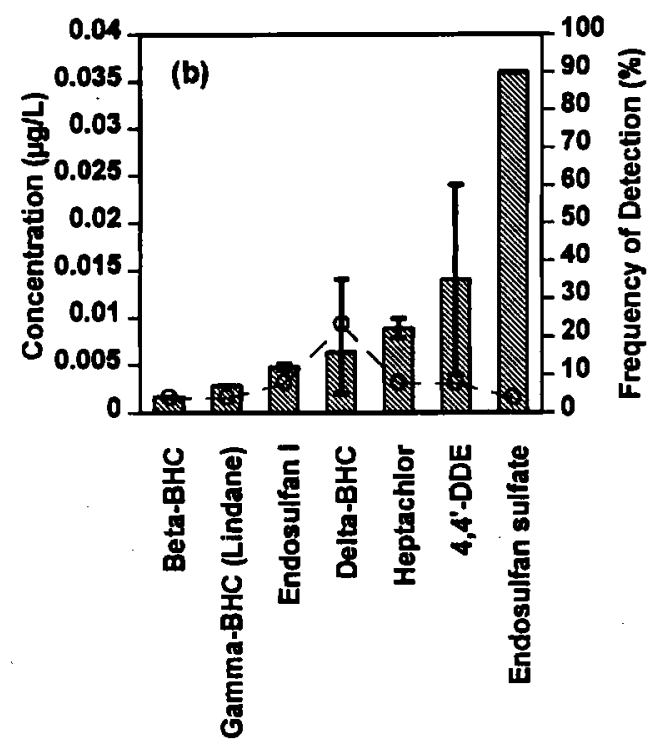

Figure 10.5. End-of-Pipe Semivolatile Organic Compounds: (a) Routine Sampling Pesticides, (b) Routing Sample 


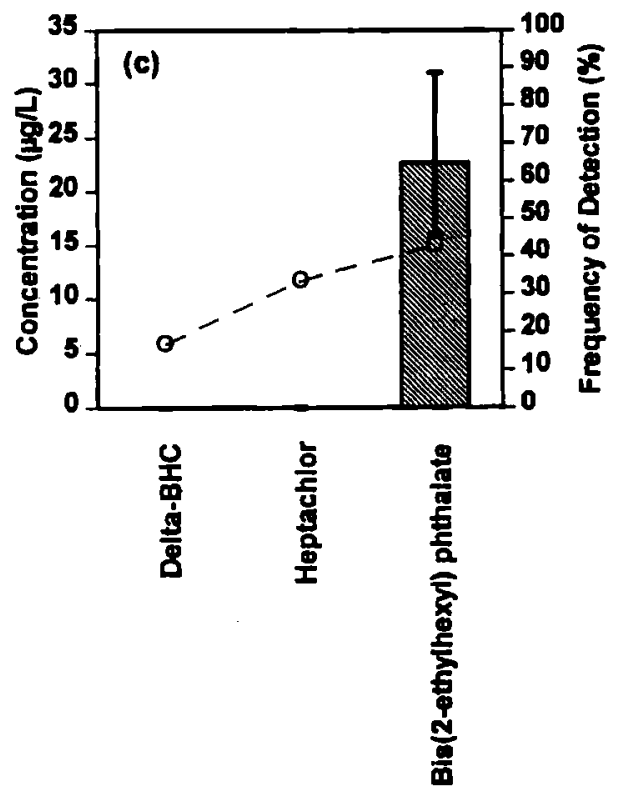

Figure 10.5. End-of-Pipe Semivolatile Organic Compounds: (c) Non business Day Sampling (Delta-BHC Average $0.01 \mu \mathrm{g} / \mathrm{L}$, Range N/A; Heptachlor Average $0.01 \mu \mathrm{g} / \mathrm{L}$, Range N/A)

\subsubsection{Radiological Parameters}

Gross alpha, gross beta, and tritium were detected at low levels in routine and nonbusiness day samples (Figure 10.6a and b). Gross alpha was detected most frequently, although its average concentrations in routine $(3.3 \mathrm{pCi} / \mathrm{L})$ and nonbusiness day samples $(2.4 \mathrm{pC} / L)$ were lowest among the three parameters. Both gross alpha and gross beta were measured over a wider range and had higher average concentrations (40 to $60 \%$ higher) in the routine samples. Tritium was only detected once in each sample set; the nonbusiness day result (423 $\mathrm{pCi} / \mathrm{L}$ ) was approximately twice as high as the routine sampling result (227 pCi/L). All measurements for radioactivity were less than the TEDF waste acceptance criteria (15 pCi/L alpha, $50 \mathrm{pCi} / \mathrm{L}$ beta, and $20,000 \mathrm{pCi} / \mathrm{L}$ tritium).
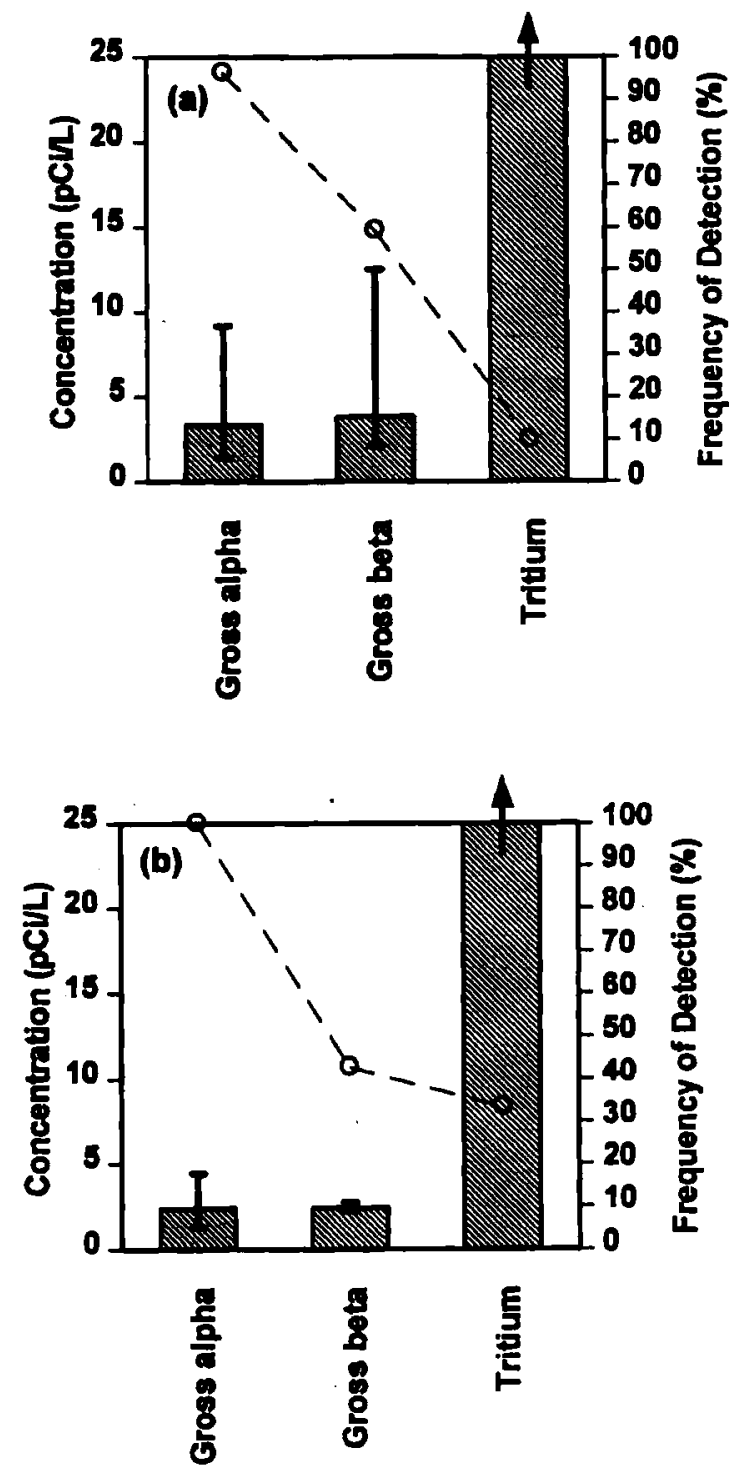

Figure 10.6. End-of-Pipe Radiological Parameter: (a) Routine Sampling (Tritium Average 227.0 PCi/L, Range N/A), (b) Nonbusiness Day Sampling (Tritium Average $423 \mathrm{pCi} / \mathrm{L}$, Range N/A) 


\subsection{Comparison of CY 1994 End-of-Pipe Data to Historical Information}

Table 10.1 lists historical and CY 1994 concentration ranges for parameters and constituents in effluent at end-of-pipe. A more detailed summary of the historical data can be found in Section A.3 of Appendix A. Comparisons were made for a total of 27 parameters and constituents. With three exceptions, all of the parameters and constituents in CY 1994 had observed concentration ranges that were within a factor of 3 of the concentration ranges observed in the historical data. The three exceptions were chloride, nitrate, and sodium; these constituents had maximum concentrations that significantly exceeded the maximum concentrations of the historical data. In addition, the CY 1994 average concentrations of chloride and sodium exceeded the maximum concentrations of the historical data, and the associated standard deviations of all three constituents greatly exceeded those averages. These latter observations suggest that a few of the CY 1994 samples were collected when excursions containing large concentrations of these constituents were occurring. Cadmium, which was reported present in the historical data, was not detected in CY 1994 end-of-pipe samples. Ranges reported for gross radioactivity were well within the levels observed for historical data.

\subsection{Comparison of CY 1994 End-of-Pipe Data to Regulatory Limits}

Table B. 2 in Appendix B summarizes the observed concentrations of parameters and constituents at end-of-pipe for CY 1994 and federal and state regulatory limits. Comparisons were made for a total of 33 parameters and constituents. Seven constituents exceeded the EPA $M C L$ and/or TEDF NPDES limits.

Bis(2-ethylhexyl)phthalate exceeded both the EPA MCL and NPDES limit. Zinc, copper, and lead frequently exceeded the NPDES limits. Occasionally, aluminum exceeded both EPA MCL and NPDES limits, whereas nitrate and gross beta occasionally exceeded the EPA MCLs. For those parameters and constituents exceeding regulatory limits, maximum levels exceeded were within a factor of 10 of the regulatory limit. 
Table 10.1. Comparison of Observed Concentration Ranges $(\mu \mathrm{g} / \mathrm{L})$ of Parameters and Constituents at End-of-Pipe During CY 1994 to Historical Data

\begin{tabular}{|c|c|c|}
\hline $\begin{array}{l}\text { Parameter or } \\
\text { Constituent }\end{array}$ & $\begin{array}{l}\text { Historical Concentration } \\
\text { Range }\end{array}$ & $\begin{array}{l}\text { Observed Concentration Range and } \\
\text { (Average } \pm \text { SD) for CY } 1994\end{array}$ \\
\hline \multicolumn{3}{|c|}{ General Chemical Parameters } \\
\hline Alkalinity & $40,000-60,000$ & $40,000-140,000(59,936 \pm 21,852)$ \\
\hline Ammonia & $100-400$ & $23-100(48 \pm 28)$ \\
\hline Total carbon & $10,000-16,000$ & $13,000-42,000(17,929 \pm 5,850)$ \\
\hline \multicolumn{3}{|c|}{ Anions: } \\
\hline Chloride & $3,000-4,000$ & $2,500-190,000(14,024 \pm 35,457)$ \\
\hline Cyanide & $10-15$ & $1-5(3 \pm 2)$ \\
\hline Fluoride & $200-250$ & $200-800(565 \pm 158)$ \\
\hline Nitrate & $1,000-3,500$ & $200-20,000(2,988 \pm 4,495)$ \\
\hline Phosphate & $1,800-8,500$ & $383-800(522 \pm 166)$ \\
\hline Sulfate & $17,000-20,000$ & $10,000-36,900(17,756 \pm 4,467)$ \\
\hline \multicolumn{3}{|c|}{ Cations } \\
\hline Aluminum & $150-300$ & $40-410(89 \pm 68)$ \\
\hline Barium & $30-40$ & $15-64(29 \pm 9)$ \\
\hline Cadmium & $2-30$ & ND \\
\hline Calcium & $-20,000$ & $18,000-45,000(23,241 \pm 6,828$ \\
\hline Copper & $10-125$ & $8-30(14 \pm 6)$ \\
\hline Iron & $100-550$ & $23-250(92 \pm 45)$ \\
\hline Lead & $5-15$ & $0.7-5.9(2.4 \pm 1.2)$ \\
\hline Magnesium & $4,000-5,000$ & $4,200-10,000(5,221 \pm 1,409)$ \\
\hline Manganese & $5-35$ & $1.5-9.3(3.0 \pm 1.7)$ \\
\hline Mercury & $0.1-2$ & $0.08-0.41(0.15 \pm 0.09)$ \\
\hline Nickel & $10-15$ & $16-18(17)$ \\
\hline Potassium & $800-1,500$ & $950-3,100(1,533 \pm 567)$ \\
\hline Sodium & $2,500-5,000$ & $3,200-95,000(9,969 \pm 17,937)$ \\
\hline Zinc & $15-500$ & $20-84(39 \pm 14)$ \\
\hline \multicolumn{3}{|c|}{ Organic Compounds } \\
\hline Acetone & $30-110$ & $13-63(33.6 \pm 16.7)$ \\
\hline Chloroform & $12-55$ & $3.4-20(11.2 \pm 4.1)$ \\
\hline \multicolumn{3}{|c|}{ Gross Radioactivity } \\
\hline Alpha activity & $1-900^{(a)}$ & $1.4-9.2(3.3 \pm 0.8)$ \\
\hline Beta activity & $1-380^{(a)}$ & $2.1-12.5(3.8 \pm 1.2)$ \\
\hline
\end{tabular}




\subsection{Waste Stream Dynamics Tests}

Waste stream dynamics tests involve the release of a known concentration and volume of a nonhazardous, fluorescent dye (Acid Red \#52) into a facility waste stream. The dye's concentration is then monitored using a fluorometer at the facility sampling point and at the end-ofpipe. Based on the fluorescence readings (which are directly proportional to concentration), important stream flow parameters such as contaminant transit times and dilution factors can be assessed.

Two facilities were chosen for an initial appraisal of stream dynamics for the 300 Area process sewer:

- Building 331, the PNL facility furthest from the end-of-pipe

- Building 3720, the PNL facility closest to the end-of-pipe.

In each experiment, continuous, realtime data collection was facilitated by diverting a portion of the stream through a flow cell mounted inside each fluorometer. The temperature and $\mathrm{pH}$ of the stream were also continuously monitored for later correction of the fluorescence measurements.

\subsection{Testing}

Initial tests at Buildings 331 and 3720 in February 1994, 1) generated information to refine test design, 2) evaluated field logistics, and

3) developed and tested the dye measurement system.

Table 11.1 summarizes the test activity during July. A total of 12 dye releases were made at Building 3720 , while 6 releases were made at Building 331. Unfortunately, seven of the releases were not useful for quantitative dilution estimates, because the dye concentration at the end-of-pipe was too high for the limited dynamic range of the fluorometer. However, the off-scale data were useful for determining transit and clearance times.

\subsection{Results}

Figures 11.1 and 11.2 display representative end-of-pipe fluorescence profiles associated with dye releases at Buildings 3720 and 331 , respectively. Normally, each dye release at Building 3720 resulted in one predominant peak lobserved initially at the building and later at the end-of-pipe) from which timing parameters and dilution factors were calculated. The data from Building 331 were more complex. Multiple peaks with decreasing intensities were observed at the end-of-pipe following each dye release (Figure 11.2). This behavior appears to result from incomplete purging of the 3906 lift-station sump located southeast of Building 315. Clearly, the multiple peaks from Building 331 releases will be important in potential event-response activities associated with this facility.

Three types of time measurements were collected in each waste stream dynamics test: arrival time, transit time, and clearance time (Figure 11.3). Arrival time is the time at which a contaminant is first detected at the end-of-pipe. Transit time is the time required for the maximum concentration to reach a given point (for example, end-of-pipe). Clearance time is the time required for a discrete stream constituent (that is, a contaminant which 
has been released into a stream) to completely flow past a given point. Clearance times were determined at both facilities and at end-of-pipe.

\subsubsection{Arrival Times and End-of-Pipe Transit Times}

The average and range of arrival times and end-of-pipe transit times for Buildings 3720 and 331 are listed in Tables 11.2 and 11.3. Generally, the transit times were about 5 to 8 minutes greater than the arrival times. For Building 3720, the average transit time was 49 minutes; the corresponding time for Building 331 was 4 hours and 21 minutes (for the primary dye peak). The longer time required to travel from Building 331 is consistent with the longer flow path from Building 331 to the endof-pipe (Figure 3.1). In principle, the average transit times in Tables 11.2 and 11.3 serve as a range that should encompass the transit times of the other 300 Area facilities. However, low flow rates at some facilities and the unknown retention properties of sumps could place other facilities outside this range.

Each facility showed a large range in transit times (Tables 11.2 and 11.3). Indeed, the ranges are greater than the corresponding average transit times. These variations are primarily caused by the activation of sump pumps and fluctuations in the process sewer flow rates.

\subsubsection{Clearance Times}

The average clearance times at the two buildings and the end-of-pipe are listed in Table 11.4. For both buildings, the band(s) of dye broadened by the time they reached the end-of-pipe. This broadening was attributed to normal dilution and dispersion of the dye as it passed through the process sewer.
However, for Building 331, the primary influence on the clearance time was the action of a sump, which resulted in an average clearance time of 4 hours, 23 minutes. This sump-enhanced increase is approximately 13 times greater than the estimated change from dispersion alone. An additional factor that may lengthen clearance times at both facilities is chemical interaction by some contaminants (for example, adsorption of metals on a pipe). Because the fluorescent dye is relatively inert, such interactions have not influenced these results.

\subsubsection{Dilution Factors}

Dilution factors for the two buildings are summarized in Table 11.5. On average, the dye was diluted by a factor of 30 as it passed from Building 3720 to the end-of-pipe; the corresponding dilution factor for Building 331 was 524 . These values are consistent with the observed dispersion (peak-width) changes associated with the two facilities.

For Building 331 , each pulse of dye created by the action of the 3906 sump was approximately two to three times more dilute than its predecessor (Table 11.5).

Thus, for an event involving the release of a contaminant from Building 331 , the number of significant pulses at the end-of-pipe will depend largely on the initial concentration of the contaminant. Consequently, the initial concentration will have a major influence on the end-ofpipe clearance time.

As these results indicate, clearance times, sump effects, and contaminant concentration will have to be considered seriously along with flow rates in determining the overall impacts of facility releases on the chemistry at the end-ofpipe. 


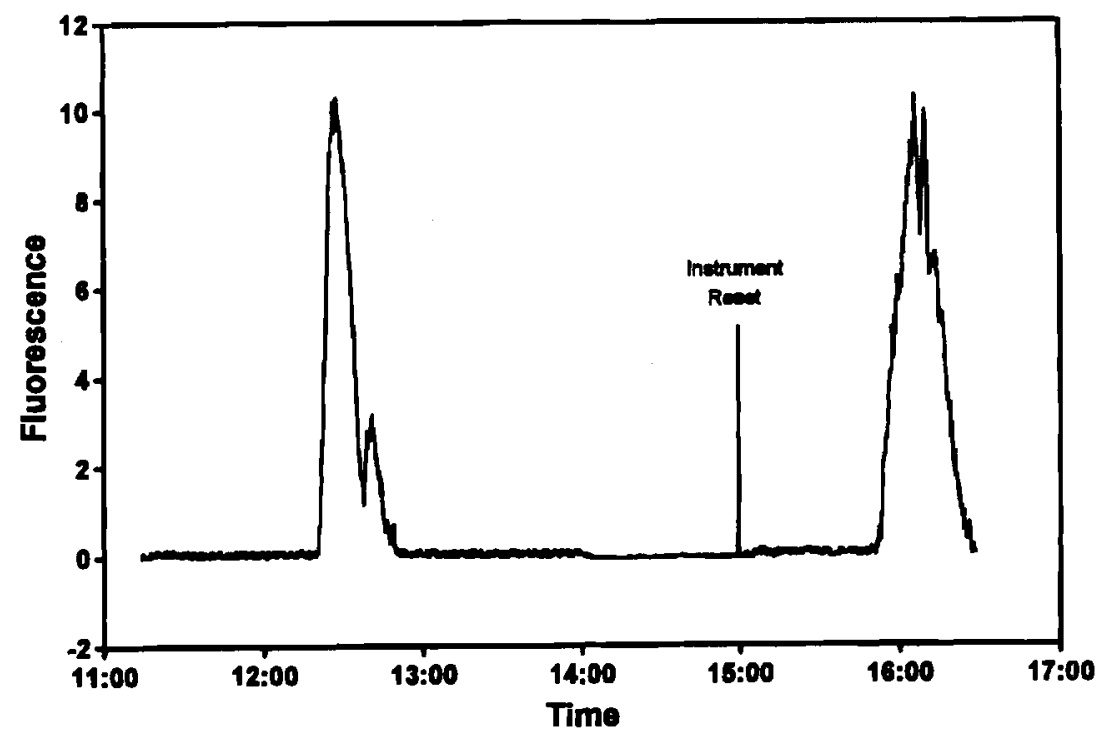

Figure 11.1. End-of-Pipe Fluorescence From Two Dye Releases at Building 3720

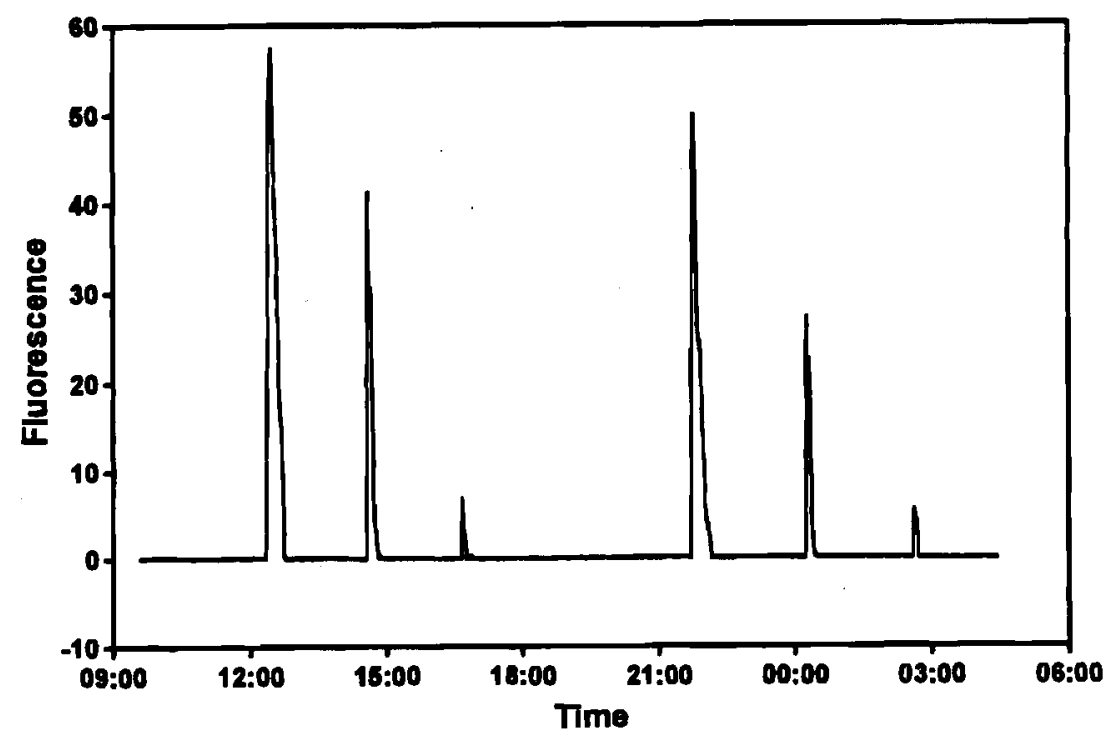

Figure 11.2. End-of-Pipe Fluorescence at Building 331 


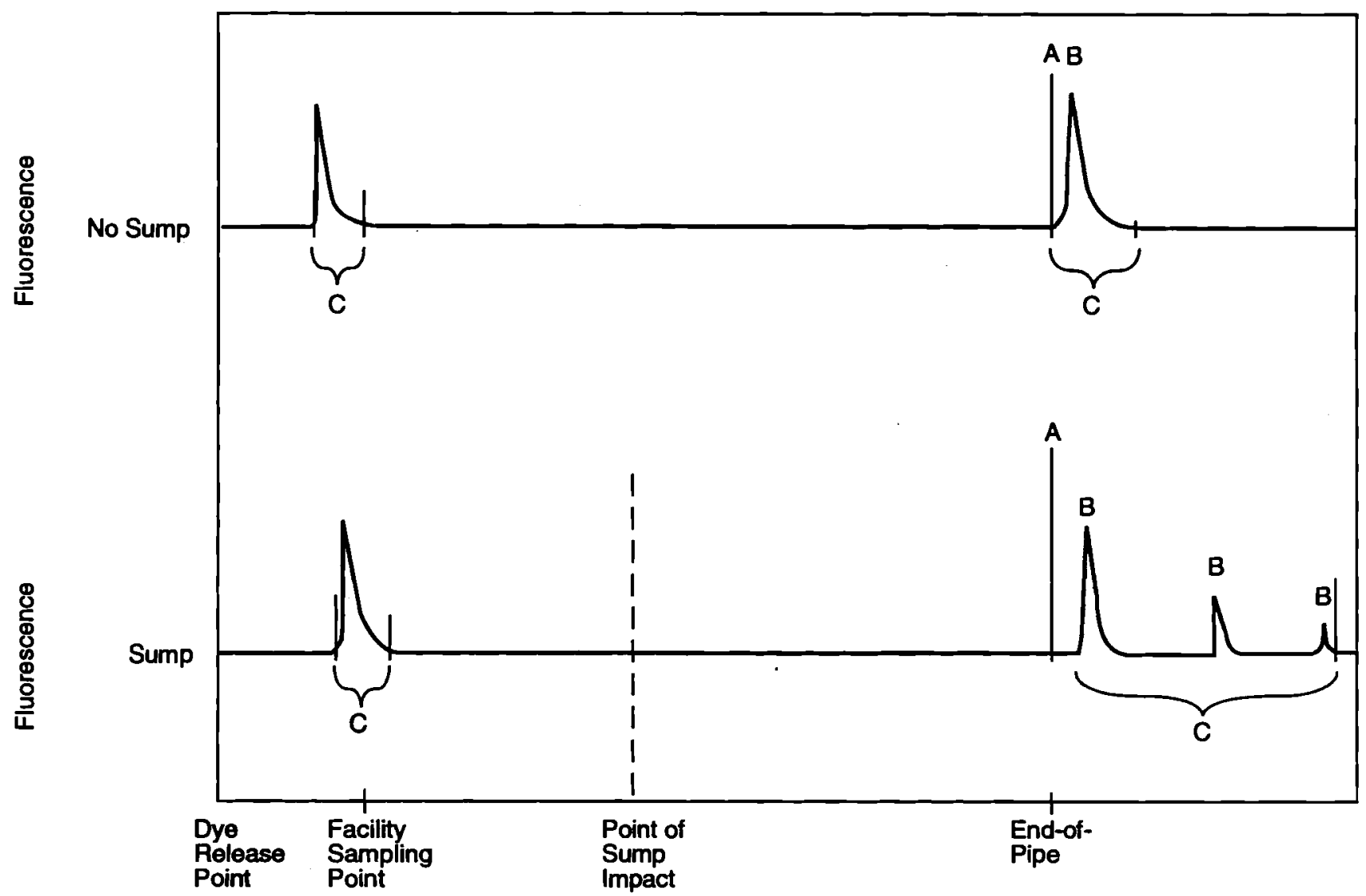

Time / Distance

$\$ 9409001.2$

$\mathrm{A}=$ arrival time. $\mathrm{B}=$ transit time. $\mathrm{C}=$ clearance time

Figure 11.3. Time Measurement from Fluorescence Data. The lower trace corresponds to a flow path with an intercepting sump. 
Table 11.1. Stream Dynamics: July Test Dates and Number of Dye Releases

\begin{tabular}{|c|c|c|c|c|c|c|}
\hline \multirow[b]{2}{*}{ Building } & \multicolumn{6}{|c|}{ Number of Dye Releases } \\
\hline & July 1 & July 7 & July 8 & July 11 & July 14 & July 21 \\
\hline 3720 & $\begin{array}{l}1^{(a, b)} \\
2^{(a)}\end{array}$ & $\begin{array}{l}1^{(a)} \\
1^{(b)}\end{array}$ & $2^{(a)}$ & $\begin{array}{c}1 \\
3^{(b)}\end{array}$ & - & - \\
\hline 331 & - & $1^{\text {(a) }}$ & - & $1^{\text {(a) }}$ & 2 & $2^{\text {(b) }}$ \\
\hline
\end{tabular}

Table 11.2. Building 3720 Arrival and Transit Times

\begin{tabular}{||c|c|c||}
\hline & Average & Range \\
\hline Arrival Time & $42 \mathrm{~min}$ & $18 \mathrm{~min}$ to $1 \mathrm{hr} 12 \mathrm{~min}$ \\
\hline Transit Time & $49 \mathrm{~min}$ & $19 \mathrm{~min}$ to $1 \mathrm{hr} 25 \mathrm{~min}$ \\
\hline
\end{tabular}

Table 11.3. Building 331 Arrival and Transit Times

\begin{tabular}{|c|c|c|c|c|c|c|}
\hline & \multicolumn{2}{|c|}{ Primary Dye Peak } & \multicolumn{2}{|c|}{ Secondary Dye Peak } & \multicolumn{2}{|c|}{ Tertiary Dye Peak ${ }^{(a)}$} \\
\hline & Average & Range & Average & Range & Average & Range \\
\hline $\begin{array}{c}\text { Arrival } \\
\text { Time }\end{array}$ & $4 \mathrm{hr} 13 \mathrm{~min}$ & $\begin{array}{c}2 \mathrm{hr} 38 \mathrm{~min} \\
\text { to } \\
7 \mathrm{hr} 30 \mathrm{~min}\end{array}$ & $6 \mathrm{hr} 16 \mathrm{~min}$ & $\begin{array}{c}3 \mathrm{hr} 35 \mathrm{~min} \\
\text { to } \\
10 \mathrm{hr} 53 \mathrm{~min}\end{array}$ & $7 \mathrm{hr} 59 \mathrm{~min}$ & $\begin{array}{c}6 \mathrm{hr} 6 \mathrm{~min} \\
\text { to } \\
10 \mathrm{hr} 34 \mathrm{~min}\end{array}$ \\
\hline $\begin{array}{c}\text { Transit } \\
\text { Time }\end{array}$ & $4 \mathrm{hr} 21 \mathrm{~min}$ & $\begin{array}{c}2 \mathrm{hr} 51 \mathrm{~min} \\
\text { to } \\
7 \mathrm{hr} 36 \mathrm{~min}\end{array}$ & $6 \mathrm{hr} 20 \mathrm{~min}$ & $\begin{array}{c}3 \mathrm{hr} 39 \mathrm{~min} \\
\text { to } \\
10 \mathrm{hr} 55 \mathrm{~min}\end{array}$ & $8 \mathrm{hr} 1 \mathrm{~min}$ & $\begin{array}{c}6 \mathrm{hr} 7 \mathrm{~min} \\
\text { to } \\
10 \mathrm{hr} 36 \mathrm{~min}\end{array}$ \\
\hline
\end{tabular}

Table 11.4. Average Clearance Times

\begin{tabular}{||c|c|c|c||}
\hline Building & At the Building & At the End-of-Pipe & Relative Increase (\%) \\
\hline 3720 & $6 \mathrm{~min} 36 \mathrm{~s}$ & $8 \mathrm{~min} 30 \mathrm{~s}$ & 29 \\
\hline 331 & $9 \min 12 \mathrm{~s}$ & $4 \mathrm{hr} 23 \mathrm{~min}$ & 2,760 \\
\hline
\end{tabular}


Table 11.5. Dilution Factors

\begin{tabular}{||c|c|c|c|c|c|c||}
\hline \multirow{2}{*}{ Building } & \multicolumn{2}{|c|}{ Primary } & \multicolumn{2}{c||}{ Secondary } & \multicolumn{2}{c||}{ Tertiary ${ }^{\text {(a) }}$} \\
\cline { 2 - 7 } & Average & Range & Average & Range & Average & Range \\
\hline 3720 & 30 & $8-54$ & - & - & - & - \\
\hline 331 & 524 & $471-616$ & 980 & $638-1561$ & 3,092 & $2,893-3,290$ \\
\hline
\end{tabular}




\subsection{Technology Evaluation}

Technologies under development (during late FY 1993 and early FY 1994) in DOE's Office of Technology Development (EM-50) were screened for potential use in the Effluent Management Program. Also screened were technologies on display at the U.S.'s largest show of modern laboratory equipment sponsored by the Spectroscopy Society of Pittsburgh and the Society for Analytical Chemists of Pittsburgh (also known as the Pittsburgh Conference) (February 27 through March 4, 1994, in Chicago, Illinois). Through the task-planning process, three technologies were selected for evaluation and possible future deployment, beginning in FY 1994. The three technologies were selected and evaluated based on the potential to improve near- and intermediate-term cost effectiveness and quality for effluent characterization and monitoring. The technologies are as follows:

- field transportable gas chromatograph/mass spectrometer (GC/MS) to measure VOCs

- adsorptive stripping voltametry (ASV) for field measurement of chemical uranium

- solid phase extraction (SPE) for preconcentration and cleanup of liquid samples in the laboratory or the field.

A fourth technology, continuous monitoring of general waste stream parameters, was also chosen for evaluation during the last quarter of 1994.

\subsection{Gas Chromatograph/Mass Spectrometer}

Of the field transportable GC/MS systems available, the SpectraTrak GC/MS was chosen and purchased because it is capable of powerful analyses in both field or laboratory use (McDonald et al. 1994). To provide complete remote capability for the GC/MS, a small 2.4KVA generator was also purchased. The SpectraTrak GC/MS has been used to measure VOCs at Sandia National Laboratory's Chemical Waste Landfill las part of DOE's Office of Technology Development program) and in Department of Defense remediation activities. Moreover, the SpectraTrak GC/MS has been used in the commercial sector addressing remediation and health and safety issues.

\subsubsection{Methods Development and Analysis of Water Samples}

The primary emphasis in 1994 was water analysis. The GC/MS can analyze either VOCs or SVOCs in water or gaseous matrices. However, because sample preparation is more laboratory intensive for SVOCs, the GC/MS was used primarily to analyze the VOCs using standard methods (for example, EPA Method 502.2) or methods developed in our laboratory. A second GC/MS was acquired to analyze SVOCs.

Purge-and-trap gas chromatography, using EPA Method 502.2, has very good sensitivity for water analysis and a reasonably high degree of selectivity for 
known or expected components. However, it is not well suited for identification of unknowns and may be somewhat prone to occasional misidentification. The analysis time is very long on a per sample basis lapproximately 75 minutes per sample). Because effluent samples may potentially contain a wide range of unknown or unexpected water soluble organic compounds, this method was used primarily in this project for quality control of samples sent to the analytical services laboratory.

To augment EPA Method 502.2, procedure development has concentrated on testing a headspace method for analysis of VOCs in waste water samples. The method chosen has adequate sensitivity, excellent identification capability, and high sample throughput (20 minutes per sample). The detection levels attainable by this method are quite respectable, typically around $1 \mu \mathrm{g} / \mathrm{L}$ for most VOC species of interest. Thus, the headspace method can be used with confidence down to and somewhat below drinking water standards for all major VOC species of interest, except vinyl chloride. Quantitative comparisons between the headspace method and purge-and-trap gas chromatography, where possible, were uniformly favorable as expected because the same calibration standard was used on both instruments. The procedure was successfully implemented both in the laboratory and in the field (300 Area) on samples from several PNL facilities.

The headspace method depends upon partitioning VOCs between the water and a confined gas space above the liquid. Samples without bubbles are collected from the headspace in commercially available 44-mL brown glass septumsealed VOC vials and stored at a low temperature (typically $4^{\circ} \mathrm{C}$ ). Just before analysis, a $20-\mathrm{mL}$ aliquot of the sample is put in a graduated cylinder with the remainder disposed to a waste container. The $20-\mathrm{mL}$ volume is returned to the original vial and immediately capped.

A 5- $\mu \mathrm{L}$ aliquot of EPA Method 8260 internal standard mixture $12,000 \mu \mathrm{g} / \mathrm{L}$ in methanol) is injected through the vial cap with a chromatography syringe. This internal standard mixture contains 1,4difluorobenzene, chlorobenzene-d5, and 1,4-dichlorobenzene-d5 (-d4 and - $d 5$ indicate deuterated analogs of the more common chlorobenzene compounds). Typically, these four compounds are not found in samples, and these compounds give unique mass signatures in the GC/MS method.

The GC/MS method combines chromatographic retention time and mass spectral information to provide an essentially unique signature for each compound; thus, internal standards can be used with each sample. The internal standards link the individual compound standards, which are prepared in an identical manner. The internal standard compensates for any variation in system response on a sample-to-sample basis. In this implementation, the pentafluorobenzene peak is used as a quantitation reference and the other three are used as recovery checks. Thus, each sample has its own standard and surrogate information provided for quality control purposes.

After adding the internal standard, the vial is placed on a block heater and heated to $75^{\circ} \mathrm{C}$. The samples are left on the block heater for at least 15 minutes before analysis to allow temperature equilibration. A 500- $\mu \mathrm{L}$ aliquot is withdrawn from the vial through the septum cap with a gas tight syringe. The sample is immediately injected into the split/ splitless injection port. The injection port is set to a split ratio of approximately $5: 1$ before injection. The instrument is equipped with a $30-\mathrm{m}$ column specially 
designed to separate even the most highly volatile organic compounds without the use of cryogenic focusing. The column temperature, using a computer program, is then ramped from $40^{\circ} \mathrm{C}$ to $200^{\circ} \mathrm{C}$ over a 20 -minute period. All compounds with any reasonable degree of volatility are eluted with most of the common compounds up through xylene eluting within the first 10 minutes.

Mass spectra spanning a mass range of 45 to 400 amu are collected once every 150 milliseconds. Data are stored continuously on the integral hard disk. Data may be quantified immediately using the software in the on-board computer or may be saved to floppy disk for off-line quantification using Hewlett-Packard's Enviroquant software, which provides superior peak auditing capabilities and improved reporting format. Each mass peak is examined visually to assure correct peak integration. If necessary, individual peaks are manually reintegrated using the interactive graphical integration capability of either software package.

While more sensitive methods for VOC analysis exist, the detection levels attainable by the headspace method described above are quite respectable. Quality control checks routinely implemented include daily tuning of the mass spectrometer, daily calibration of the target analyte responses, and the use of blanks, including column blanks, laboratory blanks, and trip blanks.

\subsubsection{Results}

To date, two major VOC liquid sampling and analysis campaigns have been carried out in the 300 Area. These two events are described in the following text.
The first sampling exercise was performed at Building 3720 during the week of June 13, 1994. The PNL mobile laboratory containing the GC/MS was moved to the back parking lot of Building 3720. Water samples for VOC analysis were collected from the building sewer pipe outfall through a $4.6-\mathrm{m}(15-\mathrm{ft})$ length of 0.6-cm (0.25-in.) stainless steel line connected to a positive displacement pump at street level. The VOC vials were filled at periodic intervals through the pump.

The principal VOC found routinely in the samples was chloroform, which was presumably associated with the chlorination of source water. Chloroform levels in Building $\mathbf{3 7 2 0}$ were somewhat higher than in past measurements and were moderately variable, ranging from 37 to $95 \mu \mathrm{g} / \mathrm{L}$. No measurable levels of the brominated trihalomethanes were observed. Very minor amounts of methylene chloride, ranging from 1 to $9 \mu \mathrm{g} / \mathrm{L}$, were also observed in some samples.

After the baseline measurements, a tracer release was performed using a test point at the far corner of the building. Extremely small quantities of methylene chloride, a mixture of xylenes, and tetrabromoethene were released in a manner designed to simulate a glassware cleanup. Based on conservative tracers such as $\mathrm{pH}$, the transit time to the sampling point was estimated to be 5 to 10 minutes. A significantly longer transit time was observed for all species. Xylene arrived first after about a 30-minute delay, then methylene chloride about 30 to 45 minutes later. The tetrabromoethene was not observed as a sharp peak; it was observed as a broad peak of tribromoethene (an apparent degradation 
product or impurity) after significant delay. These results show that the building plumbing has a significant storage capacity for a slow release of even moderately water-soluble organic compounds (Figure 12.1).

A second sampling activity was performed during the week of July 18 , 1994, focusing on sampling points at Building 320, Building 331, and near the end-of-pipe. Grab samples were collected in duplicate at approximately 1- to 2-hour intervals from each sampling point during mid-day over a 3-day period. Composite samples collected over 24 hours were taken on July 20 at all three sampling points for comparison with results from the commercial laboratory. Samples were analyzed promptly in the PNL Sigma 5 Building GC/MS laboratory.
Only chloroform was detected in the samples (that is, grab and composite) using the headspace GC/MS procedure as a screening tool. This is consistent with data reported by the commercial laboratory on samples collected during the same period. Chloroform levels varied over a wide range at all three sampling sites with the widest variability seen at Building 331 with values ranging from 7 to $250 \mu \mathrm{g} / \mathrm{L}$ in 18 measurements. Chloroform levels were observed to exceed the $100 \mu \mathrm{g} / \mathrm{L}$ EPA MCL at the Building 331 sampling point on two occasions as shown in Figure 12.2. The other two sampling points also showed significant variability but at levels well below the EPA MCL. Chloroform levels ranged from 30 to $63 \mu \mathrm{g} / \mathrm{L}$ at Building 320 and from 12 to $39 \mu \mathrm{g} / \mathrm{L}$ at the endof-pipe.

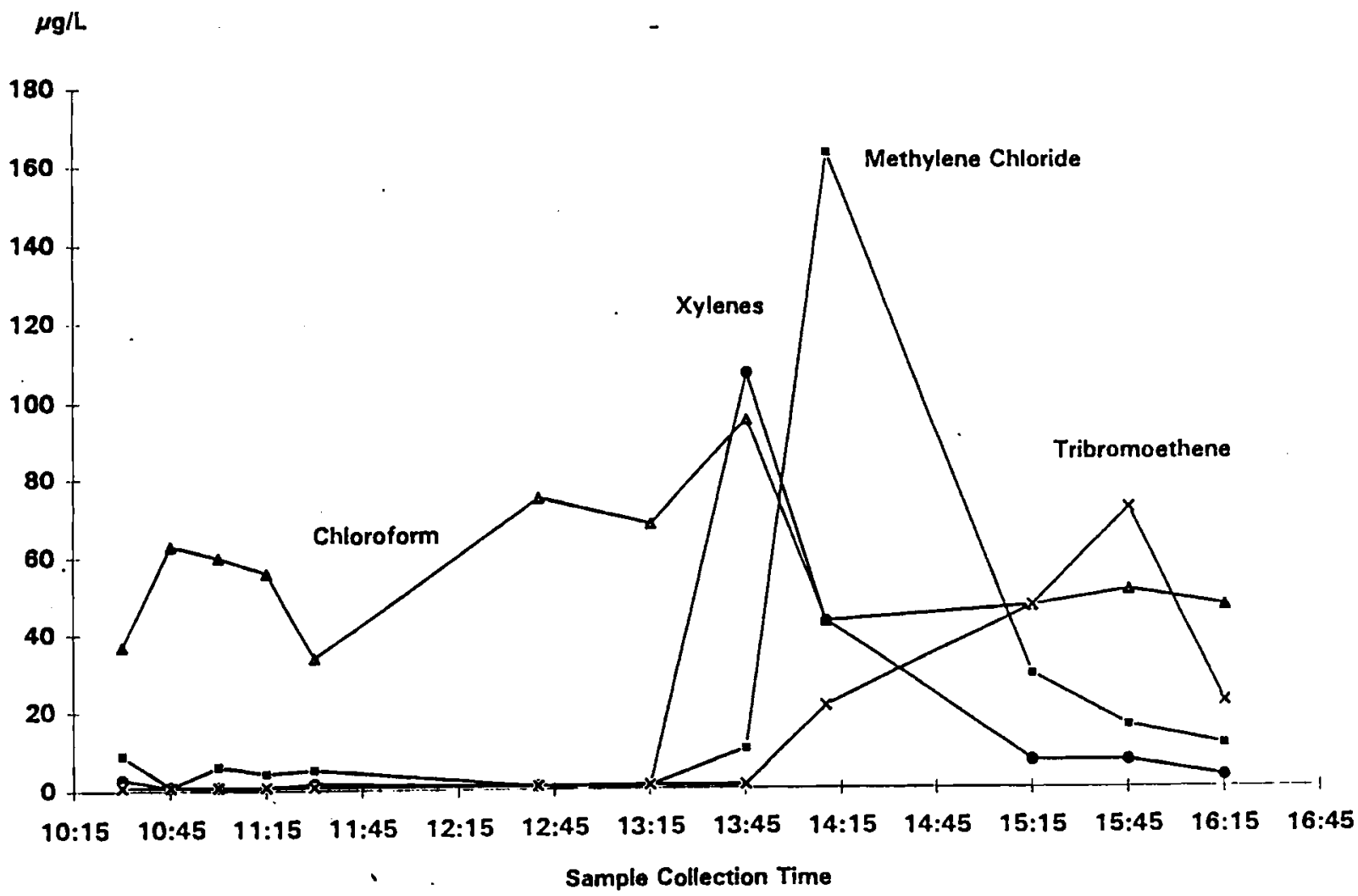

Figure 12.1. Building 3720 Volatile Organic Compound Tracer Tests 


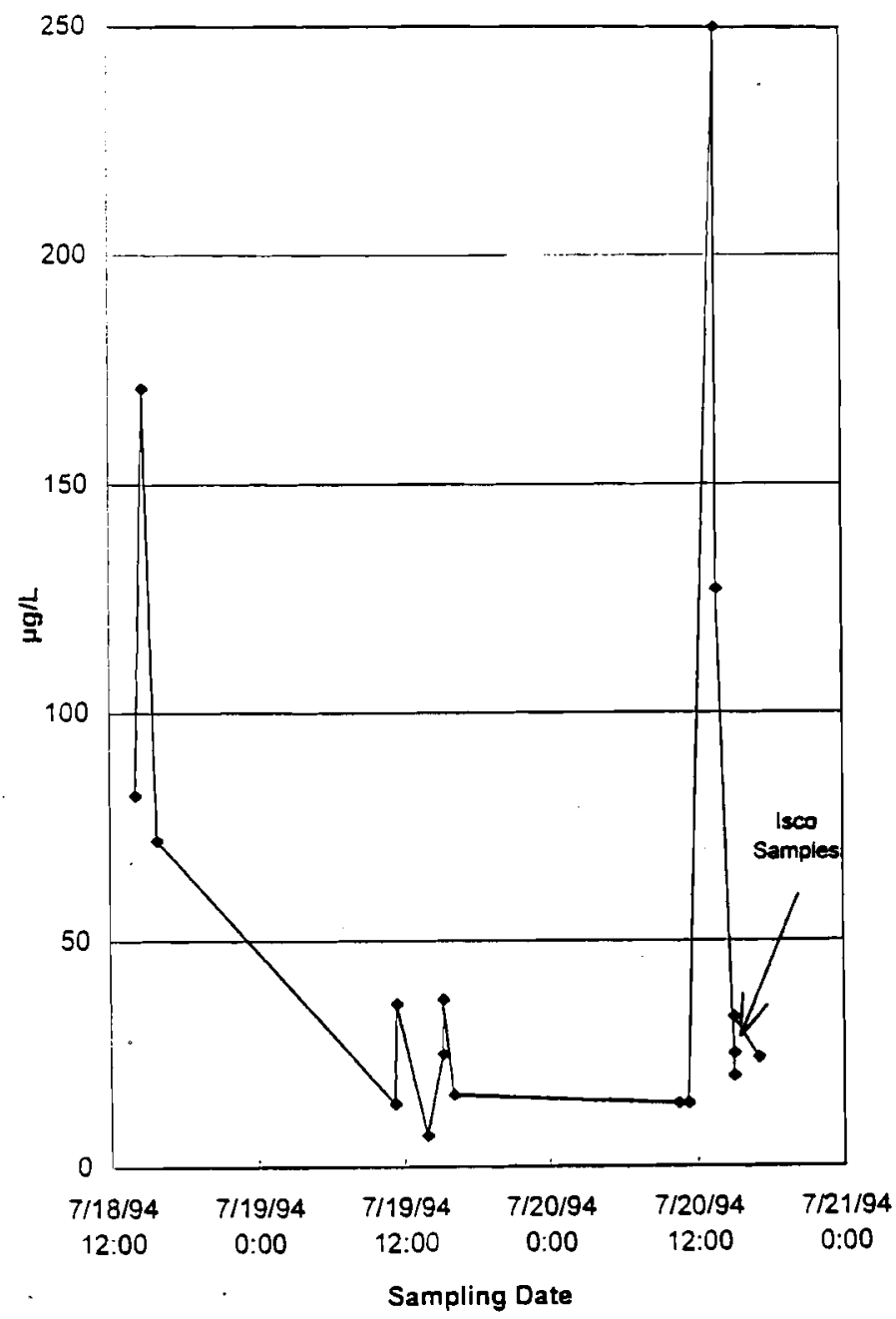

Figure 12.2. Chloroform Concentrations in Building 331 Effluent

In general, chloroform concentrations measured by PNL in grab samples and composite samples tended to be significantly higher (a factor of 2 to 3 ) than comparable measurements reported by the commercial laboratory. A review of the pertinent quarterly quality control data for the commercial laboratory showed excellent performance for chloroform on both the spike blind samples submitted by PNL and the EPA quality control samples. Cross checks between internal PNL methods have shown a high degree of reliability to the assay method and attendant standardization procedure. The most likely explanation for the discrepancy is volatile loss during the sampling process itself. The use of the Isco ${ }^{\circledR}$ samplers for volatiles sampling is known to be not fully satisfactory because of the potential for loss of analytes to. the headspace. Similar considerations apply during the compositing and subsampling step; however, to date, no better method has been identified.

\subsection{Adsorptive Stripping Voltametry}

ASV is an analytical technique that pre-concentrates selected trace metals (for example, uranium, chromium, and iron) from a ligand-treated (for example, cupferron) sample solution. The ligand forms an electrolytically stable complex that is adsorbed into the mercury during the deposition process lalso called preconcentration). This step is an effective electrochemical extraction where the analyte is preconcentrated in the mercury phase to a much higher concentration than it was in solution.

After preconcentration, the analyte is measured using advanced electrochemical methods. This combination of preconcentration and electrochemical measurement generates an extremely favorable signalto-background ratio, which allows detection limits at the parts-per-billion level for most metals. Because of the potential attributes of ASV for effluent monitoring of uranium, a flow system was laboratory and field tested. The purpose was to measure the concentration of uranium in 300 Area process sewer water.

The uranium monitoring flow system (Figure 12.3) was designed and 
laboratory tested by Jianmin Lu under the direction of Professor Joseph Wang at New Mexico State University, under a subcontract agreement. The system was designed to detect uranium in near-real time (4 to 5 minutes) with a detection limit of $5 \mu \mathrm{g} / \mathrm{L}$ uranium(VI) in solution.

The system consisted of a twochannel, variable-speed peristaltic pump. The first channel supplied a sample flow, and the second channel supplied the cupferron/acetate buffer solution flow to a plastic " $Y$ ". The uranium and cupferron reacted in a glass reaction spiral (reaction resonance time of approximately 1 minute). Then, the reaction solution was focused upwards onto a mercury drop suspended from the base of a dropping mercury electrode. The mercury drop was suspended with a $2.5-\mathrm{cm}$ (1-in.)-long segment of a $6.2 \mathrm{~mm}$ $O D \times 1.0 \mathrm{~mm}$ ID glass tube. The end of the glass tube was approximately $5 \mathrm{~mm}$ from the base of the mercury drop. The lower portion of the dropping mercury electrode and the glass tube used to focus the flow were contained in a glass reservoir below the liquid surface.

Initially, the reservoir contained distilled water, but as the system operated, sample-cupferron mixture accumulated. No memory effect was seen for the uranium measurements with this type of reservoir system. The static liquid level within the reservoir was maintained by a drain spout near the top of the reservoir (Figure 12.2). The system controller for the dropping mercury electrode was a Radiometer America Inc. TraceLab System coupled to a computer.

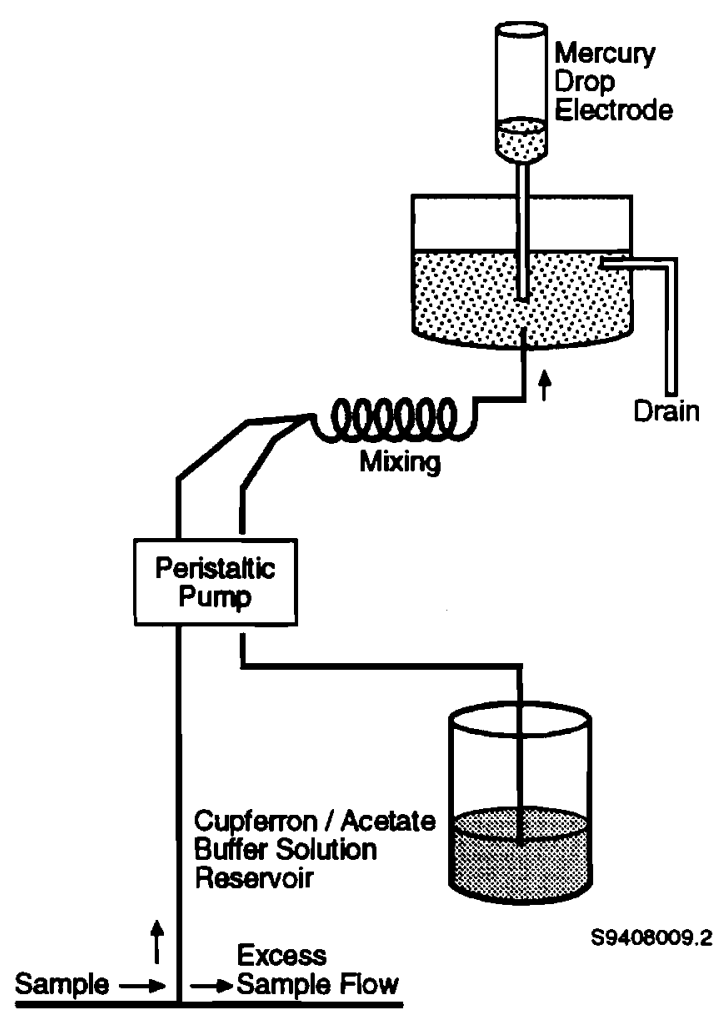

Figure 12.3. Uranium Monitoring Flow System

\subsubsection{Laboratory and Field Testing}

Flow injection analysis was initially evaluated as a sample introduction method. However, this approach failed to provide consistent results. Subsequent work focused exclusively on a continuous flow system.

Figure 12.4 shows the system response versus uranium concentration. The uranium monitoring flow system was found be linear from 0 to $200 \mu \mathrm{g} / \mathrm{L}$ uranium. From 0 to $40 \mu \mathrm{g} / \mathrm{L}$, there 
appears to be a nonlinear effect, possibly from kinetic effects of the uraniumcupferron interaction.

Figure 12.5 demonstrates the reproducibility of the uranium flow monitoring system at $50 \mu \mathrm{g} / \mathrm{L}$ uranium using a single mercury drop. The relative standard deviation of 15 measurements using a single mercury drop was $4.7 \%$. Subsequent work suggested a more realistic relative standard deviation of approximately $10 \%$.

After initial testing with distilled water, the system was used testing 300 Area process sewer water. The process sewer water was found to contain a potential interferant to the uranium measurement, believed to be a surfactant (detergent) (Figure 12.6). This caused a significant error with the integration of the uranium peak. To minimize the effect of the interferant on the uranium peak, the mercury drop was manually replaced after every three or four analyses. This procedure was used for subsequent laboratory analyses using process sewer water and during field testing.

Field testing for near-real-time monitoring of uranium in process sewer water was conducted June 14 through 16, 1994, by PNL and New Mexico State University personnel. The testing was done using the PNL mobile laboratory. This was located south of Building $\mathbf{3 7 2 0}$ adjacent to an access hole at a junction of the Building 3720 sewer line and the
300 Area process sewer line. A 0.6-cm (0.25-in.) stainless steel tube (used for volatile sampling) and a $0.6-\mathrm{cm}(0.25$-in.) polypropylene tube were inserted adjacent to the $\mathrm{pH}$ and conductivity probes into the flow stream behind the retention dam. The retention dam was previously inserted into the 3720 process stream to elevate the water level for $\mathrm{pH}$ and conductivity monitoring. A Fluid Metering Inc. variable speed 10 to $46 \mathrm{~mL} / \mathrm{min}$ ) piston pump with a Teflon/ stainless steel pump head was installed in the mobile laboratory and connected to the polypropylene tubing. During testing, the flow rate from the pump ranged from 20 to $30 \mathrm{~mL} / \mathrm{min}$. This testing was done concurrently with the GC/MS test.

The purpose of the field test was to prove that the fundamental ideas behind the uranium monitoring flow system would work (Figure 12.2). During testing, diverted flow from the sewer to the uranium monitoring flow system was provided by a variable flow pump. The flow rate ranged from 5 to $20 \mathrm{~mL} / \mathrm{min}$. The uranium monitoring flow system was "Teed" into the sampling line after the sampling pump and sampled at a flow rate of 1 to $2 \mathrm{~mL} / \mathrm{min}$. Excess flow was discarded into a drain. During the course of testing, five integrated samples--spanning 5 to 55 minutes of monitoring--were collected for uranium analysis by an inductively coupled argon plasma-mass spectrometer (ICAP-MS). These results were compared to the ASV field measurements. 


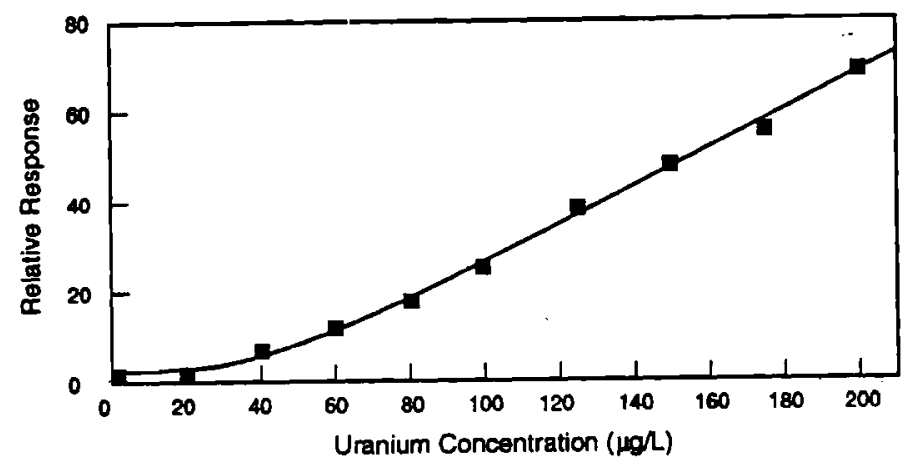

Figure 12.4. Cupferron Flow System

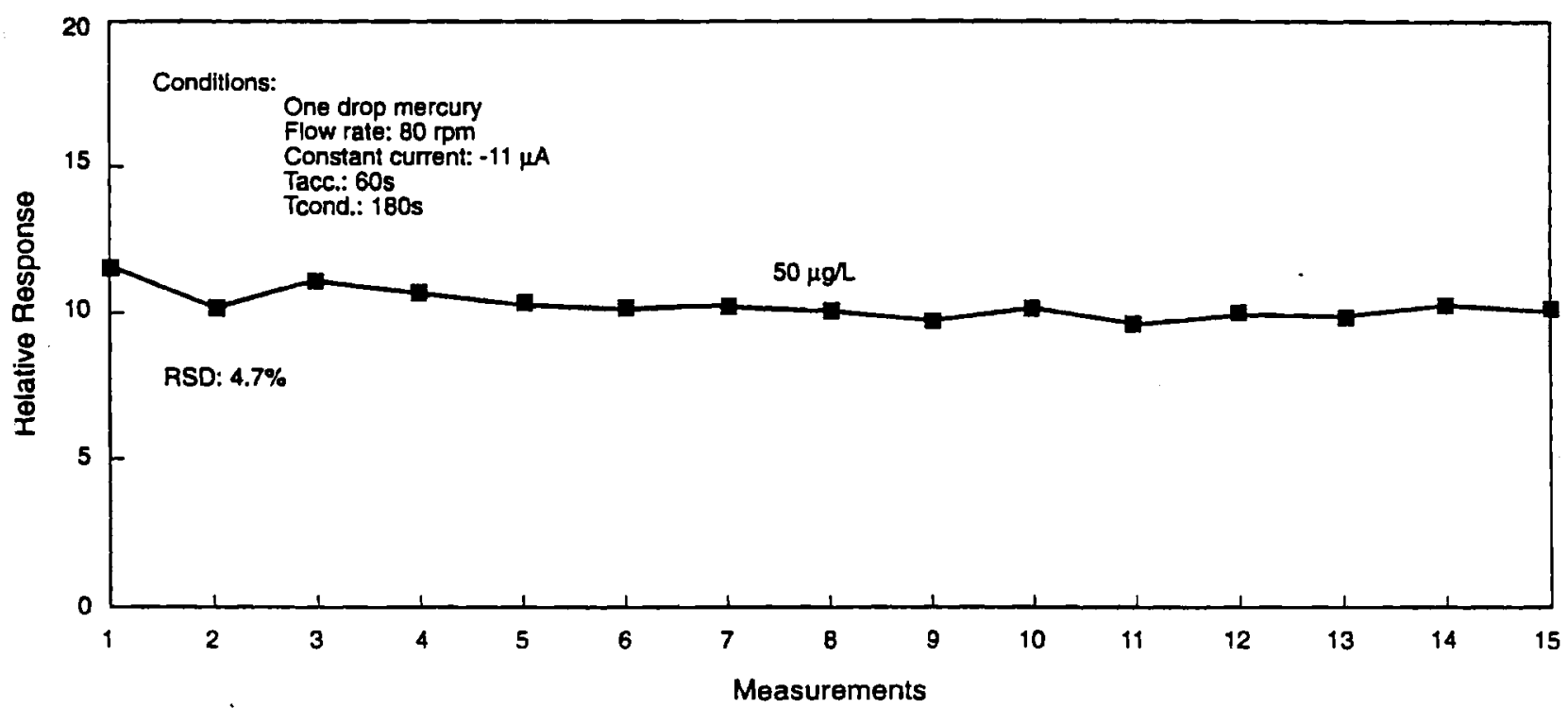

Figure 12.5. Uranium-Cupferron Flow System

S9400065.3 


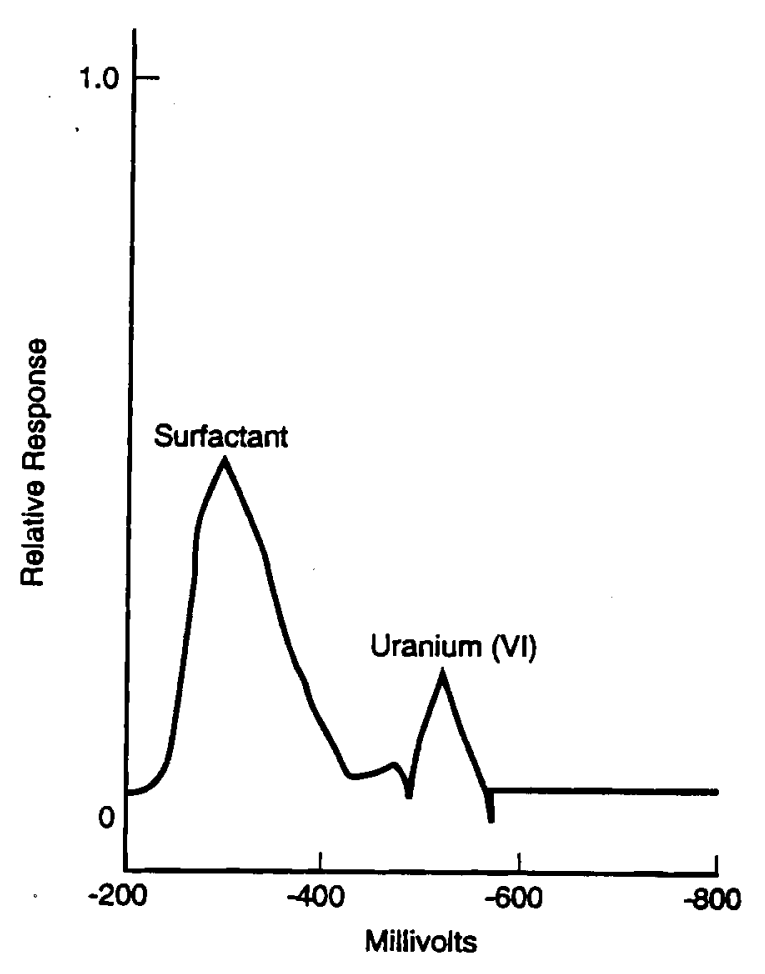

$\$ 94080402$

Figure 12.6. Uranium (VI) and Surfactant

\subsubsection{Results}

The ICAP-MS analysis of integrated grab samples measured the background concentration at approximately $30 \mu \mathrm{g} / \mathrm{L}$. Values measured by ASV during online monitoring ranged from 10 to $20 \mu \mathrm{g} / \mathrm{L}$ during the same period. The results of the field testing suggest the ASV uranium monitoring flow system can measure uranium at a detection limit of $5 \mu \mathrm{g} / \mathrm{L}$. The system response to uranium was found to depend on the $\mathrm{pH}$ of the process sewer water sample. Increasing the acetate buffer solution from 0.1 to $1 \mathrm{M}$ is expected to significantly decrease or eliminate the affects of $\mathrm{pH}$ on the uranium measurement. Near-real-time tests also showed optimal replacement of the mercury drop after every second or third measurement. These refinements should increase the accuracy and precision of the ASV measurement. Another refinement will include configuring the system to routinely calibrate and zero check itself for adaptation to long-term unattended monitoring of process effluents.

\subsection{Solid Phase Extraction}

SPE, which is strongly supported by the EPA's Office of Solid Waste, can eliminate some of the sample preparation activities that are performed in the field and/or the laboratory. Operation in the field can enhance sample stability during transport from the field. In turn, sample quality and data quality should be improved. Characterization cost effectiveness should also be enhanced by minimizing sample collection, transportation, preparation, and disposal costs. As seen at the Pittsburgh Conference, SPE technology is readily available from manufacturers for application to a broad and expanding suite of semivolatile analytes and liquid matrices. In addition, several highly automated SPE systems and integrated samplers are commercially available. These systems can process multiple samples simultaneously with minimal operator attention. Favorable results down to very low levels (nanogram/liter) have been reported for these filter disks in the open literature (Tompkins et al. 1992).

\subsubsection{Methods Development}

Commercially available SPE disks were evaluated for efficiency of concentrating (i.e., recovery) SVOCs from water. SPE disks produced by Spec (C18 bonded phase) and Empore (C8 bonded phase) were evaluated using laboratory standards. The results would serve as a quantitative basis for how they might perform extractions of SVOCs from waste 
water samples. Spec C18 disks produced the best overall recoveries of pesticides and phthalates (plasticizers) from mixtures of prepared standards.

The preferred Spec C18 disks were then tested on waste water collected from the 300 Area. In the laboratory, 1-L samples of waste water spiked with a known amount of three SVOC internal standards (nitrobenzene-d5, 2 fluorobiphenyl, and p-terphenyl-d14/ were passed through the disks by application of a mild vacuum to the filtration apparatus.

Sorbed analytes were recovered by eluting the disks with $20 \mathrm{~mL}$ of methylene chloride. The elution power of other solvents (e.g., acetone and ethyl acetate) were investigated. While the more polar solvents produced somewhat better recovery efficiency, their presence in the analysis sample led to poor GC separations. After drying over sodium sulfate, the solvent was evaporated under nitrogen to a final volume of $1 \mathrm{~mL}$ and placed in a crimp vial. The final overall concentration factor in the injected solvent was typically $1000: 1$, which allowed $\mathrm{GC}$ to be used to achieve original sample detection limits of low parts-perbillion. The extraction process could be performed in under 10 minutes. Solvent reduction of several samples was performed in parallel, reducing the time associated with sample prep. Recoveries of analytes from Spec C18 disks using the different solvents ranged from 50 to $90 \%$. Recovered extracts were subjected to one of two analysis methods; a GC with flame ionization detection was used for routine samples, and GC/MS was used on any samples showing unknown peaks. The final procedure adopted closely matched the manufacturers' recommendations. The process of screening samples using SPE coupled to GC and using GC/MS only for unknown peak identification is cost effective and helps to ensure that no constituents in the liquid waste stream sample are missed.

\subsubsection{Field Application}

SPE coupled with GC or GC/MS has been deployed successtully on the preparation and analysis of liquid waste samples collected from Buildings 320 , 331,3720 , and end-of-pipe. Analysis of SPE-prepared samples from all four locations resulted in the detection by GC/MS of the compound 2-12-butoxyethoxylethanol acetate. Estimated concentrations found at the four locations were $0.5 \mathrm{mg} / \mathrm{L}$ at Building $320,1 \mathrm{mg} / \mathrm{L}$ at Buildings 331 and 3720 , and $2 \mathrm{mg} / \mathrm{L}$ at end-of-pipe. This compound, 2-12butoxyethoxylethanol acetate, more commonly known as butyl carbitol ${ }^{\circledR}$ (Merck Index), is a component of some cleaning agents. However, the compound has not been detected by GC or GC/MS of extracts of samples of some cleaning agents commonly used in 300 Area facilities. The source of the compound in the process sewer is still under investigation.

\subsection{Continuous Monitoring Systems}

Systems for continuous monitoring of effluent flow, $\mathrm{pH}$, and conductivity have been permanently installed at the building locations where samples were collected as part of the routine sampling for the effluent monitoring task. The purpose of the systems is to gather real-time data to aid in identifying trends in sewer usage. Trends identified so far indicate that certain events have their own "fingerprint." For example, a dishwasher may cause a sharp increase in flow, conductivity, and $\mathrm{pH}$. In contrast, the use of a laboratory sink may cause a gradual change in the $\mathrm{pH}$ and conductivity with 
no measurable change in flow. Evaluation of these trends may yield some limited correlations between the real-time monitoring data and the composite sample results for each building.

At most buildings, data from each system will be collected via the Facilities Management Control System (FMCS). The FMCS is a computer network primarily dedicated to collecting information regarding building climate controls. Once upgrades to the FMCS are complete, realtime monitoring data will be available for effluent monitoring stations located at six buildings (nine separate stations). Standalone data logging systems will be required for Buildings 331 and 3720 , because the FMCS is unavailable for use at these locations.

\subsubsection{Stand-Alone Data Logging System}

A stand-alone data logging system has been constructed to meet the continuous effluent monitoring needs of Buildings 331 and 3720 . The typical configuration of a waste water monitoring system is shown in Figure 12.7. The $\mathrm{pH}$ and conductivity probes are immersed in the flowing waste water stream. Signals from the probes and flow meter are converted to engineering units and displayed locally at each station. Each measurement is then sent to a standalone data logger via a 4 to $20 \mathrm{~mA}$ current loop. The monitoring results are stored by the data logger and can be retrieved up to 1 week later using a computer.

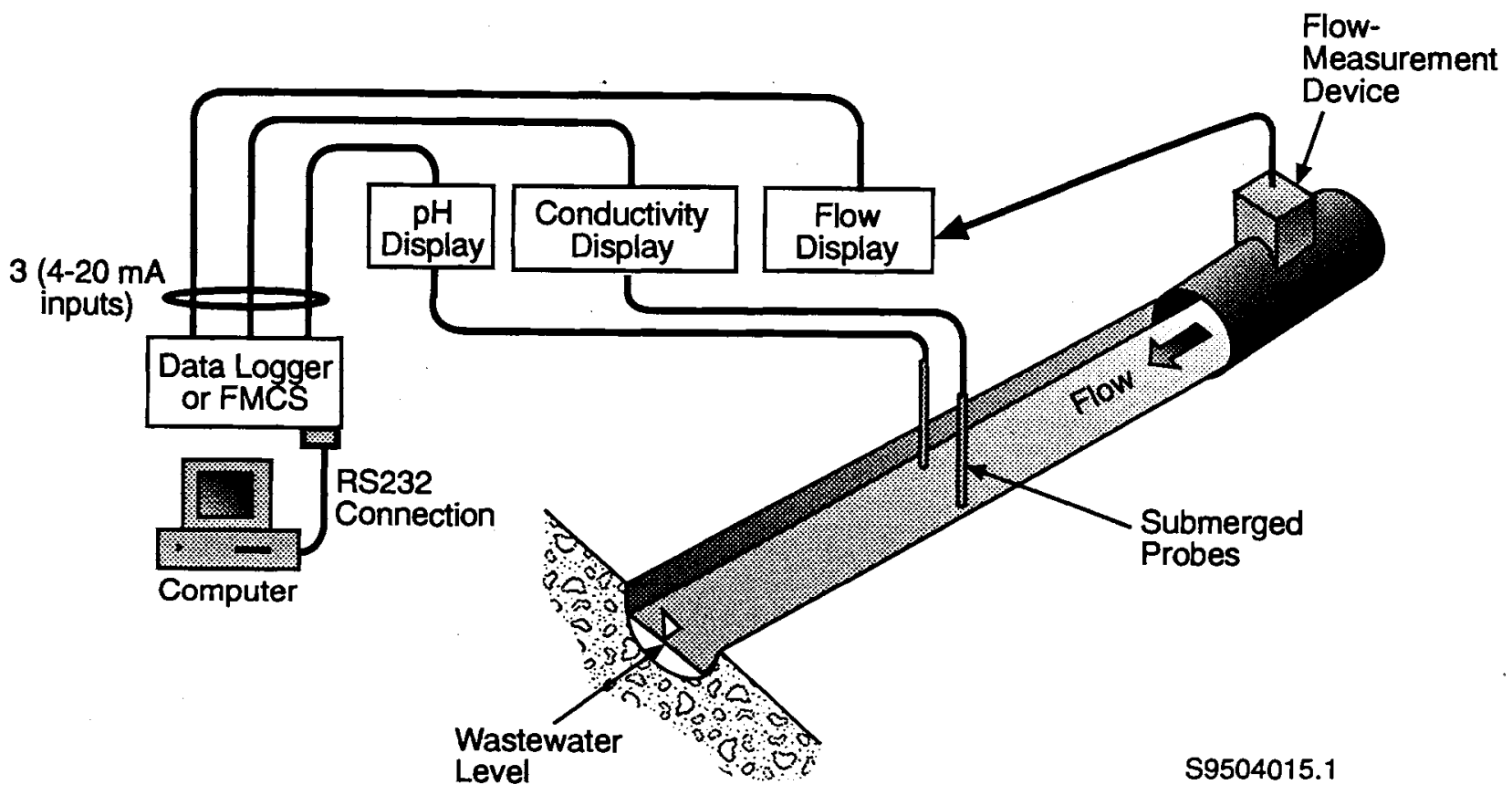

Figure 12.7. Continuous Effluent Monitoring Systems 


\subsubsection{Preliminary Results}

Some preliminary monitoring data has been collected using the stand-alone data logging system at Building 331 .

Figure 12.8 shows an example of data collected over a 24-hour period. Flow rate, $\mathrm{pH}$, and conductivity are plotted together. Data were collected every minute, with each data point representing the average of three measurements made at 20 -second intervals.

The data shows direct correlations of response of the three parameters during changes in the effluent. Recovery of the effluent from significant changes in $\mathrm{pH}$ (i.e., two log units) can take several hours.

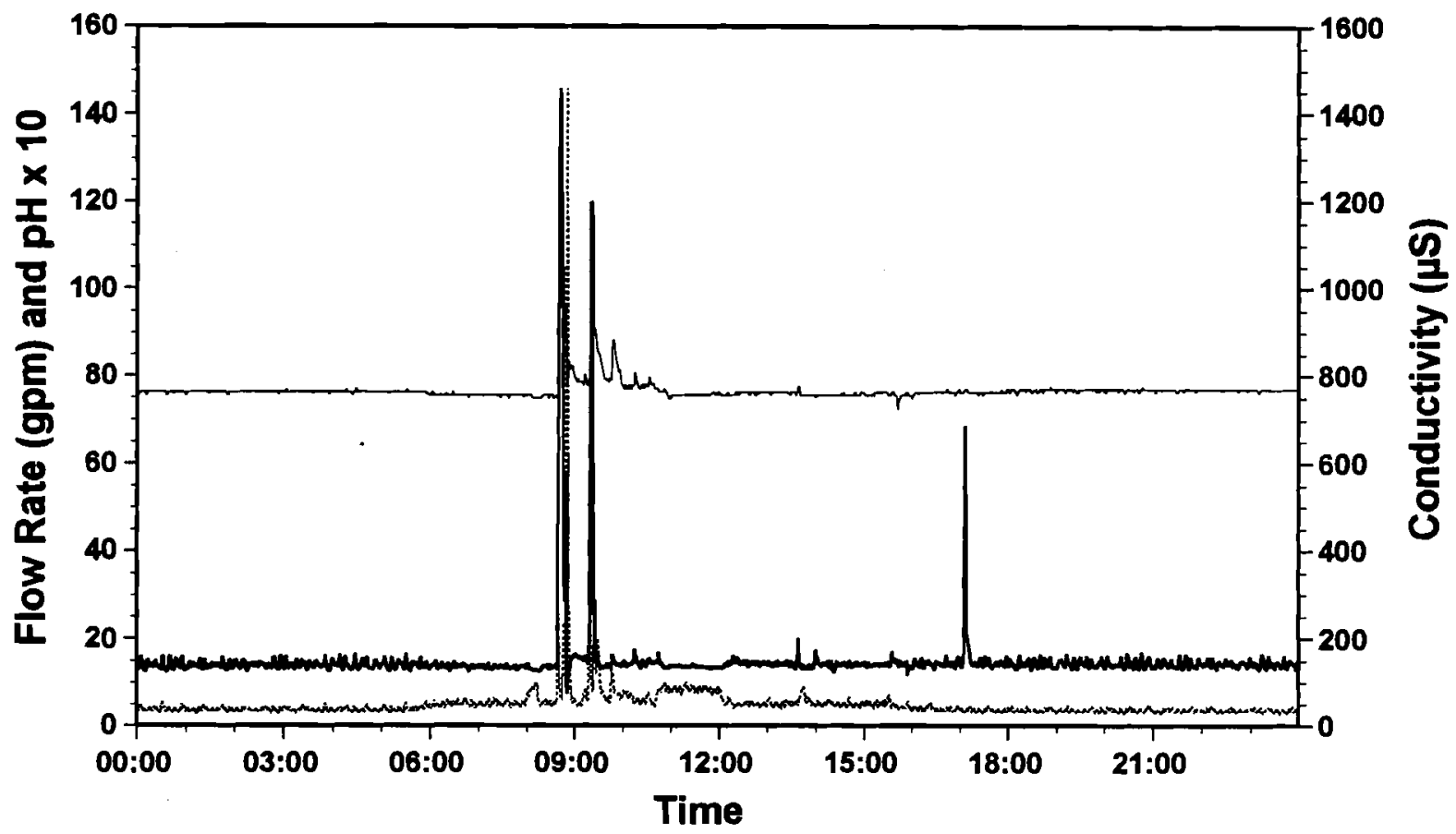

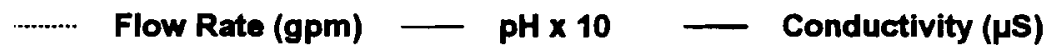

Figure 12.8. Example of Data Collected on a

Stand-Alone Data Logging System 


\subsubsection{Future Plans}

Plans are in place to further explore the chemistry of excursions by conducting event-triggered sampling. Discharge events are normally the result of routine building operations. Measured changes in the $\mathrm{pH}$ or conductivity will be used to trigger a composite sampler to collect a discrete sample for subsequent laboratory analysis. Selective sampling of waste streams based on continuous monitoring parameters should help to focus sample collection efforts for each building and yield the following benefits for the Effluent Monitoring Program:

- Improved detection of constituents in the waste water through the minimization of sample dilution. (Standard 24-hr flow proportional composite sampling techniques yield an average concentration, because both acute release and nonrelease samples are collected and then mixed.

- Efficient allocation of laboratory resources by analyzing only those samples for which the presence of constituents are expected. 


\subsection{Conclusions}

During CY 1994, PNL's Effluent Monitoring Program characterized and monitored the liquid effluent streams from six DOE-owned and PNL-operated facilities (Building 306, 320, 324, 326, 331, and 3720 ) and end-of-pipe in the 300 Area of the Hanford Site for six general classes of parameters and constituents. These classes were 1) general chemical parameters, 2) ammonia and anions, 3) metals, 4) volatile organic compounds, 5) semivolatile organic compounds, and 6) radiological parameters. To assist in delineating data quality and the contribution made by individual buildings to waste stream composition, analytical results of samples collected from building waste streams and end-of-pipe were compared against 1) background (i.e., untreated and treated influent), 2) the chemistry of facility waste streams on nonbusiness days, and 3) quality control information. In CY 1994, facility contributions to waste stream composition were compared to historical waste stream data and federal and state regulatory limits. The program also investigated the dynamics of selected building streams, generating information important to responsible management of building effluent discharges. Several characterization and monitoring technologies were evaluated for future deployment in ways that would improve program data quality and cost effectiveness.

The key conclusions from these assessments are summarized in the following sections.

\subsection{General Chemical Parameters}

Based on the magnitude of their general chemical parameters, the buildings and end-of-pipe followed this order:

$$
\begin{aligned}
& 331 \sim 326>>3720 \sim \\
& \text { end-of-pipe }>320>324 .
\end{aligned}
$$

This approximate comparison shows that Buildings 331 and 326 when compared to the other facilities and end-of-pipe have roughly the highest levels of general chemical parameters. Building 324 has roughly the lowest levels of general chemical parameters. This ranking was based on 1) the number of constituents observed, 2) their actual concentrations, and 3) frequency of observance.

Buildings 326 and 331 had 50 to $100 \%$ higher average total organic carbon concentrations relative to the influent. The average end-of-pipe concentration was similar to the source water, but endof-pipe had concentration excursions up to 9 times greater than influent levels. Total organic carbon at Building 3720 also exhibited large concentration fluctuations (up to 4 times greater than the average), but the average was approximately $20 \%$ lower than the influent. Total carbon levels at Building 326 were $65 \%$ higher relative to the untreated influent and almost twice as high as the treated influent. Buildings 306 and 331 had elevated total carbon 
concentrations, with Building 331 having excursions 4 to 5 times higher than influent levels. Chemical oxygen demand was detected most frequently at Building 326; the concentrations were generally 4 to 5 times greater than influent levels. Building 331 had an average chemical oxygen demand twice that of the influent with excursions up to 14 times greater. In general, alkalinity and total dissolved solids were relatively constant among all of the sampling locations with average concentrations 1 to 2 times greater than influent levels. However, Building 331 had total dissolved solid fluctuations up to 6 times greater than the average influent levels.

The only standard of comparison for the general chemical parameters measured is the EPA drinking water standard of $500 \mathrm{mg} / \mathrm{L}$ for total dissolved solids. Although the maximum total dissolved solid value for Building 331 approached this concentration, one of the total dissolved solid values exceeded it.

\subsection{Ammonia and Anions}

Based on the magnitude of their ammonia and anions, the buildings and end-of-pipe followed this order:

$$
\begin{gathered}
331>>326 \sim \text { end-of-pipe }> \\
306>324 \sim 320 \sim 3720 .
\end{gathered}
$$

Ammonia was detected at seven sampling locations including the alternate influent, but it was never detected in the other influent samples or in any of the blanks. Building 3720 had levels of ammonia twice as high as other locations. Building 331's average concentrations were 3 to 5 times higher; excursions at
Building 331 were 35 times higher than the average level at other locations. Cyanide was found at Buildings 331 (75\% of samples), $3720(17 \%)$, and endof-pipe $(8 \%)$ during routine sampling, but only Building 331 had detectable cyanide in any $(40 \%)$ of the nonbusiness day samples. The highest concentration of cyanide $(70 \mu \mathrm{g} / \mathrm{L})$ was observed at Building 331. The TEDF waste acceptance criteria for cyanide ( $50 \mu \mathrm{g} / \mathrm{L}$ ) was exceeded in two measurements at Building 331.

Chloride levels at end-of-pipe averaged 3 to 4 times greater than treated influent levels with maximum levels 40 times higher. Building 331 chloride levels were 3 times higher than treated influent concentrations with excursions up to 30 times higher. Other facilities and treated influent samples had comparable levels that were 2 to 3 times higher than untreated influent (Columbia River) levels.

Building 326 had the highest average nitrate concentration which was approximately 22 times greater than the treated influent average. Buildings 306 and 331 had average nitrate concentrations which were 20 and 18 times higher than the treated influent average, respectively; Building 331 had maximum concentrations which were up to 100 times greater than the influent level. The EPA drinking water standard for nitrate was exceeded at most of the facilities and at end-of-pipe.

Phosphate was detected at Buildings $331(2,800 \mu \mathrm{g} / \mathrm{L}), 326(500 \mu \mathrm{g} / \mathrm{L})$, and end-of-pipe $(1,000 \mu \mathrm{g} / \mathrm{L}) ; 20 \%$ lower levels were found in Building 331 nonbusiness day samples. 


\subsection{Metals}

In general, metals were detected in influent and effluent at trace levels (i.e., in the range of 0.1 to $10 \mu \mathrm{g} / \mathrm{L}$ ). Their presence is suspected to be the result of artifacts introduced during sample collection and analysis process and/or leaching of residuals associated with the aged building and sewer piping systems.

Mercury was found at 0.2 to $0.25 \mu \mathrm{g} / \mathrm{L}$ in 70 to $80 \%$ of the Building 3720 routine and nonbusiness day samples; maximum levels reached $1.1 \mu \mathrm{g} / \mathrm{L}$. Levels of mercury at end-ofpipe averaged $0.16 \mu \mathrm{g} / \mathrm{L}$ and were detected in $40 \%$ of the samples; the maximum level of mercury at end-of-pipe was $0.41 \mu \mathrm{g} / \mathrm{L}$. Other heavy metals were generally within 3 to 4 times the concentration of each other and the levels detected in blanks and influent samples. One end-of-pipe sample had a sodium concentration 30 times higher than influent levels. Some locations had 3 to 4 times higher concentrations of metals such as aluminum, copper, iron, and zinc; this may have resulted from facility piping differences. The TEDF waste acceptance criteria was exceeded periodically for aluminum, copper, and zinc and some of the facilities. The drinking water standards for copper and zinc were not exceeded.

\subsection{Volatile Organic Compounds}

Chlorination of influent (Columbia River water) introduces volatile byproducts (i.e., chloroform, bromoform, bromodichloromethane, and dibromochloromethane) into building source water at levels slightly higher than those observed in the building effluents.
Observed concentrations ranged from 0.5 to $40 \mu \mathrm{g} / \mathrm{L}$ in building waste streams and 0.9 to $20 \mu \mathrm{g} / \mathrm{L}$ at end-of-pipe. The observed concentration range for all four trihalomethanes at end-of-pipe was below the EPA MCL of $100 \mu \mathrm{g} / \mathrm{L}$. However, both chloroform and bromodichloromethane values exceeded the TEDF waste acceptance criteria at a number of facilities and in the treated influent.

Six other volatile halogenated hydrocarbons (i.e., 1,1,1-trichloroethane, 1,1,2-trichloroethane, 1,2-dichloroethylene, trichloroethene, tetrachloroethene, and trichlorofluoromethane) were detected infrequently in building waste streams and end-of-pipe at trace levels $(0.6$ to $2 \mu \mathrm{g} / \mathrm{L})$. None of the observed levels of these constituents exceeded EPA MCLs or TEDF NPDES limits.

Several volatile solvents were sporadically found in the routine samples of some buildings. A general ranking of the buildings and end-of-pipe based on the solvent concentrations and detection frequencies is as follows:

$$
3720>>331>320>
$$

$$
326 \sim \text { end-of-pipe }>>324 \sim 306 \text {. }
$$

Acetone was observed most frequently and at the most locations (Buildings 306, 320, 326, 331, 3720, and end-of-pipe). In most instances, the acetone concentrations were low (i.e., less than $50 \mu \mathrm{g} / \mathrm{L}$ ). However, Building 326 had five results in the range from 100 to $2,500 \mu \mathrm{g} / \mathrm{L}$, Building 331 had one result of $1,800 \mu \mathrm{g} / \mathrm{L}$, and Building 3720 had four results ranging from 200 to $500 \mu \mathrm{g} / \mathrm{L}$. Significant concentrations of acetonitrile were measured once at Buildings $320,331,3720$, and end-ofpipe. Levels ranged from $76 \mu \mathrm{g} / \mathrm{L}$ at endof-pipe to $820 \mu \mathrm{g} / \mathrm{L}$ at Building 3720 . 
Tetrahydrofuran was found with varying frequencies in the source waters and at Buildings $320,326,331,3720$, and end-of-pipe. While the tetrahydrofuran concentrations of the influent, Building 326, and end-of-pipe samples were similar to levels in the sample blanks, one result at Building 320 (36 $\mu \mathrm{g} / \mathrm{L})$ and four results at Building 3720 (13 to $400 \mu \mathrm{g} / \mathrm{L}$ ) were notably higher.

Methylene chloride was found at $10 \mu \mathrm{g} / \mathrm{L}$ in one Building 3720 sample; this concentration was significantly higher than the concentrations found in the sample blanks and exceeded the TEDF waste acceptance criteria of $5 \mu \mathrm{g} / \mathrm{L}$.

Toluene and xylenes were infrequently measured in samples from Buildings 320 , 331,3720 , and end-of-pipe. Except for one high toluene result of $400 \mu \mathrm{g} / \mathrm{L}$ at Building 3720, the concentrations ranged from approximately 0.1 to $10 \mu \mathrm{g} / \mathrm{L}$. The TEDF waste acceptance criteria for toluene is $9 \mu \mathrm{g} / \mathrm{L}$ and was exceeded at Building 3720.

Hexone and 2-butanone were detected in less than $10 \%$ of the samples at Buildings 320 and 331 ; hexone was also infrequently observed at Building 3720 and end-of-pipe. Levels of both compounds were typically below $25 \mu \mathrm{g} / \mathrm{L}$, except 2-butanone ranged from 50 to $170 \mu \mathrm{g} / \mathrm{L}$ at Building 331, and hexone was measured from 24 to $110 \mu \mathrm{g} / \mathrm{L}$ at Building 320 .

Diethyl ether was found in two samples from Building 3720; the average concentration was $22 \mu \mathrm{g} / \mathrm{L}$.

Two alcohols, ethanol and isopropanol, were measured in routine samples from Building 3720 . Although the average concentrations of both compounds were reported as approximately $15 \mu \mathrm{g} / \mathrm{L}$, the actual concentrations were probably much higher, because of limitations of the analytical method and calibration procedure which were employed. High levels of isopropanol were also found once at end-of-pipe (600 $\mu \mathrm{g} / \mathrm{L})$ and Building $326(40,800 \mu \mathrm{g} / \mathrm{L})$.

\subsection{Semivolatile Organic Compounds}

Pesticides were found in the effluents of Buildings 326 and 331 but for the most part were detected at trace levels (i.e., $<20 \mathrm{ng} / \mathrm{L}$ ). Phthalates were also detected in several building effluents $(326,331$, and 3720). Bis 12 ethylhexyllphthalate was detected at endof-pipe at levels above the EPA MCL of $6 \mu \mathrm{g} / \mathrm{L}$ but not above the TEDF waste acceptance criteria of $80 \mu \mathrm{g} / \mathrm{L}$. Diethylphthalate at Building 3720 was measured at $170 \mu \mathrm{g} / \mathrm{L}$ and exceeded the TEDF waste acceptance criteria.

\subsection{Radiological Parameters}

Building 3720 effluent consistently had gross alpha radiation levels in the range of 4 to $45 \mathrm{pCi} / \mathrm{L}$, while other buildings and end-of-pipe had much lower levels (1 to $4 \mathrm{pCi} / \mathrm{L})$. For all locations, the average gross beta activity was in the range of 3.5 to $7.4 \mathrm{pCi} / \mathrm{L}$. Tritium was frequently detected in the effluent from Buildings 306, 324 (process and retention process sewer), 326, and 331 in the range of 118 to $687 \mathrm{pCi} / \mathrm{L}$. Tritium was also detected once at end-of-pipe at an activity level of $227 \mathrm{pCi} / \mathrm{L}$. Tritium levels are greatly below the TEDF waste acceptance criteria and EPA drinking water standards. On occasion, radiological activities (gross alpha and/or gross beta) in samples was found to slightly exceed regulatory limits at 
Buildings 306,324 , and 3720 . Several gross alpha measurements at

Building 3720 exceeded the TEDF waste acceptance criteria (15 pCi/L). Gross alpha is believed to be caused by residual uranium in the piping.

\subsection{Comparison of CY 1994 End-of-Pipe Data to Historical Information and Regulatory Limits}

In general, CY 1994 concentrations of chemical and radiological parameters and constituents at end-of-pipe were similar to historical values. Exceptions were the occasional observances of high concentrations of chloride, nitrate, and sodium. These elevated concentrations are believed to be associated with excursions that were occurring at the time that samples were being collected.

During CY 1994, nitrate, aluminum, copper, lead, zinc, bis(2-ethylhexyl)phthalate, and gross beta exceeded EPA MCL or TEDF NPDES limits on a frequent or occasional basis at some of the facilities, but at end-of-pipe only the drinking water standard for bis (2ethylhexyl)phthalate was exceeded.

\subsection{Waste Stream Dynamics}

Concentrations and clearance times for contaminants at end-of-pipe were highly dependent on waste stream flow rates, dispersion, and the mechanical action of sumps. When present, the action of sumps had the greatest impact on contaminant clearance times. In the absence of sump activity, dispersion and flow rate were the controlling factors.
Dye tests performed at Buildings 331 and 3720 also showed the following results:

- Average transit times for Buildings 3720 and 331 were 49 minutes, and 4 hours, 21 minutes, respectively.

- The mechanical action of a sump intercepting the Building 331 waste stream resulted in the splitting of the dye into discrete fractions that led to subsequent dye discharges at end-ofpipe. The total number of dye pulses at end-of-pipe depended on the initial dye concentration.

- Clearance times lat the building and at end-of-pipe) for Building 3720 were less than 15 minutes in all cases. The generation of three discrete dye fractions in the Building 331 waste stream by an intercepting sump led to an average end-of-pipe clearance time of 4 hours, 23 minutes. This is 13 times greater than the estimated change from dispersion alone.

- Average dilution factors /concentration measured at a building divided by the estimated end-of-pipe concentration) for the dye as it passed from Buildings 3720 and 331 were 30 and 525 , respectively.

\subsection{Program Development}

Initial field evaluations of transportable GC/MS, ASV, SPE, and continuous monitoring for $\mathrm{pH}$, flow, and conductivity were favorable. Future application of these capabilities in concert with continuous monitoring of $\mathrm{pH}$, flow, and conductivity will allow greater clarification building waste stream chemistry during excursions. 



\subsection{References}

10 CFR 830. 1994. U.S. Department of Energy,"Nuclear Safety Management." U.S. Code of Federal Regulations (April 5).

Bisping, L. E. 1994. Hanford Site Environmental Data for Calendar Year 1993--Surface and Columbia River. PNL-9824, Pacific Northwest Laboratory, Richland, Washington, pp. 188-191 (June).

CH2M Hill and IT Corporation. 1994. Engineering Study of the 300 Area Process Wastewater Handling System. Prepared for Westinghouse Hanford Company, Richland, Washington.

DOE. See U.S. Department of Energy.

Ecology. See Washington State Department of Ecology.

EPA. See U.S. Environmental Protection Agency.

Gerber, M. S. 1992. Past Practices Technical Characterization Study-300 Area-Hanford Site. WHC-MR-0388, Westinghouse Hanford Company, Richland, Washington.

McDonald, W. C., M. D. Erickson, B. M. Abraham, and A. Roblat, Jr. 1994. "Developments and Application of Field Mass Spectrometers." Environmental Science and Technology 28(7):336A343A.

McKenney, D. E. 1989. Waste Stream Characterization Report. WHC-EP-0287, Westinghouse Hanford Company, Richland, Washington.
Millikin, E. J., R. C. Hill, J. L. Geiger, J. A. Tuck, K. A. Peterson, D. C. Hedengren, D. B. Jensen, R. G. Egge, K. A. Ayster, M. J. Brown, C. D. Woolam, M. J. Hall, J. E. Geary, R. W. Bloom, E. H. Neilsen, and D. W. Jeppson. 1990. Preliminary 300 Area Process Wastewater Stream-Specific Report. WHC-EP-0342, Addendum 1, Westinghouse Hanford Company, Richland, Washington.

Riley, R. G., and J. M. Zachara. 1992. Chemical Contaminants on DOE Lands and Selection of Contaminant Mixtures for Subsurface Science Research. DOE/ER-0547T, U.S. Department of Energy, Office of Energy Research, Washington, D.C.

Riley, R. G., M. Y. Ballinger, E. G. Damberg, J. C. Evans, A. S. Ikenberry, K. B. Olsen, R. M. Ozanich, and C. J. Thompson. 1994. Characterization and Monitoring of 300 Area Facility Liquid Waste Streams: Status Report. PNL-10147, Pacific Northwest Laboratory, Richland, Washington.

Tompkins, B. A., R. Merriweather, and R. A. Jenkins. 1992. "Determination of Eight Organochlorine Pesticides at Low Nanogram/Liter Concentrations in Groundwater Using Filter Disk Extraction and Gas Chromatography." J. AOAC International $75(6): 1091-1099$.

U.S. Department of Energy (DOE). 1988. "General Environmental Protection Program." DOE Order 5400.1. 
U.S. Department of Energy (DOE). 1990. "Radiation Protection of the Public and the Environment." DOE Order 5400.5.

U.S. Department of Energy (DOE). 1991. "Quality Assurance." DOE Order 5700.6C.

U.S. Environmental Protection Agency (EPA). 1980. Interim Guidelines for Preparing Quality Assurance Project Plans. QAMS-005/80, U.S.

Environmental Protection Agency, Washington, D.C.

U.S. Environmental Protection Agency (EPA). 1986. "USEPA Methods for Evaluating Solid Waste, Physical/Chemical Methods" SW-846, 3rd ed. Quality Control. In Volume 1A: Laboratory Manual Physical/Chemical Methods Test. U.S. Environmental Protection Agency, Washington, D.C.

U.S. Environmental Protection Agency (EPA). 1994a. Authorization to Discharge Under the National Pollutant Discharge Elimination System. Permit No. WA-0025917, U.S. Environmental Protection Agency, Seattle, Washington.
U.S. Environmental Protection Agency (EPA). 1994b. "Is Your Drinking Water Safe?" EPA 810-F-94-002,U.S.

Environmental Protection Agency, Office of Water, Washington, D.C.

Washington State Department of Ecology (WSDE), U.S. Environmental Protection Agency (EPA), and U.S. Department of Energy (DOE). 1989. Hanford Federal Facility Agreement and Consent Order. Washington State Department of Ecology, U.S. Environmental Protection Agency, and U.S. Department of Energy, Richland Operations Office, Richland, Washington.

Westinghouse Hanford Company (WHC). 1992. Hanford 300 Area Process Wastewater Characterization Data Report. WHC-SD-L045H-DP-001, Rev. 0, Westinghouse Hanford Company, Richland, Washington. 


\section{Appendix A}

Historical Information on $\mathbf{3 0 0}$ Area Process Sewer System and Liquid Waste Stream Chemistry 


\section{Appendix A}

\section{Historical Information on $\mathbf{3 0 0}$ Area Process Sewer System and Liquid Waste Stream Chemistry}

\section{A.1 Process Sewer}

The original 300 Area process sewer system was primarily made of vitrified clay pipes with acid-proof joints that connected the buildings to a process pond. Large quantities of uranium were released via the process sewer to the process pond in the first years of operation. From 1948 to 1956, liquids containing uranyl nitrate hexahydrate, ammonium nitrate, hexone, and other solvents from Building 321 operations were passed through the process sewer to cribs, which were built $8 \mathrm{~km}(5 \mathrm{mi})$ north of the 300 Area. Some process waste buildup (i.e., solid materials containing chemical and radiological residuals) may be found in process sewer drains, pipes, trenches, and sewer access holes.

As a result of the requirements in the Tri-Party Agreement (Ecology et al. 1989), flow to the process sewer was reduced significantly by 1994 by installing closed-loop cooling water systems in facilities and redirecting cooling-water waste streams from the process sewer to the sanitary sewer. As a result, the process sewer system currently receives an average of $760 \mathrm{~L} / \mathrm{min}(200 \mathrm{gal} / \mathrm{min}$ ) of liquid waste (CH2M Hill and IT Corporation 1994); this is down $79.8 \%$ from the previous level of approximately $3,800 \mathrm{~L} / \mathrm{min}(990 \mathrm{gal} / \mathrm{min})$.

\section{A.2 Retention Process Sewer}

In 1953, the retention process sewer was built for facilities with the potential for releasing radioactive material into the waste stream. Liquid wastes, considered clean but having the potential to be radiologically contaminated, are fed via the retention process sewer piping to the 307 Basins. At the 307 Basins, the liquids are screened for radiological activity. If radioactivity is not detected above release limits, the wastes are discharged to end-of-pipe. If levels exceed release limits, the wastes are pumped into the Building 340 radioactive liquid waste system tanks for subsequent landfill disposal at Hanford.

\section{A.3 300 Area Process Sewer Design and Waste Stream Composition}

The Preliminary 300 Area Process Wastewater Stream-Specific Report (Millikin et al. 1990) describes the process sewer network as being subdivided into major contributing branches. Based on the network design, approximately 20 strategic locations were identified within the process sewer for sampling. The endpoints of several branches of the process sewer corresponded to specific points where constituents released from PNL-operated buildings could be monitored. However, many of the branches reflected contributions from multiple facilities. 
Characterization data from Millikin et al. (1990) and other published reports (McKenney 1989; WHC 1992) constitute the main sources of historical data on the chemical and radiological composition of 300 Area facility liquid waste streams. These data are summarized in Table A.1. Numerous organic compounds and heavy metals were detected at upstream locations in the process sewer but not at end-of-pipe. The data are considered of limited use because all of the samples were taken as grab samples and, therefore only, represent a "snapshot" of the liquid waste stream composition. In addition, the stream has changed considerably in the last 5 years as a result of flow minimization and new regulations.

Facility activities in the 300 Area are subject to continuous changes. Thus, the chemical and radiological composition of the waste stream released from buildings and coming together at end-of-pipe is also subject to continuous change. Determination of the composition of the waste stream at any given point in time is impossible with the current characterization technology. Furthermore, comparisons between past and current data can only be made on a qualitative basis because of the high level of uncertainty associated with very limited sampling of facility waste streams.

\section{A.4 References}

$\mathrm{CH} 2 \mathrm{M}$ Hill and IT Corporation. 1994. Engineering Study of the 300 Area Process Wastewater Handling System. Prepared for Westinghouse Hanford Company, Richland, Washington.

McKenney, D. E. 1989. Waste Stream Characterization Report. WHC-EP-0287, Westinghouse Hanford Company, Richland, Washington.

Millikin, E. J., R. C. Hill, J. L. Geiger, J. A. Tuck, K. A. Peterson, D. C. Hedengren, D. B. Jensen, R. G. Egge, K. A. Ayster, M. J. Brown, C. D. Woolam, M. J. Hall, J. E. Geary, R. W. Bloom, E. H. Neilsen, and D. W. Jeppson. 1990. Preliminary 300 Area Process Wastewater Stream-Specific Report. WHC-EP-0342, Addendum 1, Westinghouse Hanford Company, Richland, Washington.

Washington State Department of Ecology, U.S. Environmental Protection Agency, and U.S. Department of Energy. 1989. Hanford Federal Facility Agreement and Consent Order. Washington State Department of Ecology, U.S. Environmental Protection Agency, and U.S. Department of Energy, Richland Operations Office, Richland, Washington.

Westinghouse Hanford Company (WHC). 1992. Hanford 300 Area Process Wastewater Characterization Data Report. WHC-SD-L045H-DP-001, Rev. 0, Westinghouse Hanford Company, Richland, Washington. 
Table A.1. Historical Data Summary of 300 Area Waste Stream Composition

\begin{tabular}{|c|c|}
\hline Parameter & $\begin{array}{c}\text { Concentration Range } \\
(\mu \mathrm{g} / \mathrm{L})\end{array}$ \\
\hline \multicolumn{2}{|c|}{ General Chemical Parameter } \\
\hline Alkalinity & $40,000-60,000$ \\
\hline Ammonia & $100-400$ \\
\hline Cyanide & $10-15$ \\
\hline Total carbon & $10,000-16,000$ \\
\hline \multicolumn{2}{|c|}{ Anions } \\
\hline Chloride & $3,000-4,000$ \\
\hline Fluoride & $200-250$ \\
\hline Nitrate & $1,000-3,500$ \\
\hline Phosphate & $1,800-8,500$ \\
\hline Sulfate & $17,000-20,000$ \\
\hline \multicolumn{2}{|c|}{ Cations } \\
\hline Aluminum & $150-300$ \\
\hline Barium & $30-40$ \\
\hline Cadmium & $2-30$ \\
\hline Calcium & $\sim 20,000$ \\
\hline Copper & $10-125$ \\
\hline Iron & $100-550$ \\
\hline Lead & $5-15$ \\
\hline Magnesium & $4,000-5,000$ \\
\hline Manganese & $5-35$ \\
\hline Mercury & $0.1-2$ \\
\hline Nickel & $10-15$ \\
\hline Potassium & $800-1,500$ \\
\hline Sodium & $2,500-5,000$ \\
\hline Zinc & $15-500$ \\
\hline \multicolumn{2}{|c|}{ Organic Compounds } \\
\hline Acetone & $30-110$ \\
\hline Chloroform & $12-55$ \\
\hline \multicolumn{2}{|c|}{ Gross Radioactivity } \\
\hline Alpha activity & $1-900^{(a)}$ \\
\hline Beta activity & $1-380^{(a)}$ \\
\hline
\end{tabular}



Appendix B

Parameter and Constituent Selection and Monitoring Process 


\section{Appendix B}

\section{Parameter and Constituent Selection and Monitoring Process}

\section{B.1 Process for Identifying Constituents to Characterize and Monitor}

In early April 1993, the Pacific Northwest Laboratory's (PNL's) Facility Effluent Monitoring Program manager sent a memo to all users of U.S. Department of Energy (DOE)-owned and PNL-operated facility process and retention process sewers in the 300 Area. The memo described the goals and objectives of the liquid effluent monitoring task and requested the users to attend a follow-up meeting to discuss sewer usage.

Approximately 2 weeks after the memo was distributed, members of the liquid effluent monitoring task team met with building managers, group leaders, and senior researchers from these facilities. The audience was further briefed on the goals and objectives of the task, and time was allowed for questions. At the end of the meeting, the users were asked to complete a wastewater discharge survey form and return it in 2 weeks. To facilitate cooperation, information was collected in an anonymous fashion. The survey requested information on types, concentrations, and volumes of liquid wastes discharged to process and retention process sewers during conduct of their work.

The survey information was compiled into a table that listed material discharged by building. The table included volumes of liquid waste discharged, estimated concentrations of constituents in the discharge, and the frequency of discharges. Information from the table was compared against constituents listed in 1) the Westinghouse Hanford Company (WHC) waste acceptance criteria, 2) U.S. Environmental Protection Agency (EPA) drinking water standards, and 3) proposed discharge limits in the National Pollutant Discharge Elimination System (NPDES) permit under negotiation with the EPA for the operation of the Treated Effluent Disposal Facility (TEDF). From this comparison, a list of targeted constituents was identified for characterizing and monitoring as part of the routine liquid effluent monitoring subtask. The classes of parameters and constituents identified for monitoring are summarized in Table B.1. In some instances, nonregulated constituents were included on the list because the task team believed they should be monitored based upon responsible management practices. The targeted constituent list was used to establish methods for sample collection and specify analytical methods for the conduct of analyses to be performed by the analytical services contractors. 
Table B.1. Classes of Parameters and Constituents Identified for Monitoring

\begin{tabular}{|l|}
\hline \multicolumn{1}{|c|}{ General Chemical Parameters } \\
\hline $\begin{array}{l}\text { alkalinity } \\
\text { chemical oxygen demand } \\
\text { total dissolved solids } \\
\text { total carbon } \\
\text { total organic carbon }\end{array}$ \\
\hline \multicolumn{1}{|c|}{ Ammonia and Anions } \\
\hline $\begin{array}{l}\text { ammonia } \\
\text { cyanide } \\
\text { sulfides } \\
\text { other anions amendable to analysis } \\
\text { by ion chromatography }\end{array}$ \\
\hline $\begin{array}{l}\text { heavy metals } \\
\text { common cations }\end{array}$ \\
\hline Volatile Organic Compounds \\
\hline Semivolatile Organic Compounds \\
\hline acids/bases/neutrals \\
\hline pesticides \\
\hline Radiological Parameters \\
\hline $\begin{array}{l}\text { gross alpha } \\
\text { gross beta } \\
\text { tritium }\end{array}$ \\
\hline
\end{tabular}

\section{B.2 Process for Identifying Constituents Requiring Continuous Monitoring or Potential Control}

As a part of responsible PNL waste management, regulated and nonregulated constituents identified in building liquid effluents using the process described in Section B. 1 are evaluated to assess their potential impact on TEDF operations and treated wastewater releases to the Columbia River. Regulated constituents are those listed in EPA drinking water standards or TEDF NPDES discharge limits. Nonregulated constituents are those chemicals and radionuclides that are not governed by a regulatory agency.

The process by which the constituents are evaluated starts with comparing the concentrations of constituents in liquid effluents to the chemistry of treated and untreated 
Columbia River water, background-level effluents, and quality control data. Backgroundlevel effluents are measured using the chemistry of the wastewater present during weekends or off-shift hours. Quality control data is derived from the analysis of blanks which normalizes wastewater data against artifacts introduced during the sampling and analysis process. This process helps identify those constituents whose source is clearly caused by a building discharge.

Concentrations of building-derived regulated constituents in liquid effluent are compared to regulatory limits (Table B.2) to assess whether further action is required (e.g., further monitoring or potential control). For nonregulated constituents, PNL uses the limits governing the discharge of toxic substances described under the general requirements section of the TEDF NPDES permit. Other factors considered in the assessment include the frequency a constituent is detected in the effluent and the confidence level of the measurements. Decisions on further action also take into account the effects of effluent transport to TEDF on constituent concentration and recognition that the effluent is treated at TEDF before it is discharged to the Columbia River.

Table B.2. Comparison of Concentration of Parameters and Constituents at End-of-Pipe with Federal and State Regulatory Limits

\begin{tabular}{|c|c|c|c|c|}
\hline $\begin{array}{l}\text { Parameter or } \\
\text { Constituent }\end{array}$ & EPA MCL $(\mu \mathrm{g} / L)^{(a)}$ & $\begin{array}{c}\text { TEDF } \\
\text { NPDES } \\
\text { Limits }^{(b)} \\
(\mu \mathrm{g} / \mathrm{L})\end{array}$ & $\begin{array}{l}\text { Toxic } \\
\text { Pollutant } \\
\text { List }^{(c)}\end{array}$ & $\begin{array}{c}\text { Range of EOP } \\
\text { Concentrations }(\mu \mathrm{g} / \mathrm{L}) \\
\text { (Average } \pm \mathrm{SD})\end{array}$ \\
\hline \multicolumn{5}{|c|}{ General Chemical Parameters } \\
\hline Total dissolved solids & 500000 & & & $\begin{array}{c}80,000-240,000 \\
(109,630 \pm 36,319)\end{array}$ \\
\hline \multicolumn{5}{|c|}{ Metals } \\
\hline Aluminum & 200 & 215 & & $\begin{array}{c}40-410 \\
(89 \pm 68)\end{array}$ \\
\hline Arsenic & 50 & 13 & yes & $2-3$ \\
\hline Barium & 2000 & & & $\begin{array}{c}15-64 \\
(29 \pm 9)\end{array}$ \\
\hline Chloride & 250000 & & & $\begin{array}{c}2,500-190,000 \\
(14,024 \pm 35,457)\end{array}$ \\
\hline Chromium & 100 & & yes & $\begin{array}{c}15-20 \\
(17 \pm 3)\end{array}$ \\
\hline Copper & 1300 & 3 & yes & $\begin{array}{c}8-30 \\
(14 \pm 6)\end{array}$ \\
\hline Cyanide & 200 & 6 & yes & $\begin{array}{c}1-5 \\
(3 \pm 2)\end{array}$ \\
\hline
\end{tabular}


Table B.2. (contd)

\begin{tabular}{|c|c|c|c|c|}
\hline $\begin{array}{l}\text { Parameter or } \\
\text { Constituent }\end{array}$ & EPA MCL $(\mu g / L)^{(a)}$ & $\begin{array}{c}\text { TEDF } \\
\text { NPDES } \\
\text { Limits }^{(b)} \\
(\mu \mathrm{g} / \mathrm{L})\end{array}$ & $\begin{array}{l}\text { Toxic } \\
\text { Pollutant } \\
\text { List }^{(\mathrm{cc})}\end{array}$ & $\begin{array}{l}\text { Range of EOP } \\
\text { Concentrations }(\mu \mathrm{g} / \mathrm{L}) \\
\text { (Average } \pm \mathrm{SD})\end{array}$ \\
\hline Iron & 300 & & & $\begin{array}{c}23-250 \\
(92 \pm 45)\end{array}$ \\
\hline Lead & & 2 & yes & $\begin{array}{c}0.7-5.9 \\
(2.4 \pm 1.2)\end{array}$ \\
\hline Manganese & 50 & 10 & & $\begin{array}{c}1.5-9.3 \\
(3.0 \pm 1.7)\end{array}$ \\
\hline Mercury & 2 & 0.9 & yes & $\begin{array}{c}0.08-0.41 \\
(0.15 \pm 0.09)\end{array}$ \\
\hline Nickel & 100 & 35 & yes & $16-18$ \\
\hline Nitrate & 10000 & & & $\begin{array}{c}200-20,000 \\
(2,988 \pm 4,495)\end{array}$ \\
\hline Selenium & 50 & 5 & yes & $1.1-2.0$ \\
\hline Sulfate & $400,000-500,000$ & & & $\begin{array}{c}10,000-36,900 \\
(17,756 \pm 4,467)\end{array}$ \\
\hline Thallium & 2 & & yes & $1.4-2.0$ \\
\hline Zinc & & 25 & yes & $\begin{array}{c}20-84 \\
(39 \pm 14)\end{array}$ \\
\hline \multicolumn{5}{|c|}{ Volatile Organic Compounds } \\
\hline 1,1,1-Trichloroethane & 200 & 5 & yes & 1.4 \\
\hline $\begin{array}{l}\text { Bis(2-ethylhexyl)- } \\
\text { phthalate }\end{array}$ & 6 & 3 & & $\begin{array}{c}2-38.0 \\
(21.9 \pm 10.5)\end{array}$ \\
\hline Dibromochloromethane & & 2.2 & yes & $\begin{array}{c}1.0-2.2 \\
(1.6 \pm 0.4)\end{array}$ \\
\hline Ethylbenzene & 700 & & yes & 0.2 \\
\hline Methylene chloride & 5 & 3 & yes & $\begin{array}{c}0.2-1.6 \\
(0.9 \pm 0.4)\end{array}$ \\
\hline Tetrachloroethene & 5 & 5 & yes & 2.0 \\
\hline Toluene & 100 & 6 & yes & 1.4 \\
\hline Trichloroethene & & 1.9 & yes & $\begin{array}{c}0.3-0.7 \\
(0.5 \pm 0.1)\end{array}$ \\
\hline Trichlorofluoromethane & 100 & & yes & $\begin{array}{c}1.4-4.4 \\
(2.4 \pm 1.7)\end{array}$ \\
\hline |Xylenes (total) & 10000 & & & $\begin{array}{c}0.5-1.6 \\
(1.1 \pm 0.4)\end{array}$ \\
\hline
\end{tabular}


Table B.2. (contd)

\begin{tabular}{|c|c|c|c|c|}
\hline $\begin{array}{l}\text { Parameter or } \\
\text { Constituent }\end{array}$ & EPA MCL $(\mu \mathrm{g} / \mathrm{L})^{(a)}$ & $\begin{array}{c}\text { TEDF } \\
\text { NPDES } \\
\text { Limits }^{(\mathbf{b})} \\
(\mu \mathrm{g} / \mathrm{L})\end{array}$ & $\begin{array}{c}\text { Toxic } \\
\text { Pollutant } \\
\text { List }^{(c)}\end{array}$ & $\begin{array}{c}\text { Range of EOP } \\
\text { Concentrations }(\mu \mathrm{g} / \mathrm{L}) \\
\text { (Average } \pm \text { SD) }\end{array}$ \\
\hline Total trihalomethanes & 100 & $6.1-27.0$ & & \\
\hline \multicolumn{5}{|c|}{ Semivolatile Organic Compounds } \\
\hline Heptachlor & 0.4 & & yes & $\begin{array}{c}0.008-0.010 \\
(0.009)\end{array}$ \\
\hline \multicolumn{5}{|c|}{ Rladiological Parameter } \\
\hline Gross alpha & $15 \mathrm{pCi} / \mathrm{L}$ & & & $\begin{array}{c}1.4-9.2 \\
(3.3 \pm 0.8)\end{array}$ \\
\hline Gross beta & $8 \mathrm{pCi} / \mathrm{L}$ & & & $\begin{array}{c}2.1-12.5 \\
(3.8 \pm 1.2)\end{array}$ \\
\hline Tritium & $20000 \mathrm{pCi} / \mathrm{L}$ & & & 227.0 \\
\hline \multicolumn{5}{|c|}{$\begin{array}{l}\text { (a) U.S. Environmental Protection Agency (EPA). 1994. "Is Your Drinking Water Safe?" EPA } \\
\text { 810-F-94-002, U.S. Environmental Protection Agency, Office of Water, Washington, D.C. } \\
\text { (b) Treated Effluent Disposal Facility (TEDF) National Pollutant Discharge Elimination System } \\
\text { (NPDES) Permit No. WA-0025917. } \\
\text { MCL = maximum contaminant level. }\end{array}$} \\
\hline
\end{tabular}



Appendix C

Description of Sampling and Analysis

Processes and Capabilities 


\section{Appendix C}

\section{Description of Sampling and Analysis Processes and Capabilities}

\section{C.1 Scope and Assignment of Responsibilities for Sampling and Analysis Processes}

Eight buildings, including process and retention (radiological) process sewers, were scheduled for routine and nonbusiness day sampling in calendar year (CY) 1994. Of these eight buildings, liquid waste streams from six (Buildings 306, 320, 324, 326, 331, and 3720 ) were sampled and analyzed for chemical and radiological constituents (Section 1.0).

Routine sampling of liquid influents and effluents is performed by Pacific Northwest Laboratory's (PNL's) Field Sampling Team. Collected samples are screened for radioactivity. Radiological screening is performed by PNL's Analytical Chemistry Laboratory with backup support from Westinghouse Hanford Company's (WHC's) 222S Laboratory. After screening, samples are sent to offsite or onsite laboratories for radiological or chemical analysis. IT Corporation (Richland, Washington) performed radiochemical analysis, and DataChem (Salt Lake City, Utah) performed chemical and general parameter analyses. Volatile organic analyses and anion analyses were performed by PNL's Sigma 5 laboratory. Received data were evaluated by the project team for completeness and adherence to the statement of work requirements. Then, the data were stored in a database for subsequent evaluation to address the task objectives.

\section{C.2 Sampling Station Type and Capability}

Sampling stations are access points at buildings for collection of process sewer and retention process sewer samples. The stations contain equipment for monitoring waste stream flow, $\mathrm{pH}$, and conductivity. Permanent sampling stations were installed at those locations where there was a high potential for discharge of hazardous constituents into the 300 Area sewer systems. Facilities with lower discharge potentials were sampled with portable sampling equipment.

Permanent sampling stations are equipped with a refrigerated sampler, flow meter, $\mathrm{pH}$ meter, and conductivity meter. The samplers collect flow-proportional composite samples 
using a peristaltic pump and $9.5-\mathrm{mm}^{3}\left(3 / 8-\mathrm{in}_{\text {. }}\right)$ Teflon $^{\oplus}$-lined tubing. Flow, $\mathrm{pH}$, and conductivity data from nine dedicated stations will be collected continuously and communicated to a centralized information center for storage and processing using the Facility Management Control System. Data collection (i.e., flow, pH, and conductivity) at nondedicated locations (Buildings 331 and 3720 ) is provided on a continuous basis via field transportable stand-alone data-acquisition equipment.

\section{C.3 Routine Composite Sampling}

The majority of the samples were collected using refrigerated, flow-proportional composite samplers at dedicated sampling locations. Because an integrated sampler and flow meter were not available at end-of-pipe, time-proportional composite samples were collected at this location from April 6, 1994, through October 26, 1994. Using portable samplers, time proportional composite samples were collected from Building $\mathbf{3 0 6}$ effluent, and treated and untreated influent. The sampler located at the Building 326 process sewer was time proportional because of insufficient flow. All samples were composited for approximately 24 hours. Samplers were programmed the day before to start collecting samples between 7 a.m. and 9 a.m. Between June 21, 1994, and September 27, 1994, samples were collected in the evening because of a shortage of sampling personnel. During this time period, samplers were programmed the day before to start collecting samples between 3 p.m. and 4 p.m. Collected samples were held in a locked, climatecontrolled facility until the results of a radiological screen analysis were reviewed against shipping requirements. When all shipping requirements were met, samples were transferred to the appropriate analytical laboratory.

From the beginning of the CY 1994 sampling campaign through September 26, 1994, sample blanks were prepared and incorporated into collections of samples that were sent to analytical laboratories. The sample blanks consisted of laboratory purified water and preservatives, as required. Tables $C .1$ through $C .3$ provide a complete listing of composite samples and sample blanks that were analyzed. From October 1, 1994, through December 1994, only trip blank (volatile organic compound) samples, were prepared and analyzed.

\section{C.4 Methods of Analysis}

Samples transferred to the various PNL and commercial analytical laboratories were analyzed for the targeted parameters and constituents using approved methods. The methods used and their specific applications are summarized in Table C.4.

${ }^{\circledR}$ Teflon is a trademark of duPont Company, Wilmington, Delaware. 
Table C.1. Code Interpretation

\begin{tabular}{|c|c|}
\hline Code & Definition \\
\hline \multicolumn{2}{|r|}{ Heading } \\
\hline Alpha & Analysis includes alpha and beta radioactivity \\
\hline Grab & $\begin{array}{l}\text { Analysis is for volatile organic analytes that were sampled directly } \\
\text { from a sewer and not composited }\end{array}$ \\
\hline ICP & $\begin{array}{l}\text { Analysis includes inductively coupled plasma metals, arsenic, lead, } \\
\text { selenium, and thallium }\end{array}$ \\
\hline \multicolumn{2}{|r|}{ Comment } \\
\hline$\overline{\mathrm{BBL}}$ & Bottle Blank \\
\hline BKG & Background Sample \\
\hline $\mathrm{CO}$ & Unusual Water Color \\
\hline $\mathrm{CL}$ & Composite Bottle Cleaned in Prep Laboratory \\
\hline DUP & Duplicate \\
\hline $\bar{F}$ & Unusual Field Conditions \\
\hline FER & Transfer Blank \\
\hline FTR & Full Trip Blank \\
\hline LW & Low Water in Composite Bottle \\
\hline $\bar{M}$ & Mechanical Problems \\
\hline NW & No Water in Composite Bottle \\
\hline NT & New Tubing \\
\hline NB & New Bottle \\
\hline $\mathbf{P}$ & Priority \\
\hline $\mathrm{QC}$ & QC Report \\
\hline $\mathbf{R}$ & Rapid \\
\hline $\mathbf{S}$ & Scheduled \\
\hline SC & Scheduled and Collected \\
\hline SCL & Scheduled and Collected for Long List of Constituents \\
\hline $\mathrm{SE}$ & Sediment in Composite Bottle \\
\hline $\mathrm{T}$ & Less Than 24 Hour Composite \\
\hline TE & Improper Sample Temperature \\
\hline TRP & Trip Blank \\
\hline W & Unusual Water Conditions \\
\hline $\mathrm{X}$ & Misc \\
\hline
\end{tabular}


Table C.2. Summary of Composite and Grab Samples Collected and Analyzed During CY 1994

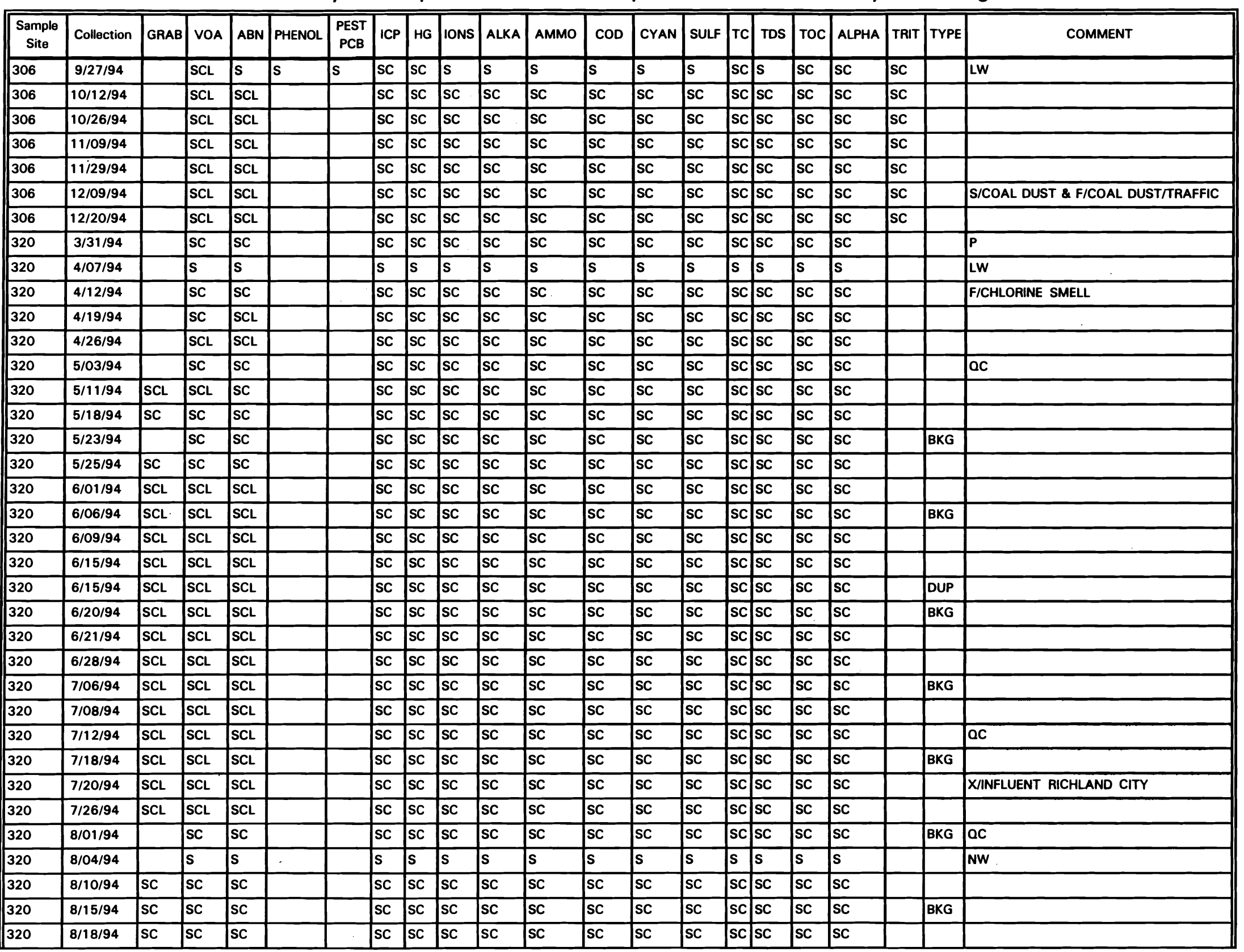


Table C.2. (contd)

\begin{tabular}{|c|c|c|c|c|c|c|c|c|c|c|c|c|c|c|c|c|c|c|c|c|c|}
\hline \begin{tabular}{|c|} 
Sample \\
Site
\end{tabular} & Collection & GRAB & VOA & ABN & PHENOL & \begin{tabular}{|l|} 
PEST \\
PCB
\end{tabular} & ICP & HG & IONS & ALKA & AMMO & COD & CYAN & SULF & TC & TDS & TOC & ALPHA & TRIT & TYPE & COMMENT \\
\hline 320 & $8 / 18 / 94$ & & $\mathbf{s}$ & $\mathbf{s}$ & & & s & s & s & s & s & s & s & s & s & s & s & s & & DUP & LW \\
\hline 320 & \begin{tabular}{|l|}
$8 / 23 / 94$ \\
\end{tabular} & sc & SC & sc & & & sc & $\mathrm{sc}$ & sc & $\mathrm{sc}$ & sc & sc & sc & sc & $\mathrm{sc}$ & sc & sc & sc & & & \\
\hline 320 & $8 / 31 / 94$ & Sc & Sc & sc & & & Sc & $\mathrm{sc}$ & sc & Sc & SC & SC & sc & sc & sc & SC & sc & SC & & & \\
\hline 320 & 9/06/94 & Sc & $\mathrm{sc}$ & sc & & & Sc & sc & sc & sc & SC & sc & sc & sc & sc & Sc & sc & sc & & & - \\
\hline 320 & $9 / 15 / 94$ & $\mathrm{sc}$ & SC & $\mathrm{sc}$ & & & $\mathrm{sc}$ & $\mathrm{sc}$ & $\mathrm{sc}$ & $\mathrm{sc}$ & $\mathrm{sc}$ & $\mathrm{sc}$ & sc & $\mathrm{sc}$ & sc & sc & sc & sc & & & \\
\hline 320 & 9/21/94 & SCL & SCL & $\mathrm{SCL}$ & & & SC & sc & sc & sc & Sc & SC & sc & sc & sc & sc & sc & sc & & & \\
\hline 320 & \begin{tabular}{|l|}
$9 / 27 / 94$ \\
\end{tabular} & SCL & $\mathrm{SCL}$ & $\mathrm{SCL}$ & & & SC & $\mathrm{sc}$ & sc & Sc & Sc & sc & Sc & sc & sc & Sc & sc & Sc & & & \\
\hline 320 & $10 / 12 / 94$ & & sc & sc & & & $\mathrm{sc}$ & $\mathrm{sc}$ & sc & sc & sc & sc & sc & sc & sc & sc & sc & Sc & & & \\
\hline 320 & $10 / 26 / 94$ & . & sc & sc & & & sc & Sc & sc & sc & sc & sc & sc & sc & $\mathrm{sc}$ & sc & sc & sc & & & \\
\hline 320 & $11 / 09 / 94$ & & sc & Sc & & & sc & Sc & sc & Sc & sc & sc & sc & sc & sc & Sc & sc & sc & & & \\
\hline 320 & $11 / 29 / 94$ & & sc & Sc & & & sc & Sc & sc & sc & SC & sc & sc & sc & $\mathrm{sc}$ & SC & sc & sc & & & \\
\hline 320 & $12 / 09 / 94$ & & sc & sc & & & sc & $\mathbf{S C}$ & sc & Sc & SC & Sc & sc & sc & $\mathrm{sc}$ & Sc & sc & Sc & & & \\
\hline 320 & $12 / 20 / 94$ & & $\mathrm{sc}$ & sc & & & sc & sc & sc & sc & $\mathrm{sc}$ & Sc & sc & sc & sc & Sc & sc & sc & & & \\
\hline 324 PS & $11 / 29 / 94$ & & SCL & $\mathrm{SCL}$ & & & s & s & $\mathbf{s}$ & $\mathbf{s}$ & s & s & s & $\mathbf{s}$ & $\mathbf{s}$ & s & s & sc & $\mathbf{s}$ & & LW \\
\hline 324 PS & $12 / 09 / 94$ & & SCL & $\mathrm{SCL}$ & & & Sc & sc & sc & sc & sc & sc & $\mathbf{s c}$ & sc & $\mathrm{sc}$ & sc & SC & sc & SC & & \\
\hline 324 PS & $12 / 20 / 94$ & & $\mathrm{SCL}$ & $\mathrm{SCL}$ & & & sc & sc & $\mathrm{sc}$ & sc & $\mathrm{sc}$ & sc & sc & sc & $\mathrm{sc}$ & sc & sc & sc & sc & & \\
\hline 324 RPS & $11 / 29 / 94$ & & SCL & $\mathrm{SCL}$ & & & sc & $\mathrm{sc}$ & sc & sc & sc & sc & $\mathrm{sc}$ & sc & $\mathrm{sc}$ & Sc & sc & SC & sc & & \\
\hline 324 RPS & $12 / 09 / 94$ & & SCL & $\mathrm{SCL}$ & & & sc & sc & sc & Sc & sc & SC & sc & sc & $\mathbf{s c}$ & SC & sc & sc & $\mathrm{sc}$ & & \\
\hline 324 RPS & $12 / 20 / 94$ & & SCL & $\mathrm{SCL}$ & & & sc & Sc & Sc & SC & SC & sc & SC & sc & $\mathrm{sc}$ & Sc & SC & SC & SC & & \\
\hline \begin{tabular}{|l|}
325 \\
DIVE
\end{tabular} & $5 / 20 / 94$ & & & & & & & & & & & & & & & & & & & & X/SCREEN ONLY \\
\hline 326 PS & $8 / 31 / 94$ & & s & s & & s & s & s & s & s & s & s & s & $\mathbf{s}$ & s & s & s & s & s & & NW \\
\hline 326 PS & 9/27/94 & & Sc & Sc & & SC & Sc & Sc & sc & Sc & SC & sc & sc & sc & $\mathrm{sc}$ & sc & sc & sc & sc & & \\
\hline 326 PS & $10 / 12 / 94$ & & $\mathrm{SCL}$ & $\mathrm{SCL}$ & & sc & sc & sc & Sc & $\mathrm{sc}$ & SC & sc & Sc & sc & $\mathrm{sc}$ & SC & Sc & sc & SC & & \\
\hline 326 PS & $10 / 26 / 94$ & & $\mathrm{SCL}$ & $\mathrm{SCL}$ & & $\mathrm{sc}$ & sc & sc & SC & SC & SC & SC & sc & sc & $\mathrm{sc}$ & sc & sc & SC & sc & & \\
\hline 326 PS & $11 / 09 / 94$ & & $\mathbf{S C L}$ & SCL & & sc & Sc & Sc & sc & SC & Sc & sc & sc & sc & $\mathrm{sc}$ & SC & sc & sc & sc & & \\
\hline 326 PS & $11 / 29 / 94$ & & SCL & $\mathrm{SCL}$ & & $\mathrm{sc}$ & SC & sc & SC & sc & sc & SC & sc & SC & $\mathrm{sc}$ & SC & $\mathrm{sc}$ & SC & SC & & \\
\hline 326 PS & $12 / 09 / 94$ & & $\mathrm{SCL}$ & $\mathrm{SCL}$ & & $\mathrm{sc}$ & sc & sc & sc & sc & sc & sc & sc & sc & sc & sc & sc & sc & sc & & \\
\hline 326 PS & $12 / 20 / 94$ & & SCL & $\mathrm{SCL}$ & & sc & sc & Sc & sc & sc & Sc & sc & Sc & sc & sc & sc & sc & SC & sc & & \\
\hline 327 PS & $12 / 20 / 94$ & & & & & & & & & & & & & & & & & sc & sc & & $\begin{array}{l}\text { X/HAZ CHEM SAMPLES } \\
\text { COLLECTED/HELD }\end{array}$ \\
\hline 327 RPS & $12 / 20 / 94$ & & & & & & & & & & & & & & . & & & sc & sc & & C/BROWN \& X/HAZ CHEM SAMPLES COL \\
\hline 329 & $8 / 04 / 94$ & & $\mathbf{s}$ & s & & $\mathbf{s}$ & $\mathbf{s}$ & $\mathbf{s}$ & s & s & s & s & $\mathbf{s}$ & $\mathbf{s}$ & $\mathbf{s}$ & $\mathbf{s}$ & s & $\mathbf{s}$ & $\mathbf{s}$ & & NW \\
\hline 331 & 3/22/94 & & sc & sc & & sc & sc & sc & sc & sc & sc & sc & sc & sc & sc & sc & sc & sc & & . & $P$ S/BROWN \\
\hline 331 & $3 / 30 / 94$ & & $\mathbf{s c}$ & sc & & sc & SC & $\mathrm{sc}$ & sc & sc & SC & $\mathbf{s}$ & sc & sc & $\mathrm{sc}$ & SC & SC & sc & & & $S \&$ X/COD BROKEN \& $P$ \\
\hline
\end{tabular}


Table C.2. (contd)

\begin{tabular}{|c|c|c|c|c|c|c|c|c|c|c|c|c|c|c|c|c|c|c|c|c|c|}
\hline $\begin{array}{c}\text { Sample } \\
\text { Site }\end{array}$ & Collection & GRAB & VOA & ABN & PHENOL & $\begin{array}{c}\text { PEST } \\
\text { PCB }\end{array}$ & ICP & HG & IONS & ALKA & AMMO & COD & CYAN & SULF & $|\mathrm{Tc}|$ & TDS & TOC & ALPHA & TRIT & TYPE & COMMENT \\
\hline 331 & $4 / 06 / 94$ & & $\mathrm{sc}$ & sc & & $\mathrm{sc}$ & $\mathrm{sc}$ & $\mathrm{sc}$ & sc & $\mathrm{sc}$ & $\mathrm{sc}$ & sc & $\mathrm{sc}$ & $\mathrm{sc}$ & sc & sc & sc & sc & & $\mathrm{s}$ & \\
\hline 331 & $4 / 13 / 94$ & & sc & $\mathrm{sc}$ & & $\mathrm{sc}$ & sc & $\mathrm{sc}$ & sc & $\mathrm{sc}$ & $\mathrm{sc}$ & sc & $\mathrm{sc}$ & $\mathrm{sc}$ & sc & sc & sc & sc & & & \\
\hline 331 & $4 / 19 / 94$ & & Sc & $\mathrm{SCL}$ & & $\mathrm{sc}$ & sc & $\mathrm{sc}$ & sc & Sc & $\mathrm{sc}$ & $\mathrm{sc}$ & sc & Sc & sc & $\mathrm{SC}$ & $\mathrm{sc}$ & sc & & & \\
\hline 331 & $4 / 26 / 94$ & & $\mathrm{SCL}$ & $\mathrm{SCL}$ & & sc & sc & $\mathrm{sc}$ & sc & $\mathrm{sc}$ & $\mathrm{sc}$ & $\mathrm{sc}$ & $\mathrm{sc}$ & SC & $\mathrm{sc}$ & SC & SC & sc & sc & & 5 \\
\hline 331 & $4 / 26 / 94$ & & SCL & $\mathrm{SCL}$ & & sc & $\mathrm{sc}$ & Sc & $\mathrm{sc}$ & sc & $\mathrm{sc}$ & & $\mathrm{sc}$ & & & & & & sc & DuP & \\
\hline 331 & $5 / 03 / 94$ & & sc & $\mathrm{sc}$ & & $\mathrm{sc}$ & sc & sc & sc & SC & sc & $\mathrm{sc}$ & $\mathrm{sc}$ & Sc & sc & SC & sc & sc & & & C/MILKY \\
\hline 331 & $5 / 11 / 94$ & $\mathrm{SCL}$ & $\mathrm{SCL}$ & $\mathrm{sc}$ & & sc & $\mathrm{sc}$ & $\mathrm{SC}$ & $\mathrm{sc}$ & $\mathrm{sc}$ & $\mathrm{sc}$ & sc & $\mathrm{sc}$ & $\mathrm{sc}$ & Sc & SC & $\mathrm{sc}$ & Sc & & & \\
\hline 331 & $5 / 18 / 94$ & Sc & sc & $\mathrm{sc}$ & & sc & sc & $\mathrm{sc}$ & $\mathrm{sc}$ & sc & $\mathrm{sc}$ & $\mathrm{sc}$ & $\mathrm{sc}$ & sc & $\mathrm{sc}$ & $\mathrm{sc}$ & sc & sc & & & C/CLOUDY \\
\hline 331 & $5 / 23 / 94$ & & $\mathbf{s}$ & $s$ & & $\mathrm{~s}$ & 5 & 5 & $\mathrm{~s}$ & 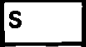 & s & $\mathbf{s}$ & s & $\mathbf{s}$ & $\mathbf{s}$ & $s$ & $\mathbf{s}$ & $\mathbf{s}$ & & & NW \\
\hline 331 & $5 / 25 / 94$ & sc & sc & $\mathrm{sc}$ & & $s c$ & SC & Sc & SC & $\mathrm{sc}$ & SC & sc & $\mathrm{sc}$ & $\mathrm{sc}$ & sc & SC & sc & sc & & & C/MILKY \\
\hline 331 & $6 / 01 / 94$ & $\mathrm{SCL}$ & SCL & $\mathrm{SCL}$ & & $\mathrm{sc}$ & sc & sc & sc & sc & SC & $\mathrm{sc}$ & Sc & sc & sc & sc & sc & sc & & & \\
\hline 331 & $6 / 06 / 94$ & $\mathrm{SCL}$ & $\mathrm{SCL}$ & sc & & $\mathrm{sc}$ & sc & sc & sc & $\mathrm{sc}$ & $\mathrm{sc}$ & $\mathrm{sc}$ & sc & sc & sc & $\mathrm{SC}$ & $\mathrm{sc}$ & Sc & & BKG & \\
\hline 331 & $6 / 09 / 94$ & $\mathrm{SCL}$ & $\mathrm{SCL}$ & $\mathrm{SCL}$ & & Sc & Sc & sc & SC & sc & Sc & Sc & sc & sc & sc & $\mathrm{sc}$ & sc & sc & & & . \\
\hline 331 & $6 / 15 / 94$ & $\mathrm{SCL}$ & $\mathrm{SCL}$ & $\mathrm{SCL}$ & & $\mathrm{sc}$ & $\mathrm{sc}$ & sc & sc & sc & $\mathrm{sc}$ & $\mathrm{sc}$ & $\mathrm{sc}$ & sc & $\mathrm{sc}$ & $\mathrm{SC}$ & $\mathrm{sc}$ & sc & & & \\
\hline 331 & $6 / 20 / 94$ & $\mathrm{SCL}$ & $\mathrm{SCL}$ & $\mathrm{SCL}$ & & $\mathrm{sc}$ & sc & sc & Sc & SC & $\mathrm{sc}$ & $\mathrm{sc}$ & $\mathrm{sc}$ & $\mathrm{sc}$ & sc & $\mathrm{sc}$ & sc & sc & & BKG & \\
\hline 331 & $6 / 21 / 94$ & $\mathrm{SCl}$ & $\mathrm{SCL}$ & $\mathrm{SCL}$ & & sc & sc & Sc & Sc & sc & SC & Sc & sc & sc & sc & SC & sc & $\mathrm{sc}$ & & & \\
\hline 331 & $6 / 28 / 94$ & $\mathrm{SCL}$ & $\mathrm{SCL}$ & $\mathrm{SCL}$ & & $\mathrm{sc}$ & sc & sc & Sc & $\mathrm{sc}$ & $\mathrm{sc}$ & sc & $\mathrm{sc}$ & $\mathrm{sc}$ & sc & Sc & sc & $s c$ & & & \\
\hline 331 & $7 / 06 / 94$ & $\mathrm{SCL}$ & $\mathrm{SCL}$ & SCL & & $\mathrm{sc}$ & sc & sc & sc & $\mathrm{sc}$ & $\mathrm{sc}$ & $\mathrm{sc}$ & sc & sc & sc & sc & sc & sc & & BKG & \\
\hline 331 & $7 / 08 / 94$ & $\mathrm{SCL}$ & $\mathrm{SCL}$ & $\mathrm{SCL}$ & & $\mathrm{sc}$ & sc & $\mathrm{sc}$ & $\mathrm{sc}$ & $\mathrm{sc}$ & SC & $\mathrm{sc}$ & Sc & $\mathrm{sc}$ & $\mathrm{sc}$ & SC & sc & $\mathrm{sc}$ & & & \\
\hline 331 & $7 / 12 / 94$ & $\mathrm{SCL}$ & $\mathrm{SCL}$ & $\mathrm{SCL}$ & & sc & sc & $\mathrm{sc}$ & sc & sc & SC & Sc & SC & sc & sc & sc & $\mathrm{sc}$ & $\mathrm{sc}$ & & & \\
\hline 331 & $7 / 18 / 94$ & $\mathrm{SCL}$ & $\mathrm{SCL}$ & $\mathrm{SCL}$ & & $\mathrm{sc}$ & sc & sc & $\mathrm{sc}$ & $\mathrm{sc}$ & SC & $\mathrm{sc}$ & sc & $\mathrm{sc}$ & $\mathrm{sc}$ & sc & $\mathbf{s c}$ & sc & & BKG & \\
\hline 331 & $7 / 20 / 94$ & $\mathrm{SCL}$ & $S C L$ & $\mathrm{SCL}$ & & $\mathrm{sc}$ & sc & Sc & $\mathrm{sc}$ & $\mathrm{sc}$ & SC & $\mathrm{sc}$ & sc & $\mathrm{sc}$ & sc & sc & $\mathrm{sc}$ & sc & & & XINFLUENT RICHLAND CITY \\
\hline 331 & $7 / 26 / 94$ & $\mathrm{SCL}$ & $\mathbf{S C L}$ & SCL & & SC & sc & sc & sc & sc & SC & SC & Sc & sc & sc & SC & sc & sc & & & \\
\hline 331 & $8 / 01 / 94$ & & 5 & $\mathrm{~s}$ & & $\mathrm{~s}$ & $s$ & $s$ & $\mathrm{~s}$ & $s$ & 5 & $\mathrm{~s}$ & $s$ & $s$ & $s$ & 5 & s & $s$ & & BKG & NW \\
\hline 331 & $8 / 04 / 94$ & $\mathrm{sc}$ & $\mathrm{sc}$ & sc & & $\mathrm{sc}$ & SC & sc & sc & sc & sc & $\mathrm{sc}$ & sc & sc & sc & $\mathrm{sc}$ & $\mathrm{sc}$ & sc & & & oc \\
\hline 331 & $8 / 10 / 94$ & $\mathrm{sc}$ & sc & sc & & sc & sc & sc & $\mathrm{sc}$ & $\mathrm{sc}$ & Sc & sc & sc & sc & sc & sc & $s c$ & sc & & & \\
\hline 331 & $8 / 15 / 94$ & $\mathrm{sc}$ & $\mathrm{sc}$ & sc & & Sc & sc & SC & sc & SC & SC & $s c$ & sc & sc & $\mathrm{sc}$ & $\mathrm{sc}$ & $\mathrm{sc}$ & SC & & BKG & \\
\hline 331 & $8 / 18 / 94$ & $\mathrm{sc}$ & sc & $\mathrm{sc}$ & & sc & sc & SC & sc & $\mathrm{sc}$ & SC & sc & $\mathrm{sc}$ & sc & sc & Sc & $s c$ & sc & & & $O c$ \\
\hline 331 & $8 / 23 / 94$ & sc & sc & $\mathrm{sc}$ & & sc & sc & sc & sc & $\mathrm{sc}$ & SC & sc & sc & sc & $\mathrm{sc}$ & SC. & sc & sc & & & C/MILKY \\
\hline 331 & $8 / 23 / 94$ & $\mathrm{sc}$ & sc & $\mathrm{sc}$ & & Sc & sc & $\mathrm{s}$ & sc & $s$ & $s$ & $\mathrm{sc}$ & $s$ & s & $s$ & 5 & $s$ & sc & & DUP & $L W$ \\
\hline 331 & $8 / 31 / 94$ & & 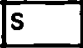 & $s$ & & $s$ & s & $s$ & 5 & 5 & 5 & 5 & 5 & 5 & $s$ & $s$ & $s$ & 5 & & & NW \\
\hline 331 & 9/06/94 & $\mathrm{sc}$ & sc & sc & & SC & sc & SC & sc & sc & SC & sc & sc & sc & sc & $\mathrm{sc}$ & sc & sc & & & \\
\hline 331 & $9 / 15 / 94$ & & $\mathrm{sc}$ & $\mathrm{sc}$ & & 5 & 5 & sc & sc & $\mathrm{sc}$ & sc & sc & $s$ & sc & $\mathrm{sc}$ & 5 & sc & 5 & & & $L W$ \\
\hline 331 & $9 / 21 / 94$ & $\mathrm{SCL}$ & SCL & $\mathrm{SCL}$ & & Sc & sc & sc & $\mathrm{sc}$ & $\mathrm{sc}$ & SC & $\mathrm{sc}$ & sc & sc & sc & $\mathrm{sc}$ & sc & sc & & & \\
\hline 331 & $9 / 27 / 94$ & $\mathrm{SCL}$ & $\mathrm{SCL}$ & $\mathrm{SCL}$ & & SC & $s$ & $s$ & $\mathrm{sc}$ & sc & SC & sc & 5 & sc & sc & $\mathrm{sc}$ & $\mathrm{sc}$ & $\mathrm{sc}$ & & & LW \\
\hline
\end{tabular}


Table C.2. (contd)

\begin{tabular}{|c|c|c|c|c|c|c|c|c|c|c|c|c|c|c|c|c|c|c|c|c|c|}
\hline $\begin{array}{c}\text { Sample } \\
\text { Site }\end{array}$ & Collection & GRAB & VOA & ABN & PHENOL & \begin{tabular}{|c|} 
PEST \\
PCB \\
\end{tabular} & ICP & HG & IONS & ALKA & AMMO & COD & CYAN & SULF & $\mathrm{TC}$ & TDS & TOC & ALPHA & TRIT & TYPE & COMMENT \\
\hline 331 & $10 / 12 / 94$ & & sc & sc & & $\mathrm{sc}$ & sc & SC & SC & sc & Sc & Sc & sc & SC & sc & SC & SC & SC & & & \\
\hline 331 & $10 / 26 / 94$ & & $\mathrm{sc}$ & SC & & $\mathrm{sc}$ & sc & $\mathrm{sc}$ & sc & $\mathrm{sc}$ & $\mathrm{sc}$ & Sc & $\mathrm{sc}$ & $\mathrm{sc}$ & $\mathrm{sc}$ & SC & Sc & SC & & & \\
\hline 331 & $11 / 09 / 94$ & & Sc & SC & & sc & SC & SC & SC & SC & sc & SC & $\mathrm{sc}$ & SC & $\mathbf{s c}$ & SC & SC & SC & & & \\
\hline 331 & $11 / 29 / 94$ & & sc & SC & & Sc & SC & sc & sc & Sc & sc & sc & sc & sc & $\mathrm{sc}$ & sc & SC & sc & & & \\
\hline 331 & $12 / 09 / 94$ & & sc & SC & & Sc & SC & sc & sc & Sc & sc & SC & Sc & Sc & $\mathrm{sc}$ & sc & SC & SC & & & S/BROWN \\
\hline 331 & $12 / 20 / 94$ & & $\mathrm{sc}$ & SC & & SC & SC & SC & SC & SC & SC & SC & Sc & sc & $\mathbf{s c}$ & SC & SC & SC & & & \\
\hline 340 & $6 / 15 / 94$ & & & $\mathbf{S C L}$ & & & & & & & & & & & & & & & & & \\
\hline 3720 & $3 / 30 / 94$ & & sc & sc & & & sc & sc & sc & Sc & sc & sc & sc & sc & $\mathrm{sc}$ & sc & sc & sc & & & P \& R/RADS \& S \\
\hline 3720 & $4 / 06 / 94$ & & sc & SC & & & Sc & $\mathrm{sc}$ & Sc & Sc & Sc & Sc & Sc & sc & $\mathrm{sc}$ & $\mathbf{s c}$ & SC & sc & & & \\
\hline 3720 & 4/19/94 & & $\mathbf{s}$ & $\mathbf{s}$ & & & $\mathbf{s}$ & $\mathbf{s}$ & $\mathbf{s}$ & $\mathbf{s}$ & $\mathbf{s}$ & $\mathbf{s}$ & s & $\mathbf{s}$ & $\mathbf{s}$ & $\mathbf{s}$ & $\mathbf{s}$ & $\mathbf{s}$ & & & NW \\
\hline 3720 & $4 / 26 / 94$ & & $\mathrm{~s}$ & $s$ & & & $\mathbf{s}$ & $s$ & $s$ & $s$ & $s$ & $s$ & $\mathrm{~s}$ & $\mathrm{~s}$ & $\mathbf{s}$ & $s$ & s & $s$ & & & NW \\
\hline 3720 & $5 / 03 / 94$ & & sc & $\mathrm{SCL}$ & & & SC & SC & SC & $\mathrm{SC}$ & $\mathrm{sc}$ & SC & $\mathrm{sc}$ & $\mathrm{sc}$ & $\mathrm{sc}$ & SC & SC & $\mathrm{sc}$ & & & \\
\hline 3720 & $5 / 11 / 94$ & & SCL & $\mathrm{SCL}$ & & & SC & SC & SC & $\mathrm{sc}$ & SC & SC & sc & Sc & $\mathrm{sc}$ & Sc & SC & SC & & & \\
\hline 3720 & $5 / 18 / 94$ & & sc & SC & & & SC & SC & SC & SC & SC & sc & Sc & Sc & $\mathrm{sc}$ & Sc & SC & SC & & & \\
\hline 3720 & $5 / 23 / 94$ & & sc & SC & & & SC & SC & SC & SC & Sc & SC & sc & $\mathrm{sc}$ & $\mathrm{sc}$ & SC & SC & SC & & BKG & \\
\hline 3720 & $5 / 25 / 94$ & & sc & SC & & & SC & SC & SC & SC & SC & SC & SC & Sc & $\mathrm{sc}$ & sc & SC & SC & & & \\
\hline 3720 & $6 / 01 / 94$ & SCL & $\mathrm{SCL}$ & $\mathrm{SCL}$ & & & SC & $\mathrm{SC}$ & SC & SC & $\mathrm{sc}$ & sc & Sc & $\mathrm{sc}$ & $\mathrm{sc}$ & SC & SC & $\mathrm{sc}$ & & & \\
\hline 3720 & $6 / 06 / 94$ & & s & $\mathbf{s}$ & & & $\mathbf{s}$ & $\mathbf{s}$ & s & s & s & s & $\mathrm{s}$ & s & s & s & $s$ & s & & BKG & NW \\
\hline 3720 & $6 / 09 / 94$ & SCL & SCL & SCL & & & SC & SC & SC & SC & SC & SC & SC & Sc & $\mathrm{sc}$ & SC & SC & SC & & & \\
\hline 3720 & $6 / 15 / 94$ & $\mathrm{SCL}$ & $\mathrm{SCL}$ & $\mathrm{SCL}$ & & & SC & SC & SC & $\mathrm{sc}$ & $\mathrm{sc}$ & SC & $\mathrm{sc}$ & SC & $\mathrm{sc}$ & SC & SC & sc & & & F/GENERATOR RUNNING \\
\hline 3720 & $6 / 20 / 94$ & $\mathrm{SCL}$ & SCL & $\mathbf{S C L}$ & & & $\mathbf{S C}$ & sc & SC & sc & sc & sc & $\mathrm{sc}$ & sc & $\mathbf{s c}$ & sc & SC & sc & & BKG & \\
\hline 3720 & $6 / 21 / 94$ & SCL & $\mathrm{SCL}$ & SCL & & & SC & sc & SC & Sc & Sc & SC & sc & Sc & $\mathrm{sc}$ & Sc & SC & sc & & & ac \\
\hline 3720 & $6 / 28 / 94$ & $\mathrm{SCL}$ & $\mathrm{SCL}$ & $\mathbf{S C L}$ & & & $\mathbf{S C}$ & SC & SC & $\mathrm{sc}$ & sc & SC & sc & $\mathrm{sc}$ & $\mathrm{sc}$ & SC & SC & sc & & & \\
\hline 3720 & $7 / 06 / 94$ & $\mathrm{SCL}$ & $\mathrm{SCL}$ & SCL & sc & & $\mathbf{s c}$ & sc & sc & sc & sc & sc & sc & sc & $\mathrm{sc}$ & sc & SC & sc & & BKG & \\
\hline 3720 & $7 / 08 / 94$ & $\mathrm{SCL}$ & $\mathrm{SCL}$ & $\mathbf{S C L}$ & sc & & $\mathbf{S C}$ & sc & sc & sc & sc & sc & sc & sc & $\mathrm{sc}$ & sc & sc & sc & & & C/LAVENDER \\
\hline 3720 & $7 / 12 / 94$ & SCL & $\mathrm{SCL}$ & $\mathbf{s}$ & $\mathbf{s}$ & & SC & SC & SC & SC & SC & SC & $\mathbf{s}$ & $\mathbf{s}$ & $\mathbf{s c}$ & $\mathbf{S C}$ & SC & SC & & & LW \\
\hline 3720 & 7/12/94 & SCL & $\mathrm{SCL}$ & $\mathbf{S C L}$ & $\mathbf{S C}$ & & $\mathbf{S C}$ & SC & SC & SC & SC & SC & Sc & SC & $\mathbf{s c}$ & $\mathbf{S C}$ & $\mathbf{S C}$ & & & DUP & LW \\
\hline 3720 & $7 / 18 / 94$ & SCL & $\mathrm{SCL}$ & SCL & SC & & SC & SC & SC & SC & SC & SC & sc & SC & $\mathrm{sc}$ & SC & SC & SC & & BKG & \\
\hline 3720 & $7 / 20 / 94$ & & $\mathrm{~s}$ & $\mathbf{s}$ & $\mathbf{s}$ & & $\mathbf{S}$ & s & s & s & s & $\mathbf{S}$ & s & $s$ & $\mathbf{S}$ & $\mathbf{s}$ & $\mathbf{S}$ & s & & & NW \\
\hline 3720 & $7 / 26 / 94$ & SCL & $\mathrm{SCL}$ & $\mathrm{SCL}$ & SC & & SC & $s$ & SC & $\mathrm{sc}$ & Șc & SC & $s$ & $s$ & $s$ & $s$ & 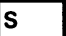 & SC & & & LW \\
\hline 3720 & $8 / 01 / 94$ & Sc & $\mathrm{sc}$ & SC & SC & & SC & SC & SC & SC & SC & SC & $\mathrm{sc}$ & SC & $\mathbf{s c}$ & SC & SC & SC & & BKG & \\
\hline 3720 & $8 / 04 / 94$ & sc & sc & SC & SC & & SC & SC & SC & SC & SC & SC & $\mathrm{sc}$ & Sc & $\mathrm{sc}$ & SC & SC & SC & & & \\
\hline 3720 & $8 / 10 / 94$ & sc & $\mathrm{sc}$ & SC & SC & & SC & SC & Sc & $\mathrm{sc}$ & Sc & SC & Sc & sc & $\mathbf{s c}$ & Sc & SC & SC & & & \\
\hline 3720 & $8 / 15 / 94$ & Sc & sc & SC & SC & & SC & SC & SC & SC & $\mathrm{SC}$ & SC & Sc & sc & $\mathrm{sc}$ & SC & SC & SC & & BKG & \\
\hline 3720 & $8 / 18 / 94$ & sc & $\mathrm{sc}$ & SC & SC & & SC & SC & SC & SC & $\mathrm{SC}$ & SC & Sc & $\mathrm{sc}$ & $\mathrm{sc}$ & SC & SC & Sc & & & \\
\hline
\end{tabular}


Table C.2. (contd)

\begin{tabular}{|c|c|c|c|c|c|c|c|c|c|c|c|c|c|c|c|c|c|c|c|c|c|}
\hline \begin{tabular}{|c} 
Sample \\
Site
\end{tabular} & Collection & GRAB & VOA & ABN & PHENOL & \begin{tabular}{|c|} 
PEST \\
PCB \\
\end{tabular} & ICP & HG & IONS & ALKA & AMMO & COD & CYAN & SULF & $\mid \mathrm{TC}$ & TDS & TOC & ALPHA & TRIT & TYPE & COMMENT \\
\hline 3720 & $8 / 23 / 94$ & sc & sc & sc & $\mathrm{sc}$ & & sc & sc & sc & sc & sc & sc & sc & sc & $\mathrm{sc}$ & sc & sc & sc & & & C/PINK \\
\hline 3720 & $8 / 31 / 94$ & sc & sc & sc & $\mathrm{sc}$ & & sc & sc & sc & sc & sc & sc & sc & $\mathrm{sc}$ & $\mathrm{sc}$ & sc & sc & sc & & & \\
\hline 3720 & $9 / 06 / 94$ & sc & sc & Sc & sc & & sc & Sc & sc & sc & sc & $\mathrm{sc}$ & sc & sc & $\mathrm{sc}$ & sc & sc & $\mathrm{sc}$ & & & \\
\hline 3720 & 9/15/94 & sc & sc & sc & sc & & sc & sc & sc & sc & sc & sc & sc & sc & $\mathrm{sc}$ & sc & sc & sc & & & ac \\
\hline 3720 & $9 / 21 / 94$ & $\mathrm{SCL}$ & $\mathrm{SCL}$ & $\mathrm{SCL}$ & $\mathrm{sc}$ & & sc & sc & sc & sc & sc & sc & sc & sc & $\mathrm{sc}$ & sc & sc & sc & & & \\
\hline 3720 & $9 / 27 / 94$ & $\mathrm{SCL}$ & $\mathrm{SCL}$ & $\mathrm{SCL}$ & $\mathrm{sc}$ & & sc & sc & sc & sc & sc & sc & sc & sc & $\mathrm{sc}$ & sc & sc & sc & & & \\
\hline 3720 & $9 / 27 / 94$ & $\mathrm{SCL}$ & $S C L$ & $\mathrm{SCL}$ & & & sc & & sc & sc & sc & sc & $\mathbf{s}$ & sc & $\mathrm{sc}$ & & sc & sc & & DuP & \\
\hline 3720 & $10 / 12 / 94$ & & sc & sc & $\mathrm{sc}$ & & sc & sc & sc & Sc & sc & sc & sc & sc & $\mathrm{sc}$ & sc & sc & sc & & & \\
\hline 3720 & $10 / 26 / 94$ & & $\mathbf{s}$ & $s$ & s & & $s$ & $s$ & $s$ & $s$ & $\mathbf{s}$ & $\mathbf{s}$ & $\mathbf{s}$ & $\mathbf{s}$ & $\mathbf{s}$ & $\mathbf{s}$ & $\mathbf{s}$ & $\mathbf{s}$ & & & M/ELECTRICAL OUT \\
\hline 3720 & $11 / 09 / 94$ & & s & $\mathbf{s}$ & $\mathbf{s}$ & & s & s & s & s & $\mathbf{s}$ & $\mathbf{s}$ & $\mathbf{s}$ & $\mathbf{s}$ & $\mathbf{s}$ & $\mathbf{s}$ & $\mathbf{s}$ & s & & & M/ELECTRICAL OUT \\
\hline 3720 & $11 / 29 / 94$ & & sc & sc & sc & & sc & sc & sc & $\mathbf{s c}$ & sc & sc & sc & sc & $\mathbf{s c}$ & sc & sc & sc & & & \\
\hline 3720 & $12 / 09 / 94$ & & sc & sc & sc & & sc & sc & sc & sc & sc & sc & sc & sc & sc & sc & sc & sc & & & \\
\hline 3720 & $12 / 20 / 94$ & & sc & sc & $\mathrm{sc}$ & & sc & sc & sc & sc & sc & sc & sc & sc & $\mathrm{sc}$ & sc & sc & sc & & & \\
\hline $382 B$ & $8 / 04 / 94$ & $S C L$ & $S C L$ & $\mathrm{SCL}$ & & sc & sc & sc & sc & sc & sc & sc & sc & sc & $s c$ & sc & sc & & & & \\
\hline EOP & $4 / 06 / 94$ & & sc & sc & & $s$ & sc & sc & sc & sc & $\mathbf{s}$ & $s$ & sc & s & sc & s & sc & sc & sc & & LW \\
\hline EOP & $4 / 14 / 94$ & & sc & sc & & $\mathbf{s}$ & sc & $\mathbf{s c}$ & sc & sc & sc & sc & sc & sc & $\mathrm{sc}$ & sc & sc & sc & sc & & LW \\
\hline EOP & $4 / 19 / 94$ & & $s$ & $\mathbf{s}$ & & $\mathbf{s}$ & $\mathbf{s}$ & $\mathbf{s}$ & $s$ & $\mathbf{s}$ & s & $s$ & $\mathbf{s}$ & s & $\mathbf{s}$ & $\mathbf{s}$ & $\mathbf{s}$ & $\mathbf{s}$ & $\mathbf{s}$ & & NW \\
\hline EOP & $5 / 03 / 94$ & & $\mathrm{SCL}$ & $\mathrm{SCL}$ & & $\mathbf{s}$ & sc & sc & sc & sc & sc & sc & $\mathbf{s}$ & sc & $\mathrm{sc}$ & sc & sc & $\mathbf{s}$ & sc & & LW \& FIDIRTY \\
\hline EOP & $5 / 11 / 94$ & & $\mathrm{SCL}$ & $\mathrm{SCL}$ & & sc & sc & $\mathbf{s}$ & sc & $\mathbf{s}$ & s & sc & sc & sc & $\mathrm{sc}$ & sc & sc & sc & sc & & LW \& F/DIRTY \\
\hline EOP & 5/18/94 & & $\mathrm{sc}$ & $\mathrm{sc}$ & & sc & $\mathrm{sc}$ & sc & sc & $s c$ & sc & sc & sc & sc & $\mathrm{sc}$ & sc & sc & sc & sc & & \\
\hline EOP & $5 / 23 / 94$ & & sc & sc & & sc & sc & sc & sc & sc & sc & sc & sc & sc & $\mathrm{sc}$ & sc & sc & sc & SC & BKG & F/DIRTY \\
\hline EOP & 5/25/94 & & sc & sc & & sc & sc & sc & sc & sc & sc & sc & sc & $\mathrm{sc}$ & $\mathrm{sc}$ & sc & sc & sc & sc & & \\
\hline EOP & $6 / 01 / 94$ & & $S C L$ & $\mathbf{s}$ & & sc & sc & sc & sc & sc & sc & sc & sc & sc & $\mathrm{sc}$ & sc & sc & $\mathbf{s c}$ & sc & & X/ABNL IN WRONG BOTTLE \\
\hline EOP & 6/06/94 & $\mathrm{SCL}$ & SCL & $\mathrm{SCL}$ & & sc & sc & sc & sc & sc & sc & sc & sc & sc & $\mathrm{sc}$ & SC & sc & sc & sc & BKG & \\
\hline EOP & 6/09/94 & $\mathrm{SCL}$ & $\mathrm{SCL}$ & $\mathrm{SCL}$ & & sc & sc & sc & sc & sc & sic & sc & sc & sc & sc & sc & sc & sc & sc & & \\
\hline EOP & 6/15/94 & $\mathrm{SCL}$ & SCL & SCL & & sc & sc & sc & sc & sc & sc & sc & sc & sc & $\mathrm{sc}$ & sc & sc & sc & sc & & \\
\hline EOP & $6 / 20 / 94$ & $\mathrm{SCL}$ & $\mathrm{SCL}$ & $\mathrm{SCL}$ & & sc & sc & sc & sc & Sc & sc & sc & sc & sc & sc & SC & sc & sc & sc & BKG & \\
\hline EOP & $6 / 21 / 94$ & $S C L$ & $\mathrm{SCL}$ & $\mathrm{SCL}$ & & sc & sc & sc & sc & sc & sc & SC & sc & sc & sc & SC & sc & SC & SC & & \\
\hline EOP & $6 / 28 / 94$ & & 5 & s & & s & $s$ & s & $s$ & s & s & s & $s$ & $s$ & s & s & s & s & $s$ & & NW \\
\hline EOP & $7 / 06 / 94$ & & s & 5 & & s & s & s & s & s & s & s & s & $s$ & s & $s$ & $s$ & 5 & s & BKG & NW \\
\hline EOP & $7 / 08 / 94$ & $\mathrm{SCL}$ & $\mathrm{SCL}$ & $\mathrm{SCL}$ & & sc & sc & sc & sc & sc & sc & sc & sc & sc & $\mathrm{sc}$ & Sc & sc & sc & & & \\
\hline EOP & $7 / 12 / 94$ & $\mathrm{SCL}$ & $S C L$ & $\mathrm{SCL}$ & & sc & sc & sc & sc & sc & sc & sc & sc & sc & sc & sc & sc & sc & & & \\
\hline EOP & $7 / 18 / 94$ & $\mathrm{SCL}$ & $\mathrm{SCL}$ & $\mathrm{SCL}$ & & sc & sc & sc & sc & Sc & sc & sc & sc & sc & sc & sc & sc & sc & & BKG & $\mathrm{ac}$ \\
\hline EOP & $7 / 20 / 94$ & $\mathrm{SCL}$ & $\mathrm{SCL}$ & $\mathrm{SCL}$ & & sc & sc & sc & sc & sc & sc & sc & sc & sc & $\mathrm{sc}$ & sc & sc & sc & & & XIINFLUENT RICHLAND CITY \\
\hline EOP & $7 / 26 / 94$ & $\mathrm{SCL}$ & $\mathrm{SCL}$ & $\mathrm{SCL}$ & & sc & sc & $\mathbf{s}$ & $\mathbf{s}$ & sc & sc & $\operatorname{scsc}$ & $s$ & sc & sc & sc & $s$ & & & & LW \\
\hline
\end{tabular}


Table C.2. (contd)

\begin{tabular}{|c|c|c|c|c|c|c|c|c|c|c|c|c|c|c|c|c|c|c|c|c|c|}
\hline $\begin{array}{c}\text { Sample } \\
\text { Site }\end{array}$ & Collection & GRAB & VOA & ABN & PHENOL & \begin{tabular}{|c|} 
PEST \\
PCB \\
\end{tabular} & ICP & HG & IONS & ALKA & АMMO & COD & CYAN & SULF & TC & TDS & TOC & ALPHA & TRIT & TYPE & COMMENT \\
\hline EOP & $7 / 26 / 94$ & $\mathrm{SCL}$ & $\mathrm{SCL}$ & $\mathrm{SCL}$ & & SC & sc & s & s & $\mathrm{sc}$ & $s$ & $\mathrm{sc}$ & $\mathrm{sc}$ & $s$ & $\mathrm{sc}$ & s & sc & $\mathrm{SC}$ & & DUP & $L W$ \\
\hline EOP & $8 / 01 / 94$ & Sc & sc & sc & & sc & sc & $s c$ & $s c$ & $\mathrm{sc}$ & SC & $\mathrm{sc}$ & sc & sc & sc & sc & sc & sc & & BKG & \\
\hline EOP & $8 / 01 / 94$ & $\mathrm{SC}$ & Sc & Sc & & $s$ & sc & $\mathbf{s}$ & sc & Sc & $\mathbf{s c}$ & sc & $\mathrm{sc}$ & $s$ & $\mathbf{s}$ & $\mathrm{s}$ & $\mathrm{sc}$ & $\mathbf{s c}$ & & DUP & LW \\
\hline EOP & $8 / 04 / 94$ & $\mathrm{sc}$ & Sc & Sc & & sc & sc & sc & sc & SC & SC & $\mathrm{sc}$ & $\mathrm{sc}$ & SC & $\mathrm{sc}$ & sc & $\mathrm{sc}$ & SC & & & \\
\hline EOP & $8 / 10 / 94$ & sc & Sc & Sc & & SC & Sc & sc & SC & SC & SC & Sc & $\mathrm{sc}$ & SC & sc & SC & Sc & SC & & & \\
\hline EOP & $8 / 15 / 94$ & sc & sc & sc & & sc & sc & Sc & sc & Sc & SC & Sc & sc & SC & sc & Sc & Sc & SC & & BKG & \\
\hline EOP & $8 / 18 / 94$ & SC & SC & SC & & Sc & SC & sc & sc & Sc & SC & Sc & $\mathrm{SC}$ & $\mathrm{SC}$ & sc & $\mathrm{SC}$ & $\mathrm{sc}$ & SC & & & $s$ \\
\hline EOP & $8 / 23 / 94$ & sc & SC & Sc & & sc & SC & Sc & sc & SC & SC & sc & sc & SC & sc & sc & SC & SC & & & $a c$ \\
\hline EOP & $8 / 31 / 94$ & SC & SC & Sc & & Sc & sc & sc & sc & sc & SC & $\mathrm{sc}$ & SC & Sc & $\mathrm{sc}$ & Sc & Sc & SC & & & \\
\hline EOP & 9/06/94 & sc & SC & SC & & sc & Sc & sc & sc & Sc & SC & Sc & $\mathrm{SC}$ & Sc & sc & SC & Sc & SC & & & \\
\hline EOP & $9 / 15 / 94$ & Sc & SC & $\mathrm{sc}$ & & SC & sc & Sc & $\mathrm{sc}$ & $\mathrm{sc}$ & SC & $\mathrm{sc}$ & $\mathrm{SC}$ & $\mathrm{SC}$ & $\mathrm{sc}$ & $\mathrm{SC}$ & $\mathrm{sc}$ & SC & & & \\
\hline EOP & $9 / 21 / 94$ & $\mathrm{SCL}$ & $\mathrm{SCL}$ & $\mathbf{S C L}$ & sc & $\mathrm{SC}$ & SC & sc & $\mathrm{sc}$ & $\mathrm{sc}$ & SC & $\mathrm{sc}$ & $\mathrm{sc}$ & $\mathrm{sc}$ & $\mathrm{sc}$ & Sc & $\mathrm{sc}$ & $\mathrm{sc}$ & & & \\
\hline EOP & $9 / 27 / 94$ & SCL & SCL & $\mathbf{S C L}$ & & SC & sc & sc & sc & sc & sc & $\mathrm{sc}$ & $\mathrm{SC}$ & Sc & $\mathrm{sc}$ & SC & sc & SC & & & \\
\hline EOP & $10 / 12 / 94$ & & Sc & SC & & Sc & sc & sc & sc & sc & sc & Sc & $\mathrm{sc}$ & SC & $\mathrm{sc}$ & sc & sc & SC & & & \\
\hline EOP & $10 / 26 / 94$ & & sc & $\mathrm{sc}$ & & Sc & SC & sc & sc & SC & Sc & SC & $\mathrm{sc}$ & Sc & $\mathrm{sc}$ & $\mathrm{sc}$ & sc & $\mathrm{SC}$ & & & \\
\hline EOP & $11 / 09 / 94$ & & $\mathbf{s c}$ & sc & sc & sc & sc & $\mathbf{s c}$ & sc & sc & sc & Sc & $\mathrm{sc}$ & SC & sc & sc & sc & sc & & & \\
\hline EOP & $11 / 29 / 94$ & & Sc & SC & sc & SC & sc & Sc & sc & sc & SC & sc & $\mathrm{sc}$ & Sc & $\mathrm{sc}$ & $\mathrm{sc}$ & sc & SC & & & \\
\hline EOP & $12 / 09 / 94$ & & $\mathrm{sc}$ & SC & SC & sc & SC & SC & sc & SC & SC & $\mathrm{sc}$ & SC & SC & sc & Sc & SC & SC & & & \\
\hline EOP & $12 / 20 / 94$ & & $\mathbf{s}$ & $\mathbf{s}$ & & $\mathbf{s}$ & $\mathbf{s}$ & $\mathbf{s}$ & $\mathbf{s}$ & $\mathbf{s}$ & $\mathbf{s}$ & s & $\mathbf{s}$ & s & $\mathbf{s}$ & $\mathbf{s}$ & s & $\mathbf{s}$ & & & NW \\
\hline RIVER & $5 / 11 / 94$ & SCL & $\mathrm{SCL}$ & SCL & & SC & sc & $\mathbf{s}$ & s & s & & & & & $\mathrm{sc}$ & $\mathrm{s}$ & $\mathrm{sc}$ & & & & $L W$ \\
\hline RIVER & $5 / 25 / 94$ & sc & SCL & $\mathbf{S C L}$ & & sc & sc & $\mathbf{s c}$ & $\mathbf{s c}$ & SC & & & & & sc & Sc & sc & & & & \\
\hline RIVER & 6/09/94 & $\mathbf{S C L}$ & SCL & SCL & & SC & sc & sc & sc & $\mathbf{S C}$ & & & & & $\mathrm{sc}$ & $\mathrm{sc}$ & SC & & & & \\
\hline RIVER & 6/21/94 & $\mathrm{SCL}$ & $\mathrm{SCL}$ & $\mathbf{S C L}$ & & SC & Sc & SC & sc & $\mathrm{sc}$ & & & & & $\mathrm{sc}$ & $\mathrm{sc}$ & Sc & & & & \\
\hline RIVER & 7/08/94 & $\mathrm{SCL}$ & SCL & $\mathrm{SCL}$ & & sc & sc & sc & sc & sc & SC & sc & $\mathrm{sc}$ & sc & $\mathbf{s c}$ & sc & sc & & & & ac \\
\hline $\begin{array}{l}\text { TREAT } \\
\text { MENT }\end{array}$ & $5 / 11 / 94$ & SCL & SCL & SCL & & sc & $\mathbf{s}$ & $\mathbf{s}$ & sc & $\mathbf{s}$ & & & & & sc & s & sc & & & & LW \& F/GENERATOR RUNNING \\
\hline $\begin{array}{l}\text { TREAT } \\
\text { MENT }\end{array}$ & $5 / 25 / 94$ & SC & SCL & SCL & & sc & sc & sc & sc & sc & & & Sc & sc & $\mathrm{sc}$ & & & & & & \\
\hline $\begin{array}{l}\text { TREAT } \\
\text { MENT }\end{array}$ & 6/01/94 & & & & & & & & & & & & & & & & & & & & \\
\hline $\begin{array}{l}\text { TREAT } \\
\text { MENT }\end{array}$ & 6/09/94 & SCL & SCL & SCL & & sc & sc & Sc & sc & sc & & & sc & sc & $\mathrm{sc}$ & & & & & & \\
\hline $\begin{array}{l}\text { TREAT } \\
\text { MENT }\end{array}$ & $6 / 21 / 94$ & SCL & SCL & SCL & & sc & sc & sc & sc & sc & & & sc" & sc & $\mathrm{sc}$ & & & & & & \\
\hline $\begin{array}{l}\text { TREAT } \\
\text { MENT }\end{array}$ & $\begin{array}{l}7 / 08 / 94 \\
.\end{array}$ & $\mathrm{SCL}$ & SCL & $\mathbf{S C L}$ & & sc1 & sc & sc & sc & Sc & sc & sc & sc & sc1 & sc & sc & sc & & & & LW \\
\hline
\end{tabular}


Table C.3. Summary of OC Samples Prepared and Analyzed During CY 1994

\begin{tabular}{|c|c|c|c|c|c|c|c|c|c|c|c|c|c|c|c|c|c|c|c|c|c|}
\hline $\begin{array}{l}\text { Sample } \\
\text { Site }\end{array}$ & Collection & VOA & GRAB & ABN & PHENOL & $\begin{array}{c}\text { PEST } \\
\text { PCB }\end{array}$ & ICP & $\mathrm{HG}$ & IONS & ALKA & АMMO & COD & CYAN & SULF & $\mid \mathrm{TC}$ & TDS & Toc & ALPHA & |TRIT & TYPE & $\begin{array}{l}\text { Comment/ } \\
\text { Building } \\
\text { Association }\end{array}$ \\
\hline BBL 2 & 9/21/94 & $\mathrm{sCl}$ & & $\mathrm{SCL}$ & Sc & SC & $\mathrm{sc}$ & $\mathrm{sc}$ & Sc & SC & SC & sc & SC & sc & $\mathrm{sc}$ & SC & Sc & & & & \\
\hline BBL 3 & $9 / 21 / 94$ & $\mathrm{SCL}$ & & $\mathrm{SCL}$ & SC & SC & $\mathrm{sc}$ & & SC & SC & & & SC & SC & & & & & & & \\
\hline BBL 4 & $9 / 21 / 94$ & & & sc & SC & & $\mathrm{sc}$ & & & & & & SC & & & & & & & & \\
\hline BBL 5 & $9 / 21 / 94$ & & & & & & $\mathrm{sc}$ & & & & & & SC & & & & & & & & \\
\hline BBL 6 & $9 / 21 / 94$ & & & SC & SC & SC & & $\mathrm{sc}$ & & & & & & & & & sc & & & & \\
\hline BBL 6 & $9 / 21 / 94$ & $\mathrm{sc}$ & & SC & $\mathrm{SC}$ & SC & $\mathrm{sc}$ & $\mathrm{sc}$ & & & & Sc & SC & SC & & sc & sc & & & & \\
\hline BBL 7 & $9 / 29 / 94$ & $\mathrm{sc}$ & & SC & $\mathrm{SC}$ & SC & $\mathrm{sc}$ & $s c$ & & & & $\mathrm{SC}$ & $\mathrm{SC}$ & SC & & Sc & $\mathrm{sc}$ & & & & \\
\hline BBL 7 & 9/29/94 & sc & & Sc & SC & SC & sc & $\mathrm{sc}$ & & & & SC & SC & SC & & Sc & sc & & & & \\
\hline BBL 7 & 9/29/94 & $\mathrm{sc}$ & & & & & $\mathrm{sc}$ & $\mathrm{sc}$ & & & & Sc & SC & SC & & & $\mathrm{sc}$ & & & & \\
\hline BBL 7 & 9/29/94 & $\mathrm{SC}$ & & & & & & & & & & & & & & & & & & & \\
\hline BBL 7 & 9/29/94 & $\mathrm{sc}$ & & & & & & & & & & & & & & & & & & & \\
\hline BBL 7 & 9/29/94 & Sc & & & & & & & & & & & & & & & & & & & \\
\hline BBL 7 & 9/29/94 & sc & & & & & & & & & & & & & & & & & & & \\
\hline EQUIP BLANK & $2 / 24 / 94$ & sc & & Sc & & SC & sc & $\mathrm{sc}$ & SC & SC & $\mathrm{SC}$ & Sc & $\mathrm{SC}$ & $\mathrm{SC}$ & sc & \begin{tabular}{|l|}
$\mathrm{sc}$ \\
\end{tabular} & SC & sc & sc & & $R$ \\
\hline EQUIP BLANK & $2 / 24 / 94$ & Sc & & SC & & $\mathrm{sc}$ & $\mathrm{sc}$ & $\mathrm{sc}$ & SC & sc & SC & Sc & $\mathrm{sc}$ & $\mathrm{SC}$ & $\mathrm{sc}$ & sc & $\mathrm{sc}$ & $\mathrm{sc}$ & $\mathrm{sc}$ & & $\mathbf{R}$ \\
\hline EQUIP BLANK & $2 / 24 / 94$ & Sc & & SC & & SC & $\mathrm{sc}$ & $\mathrm{sc}$ & $\mathrm{SC}$ & SC & $\mathrm{SC}$ & SC & $\mathrm{SC}$ & SC & $\mathrm{SC}$ & \begin{tabular}{|l|}
$\mathrm{sc}$ \\
\end{tabular} & sc & SC & \begin{tabular}{|l|}
$\mathrm{SC}$ \\
\end{tabular} & & $R$ \\
\hline \begin{tabular}{|l|l|} 
FER 1 \\
\end{tabular} & $3 / 30 / 94$ & sc & & & & & & & & & & & & & & & & & & & 331 \\
\hline $\begin{array}{|ll|}\text { FER } \quad 2 \\
\end{array}$ & $4 / 06 / 94$ & $\mathrm{SC}$ & & & & & & & & & & & & & & & & & & & 331 \\
\hline $\begin{array}{|ll|}\text { FER } 3 \\
\end{array}$ & $6 / 06 / 94$ & Sc & & & & & & & & & & & & & & & & & & & 331 \\
\hline \begin{tabular}{|l|l|} 
FER 4 \\
\end{tabular} & $6 / 21 / 94$ & sc & & & & & & & & & & & & & & & & & & & 320 \\
\hline $\begin{array}{|ll|}\text { FER } \quad 5 \\
\end{array}$ & $7 / 06 / 94$ & SC & & & & & & & & & & & & & & & & & & & 3720 \\
\hline FER 6 & $7 / 12 / 94$ & $\mathrm{sc}$ & & & & & & & & & & & & & & & & & & & 320 \\
\hline FER 7 & $7 / 20 / 94$ & $\mathrm{sc}$ & & & & & & & & & & & & & & & & & & & 320 \\
\hline $\begin{array}{|ll|}\text { FER } 8 \\
\end{array}$ & $7 / 26 / 94$ & $\mathrm{SC}$ & & & & & & & & & & & & & & & & & & & 331 \\
\hline FER 10 & $8 / 15 / 94$ & SC & & & & & & & & & & & & & & & & & & & 320 \\
\hline FER 11 & $9 / 06 / 94$ & $\mathrm{sc}$ & & & & & & & & & & & & & & & & & & & 320 \\
\hline FTR 1 & $4 / 26 / 94$ & $\mathrm{SCL}$ & & $\mathrm{SCL}$ & & & $\mathrm{sc}$ & $\mathrm{sc}$ & SC & $\mathrm{SC}$ & SC & SC & SC & SC & $\mathrm{sc}$ & SC & sc & SC & & & 320 \\
\hline \begin{tabular}{|ll} 
FTR $\quad 2$ \\
\end{tabular} & $5 / 18 / 94$ & \begin{tabular}{|l|l|}
$\mathrm{sc}$ \\
\end{tabular} & & \begin{tabular}{|l|}
$\mathrm{SC}$ \\
\end{tabular} & & $\mathrm{SC}$ & $\mathrm{sc}$ & SC & SC & SC & SC & $\mathrm{SC}$ & SC & $\mathrm{SC}$ & $\mathrm{sc}$ & SC & SC & SC & & & 331 \\
\hline \begin{tabular}{|l|} 
FTR 3 \\
\end{tabular} & $7 / 08 / 94$ & $\mathrm{SCL}$ & & $\mathrm{SCL}$ & & $\mathrm{sc}$ & Sc & SC & $\mathrm{SC}$ & sc & $\mathrm{sc}$ & Sc & SC & $\mathrm{sc}$ & $\mathrm{sc}$ & SC & sc & SC & & & EOP \\
\hline FTR 4 & $7 / 26 / 94$ & $\mathrm{SCL}$ & & $\mathrm{SCL}$ & SC & & $\mathrm{sc}$ & Sc & SC & $\mathrm{sc}$ & sc & Sc & SC & $\mathrm{SC}$ & $\mathrm{sc}$ & $S C$ & sc & SC & & & 3720 \\
\hline FTR 225 & $9 / 21 / 94$ & $\mathrm{SCL}$ & & $\mathrm{SCL}$ & & & sc & $\mathrm{sc}$ & SC & SC & SC & SC & SC & SC & $\mathrm{sc}$ & $S C$ & $\mathrm{SC}$ & SC & & & 320 \\
\hline
\end{tabular}


Table C.3. (contd)

\begin{tabular}{|c|c|c|c|c|c|c|c|c|c|c|c|c|c|c|c|c|c|c|c|c|c|}
\hline $\begin{array}{c}\text { Sample } \\
\text { Site }\end{array}$ & Collection & VOA & GRAB & ABN & PHENOL & \begin{tabular}{|l} 
PEST \\
PCB
\end{tabular} & ICP & HG & IONS & ALKA & AMMO & $\cos$ & CYAN & N SULF & TC & TDS & $|T O C|$ & ALPHA & TRIT & TYPE & $\begin{array}{c}\text { Comment/ } \\
\text { Building } \\
\text { Association }\end{array}$ \\
\hline $\begin{array}{|ll|}\mid T R P & 1\end{array}$ & $3 / 30 / 94$ & $\mathrm{sc}$ & & & & & & & & & & & & & & & & & & & 331 \\
\hline TRP 2 & $4 / 06 / 94$ & SC & & & & & & & & & & & & & & & & & & & 331 \\
\hline TRP 3 & \begin{tabular}{|l|l|}
$4 / 14 / 94$ \\
\end{tabular} & SC & & & & & & & & & & & & & & & & & & & EOP \\
\hline $\mid$\begin{tabular}{|l|l|} 
TRP & 4
\end{tabular} & $5 / 11 / 94$ & $\mathrm{sc}$ & & & & & & & & & & & & & & & & & & & RIVER \\
\hline TRP 5 & $5 / 23 / 94$ & SC & & & & & & & & & & & & & & & & & & & 320 \\
\hline TRP 6 & $6 / 06 / 94$ & SC & & & & & & & & & & & & & & & & & & & 331 \\
\hline TRP 7 & $6 / 09 / 94$ & $\mathrm{sc}$ & & & & & & & & & & & & & & & & & & & 331 \\
\hline TRP 8 & $6 / 15 / 94$ & SC & & & & & & & & & & & & & & & & & & & 331 \\
\hline TRP 9 & $6 / 20 / 94$ & $\mathrm{sc}$ & & & & & & & & & & & & & & & & & & & 331 \\
\hline TRP 10 & $6 / 21 / 94$ & Sc & & & & & & & & & & & & & & & & & & & 320 \\
\hline TRP 11 & \begin{tabular}{|l|l|}
$7 / 06 / 94$ \\
\end{tabular} & SC & & & & & & & & & & & & & & & & & & & 3720 \\
\hline TRP 12 & $7 / 12 / 94$ & $\mathrm{sc}$ & & & & & & & & & & & & & & & & & & & 320 \\
\hline TRP 13 & $7 / 20 / 94$ & SC & & & & & & & & & & & & & & & & & & & 320 \\
\hline TRP 14 & \begin{tabular}{|l|l|}
$7 / 26 / 94$ \\
\end{tabular} & $\mathrm{sc}$ & & & & & & & & & & & & & & & & & & & 331 \\
\hline TRP 15 & $8 / 01 / 94$ & SC & & & & & & & & & & & & & & & & & & & 320 \\
\hline TRP 16 & $8 / 15 / 94$ & $\mathrm{SC}$ & & & & & & & & & & & & & & & & & & & 320 \\
\hline TRP 17 & $8 / 18 / 94$ & $\mathrm{sc}$ & & & & & & & & & & & & & & & & & & & 320 \\
\hline TRP 18 & $8 / 23 / 94$ & sc & & & & & & & & & & & & & & & & & & & 320 \\
\hline TRP 19 & $8 / 31 / 94$ & $\mathrm{sc}$ & & & & & & & & & & & & & & & & & & & EOP \\
\hline TRP 20 & 9/06/94 & SC & & & & & & & & & & & & & & & & & & & 320 \\
\hline TRP 21 & 9/15/94 & $\mathrm{sc}$ & & & & & & & & & & & & & & & & & & & 320 \\
\hline TRP 22 & 9/21/94 & $\mathrm{SC}$ & & & & & & & & & & & & & & & & & & & 320 \\
\hline TRP 23 & |9/27/94 & sc & & & & & & & & & & & & & & & & & & & 3720 \\
\hline TRP 24 & $10 / 12 / 94$ & $\mathrm{SC}$ & & & & & & & & & & & & & & & & & & & 331 \\
\hline TRP 25 & $10 / 26 / 94$ & $\mathrm{Sc}$ & & & & & & & & & & & & & & & & & & & 331 \\
\hline TRP 26 & $11 / 09 / 94$ & sc & & & & & & & & & & & & & & & & & & & 320 \\
\hline TRP 27 & $11 / 29 / 94$ & $\mathrm{SC}$ & & & & & & & & & & & & & & & & & & & 320 \\
\hline TRP 28 & $12 / 09 / 94$ & $\mathrm{sc}$ & & & & & & & & & & & & & & & & & & & 331 \\
\hline TRP 29 & $12 / 20 / 94$ & $\mathrm{sc}$ & & & & & & & & & & & & & & & & & & & 324 PS \\
\hline
\end{tabular}


Table C.4. Analytical Methods Used to Characterize Waste Stream Samples

\begin{tabular}{|c|c|c|}
\hline Parameter & Method Number & Basis of Method \\
\hline \multicolumn{3}{|c|}{ General Chemical Parameter } \\
\hline Alkalinity & $310.2^{(2)}$ & Titrimetry \\
\hline Chemical oxygen demand & $410.4^{(a)}$ & Colorimetry \\
\hline Total dissolved solids & $209 B^{(b)}$ & Gravimetry \\
\hline Total carbon & $\mathrm{D2579A}^{(\mathrm{c})}$ & Combustion/infrared absorption \\
\hline Total organic carbon & $9060^{(d)}$ & Combustion/infrared absorption \\
\hline \multicolumn{3}{|c|}{ Ammonia and Anions } \\
\hline Ammonia & D1426C (c) & Colorimetry \\
\hline Cyanide & $9012^{(d)}$ & Colorimetry \\
\hline Sulfides & $9030^{(d)}$ & Titrimetry \\
\hline Other anions & D4327-88(c) & Ion chromatography \\
\hline \multicolumn{3}{|c|}{ Matals: } \\
\hline Arsenic & $7060^{(d)}$ & Atomic absorption \\
\hline Lead & $7421^{(d)}$ & Atomic äbsorption \\
\hline Mercury & $7470^{(d)}$ & Atomic absorption \\
\hline Selenium & $7740^{(d)}$ & Atomic absorption \\
\hline Thallium & $7841^{(d)}$ & Atomic absorption \\
\hline Other metals & $6010^{(d)}$ & Inductively coupled plasma/atomic emission \\
\hline \multicolumn{3}{|c|}{ Organic compounds } \\
\hline Volatile organics & $8240^{(d)}, 502.2^{(e)}$ & Gas chromatography/mass spectrometry \\
\hline Semivolatile organics & $8270^{(d)}$ & Gas chromatography/mass spectrometry \\
\hline Pesticides & $8080^{(d)}$ & Gas chromatography \\
\hline Phenols & $8040^{(d)}$ & Gas chromatography \\
\hline \multicolumn{3}{|c|}{ Radiological Parameters } \\
\hline Gross alpha & $9310^{(d)}$ & Liquid scintillation \\
\hline Gross beta & $9310^{(d)}$ & Liquid scintillation \\
\hline Tritium & $906^{(1)}$ & Liquid scintillation \\
\hline \multicolumn{3}{|c|}{$\begin{array}{l}\text { (a) U.S. Environmental Protection Agency (EPA). 1983. Methods for Chemical Analysis of Water and Wastes, EPA/600/4-79/020, Environmental Monitoring and } \\
\text { Support Laboratory, U.S. Environmental Protection Agency, Cincinnati, Ohio. } \\
\text { (b) American Public Health Association, American Water Works Association, and Water Pollution Control Federation. 1985. Standard Methods for the } \\
\text { Examination of Water and Wastewater, 16th Edition. American Public Health Association, American Water Works Association, and Water Pollution Control } \\
\text { Federation, Washington, D.C. } \\
\text { (c) American Society for Testing and Materials (ASTM). 1986. Annual Book of ASTM Standards, Volume } 11.01 \text { and 11.02. American Society for Testing } \\
\text { Materials, Philadelphia, Pennsylvania. } \\
\text { (d) U.S. Environmental Protection Agency (EPA). 1986. USEPA Methods for Evaluating Solid Waste: Physica//Chemical Methods, SW-846, 3rd ed. Office of } \\
\text { Solid Waste and Emergency Response, U.S. Environmental Protection Agency, Washington, D.C. Note: this method was used for all volatile organic samples } \\
\text { collected before October 1, 1994. } \\
\text { (e) In-house method based on EPA method 502.2 (EPA 1983). This method was used on samples collected between 10/1/94 and 12/31/94. } \\
\text { (f) Krieger, H. L. and E. L. Whittaker. 1980. Section 10, Tritium in Drinking Water, Method 906.O, Prescribed Procedures for Measurement of Radioactivity in } \\
\text { Drinking Water, EPA/600/4-80/032. U.S. Environmental Protection Agency, Cincinnati, Ohio. }\end{array}$} \\
\hline
\end{tabular}


Appendix D

Quality Control Data: Sample Blanks and Duplicate Samples 


\section{Appendix D}

\section{Quality Control Data: Sample Blanks and Duplicate Samples}

The results from the analysis of the quality control blanks and duplicate samples are summarized in this appendix.

\section{D.1 Reagent Blanks}

A comprehensive listing of the analytes that were detected in reagent blanks is shown in Figure D.1. Although the concentrations of reagent blank contaminants were not reported by the analytical service contractors, the frequency at which a chemical is detected in the blanks can indicate the potential for laboratory contamination of fieldcollected samples. Lead and methylene chloride were detected most frequently, appearing in approximately 51 and $77 \%$ of the reagent blanks, respectively. Alkalinity, total carbon, iron, sodium, aluminum, and zinc were also detected in greater than $10 \%$ of the associated reagent blanks. 


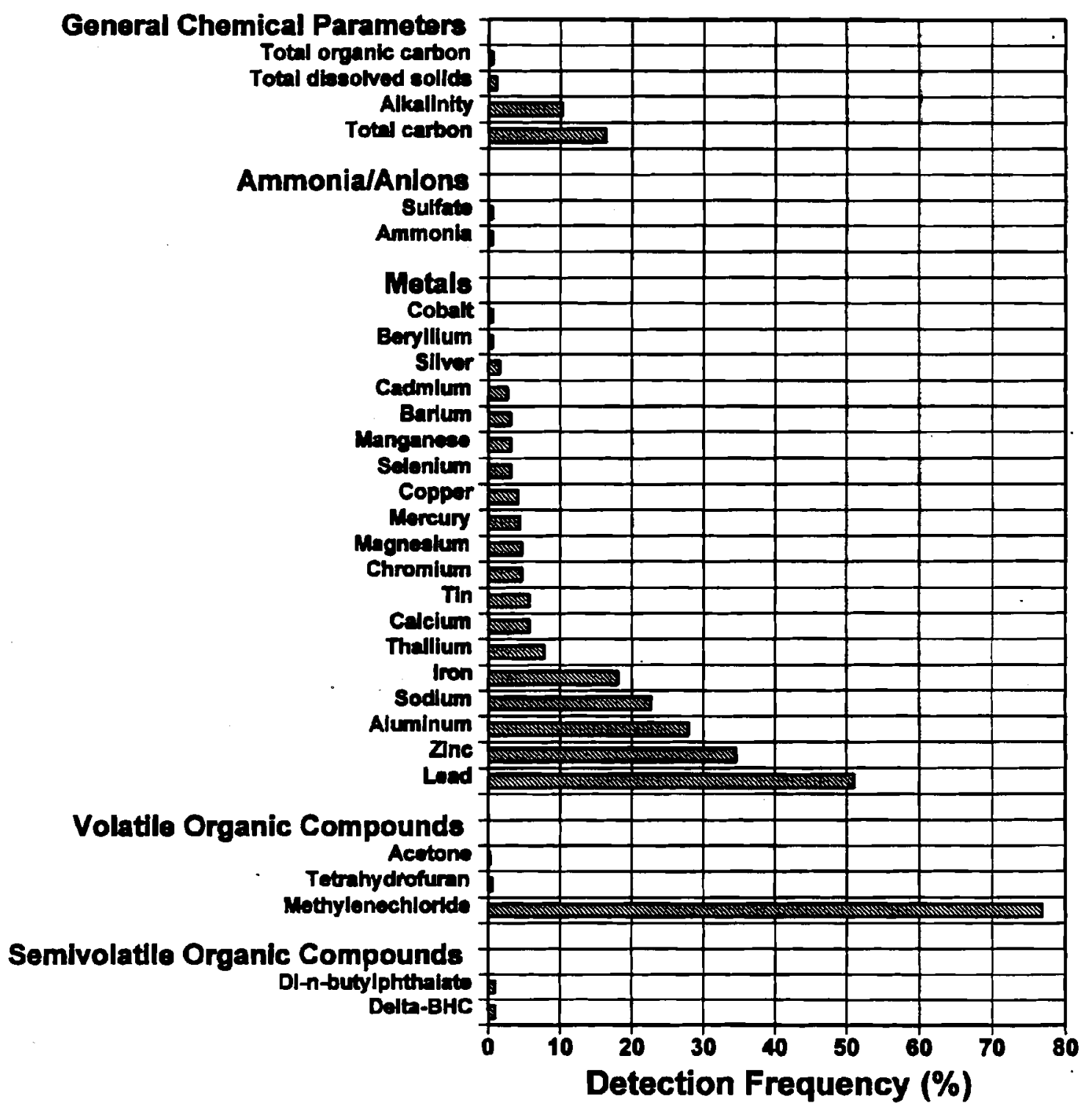

Figure D.1. Laboratory Reagent Blanks

D.2 


\section{D.2 Bottle Blanks}

The results from the analyses of bottle blanks are summarized in Figure D.2. Most of the detected constituents were measured at levels much lower than building effluent concentrations, suggesting minimal bottle contamination. However, sulfides, lead, thallium, and methylene chloride were all measured at concentrations comparable to those found in the effluent samples. Other important results include the frequent detection of iron and zinc, and the low, yet significant concentrations of aluminum, acetone, chloroform, tetrahydrofuran, trichloroethene, and toluene. Chromium was detected at concentrations comparable to some of the effluent samples, but the impact on sample data quality is somewhat diminished by its low frequency of detection (approximately $12 \%$ ). Several constituents le.g., aluminum, iron, lead, sodium, total carbon, zinc, and methylene chloride) were also detected in the reagent blanks, implying some cases of laboratory contamination rather than bottle contamination. For additional information, see Tables D. 1 through D.5.
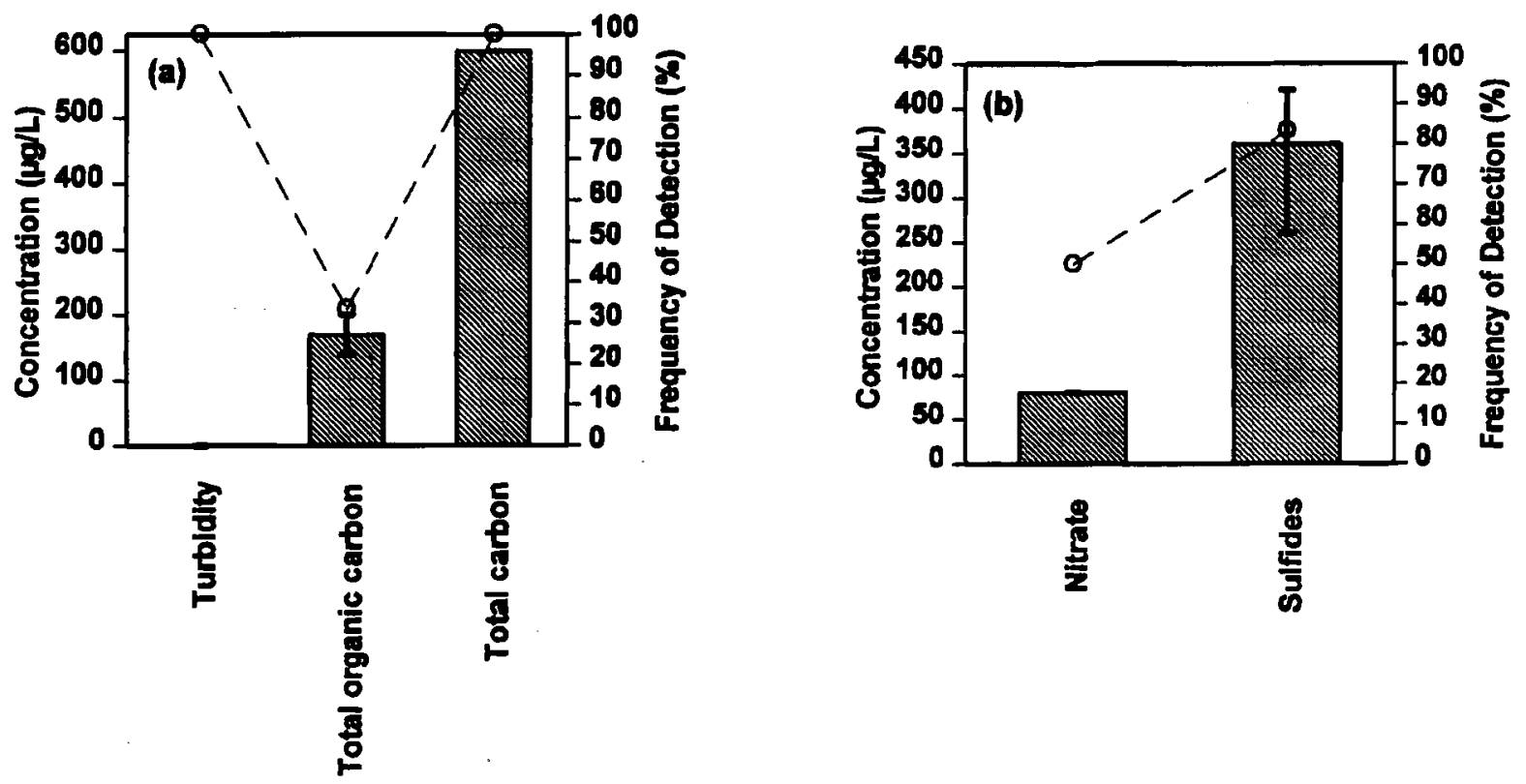

Figure D.2. Concentrations of Parameters and Constituents Found in Bottle Blanks: (a) General Chemical Parameters (Turbidity Average 0.08 NTU, Range 0.08 to 0.09 NTU), (b) Anions, 

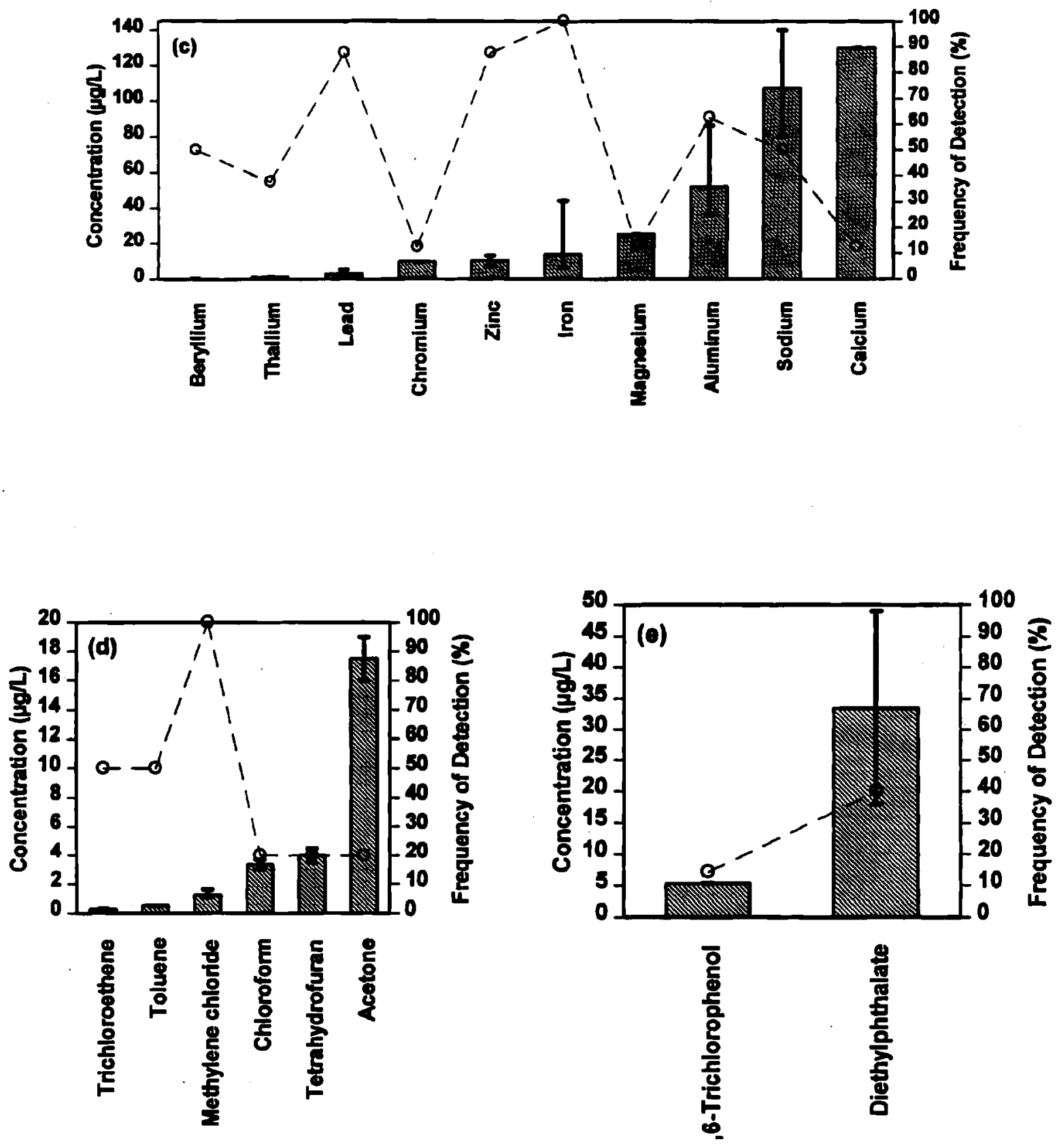

Figure D.2 (contd). Concentrations of Parameters and Constituents Found in Bottle Blanks: (c) Metals (Beryllium Average $0.3 \mu \mathrm{g} / \mathrm{L}$, Range 0.9 to $1.4 \mu \mathrm{g} / \mathrm{L}$; Thallium $1.0 \mu \mathrm{g} / \mathrm{L}$; Range 0.9 to $1.4 \mu \mathrm{g} / \mathrm{L}$ ), (d) Volatile Organic Compounds, (e) Semivolatile Organic Compounds 
Table D.1. Bottle Blanks: General Chemical Parameters

\begin{tabular}{|c|c|c|c|c|}
\hline \multirow[b]{2}{*}{ Parameter } & \multirow[b]{2}{*}{ Frequency ${ }^{(a)}$} & \multicolumn{3}{|c|}{ Concentration $(\mu \mathrm{g} / \mathrm{L})$} \\
\hline & & Range & Average & $\begin{array}{l}\text { Standard } \\
\text { Deviation }\end{array}$ \\
\hline Total carbon & $1 / 1$ & 一 & 600 & - \\
\hline Total organic carbon & $2 / 6$ & $140-200$ & 170 & - \\
\hline Turbidity & $2 / 2$ & $0.08-0.09^{(b)}$ & $0.08^{(b)}$ & - \\
\hline
\end{tabular}

Table D.2. Bottle Blanks: Ammonia and Anions

\begin{tabular}{||l|c|c|c|c||}
\hline \multirow{2}{*}{\begin{tabular}{l} 
Constituent \\
\cline { 3 - 5 }
\end{tabular}} & \multirow{2}{*}{ Frequency $^{(\mathrm{a})}$} & \multicolumn{2}{c|}{ Concentration $(\mu \mathrm{g} / \mathrm{L})$} \\
\cline { 3 - 5 } & & Range & Average & $\begin{array}{c}\text { Standard } \\
\text { Deviation }\end{array}$ \\
\hline Nitrate & $1 / 2$ & - & 80 & - \\
\hline Sulfides & $5 / 6$ & $260-420$ & 360 & 68 \\
\hline \hline
\end{tabular}

(a) Number of samples with detectable concentrations/total number of samples analyzed.

Table D.3. Bottle Blanks: Metals

\begin{tabular}{||l|c|c|c|c||}
\hline \multirow{2}{*}{ Constituent } & \multirow{2}{*}{ Frequency $^{(a)}$} & \multicolumn{3}{c|}{ Concentration $(\mu \mathrm{g} / \mathrm{L})$} \\
\cline { 3 - 5 } & & Range & Average & $\begin{array}{c}\text { Standard } \\
\text { Deviation }\end{array}$ \\
\hline Aluminum & $5 / 8$ & $36-86$ & 52 & 20 \\
\hline Beryllium & $4 / 8$ & $0.3-0.4$ & 0.3 & 0.1 \\
\hline Calcium & $1 / 8$ & - & 130 & - \\
\hline Chromium & $1 / 8$ & - & 10 & - \\
\hline Iron & $8 / 8$ & $6-44$ & 14 & 12 \\
\hline Lead & $7 / 8$ & $2.0-5.4$ & 3 & 1 \\
\hline Magnesium & $1 / 8$ & - & 25 & - \\
\hline Sodium & $4 / 8$ & $80-140$ & 108 & 25 \\
\hline Thallium & $3 / 8$ & $0.9-1.4$ & 1 & 0.3 \\
\hline Zinc & $7 / 8$ & $7-13$ & 11 & 2 \\
\hline \hline Ta) Number & & & & -13 \\
\hline
\end{tabular}

(a) Number of samples with detectable concentrations/total number of samples analyzed. 
Table D.4. Bottle Blanks: Volatile Organic Compounds

\begin{tabular}{|c|c|c|c|c|}
\hline \multirow[b]{2}{*}{ Constituent } & \multirow[b]{2}{*}{ Frequency $^{(a)}$} & \multicolumn{3}{|c|}{ Concentration $(\mu \mathrm{g} / \mathrm{L})$} \\
\hline & & Range & Average & $\begin{array}{l}\text { Standard } \\
\text { Deviation }\end{array}$ \\
\hline Acetone & $2 / 10$ & $16-19$ & 17.5 & - \\
\hline Chloroform & $2 / 10$ & $3.0-3.7$ & 3.4 & - \\
\hline Methylene chloride & $10 / 10$ & $1.1-1.6$ & 1.2 & 0.2 \\
\hline Tetrahydrofuran & $2 / 10$ & $3.5-4.5$ & 4.0 & - \\
\hline Toluene & $1 / 10$ & - & 0.5 & - \\
\hline Trichloroethene & $1 / 10$ & - & 0.3 & - \\
\hline
\end{tabular}

(a) Number of samples with detectable concentrations/total number of samples analyzed.

Table D.5. Bottle Blanks: Semivolatile Organic Compounds

\begin{tabular}{|c|c|c|c|c|}
\hline \multirow[b]{2}{*}{ Constituent } & \multirow[b]{2}{*}{ Frequency $^{(a)}$} & \multicolumn{3}{|c|}{ Concentration $(\mu \mathrm{g} / \mathrm{L})$} \\
\hline & & Range & Average & $\begin{array}{l}\text { Standard } \\
\text { Deviation }\end{array}$ \\
\hline Diethylphthalate & $2 / 5$ & $18-49$ & 34.0 & - \\
\hline 2,4,6-Trichlorophenol & $1 / 7$ & - & 5.3 & - \\
\hline
\end{tabular}

(a) Number of samples with detectable concentrations/total number of samples analyzed.

\section{D.3 Equipment Blanks}

The results from the analyses of the three equipment blanks are summarized in Figure D.3. The most significant results were obtained on a few metals and volatile organic compounds. Chromium, lead, manganese, and vanadium were each identified at concentrations similar to the levels observed in building effluents. Likewise, the volatile organic compounds methylene chloride and tetrahydrofuran were also measured at levels near those observed in effluent samples. Less substantial levels of nitrate, chemical oxygen demand, and chloroform were also observed in the equipment blanks. For additional information, see Tables D.6 through D.10. 

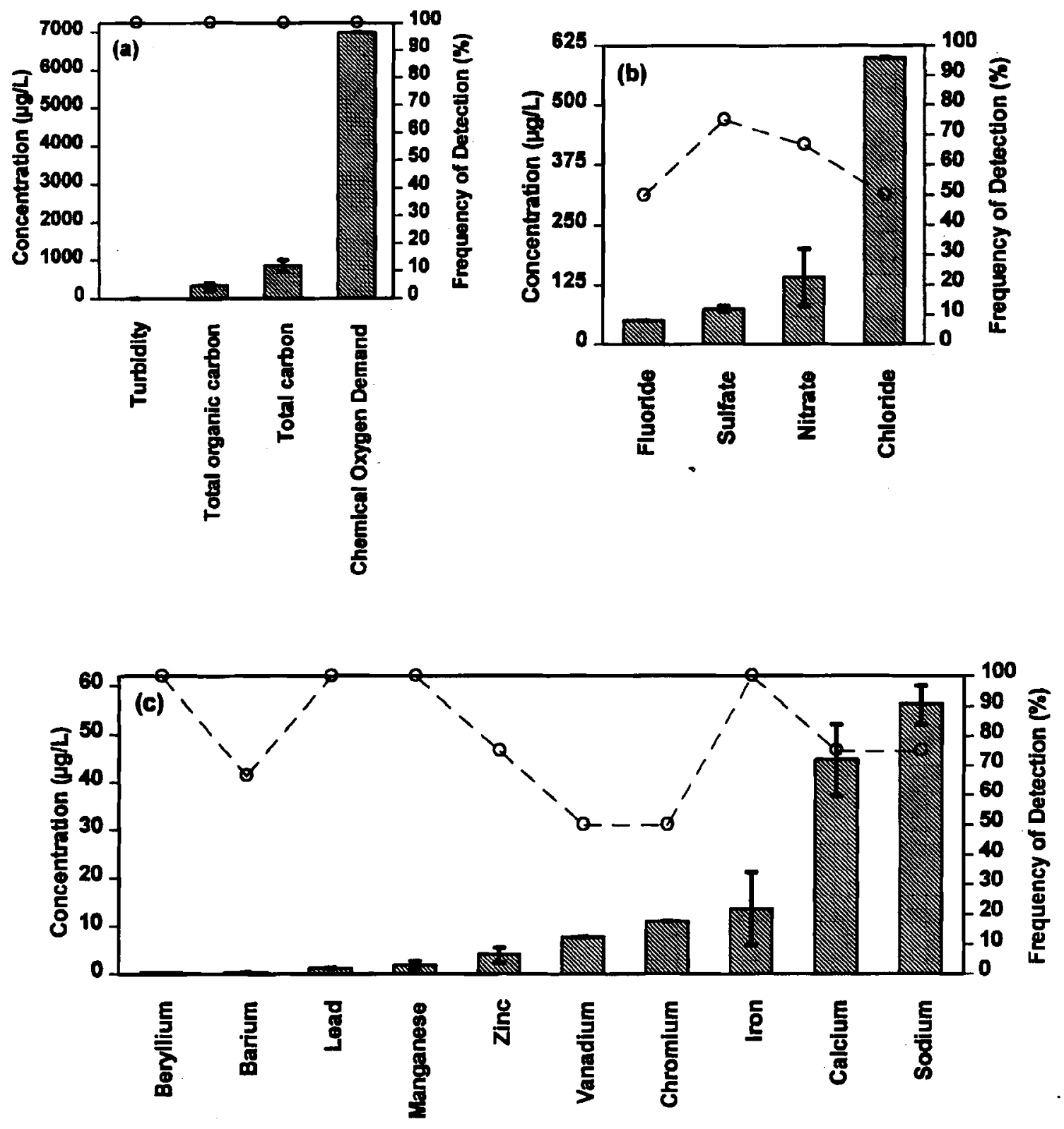

Figure D.3. Concentrations of Parameters and Constituents Found in Equipment Blanks: (a) General Chemical Parameters (Turbidity Average 0.05 NTU, Range N/A), (b) Anions, (c) Metals (Beryllium Average $0.3 \mu \mathrm{g} / \mathrm{L}$, Range N/A) 


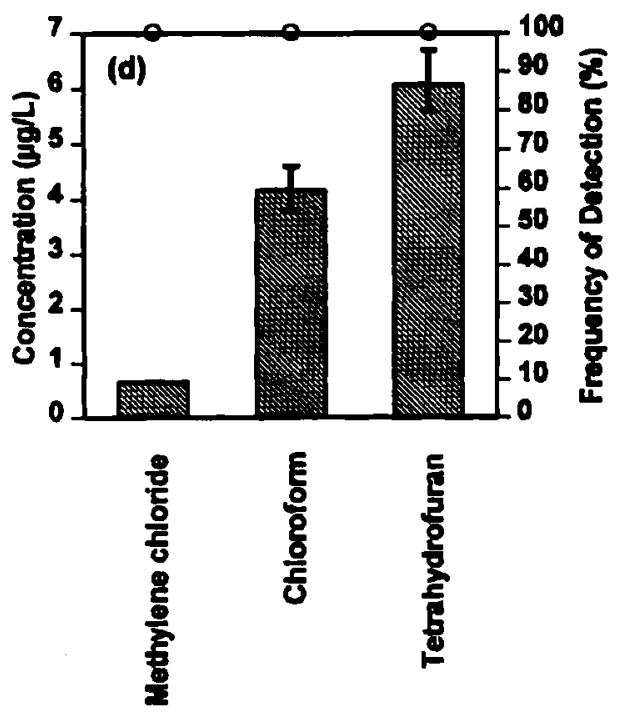

Figure D.3 (contd). Concentrations of Parameters and Constituents Found in Equipment Blanks: (d) Volatile Organic Compounds 
Table D.8. Equipment Blanks: Metals

\begin{tabular}{|c|c|c|c|c|}
\hline \multirow[b]{2}{*}{ Constituent } & \multirow[b]{2}{*}{ Frequency ${ }^{(a)}$} & \multicolumn{3}{|c|}{ Concentration $(\mu \mathrm{g} / \mathrm{L})$} \\
\hline & & Range & Average & $\begin{array}{l}\text { Standard } \\
\text { Deviation }\end{array}$ \\
\hline Barium & $2 / 3$ & - & 0.5 & - \\
\hline Beryllium & $1 / 1$ & - & 0.3 & - \\
\hline Calcium & $3 / 4$ & $37-52$ & 45 & 7.5 \\
\hline Chromium & $1 / 2$ & - & 11 & - \\
\hline Iron & $2 / 2$ & $6-21$ & 14 & - \\
\hline Lead & $1 / 1$ & - & 1.3 & - \\
\hline Manganese & $2 / 2$ & $1-3$ & 2 & - \\
\hline Sodium & $3 / 4$ & $52-60$ & 56 & 4 \\
\hline Vanadium & $1 / 2$ & - & 8 & - \\
\hline Zinc & $3 / 4$ & $2-6$ & 4 & 2 \\
\hline
\end{tabular}

Table D.9. Equipment Blanks: Volatile Organic Compounds

\begin{tabular}{|c|c|c|c|c|}
\hline \multirow[b]{2}{*}{ Constituent } & \multirow[b]{2}{*}{ Frequency ${ }^{(a)}$} & \multicolumn{3}{|c|}{ Concentration $(\mu \mathrm{g} / \mathrm{L})$} \\
\hline & & Range & Average & $\begin{array}{l}\text { Standard } \\
\text { Deviation }\end{array}$ \\
\hline Chloroform & $3 / 3$ & $3.8-4.6$ & 4.2 & 0.4 \\
\hline Methylene chloride & $1 / 1$ & - . & 0.7 & - \\
\hline Tetrahydrofuran & $3 / 3$ & $5.6-6.7$ & 6.1 & 0.6 \\
\hline
\end{tabular}

(a) Number of samples with detectable concentrations/total number of samples analyzed.

Table D.10. Equipment Blanks: Radiological Parameters

\begin{tabular}{|c|c|c|c|c|}
\hline \multirow{2}{*}{ Parameter } & \multirow{2}{*}{ Frequency ${ }^{(a)}$} & \multicolumn{3}{|c|}{ Concentration (pCi/L) } \\
\hline & & Range & Average & $2 \mathrm{SEM}^{(\mathrm{b})}$ \\
\hline Gross beta & $1 / 3$ & - & 2.3 & - \\
\hline
\end{tabular}




\section{D.4 Field-Transfer Blanks}

The results from the analyses of the field-transfer blanks are summarized in Figure D.4. The concentrations of acetone and methylene chloride are significant when compared to some of the building effluent sample concentrations. Acetone, which was detected in a Building 331 transfer blank, was also measured at approximately the same concentration in the associated Building 331 effluent sample. Thus, acetone vapors may have been present at the Building 331 sampling site when the two samples were collected. The frequent detection of methylene chloride in the reagent blanks suggests laboratory contamination was the source of this constituent. For additional information, see Table D.11.

Table D.11. Field-Transfer Blanks: Volatile Organic Compounds

\begin{tabular}{|c|c|c|c|c|}
\hline \multirow[b]{2}{*}{ Constituent } & \multirow[b]{2}{*}{ Frequency ${ }^{(\mathbf{a})}$} & \multicolumn{3}{|c|}{ Concentration $(\mu \mathrm{g} / \mathrm{L})$} \\
\hline & & Range & Average & $\begin{array}{l}\text { Standard } \\
\text { Deviation }\end{array}$ \\
\hline Acetone & $2 / 11$ & - & 21.0 & - \\
\hline Methylene chloride & $8 / 10$ & $0.4-1.2$ & 0.8 & 0.4 \\
\hline Toluene & $1 / 10$ & - & 0.2 & - \\
\hline
\end{tabular}

(a) Number of samples with detectable concentrations/total number of samples analyzed.

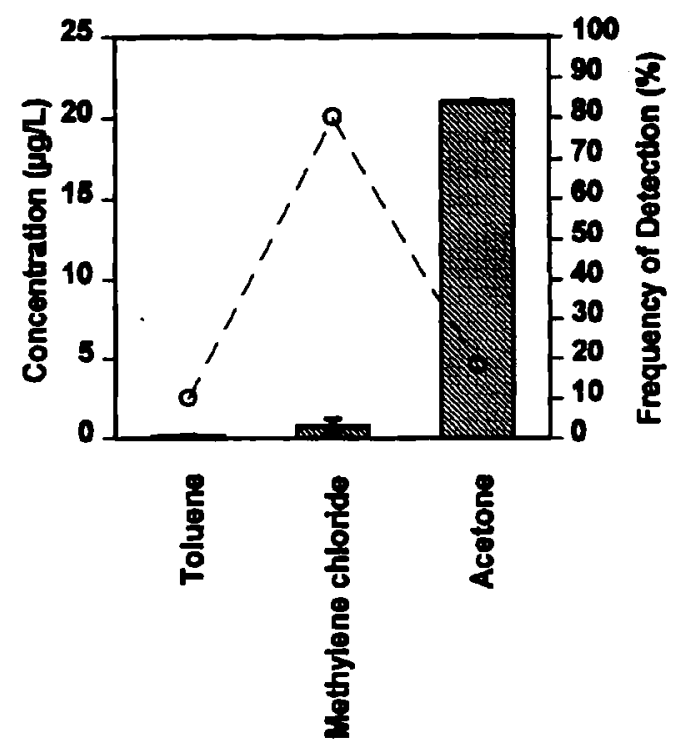

Figure D.4. Concentrations of Parameters and Constituents Found in Transfer Blanks (Toluene Average $0.2 \mu \mathrm{g} / \mathrm{L}$, Range N/A) 


\section{D.5 Full-and Daily-Trip Blanks}

The results from the analyses of the full- and daily-trip blanks are summarized in Figure D.5. None of the general chemical parameters were measured in significant quantities. Aluminum, chromium, iron, lead, and nickel were measured at notable concentrations. Of these metals, aluminum, iron, and lead were also measured in the associated effluent samples from Buildings 320, 331, 3720, and end-of-pipe. However, because these metals were frequently detected in the reagent blanks, laboratory contamination is probably their source. Sulfides (not shown) were also measured in $80 \%$ of the full-trip blanks at relatively low levels (290 $\mu \mathrm{g} / \mathrm{L})$.

Low concentrations of acetone, chloroform, methylene chloride, and tetrahydrofuran were observed in both the full and daily trip blanks. Acetone was detected at the highest concentrations and was also observed in an associated Building 3720 sample. Chloroform and methylene chloride were also detected in both the blanks and the corresponding building-effluent samples. However, laboratory contamination is suspected as the source of methylene chloride in these and most of the effluent samples. For additional information, see Tables D.12 through D.15.

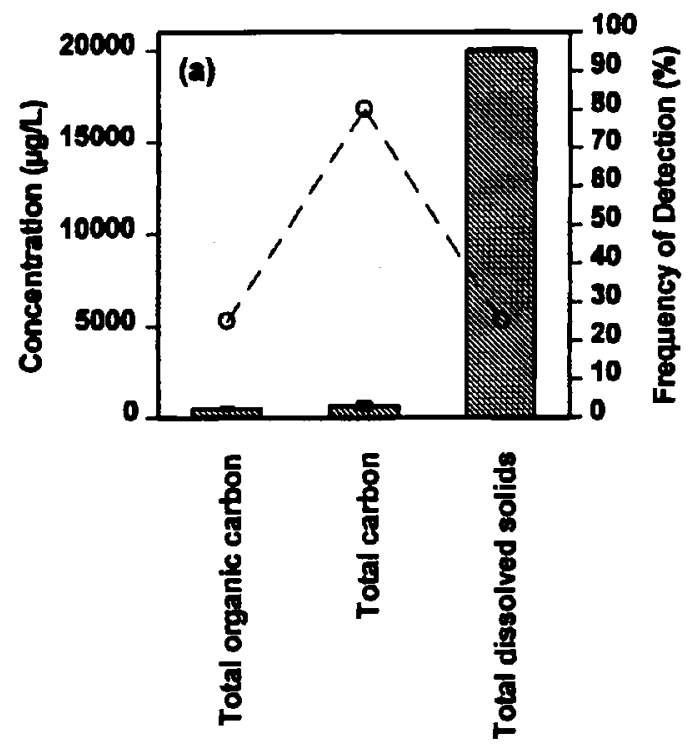

Figure D.5. Concentrations of Parameters and Constituents Found in Full and Daily Trip Blanks (a) Full-Trip Blanks General Chemical Parameters 

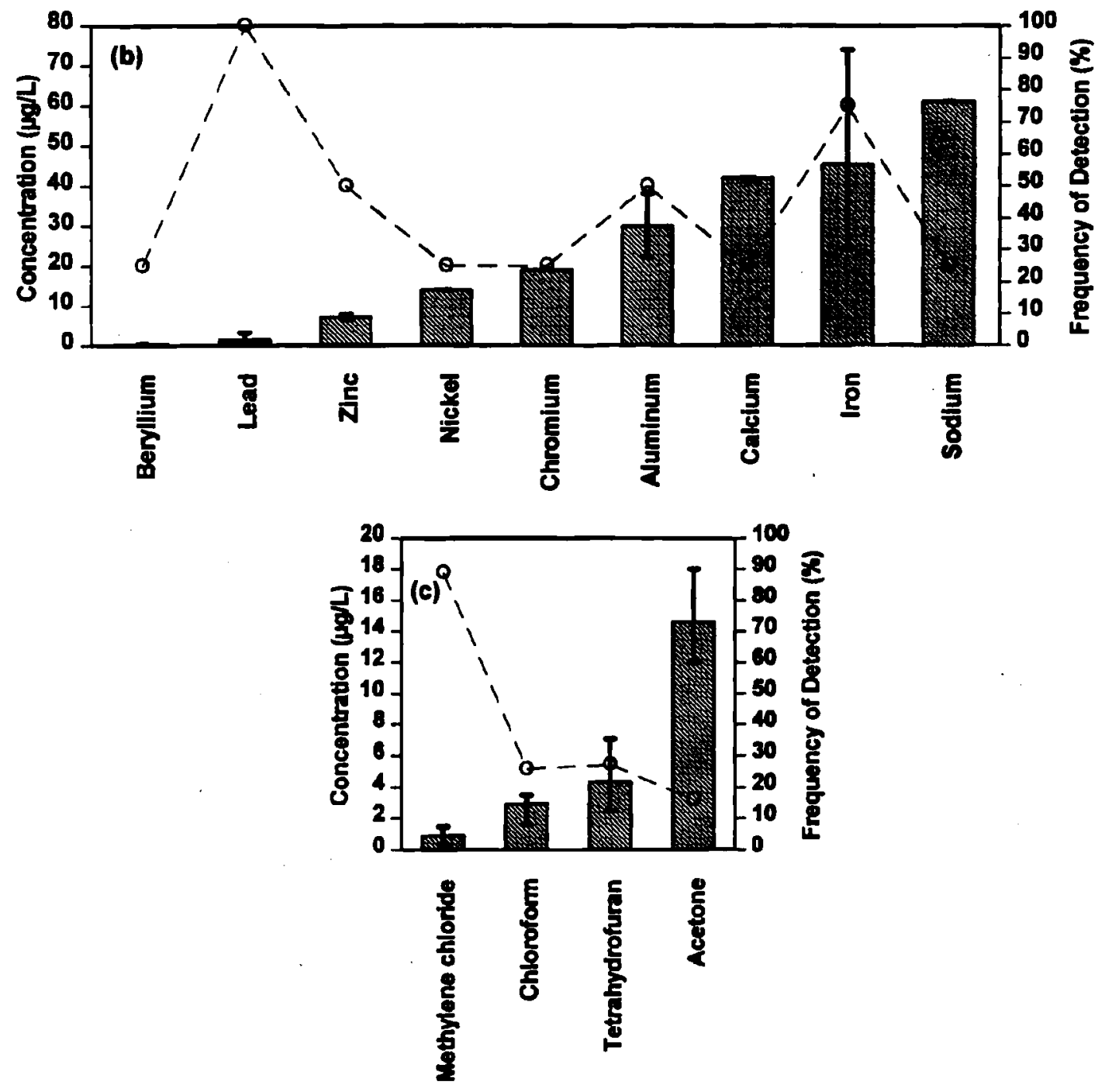

Figure D.5. Concentrations of Parameters and Constituents Found in Full and Daily Trip Blanks (b) Full-Trip Blanks Metals (Beryllium Average $0.3 \mu \mathrm{g} / \mathrm{L}$, Range N/A), (c) Full and Daily Trip Blanks Volatile Organic Compounds 
Table D.12. Full-Trip Blanks: General Chemical Parameters

\begin{tabular}{||l|c|c|c|c||}
\hline \multirow{2}{*}{\multicolumn{1}{|c|}{ Parameter }} & \multirow{2}{*}{ Frequency $^{(a)}$} & \multicolumn{2}{c|}{ Concentration $(\mu \mathrm{g} / \mathrm{L})$} \\
\cline { 3 - 5 } & & Range & Average & $\begin{array}{c}\text { Standard } \\
\text { Deviation }\end{array}$ \\
\hline Total carbon & $4 / 5$ & $500-800$ & 650 & 129 \\
\hline Total dissolved solids & $1 / 4$ & - & 20000 & - \\
\hline Total organic carbon & $1 / 4$ & - & 500 & - \\
\hline \hline
\end{tabular}

Table D.13. Full-Trip Blanks: Ammonia and Anions

\begin{tabular}{|c|c|c|c|c|}
\hline \multirow[b]{2}{*}{ Constituent } & \multirow[b]{2}{*}{ Frequency $^{(a)}$} & \multicolumn{3}{|c|}{ Concentration $(\mu \mathrm{g} / \mathrm{L})$} \\
\hline & & Range & Average & $\begin{array}{l}\text { Standard } \\
\text { Deviation }\end{array}$ \\
\hline Sulfides & $4 / 5$ & $200-400$ & 290 & 84 \\
\hline
\end{tabular}

(a) Number of samples with detectable concentrations/total number of samples analyzed.

Table D.14. Full-Trip Blanks: Metals

\begin{tabular}{||l|c|c|c|c||}
\hline \multirow{2}{*}{ Constituent } & \multirow{2}{*}{ Frequency $^{(\mathrm{a})}$} & \multicolumn{2}{c|}{ Concentration $(\mu \mathrm{g} / \mathrm{L})$} \\
\cline { 3 - 5 } & & Range & Average & $\begin{array}{c}\text { Standard } \\
\text { Deviation }\end{array}$ \\
\hline Aluminum & $2 / 4$ & $22-38$ & 30 & - \\
\hline Beryllium & $1 / 4$ & - & 0.3 & - \\
\hline Calcium & $1 / 4$ & - & 42 & - \\
\hline Chromium & $1 / 4$ & - & 19 & - \\
\hline Iron & $3 / 4$ & $24-74$ & 45 & 26 \\
\hline Lead & $5 / 5$ & $0.6-3.2$ & 1.5 & 1.1 \\
\hline Nickel & $1 / 4$ & - & 14 & - \\
\hline Sodium & $1 / 4$ & - & 61 & - \\
\hline Zinc & $2 / 4$ & $7-8$ & 7 & - \\
\hline \hline Ta) & & - & - & - \\
\hline
\end{tabular}

(a) Number of samples with detectable concentrations/total number of samples analyzed. 
Table D.15. Full-Trip and Daily-Trip Blanks: Volatile Organic Compounds

\begin{tabular}{|c|c|c|c|c|}
\hline \multirow[b]{2}{*}{ Constituent } & \multirow[b]{2}{*}{ Frequency $^{(a)}$} & \multicolumn{3}{|c|}{ Concentration ( $\mu \mathrm{g} / \mathrm{L})$} \\
\hline & & Range & Average & $\begin{array}{l}\text { Standard } \\
\text { Deviation }\end{array}$ \\
\hline Acetone & $5 / 31$ & $12.0-18.0$ & 14.6 & 2.2 \\
\hline Chloroform & $8 / 31$ & $1.6-3.5$ & 2.9 & 0.7 \\
\hline Methylene chloride & $24 / 27$ & $0.4-1.5$ & 0.9 & 0.4 \\
\hline Tetrahydrofuran & $9 / 33$ & $2.5-7.1$ & 4.4 & 1.5 \\
\hline
\end{tabular}

(a) Number of samples with detectable concentrations/total number of samples analyzed.

\section{D.6 Duplicate Samples}

A total of seven duplicate samples were collected and analyzed during CY 1994 to assess analytical laboratory reproducibility. However, because of the limited sample volume obtainable from the composite samplers, not all constituent classes were analyzed for in any given pair of duplicate samples. Figure D.6 summarizes the analytical results for each compound class.

The primary information in this figure is the average of the relative percent differences (RPDs) calculated from all of the matching pairs of results for each analyte. This is indicated by the height of each column. In other words, the height of each column represents the significance of the differences found between the matching results. The black diamond over the analyte name indicates how close the average concentration is to the method detection limit (MDL). A value of one or higher indicates that the average concentration was equal to or less than the MDL. For analytes measured at trace concentrations (i.e., near the MDL), the chance for false detection is higher, and the measurement reproducibility is lower. Thus, the measurement precision of parameters or constituents in Figure D.6 with a high RPD and a low MDL to average-concentration ratio are of the most concern.

For most analytes, the average RPD was $25 \%$ or less (i.e., fairly low). However, seven metals, four organic compounds, and two radiological parameters had average RPDs greater than $25 \%$. The metals iron, potassium, manganese, tin, arsenic, nickel, and silver, showed significant variability, although the latter four were measured near their MDLs. The source of the lower precision associated with the iron, potassium, and manganese measurements is unknown but may be caused by sample contamination, measurement interferences, or poor analytical technique. Carbon disulfide, bis(2-ethylhexyl)phthalate, di-n-butylphthalate, and gamma-BHC all had RPDs of $100 \%$, but carbon disulfide was the only organic constituent which exhibited a low precision at concentrations well above the MDL. All three of the radiological parameters had average concentrations within a factor 
of 1.5 of the MDLs; this appears to account for the high RPDs for gross alpha (31.8\%) and gross beta $(42.2 \%)$.

Overall, these results suggest that the level of precision associated with CY 1994 analytical measurements on effluent samples should not have a significant impact on data interpretation. However, these results illustrate the lower precision associated with analytes frequently measured at trace levels, such as metals, pesticides, and radiological parameters. Additional caution should be applied when drawing conclusions from such results. Tabulated information on the duplicate samples' results can be found in Table D.16.

Table D.16. Summary of Duplicate Sample Results

\begin{tabular}{|c|c|c|c|}
\hline Compound & $\begin{array}{l}\text { Number of } \\
\text { Duplicates }^{\text {(a) }}\end{array}$ & $\begin{array}{c}\text { Average } \\
\left.\text { Difference }{ }^{(b)}\right) \\
(\mu \mathrm{g} / \mathrm{L})\end{array}$ & $\begin{array}{c}\text { Average } \\
\text { RPD }\end{array}$ \\
\hline \multicolumn{4}{|c|}{ General Chemical Parameters } \\
\hline Alkalinity & 5 & 200 & 0.4 \\
\hline Chemical Oxygen Demand & 3 & 1000 & 11.9 \\
\hline Total carbon & 3 & 333 & 2.5 \\
\hline Total dissolved solids & 2 & 0 & 0 \\
\hline Total organic carbon & 4 & 0 & 0 \\
\hline \multicolumn{4}{|c|}{ Ammonia and Anions } \\
\hline Ammonia & 1 & 0 & 0 \\
\hline Chloride & 5 & 80 & 1.5 \\
\hline Cyanide & 1 & 0 & 0.0 \\
\hline Fluoride & 5 & 20 & 3.6 \\
\hline Nitrate & 5 & 40 & 1.4 \\
\hline Phosphate & 1 & 200 & 8.7 \\
\hline Sulfate & 5 & 200 & 1.9 \\
\hline \multicolumn{4}{|c|}{ Metals } \\
\hline Aluminum & 6 & 27.2 & 14.8 \\
\hline Arsenic & 1 & 2.0 & 100.0 \\
\hline Barium & 6 & 1.2 & 5.0 \\
\hline Calcium & 6 & 833.3 & 3.4 \\
\hline
\end{tabular}


Table D.16. (contd)

\begin{tabular}{|c|c|c|c|}
\hline Compound & $\begin{array}{l}\text { Number of } \\
\text { Duplicates }^{(\mathrm{a})}\end{array}$ & $\begin{array}{c}\text { Average }^{(1)} \\
\text { Difference }^{(\mathrm{b})} \\
(\mu \mathrm{g} / \mathrm{L})\end{array}$ & $\begin{array}{c}\text { Average } \\
\text { RPD }^{(c)}\end{array}$ \\
\hline Chromium & 1 & 3.0 & 14.6 \\
\hline Copper & 6 & 3.1 & 17.5 \\
\hline Iron & 5 & 40.2 & 27.1 \\
\hline Lead & 6 & 0.5 & 20.7 \\
\hline Magnesium & 6 & 233.3 & 4.7 \\
\hline Manganese & 5 & 1.3 & 50.9 \\
\hline Mercury & 1 & 0.03 & 10.2 \\
\hline Nickel & 1 & 17.00 & 100.0 \\
\hline Potassium & 6 & 383.3 & 27.9 \\
\hline Silver & 1 & 3.6 & 100.0 \\
\hline Sodium & 6 & 283.3 & 5.6 \\
\hline Tin & 2 & 22.0 & 63.3 \\
\hline Zinc & 6 & 6.0 & 10.9 \\
\hline \multicolumn{4}{|c|}{ Volatile Organic Compound } \\
\hline Acetone & 1 & 3.0 & 8.5 \\
\hline Carbon disulfide & 1 & 2.5 & 100.0 \\
\hline Chloroform & 6 & 0.6 & 4.1 \\
\hline Methylene chloride & 5 & 0.04 & 8.0 \\
\hline Trichloroethene & 1 & 0.1 & 6.5 \\
\hline \multicolumn{4}{|c|}{ Semivolatile Organic Compounds } \\
\hline Beta-BHC & 1 & 0.000 & 1.0 \\
\hline Bis(2-ethylhexyl) phthalate & 1 & 3.6 & 100.0 \\
\hline Delta-BHC & 1 & 0.001 & 11.5 \\
\hline Di-n-butylphthalate & 2 & 3.9 & 100.0 \\
\hline Gamma-BHC & 1 & 0.002 & 100.0 \\
\hline
\end{tabular}


Table D.16. (contd)

\begin{tabular}{|c|c|c|c|}
\hline Compound & $\begin{array}{c}\text { Number of } \\
\text { Duplicates }^{(a)}\end{array}$ & $\begin{array}{c}\text { Average } \\
\text { Difference }^{(b)} \\
(\mu \mathrm{g} / \mathrm{L})\end{array}$ & $\begin{array}{l}\text { Average } \\
\text { RPD }^{(c)}\end{array}$ \\
\hline \multicolumn{4}{|c|}{ Radiological Parameters } \\
\hline Gross alpha (pCi/L) & 3 & 1.4 & 31.8 \\
\hline Gross beta (pCi/L) & 3 & 1.9 & 42.2 \\
\hline Tritium (pCi/L) & 1 & 50 & 16.4 \\
\hline \multicolumn{4}{|c|}{$\begin{array}{l}\text { (a) Number of duplicate results with a positive detect in at least one of the two } \\
\text { samples. } \\
\text { (b) Average of the absolute values of the differences calculated from each pair } \\
\text { of duplicate results. } \\
\text { (c) Average of the relative percent differences calculated from each pair of } \\
\text { duplicate results. }\end{array}$} \\
\hline
\end{tabular}



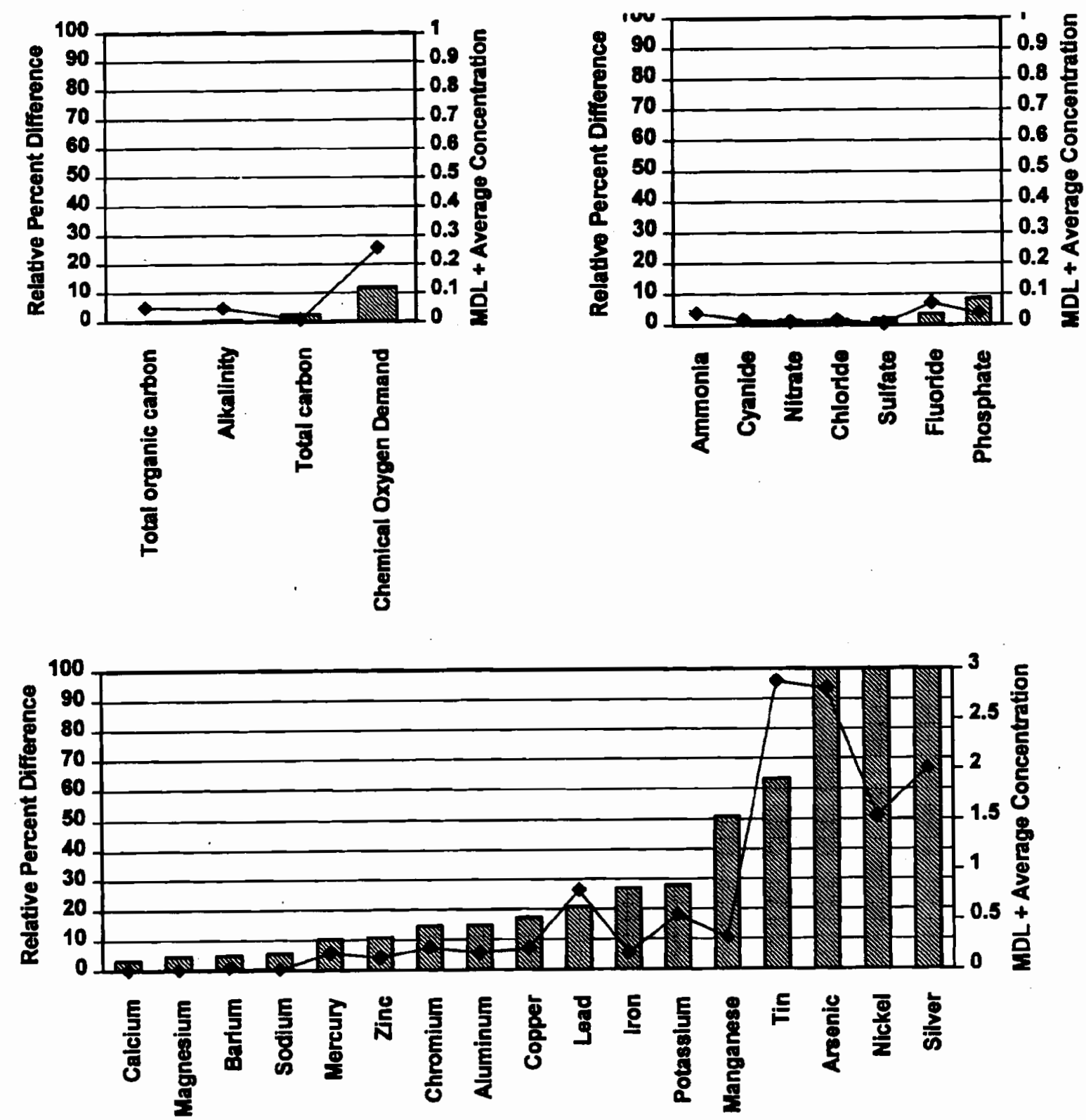

Figure D.6. Concentrations of Parameters and Constituents Found in Duplicates: (a) General Chemical Parameters (Total Organic Carbon RPD $=0$; Alkalinity RPD $=0.4$ ), (b) Ammonia and Anions (Ammonia RPD $=0$; Cyanide RPD $=0$ ), (c) Metals 

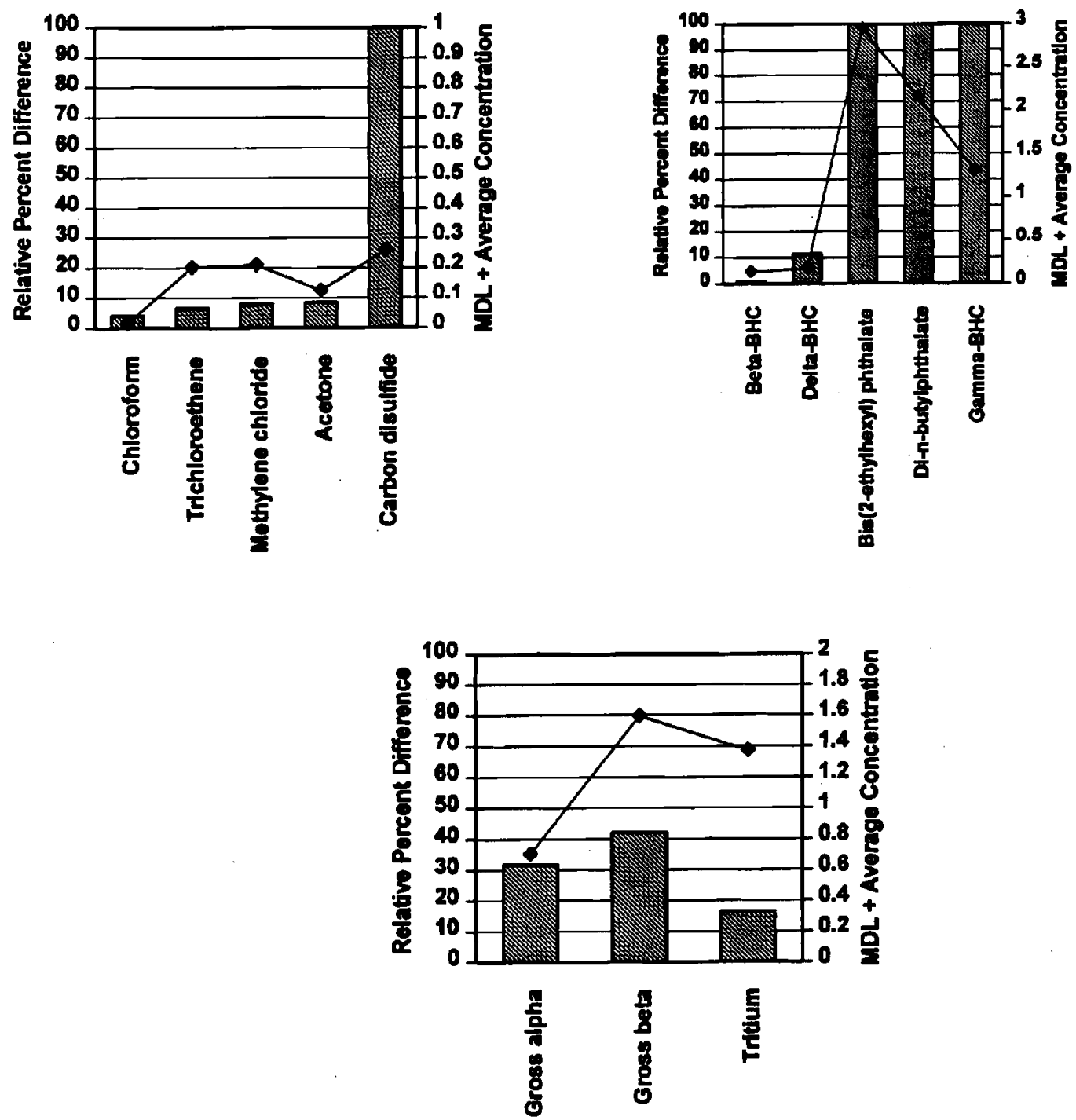

Figure D.6 (cond). Concentrations of Parameters and Constituents Found in Duplicates: (d) Volatile Organic Compounds, (e) Semivolatile Organic Compounds (Beta-BHC RPD $=1.0$ ), (f) Radiological Parameters 



\section{Appendix E}

Data on Influent Water Chemistry 


\section{Appendix E}

\section{Data on Influent Water Chemistry}

This appendix provides additional detailed information about the untreated, treated, and alternate influents. The figures and tables are organized into the same groupings as the chapters: general chemical parameters (Figures E.1 through E.3, and Tables E. 1 through E.3), ammonia and anions (Figures E.4 through E.6, and Tables E.4 through E.6), metals (Figures E.7 through E.9, and Tables E.7 through E.9), volatile organic compounds (Figures E.10 through E.12, and Tables E.10 through E.12) and semivolatile organic compounds (Figure E.13 and Table E.13). Radiological analyses were not performed on influent samples. 


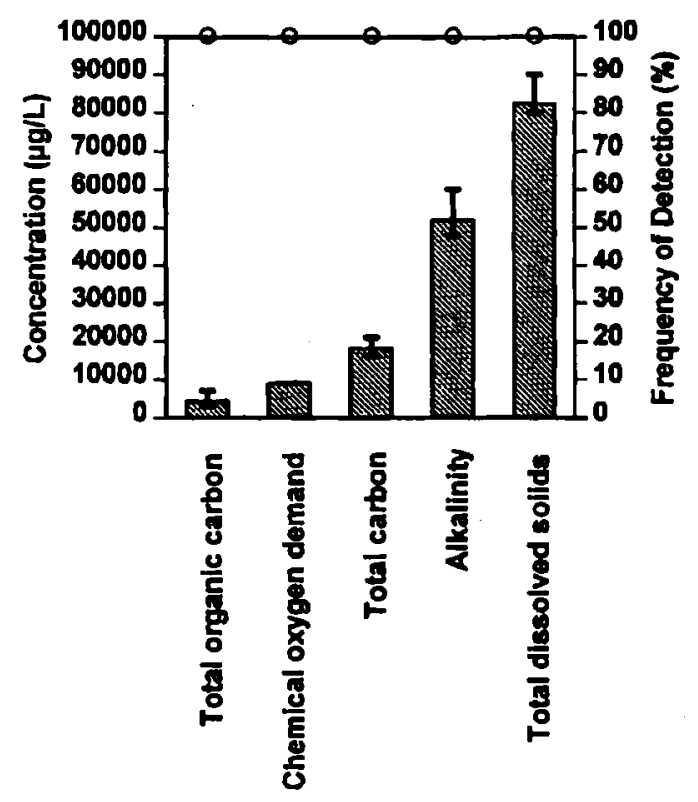

Figure E.1. Untreated Influent General Chemical Parameters

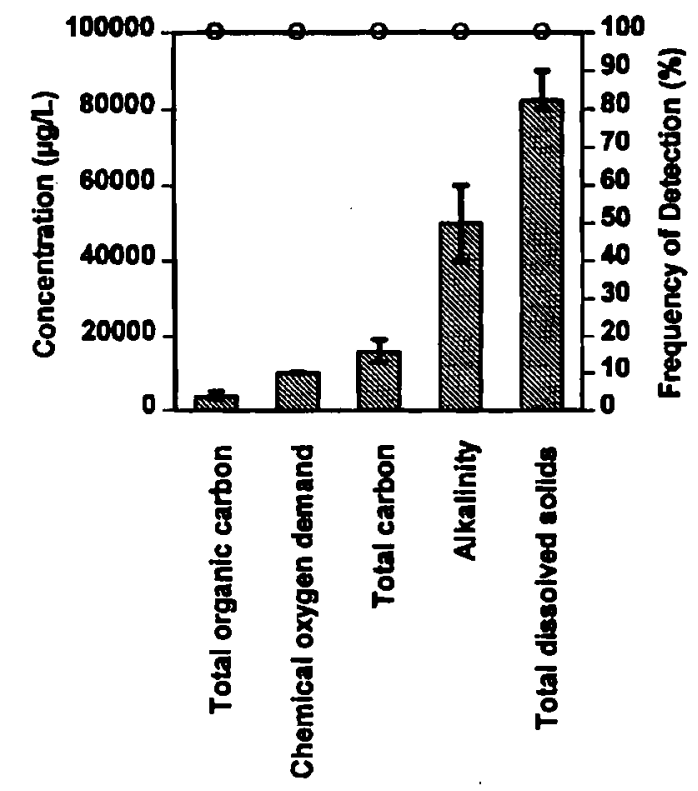

Figure E.2. Treated Influent General Chemical Parameters

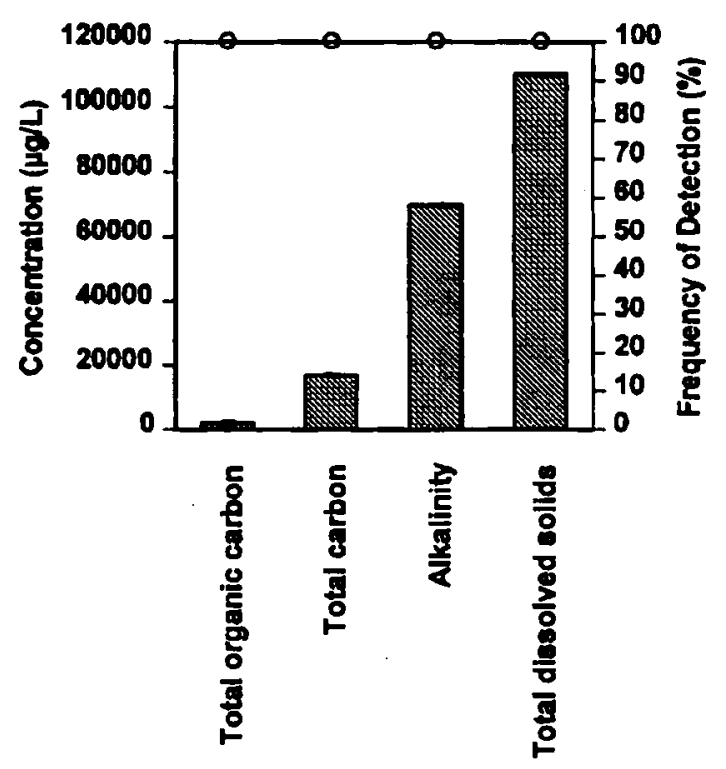

Figure E.3. Alternate Influent General Chemical Parameters 
Table E.1. Untreated Influent: General Chemical Parameters

\begin{tabular}{||l|c|c|c|c||}
\hline \multirow{2}{*}{ Parameter } & \multirow{2}{*}{ Frequency } & \multicolumn{3}{c|}{ Concentration $(\mu \mathrm{g} / \mathrm{L})$} \\
\cline { 3 - 5 } & & Range & Average & $\begin{array}{c}\text { Standard } \\
\text { Deviation }\end{array}$ \\
\cline { 3 - 5 } & $4 / 4$ & $48000-60000$ & 52000 & 5000 \\
\hline Alkalinity & $1 / 1$ & - & 9000 & - \\
\hline Chemical Oxygen Demand & $5 / 5$ & $16000-21000$ & 18200 & 2280 \\
\hline Total carbon & $4 / 4$ & $80000-90000$ & 82500 & 5000 \\
\hline Total dissolved solids & $5 / 5$ & $3000-7000$ & 4400 & 1517 \\
\hline Total organic carbon & $\begin{array}{l}\text { Number of samples with detectable concentrations/total number of samples } \\
\text { analyzed. }\end{array}$ \\
\hline \hline
\end{tabular}

Table E.2. Treated Influent: General Chemical Parameters

\begin{tabular}{||l|c|c|c|c||}
\hline \multirow{2}{*}{ Parameter } & \multirow{2}{*}{ Frequency } & \multicolumn{2}{c|}{ Concentration ( $\mu \mathrm{g} / \mathrm{L})$} \\
\cline { 3 - 5 } & & Range & Average & $\begin{array}{c}\text { Standard } \\
\text { Deviation }\end{array}$ \\
\cline { 3 - 5 } & & $40000-60000$ & 50000 & 11550 \\
\hline Alkalinity & $4 / 4$ & - & 10000 & - \\
\hline Chemical Oxygen Demand & $1 / 1$ & $13000-19000$ & 15800 & 2588 \\
\hline Total carbon & $5 / 5$ & $80000-90000$ & 82500 & 5000 \\
\hline Total dissolved solids & $4 / 4$ & $3000-5000$ & 3800 & 837 \\
\hline Total organic carbon & $5 / 5$ & & \\
\hline \hline $\begin{array}{l}\text { (a) Number of samples with detectable concentrations/total number of samples } \\
\text { analyzed. }\end{array}$
\end{tabular}

Table E.3. Alternate Influent: General Chemical Parameters

\begin{tabular}{|c|c|c|c|c|}
\hline \multirow[b]{2}{*}{ Parameter } & \multirow[b]{2}{*}{ Frequency ${ }^{(a)}$} & \multicolumn{3}{|c|}{ "Concentration ( $\mu \mathrm{g} / \mathrm{L})$} \\
\hline & & Range & Average & $\begin{array}{l}\text { Standard } \\
\text { Deviation }\end{array}$ \\
\hline Alkalinity & $1 / 1$ & - & 70000 & - \\
\hline Total carbon & $1 / 1$ & - & 17000 & - \\
\hline Total dissolved solids & $1 / 1$ & - & 110000 & - \\
\hline Total organic carbon & $1 / 1$ & - & 2000 & - \\
\hline $\begin{array}{l}\text { Number of samp } \\
\text { analyzed. }\end{array}$ & etectable & $\overline{\text { ons } / \mathrm{t}}$ & ber of $s$ & \\
\hline
\end{tabular}




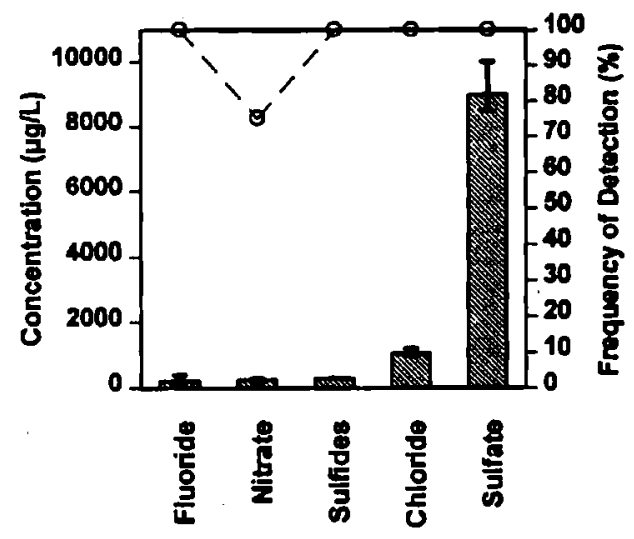

Figure E.4. Untreated Influent Ammonia and Figure E.5. Treated Influent Ammonia and Anions

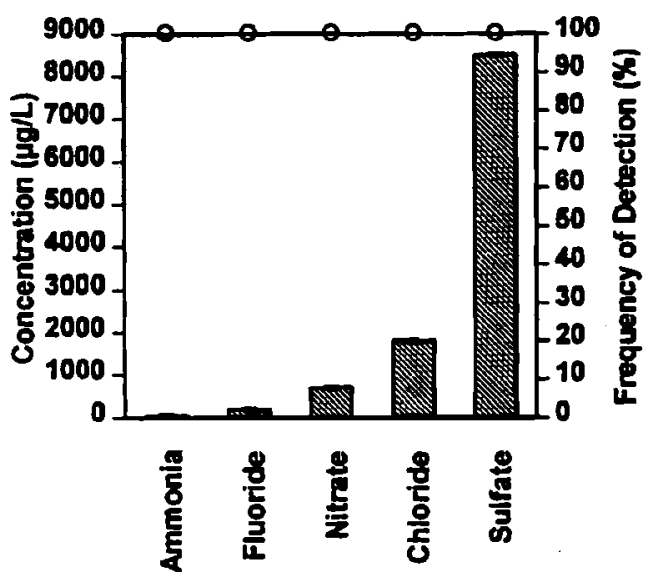

Figure E.6. Alternate Influent Ammonia and Anions (Ammonia Average $30 \mu \mathrm{g} / \mathrm{L}$, Range N/A)

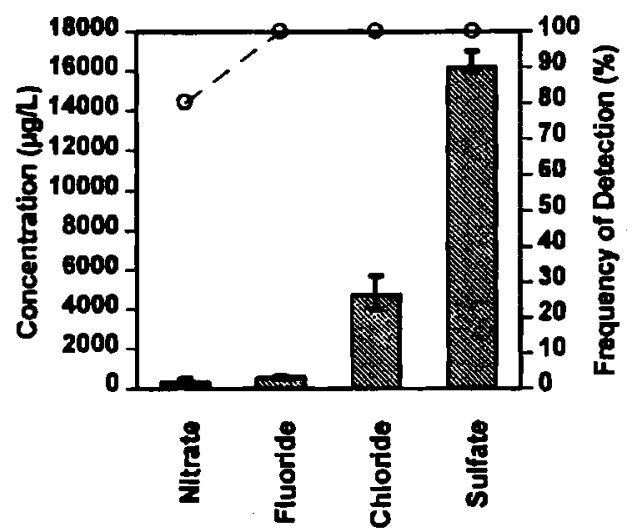

Anions 
Table E.4. Untreated Influent: Ammonia and Anions

\begin{tabular}{|c|c|c|c|c|}
\hline \multirow[b]{2}{*}{ Constituent } & \multirow[b]{2}{*}{ Frequency $^{(a)}$} & \multicolumn{3}{|c|}{ Concentration $(\mu \mathrm{g} / \mathrm{L})$} \\
\hline & & Range & Average & $\begin{array}{l}\text { Standard } \\
\text { Deviation }\end{array}$ \\
\hline Chloride & $4 / 4$ & $1000-1200$ & 1075 & 96 \\
\hline Fluoride & $4 / 4$ & $100-400$ & 225 & 126 \\
\hline Nitrate & $3 / 4$ & $200-300$ & 267 & 58 \\
\hline Sulfate & $4 / 4$ & $8500-10000$ & 9000 & 707 \\
\hline Sulfides & $1 / 1$ & - & 300 & - \\
\hline $\begin{array}{l}\text { (a) Number of san } \\
\text { analyzed. }\end{array}$ & detectable & entrations/tota & ber of & \\
\hline
\end{tabular}

Table E.5. Treated Influent: Ammonia and Anions

\begin{tabular}{|c|c|c|c|c|}
\hline \multirow[b]{2}{*}{ Constituent } & \multirow[b]{2}{*}{ Frequency $^{(a)}$} & \multicolumn{3}{|c|}{ Concentration $(\mu \mathrm{g} / \mathrm{L})$} \\
\hline & & Range & Average & $\begin{array}{l}\text { Standard } \\
\text { Deviation }\end{array}$ \\
\hline Chloride & $5 / 5$ & $4000-5700$ & 4740 & 709 \\
\hline Fluoride & $5 / 5$ & $500-600$ & 540 & 55 \\
\hline Nitrate & $4 / 5$ & $100-500$ & 325 & 171 \\
\hline Sulfate & $5 / 5$ & $16000-17000$ & 16200 & 447 \\
\hline $\begin{array}{l}\text { Number of sam } \\
\text { analyzed. }\end{array}$ & etectable & ntrations/total & nber of $s$ & \\
\hline
\end{tabular}

Table E.6. Alternate Influent: Ammonia and Anions

\begin{tabular}{|c|c|c|c|c|}
\hline \multirow[b]{2}{*}{ Constituent } & \multirow[b]{2}{*}{ Frequency ${ }^{(a)}$} & \multicolumn{3}{|c|}{ Concentration $(\mu \mathrm{g} / \mathrm{L})$} \\
\hline & & Range & Average & $\begin{array}{l}\text { Standard } \\
\text { Deviation }\end{array}$ \\
\hline Ammonia & $1 / 1$ & - & 30 & - \\
\hline Chloride & $1 / 1$ & - & 1800 & - \\
\hline Fluoride & $1 / 1$ & - & 200 & - \\
\hline Nitrate & $1 / 1$ & - & 700 & - \\
\hline Sulfate & $1 / 1$ & - & 8500 & - \\
\hline $\begin{array}{l}\text { Number of san } \\
\text { analyzed. }\end{array}$ & table cc & ions/t & nber of $s$ & \\
\hline
\end{tabular}



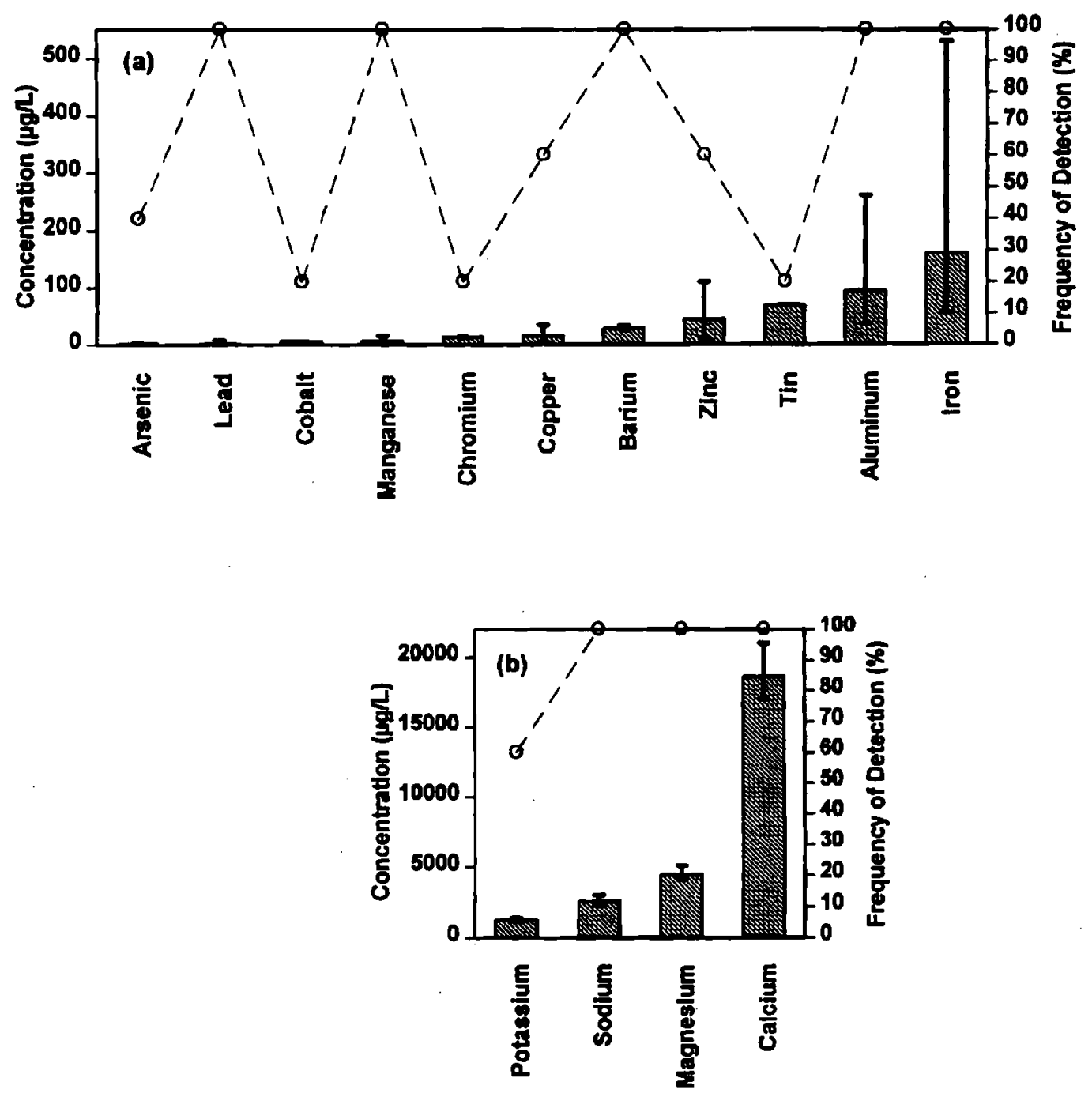

Figure E.7. Untreated Influent Metals: (a) Concentration Less than $500 \mu \mathrm{g} / \mathrm{L}$ (Arsenic Average $2 \mu \mathrm{g} / \mathrm{L}$, Range N/A; Lead Average $2.4 \mu \mathrm{g} / \mathrm{L}$, Range 0.6 to $8.1 \mu \mathrm{g} / \mathrm{L}$ ), (b) Concentration Greater than $500 \mu \mathrm{g} / \mathrm{L}$ 

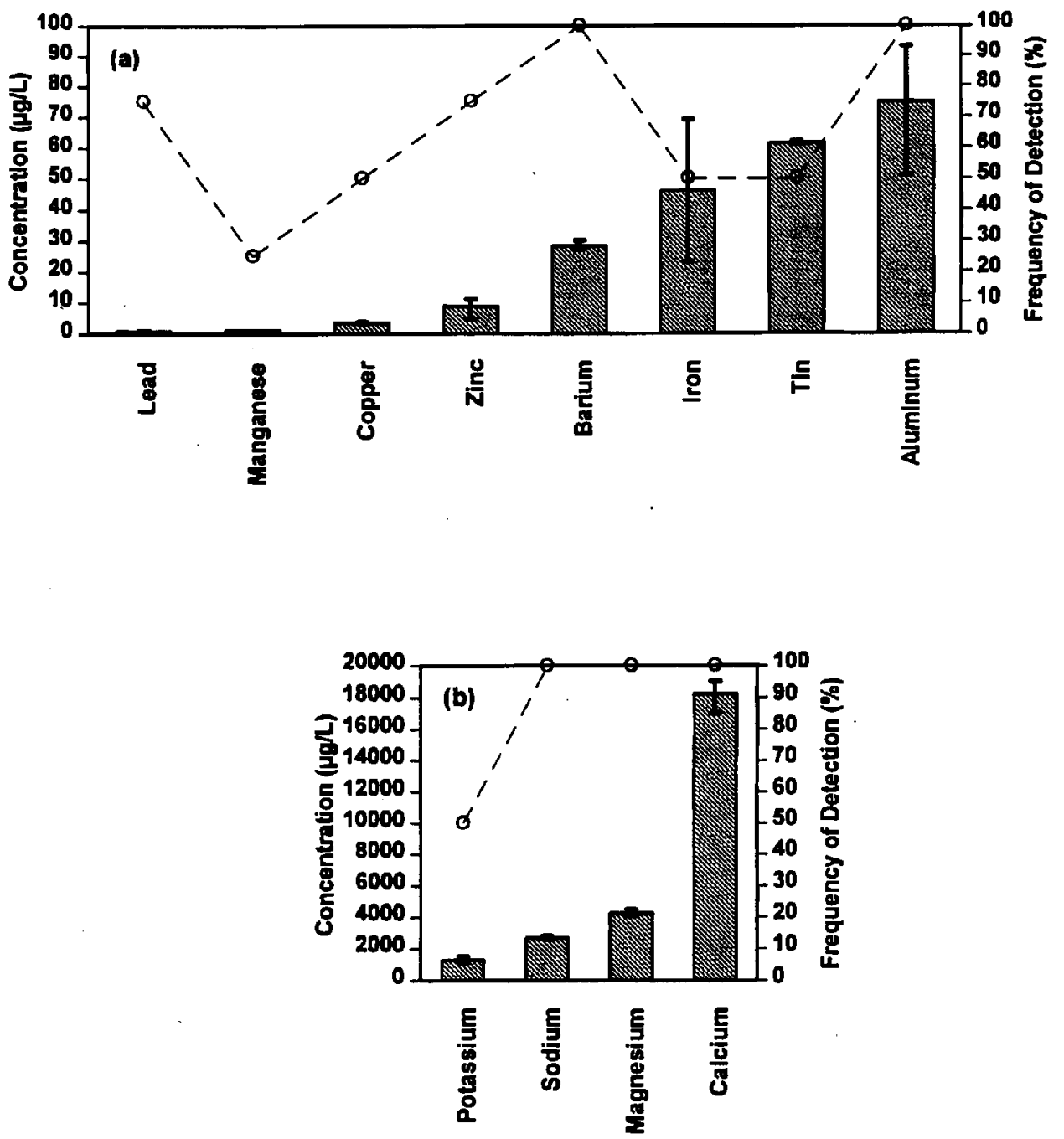

Figure E.8. Treated Influent Metals: (a) Concentration Less than $100 \mu \mathrm{g} / \mathrm{L}$ (Lead Average $0.9 \mu \mathrm{g} / \mathrm{L}$, Range 0.7 to $1.2 \mu \mathrm{g} / \mathrm{L}$; Manganese Average $1.1 \mu \mathrm{g} / \mathrm{L}$, Range N/A), (b) Concentration Greater than $100 \mu \mathrm{g} / \mathrm{L}$ 

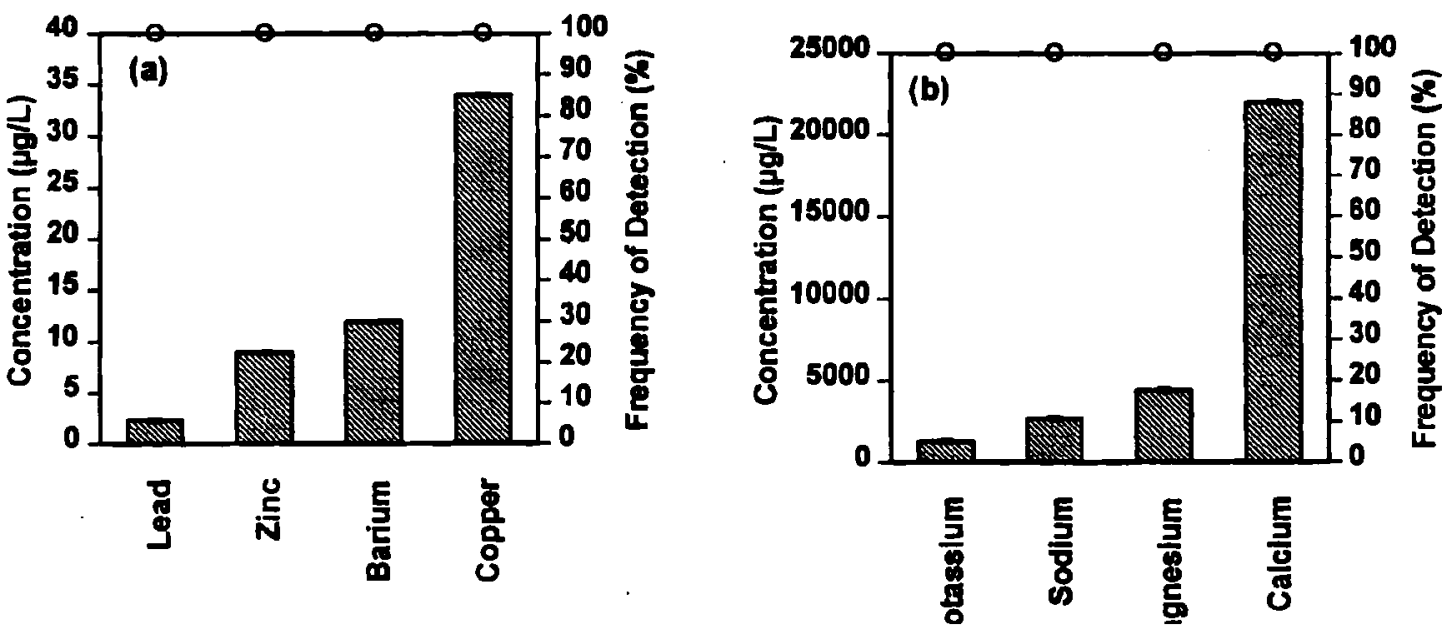

Figure E.9. Alternate Influent Metals: (a) Concentration Less than $40 \mu \mathrm{g} / \mathrm{L}$, (b) Concentration Greater than $40 \mu \mathrm{g} / \mathrm{L}$ 
Table E.7. Untreated Influent: Metals

\begin{tabular}{||l|c|c|c|c||}
\hline \multirow{2}{*}{ Constituent } & \multirow{2}{*}{ Frequency ${ }^{(a)}$} & \multicolumn{3}{c|}{ Concentration $(\mu \mathrm{g} / \mathrm{L})$} \\
\cline { 3 - 5 } & & Range & Average & $\begin{array}{c}\text { Standard } \\
\text { Deviation }\end{array}$ \\
\hline Aluminum & $5 / 5$ & $36-260$ & 93 & 94 \\
\hline Arsenic & $2 / 5$ & - & 2 & - \\
\hline Barium & $5 / 5$ & $27-33$ & 29 & 2 \\
\hline Calcium & $5 / 5$ & $17000-21000$ & 18600 & 1517 \\
\hline Chromium & $1 / 5$ & - & 13 & - \\
\hline Cobalt & $1 / 5$ & - & 7 & - \\
\hline Copper & $3 / 5$ & $4.4-35.0$ & 15.2 & 17.2 \\
\hline Iron & $5 / 5$ & $56-530$ & 160 & 207 \\
\hline Lead & $5 / 5$ & $0.6-8.1$ & 2.4 & 3.2 \\
\hline Magnesium & $5 / 5$ & $4100-5100$ & 4440 & 397 \\
\hline Manganese & $5 / 5$ & $4-16$ & 7 & 5 \\
\hline Potassium & $3 / 5$ & $1200-1400$ & 1267 & 115 \\
\hline Sodium & $5 / 5$ & $2300-3000$ & 2600 & 292 \\
\hline Tin & $1 / 5$ & - & 69 & - \\
\hline Zinc & $3 / 5$ & $10-110$ & 44 & 57 \\
\hline (a) Number of samples with detectable concentrations/total number of samples \\
\hline
\end{tabular}


Table E.8. Treated Influent: Metals

\begin{tabular}{|c|c|c|c|c|}
\hline \multirow[b]{2}{*}{ Constituent } & \multirow[b]{2}{*}{ Frequency $y^{(\mathrm{a})}$} & \multicolumn{3}{|c|}{ Concentration $(\mu \mathrm{g} / \mathrm{L})$} \\
\hline & & Range & Average & $\begin{array}{l}\text { Standard } \\
\text { Deviation }\end{array}$ \\
\hline Aluminum & $4 / 4$ & $51-93$ & 75 & 19 \\
\hline Barium & $4 / 4$ & $27-30$ & 28 & 1 \\
\hline Calcium & $4 / 4$ & $17000-19000$ & 18250 & 957 \\
\hline Copper & $2 / 4$ & $3.1-3.7$ & 3 & - \\
\hline Iron & $2 / 4$ & $23-69$ & 46 & - \\
\hline Lead & $3 / 4$ & $0.7-1.2$ & 0.9 & 0.3 \\
\hline Magnesium & $4 / 4$ & $4100-4500$ & 4275 & 206 \\
\hline Manganese & $1 / 4$ & - & 1.1 & - \\
\hline Potassium & $2 / 4$ & $1100-1500$ & 1300 & - \\
\hline Sodium & $4 / 4$ & $2600-2800$ & 2675 & 96 \\
\hline Tin & $2 / 4$ & $61-62$ & 62 & - \\
\hline Zinc & $3 / 4$ & $5-11$ & 9 & 4 \\
\hline $\begin{array}{l}\text { (a) Number of sar } \\
\text { analyzed. }\end{array}$ & tectable & trations/total & ber of $s$ & les \\
\hline
\end{tabular}

Table E.9. Alternate Influent: Metals

\begin{tabular}{||l|c|r|r|c||}
\hline \multirow{2}{*}{ Constituent } & \multirow{2}{*}{ Frequency } & \multicolumn{3}{c||}{ Concentration $(\mu \mathrm{g} / \mathrm{L})$} \\
\cline { 3 - 5 } & & Range & Average & $\begin{array}{c}\text { Standard } \\
\text { Deviation }\end{array}$ \\
\hline Barium & $1 / 1$ & - & 12 & - \\
\hline Calcium & $1 / 1$ & - & 22000 & - \\
\hline Copper & $1 / 1$ & - & 34 & - \\
\hline Lead & $1 / 1$ & - & 2 & - \\
\hline Magnesium & $1 / 1$ & - & 4400 & - \\
\hline Potassium & $1 / 1$ & - & 1300 & - \\
\hline Sodium & $1 / 1$ & - & 2700 & - \\
\hline Zinc & $1 / 1$ & - & 9 & - \\
\hline \hline $\begin{array}{l}\text { (a) Number of samples with detectable concentrations/total number of samples } \\
\text { analyzed. }\end{array}$
\end{tabular}




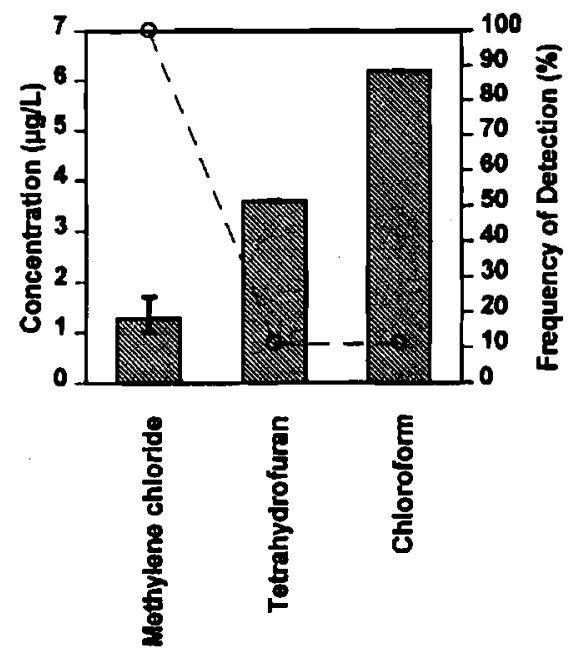

Figure E.10. Untreated Influent Volatile Organic Compounds

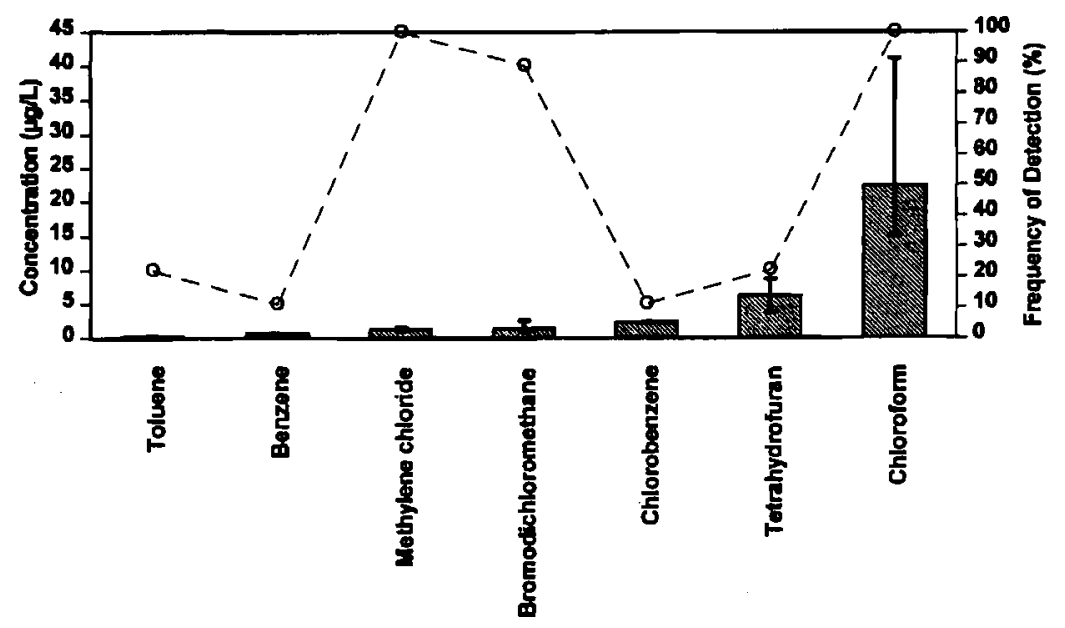

Figure E.11. Treated Influent Volatile Organic Compounds (Toluene Average $0.3 \mu \mathrm{g} / \mathrm{L}$, Range 0.1 to $0.4 \mu \mathrm{g} / \mathrm{L})$ 


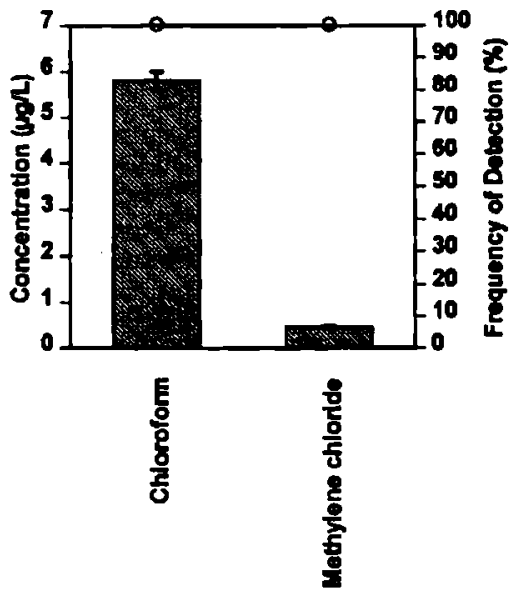

Figure E.12. Alternate Influent Volatile Organic Compounds 
Table E.10. Untreated Influent: Volatile Organic Compounds

\begin{tabular}{||l|c|c|c|c||}
\hline \hline \multirow{2}{*}{ Constituent } & \multirow{2}{*}{ Frequency } & \multicolumn{3}{c|}{ Concentration $(\mu \mathrm{g} / \mathrm{L})$} \\
\cline { 3 - 5 } & & Range & Average & $\begin{array}{c}\text { Standard } \\
\text { Deviation }\end{array}$ \\
\hline Chloroform & $1 / 9$ & - & 6.2 & - \\
\hline Methylene chloride & $10 / 10$ & $1.0-1.7$ & 1.3 & 0.2 \\
\hline Tetrahydrofuran & $1 / 9$ & - & 3.6 & - \\
\hline \hline $\begin{array}{l}\text { (a) Number of samples with detectable concentrations/total number of samples } \\
\text { analyzed. }\end{array}$
\end{tabular}

Table E.11. Treated Influent: Volatile Organic Compounds

\begin{tabular}{||l|c|c|c|c||}
\hline \multirow{2}{*}{\multicolumn{1}{c|}{ Constituent }} & \multirow{2}{*}{ Frequency $^{\text {(a) }}$} & & \multicolumn{2}{c|}{ Concentration (ug/L) } \\
\cline { 3 - 5 } & & Range & Average & $\begin{array}{c}\text { Standard } \\
\text { Deviation }\end{array}$ \\
\hline Benzene & $1 / 9$ & - & 0.7 & - \\
\hline Bromodichloromethane & $8 / 9$ & $0.9-2.5$ & 1.4 & 0.5 \\
\hline Chlorobenzene & $1 / 9$ & - & 2.3 & - \\
\hline Chloroform & $10 / 10$ & $15.0-41.0$ & 22.4 & 7.3 \\
\hline Methylene chloride & $10 / 10$ & $1.1-1.6$ & 1.3 & 0.2 \\
\hline Tetrahydrofuran & $2 / 9$ & $3.7-8.6$ & 6.2 & - \\
\hline Toluene & $2 / 9$ & $0.1-0.4$ & 0.3 & - \\
\hline \hline
\end{tabular}

(a) Number of samples with detectable concentrations/total number of samples analyzed.

Table E.12. Alternate Influent: Volatile Organic Compounds

\begin{tabular}{||l|c|c|c|c||}
\hline \multirow{2}{*}{ Constituent } & \multirow{2}{*}{ Frequency $^{(\mathrm{a})}$} & \multicolumn{3}{c|}{ Concentration $(\mu \mathrm{g} / \mathrm{L})$} \\
\cline { 3 - 5 } & & Range & Average & $\begin{array}{c}\text { Standard } \\
\text { Deviation }\end{array}$ \\
\hline Chloroform & $2 / 2$ & $5.6-6.0$ & 5.8 & - \\
\hline Methylene chloride & $2 / 2$ & $0.4-0.5$ & 0.5 & - \\
\hline \hline
\end{tabular}

(a) Number of samples with detectable concentrations/total number of samples analyzed. 


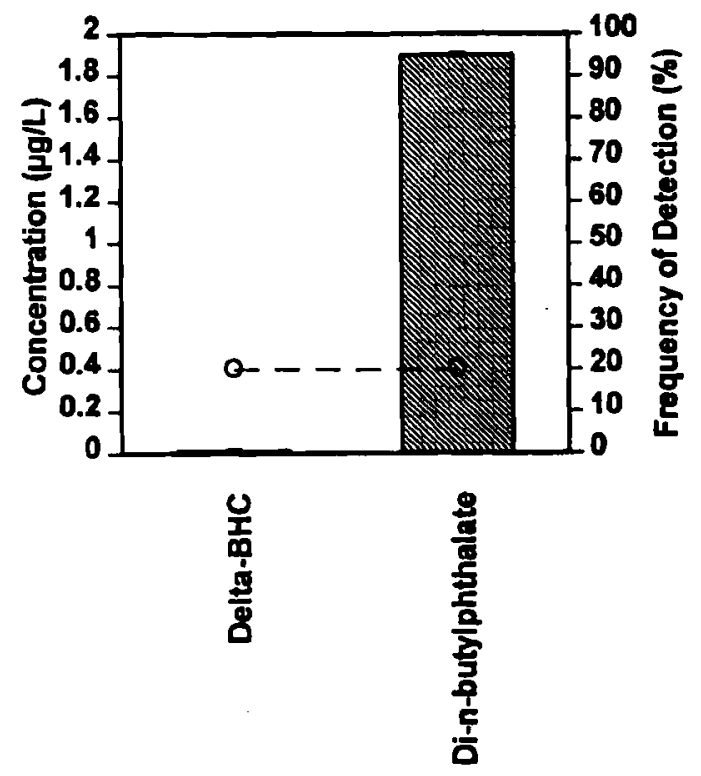

Figure E.13. Treated Influent Semivolatile Organic Compounds (Delta-BHC Average $0.0065 \mu \mathrm{g} / \mathrm{L}$, Range N/A)

Table E.13. Treated Influent: Semivolatile Organic Compounds

\begin{tabular}{|c|c|c|c|c|}
\hline \multirow[b]{2}{*}{ Constituent } & \multirow[b]{2}{*}{ Frequency $^{(a)}$} & \multicolumn{3}{|c|}{ Concentration $(\mu \mathrm{g} / \mathrm{L})$} \\
\hline & & Range & Average & $\begin{array}{l}\text { Standard } \\
\text { Deviation }\end{array}$ \\
\hline \multicolumn{5}{|c|}{ Acid/Bases/Neutrals (ABNs) } \\
\hline Di-n-butylphthalate & $1 / 5$ & - & 1.9 & - \\
\hline \multicolumn{5}{|c|}{ Pesticides } \\
\hline Delta-BHC & $1 / 5$ & - & 0.0065 & $\overline{-}$ \\
\hline
\end{tabular}




\title{
Appendix F
}

\author{
Detailed Tabular Information on the \\ Parameters and Constituents Detected \\ in Buildings 306, 320, 324, 326, 331, \\ 3720, and End-of-Pipe
}




\section{Appendix F}

\section{Detailed Tabular Information on the Parameters and Constituents Detected in Buildings 306, 320, 324, 326, 331, 3720, and End-of-Pipe}

This appendix contains tabulated information on the parameters and constituents detected in the effluent samples from Buildings $306,320,324,326,331$, and 3720 . Information is also provided on samples taken at end-of-pipe.

Table F.1. Building 306: General Chemical Parameters

\begin{tabular}{||l|c|c|c|c|}
\hline \multirow{2}{*}{\multicolumn{1}{c|}{ Parameter }} & \multirow{2}{*}{ Frequency $^{(\mathrm{a})}$} & \multicolumn{2}{c|}{ Concentration $(\mu \mathrm{g} / \mathrm{L})$} \\
\cline { 3 - 5 } & & Range & Average & $\begin{array}{c}\text { Standard } \\
\text { Deviation }\end{array}$ \\
\hline Alkalinity & $6 / 6$ & $60000-120000$ & 86667 & 25033 \\
\hline Chemical Oxygen Demand & $6 / 6$ & $4500-13000$ & 8850 & 3068 \\
\hline Total carbon & $7 / 7$ & $18000-30000$ & 23143 & 4634 \\
\hline Total dissolved solids & $6 / 6$ & $100000-180000$ & 140000 & 36332 \\
\hline Total organic carbon & $7 / 7$ & $2000-5000$ & 3143 & 1069 \\
\hline \hline
\end{tabular}

(a) Number of samples with detectable concentrations/total number of samples analyzed.

Table F.2. Building 306: Ammonia and Anions

\begin{tabular}{||l|c|c|r|c||}
\hline \multirow{2}{*}{\multicolumn{1}{c|}{ Constituent }} & \multirow{2}{*}{ Frequency $^{(a)}$} & \multicolumn{2}{c|}{ Concentration $(\mu \mathrm{g} / \mathrm{L})$} \\
\cline { 3 - 5 } & & Range & Average & $\begin{array}{c}\text { Standard } \\
\text { Deviation }\end{array}$ \\
\hline Ammonia & $3 / 6$ & $40-100$ & 60 & 35 \\
\hline Chloride & $6 / 6$ & $4740-11700$ & 7650 & 2636 \\
\hline Fluoride & $5 / 6$ & $231-459$ & 333 & 109 \\
\hline Nitrate & $6 / 6$ & $1450-13500$ & 6865 & 4356 \\
\hline Sulfate & $6 / 6$ & $13400-22600$ & 17650 & 3106 \\
\hline Sulfides & $3 / 6$ & $220-300$ & 273 & 46 \\
\hline \hline
\end{tabular}

(a) Number of samples with detectable concentrations/total number of samples analyzed. 
Table F.3. Building 306: Metals

\begin{tabular}{||l|c|c|c|c||}
\hline \multirow{2}{*}{ Constituent } & \multirow{2}{*}{ Frequency } & \multicolumn{3}{c|}{ Concentration $(\mu \mathrm{gg} / \mathrm{L})$} \\
\cline { 3 - 5 } & & Range & Average & $\begin{array}{c}\text { Standard } \\
\text { Deviation }\end{array}$ \\
\cline { 3 - 5 } & $5 / 7$ & $33-190$ & 72 & 66 \\
\hline Aluminum & $1 / 7$ & - & 3 & - \\
\hline Arsenic & $7 / 7$ & $26-43$ & 35 & 6 \\
\hline Barium & $7 / 7$ & $22000-41000$ & 30143 & 7128 \\
\hline Calcium & $7 / 7$ & $9.4-56$ & 18 & 17 \\
\hline Copper & $7 / 7$ & $160-910$ & 285.7 & 275.6 \\
\hline Iron & $2 / 7$ & $3.2-7.2$ & 5 & - \\
\hline Lead & $7 / 7$ & $4800-8800$ & 6571.4 & 1453.4 \\
\hline Magnesium & $7 / 7$ & $7.2-21$ & 14 & 5 \\
\hline Manganese & $1 / 7$ & - & 0.1 & - \\
\hline Mercury & $7 / 7$ & $1200-3100$ & 1985.71 & 753.7 \\
\hline Potassium & $1 / 7$ & - & 1 & - \\
\hline Selenium & $1 / 7$ & - & 4 & - \\
\hline \begin{tabular}{l} 
Silver \\
\hline Sodium
\end{tabular} & $7 / 7$ & $3400-11000$ & 6557 & 2693 \\
\hline Thallium & $7 / 7$ & - & 1 & - \\
\hline Zinc & $7 / 7$ & $66-280$ & 105 & 78 \\
\hline \hline (a) Number of samples with detectable concentrations/total number of samples \\
analyzed.
\end{tabular}

Table F.4. Building 306: Volatile Organic Compounds

\begin{tabular}{||l|c|c|c|c||}
\hline \multirow{2}{*}{ Constituent } & \multirow{2}{*}{ Frequency } & \multicolumn{3}{c|}{ Concentration $(\mu \mathrm{g} / \mathrm{L})$} \\
\cline { 3 - 5 } & & Range & Average & $\begin{array}{c}\text { Standard } \\
\text { Deviation }\end{array}$ \\
\hline Acetone & $2 / 8$ & $14-15$ & 14.5 & - \\
\hline Bromoform & $1 / 8$ & - & 2.0 & - \\
\hline Chloroform & $7 / 8$ & $0.9-1.8$ & 1.4 & 0.3 \\
\hline Methylene chloride & $2 / 8$ & $1.1-1.2$ & 1.2 & - \\
\hline \hline
\end{tabular}


Table F.5. Building 306: Radiological Parameters

\begin{tabular}{||l|c|c|c|c||}
\hline \multirow{2}{*}{ Parameter } & \multirow{2}{*}{ Frequency $^{(\mathrm{a})}$} & \multicolumn{3}{c|}{ Concentration (pCi/L) } \\
\cline { 3 - 5 } & & Range & Average & 2 SEM $^{(\mathrm{b})}$ \\
\hline Gross alpha & $7 / 7$ & $0.9-6.4$ & 3.7 & 1.3 \\
\hline Gross beta & $5 / 7$ & $2.4-19.7$ & 7.4 & 6.4 \\
\hline Tritium & $5 / 7$ & $155.0-687.0$ & 326.2 & 188.9 \\
\hline \hline $\begin{array}{l}\text { (a) Number of samples with detectable concentrations/total number of samples analyzed. } \\
\text { (b) Two times the standard error of the calculated mean. }\end{array}$ \\
\hline
\end{tabular}

Table F.6. Building 320: General Chemical Parameters Detected in Routine Samples

\begin{tabular}{|c|c|c|c|c|}
\hline \multirow[b]{2}{*}{ Parameter } & \multirow[b]{2}{*}{ Frequency ${ }^{(a)}$} & \multicolumn{3}{|c|}{ Concentration $(\mu \mathrm{g} / \mathrm{L})$} \\
\hline & & Range & Average & $\begin{array}{l}\text { Standard } \\
\text { Deviation }\end{array}$ \\
\hline Alkalinity & $32 / 32$ & $40000-130000$ & 60469 & 19596 \\
\hline Chemical Oxygen Demand & $6 / 32$ & $3000-13000$ & 7200 & 3720 \\
\hline Total carbon & $32 / 32$ & $11000-31000$ & 16219 & 4301 \\
\hline Total dissolved solids & $32 / 32$ & $70000-210000$ & 104063 & 33491 \\
\hline Total organic carbon & $32 / 32$ & $1000-3000$ & 1781 & 608 \\
\hline
\end{tabular}

(a) Number of samples with detectable concentrations/total number of samples analyzed.

Table F.7. Building 320: General Chemical Parameters Detected in Nonbusiness Day Samples

\begin{tabular}{|c|c|c|c|c|}
\hline \multirow[b]{2}{*}{ Parameter } & \multirow[b]{2}{*}{ Frequency $^{(a)}$} & \multicolumn{3}{|c|}{ Concentration $(\mu \mathrm{g} / \mathrm{L})$} \\
\hline & & Range & Average & $\begin{array}{l}\text { Standard } \\
\text { Deviation }\end{array}$ \\
\hline Alkalinity & $7 / 7$ & $40000-70000$ & 52290 & 9780 \\
\hline Total carbon & $7 / 7$ & $12000-17000$ & 13857 & 2035 \\
\hline Total dissolved solids & $7 / 7$ & $80000-110000$ & 91430 & 10690 \\
\hline Total organic carbon & $7 / 7$ & $1000-3000$ & 1714 & 756 \\
\hline
\end{tabular}

(a) Number of samples with detectable concentrations/total number of samples analyzed. 
Table F.8. Building 320: Ammonia and Anions Detected in Routine Samples

\begin{tabular}{|c|c|c|c|c|}
\hline \multirow[b]{2}{*}{ Constituent } & \multirow[b]{2}{*}{ Frequency $^{(a)}$} & \multicolumn{3}{|c|}{ Concentration $(\mu \mathrm{g} / \mathrm{L})$} \\
\hline & & Range & Average & $\begin{array}{l}\text { Standard } \\
\text { Deviation }\end{array}$ \\
\hline Ammonia & $2 / 32$ & - & 30 & - \\
\hline Chloride & $32 / 32$ & $2100-11800$ & 5025 & 1854 \\
\hline Fluoride & $29 / 32$ & $274-700$ & 516 & 112 \\
\hline Nitrate & $32 / 32$ & $100-15600$ & 1997 & 3611 \\
\hline Sulfate & $32 / 32$ & $10000-23500$ & 16472 & 2205 \\
\hline Sulfides & $9 / 32$ & $220-400$ & 296 & 50 \\
\hline
\end{tabular}

(a) Number of samples with detectable concentrations/total number of samples analyzed.

Table F.9. Building 320: Ammonia and Anions Detected in Nonbusiness Day Samples

\begin{tabular}{|c|c|c|c|c|}
\hline \multirow[b]{2}{*}{ Constituent } & \multirow[b]{2}{*}{ Frequency ${ }^{(a)}$} & \multicolumn{3}{|c|}{ Concentration $(\mu \mathrm{g} / \mathrm{L})$} \\
\hline & & Range & Average & $\begin{array}{l}\text { Standard } \\
\text { Deviation }\end{array}$ \\
\hline Ammonia & $1 / 7$ & - & 50 & - \\
\hline Chloride & $7 / 7$ & $1800-5500$ & 4343 & 1204 \\
\hline Fluoride & $7 / 7$ & $200-900$ & 571 & 221 \\
\hline Nitrate & $7 / 7$ & $200-1700$ & 729 & 482 \\
\hline Sulfate & $7 / 7$ & $8500-18000$ & 15643 & 3275 \\
\hline Sulfides & $4 / 7$ & $200-300$ & 225 & 50 \\
\hline
\end{tabular}


Table F.10. Building 320: Metals Detected in Routine Samples

\begin{tabular}{|c|c|c|c|c|}
\hline \multirow[b]{2}{*}{ Constituent } & \multirow[b]{2}{*}{ Frequency ${ }^{\text {(a) }}$} & \multicolumn{3}{|c|}{ Concentration $(\mu \mathrm{g} / \mathrm{L})$} \\
\hline & & Range & Average & $\begin{array}{l}\text { Standard } \\
\text { Deviation }\end{array}$ \\
\hline Aluminum & $31 / 32$ & $29-140$ & 65 & 29 \\
\hline Antimony & $2 / 32$ & $37-39$ & 38 & - \\
\hline Arsenic & $1 / 32$ & - & 0.7 & - \\
\hline Barium & $32 / 32$ & $16-46$ & 29 & 6 \\
\hline Beryllium & $1 / 32$ & - & 0.4 & - \\
\hline Cadmium & $2 / 32$ & $3.5-4.3$ & 3.9 & - \\
\hline Calcium & $32 / 32$ & $18000-44000$ & 22031 & 6167 \\
\hline Chromium & $4 / 32$ & $6-18$ & 11 & 6 \\
\hline Cobalt & $2 / 32$ & $7.5-7.6$ & 7.6 & - \\
\hline Copper & $32 / 32$ & $3.5-13$ & 6.9 & 2.1 \\
\hline Iron & $26 / 32$ & $9-71$ & 30 & 13 \\
\hline Lead & $20 / 32$ & $0.6-15.0$ & 2.1 & 3.2 \\
\hline Magnesium & $32 / 32$ & $4000-9300$ & 4869 & 1245 \\
\hline Manganese & $19 / 32$ & $0.9-7.1$ & 1.5 & 1.4 \\
\hline Mercury & $7 / 32$ & $0.1 \cdot 0.5$ & 0.2 & 0.1 \\
\hline Potassium & $20 / 32$ & $860-2900$ & 1444 & 515 \\
\hline Selenium & $5 / 32$ & $0.7-2.3$ & 1.1 & 0.7 \\
\hline Sodium & $32 / 32$ & $2300-11000$ & 3531 & 1999 \\
\hline Thallium & $6 / 32$ & $0.6-1.6$ & 0.8 & 0.4 \\
\hline Tin & $4 / 32$ & $26-82$ & 46 & 25 \\
\hline Zinc & $32 / 32$ & $11-120$ & 29 & 19 \\
\hline
\end{tabular}

(a) Number of samples with detectable concentrations/total number of samples analyzed. 
Table F.11. Building 320: Metals Detected in Nonbusiness Day Samples

\begin{tabular}{|c|c|c|c|c|}
\hline \multirow[b]{2}{*}{ Constituent } & \multirow[b]{2}{*}{ Frequency $^{(a)}$} & \multicolumn{3}{|c|}{ Concentration ( $\mu \mathrm{g} / \mathrm{L})$} \\
\hline & & Range & Average & $\begin{array}{l}\text { Standard } \\
\text { Deviation }\end{array}$ \\
\hline Aluminum & $7 / 7$ & $26-170$ & 71 & 47 \\
\hline Arsenic & $1 / 7$ & 一 & 2 & - \\
\hline Barium & $7 / 7$ & $15-31$ & 27 & 5 \\
\hline Cadmium & $1 / 7$ & 一 & 4 & - \\
\hline Calcium & $7 / 7$ & $18000-22000$ & 19286 & 1254 \\
\hline Copper & $7 / 7$ & $3.4-14.0$ & 6.9 & 3.3 \\
\hline Iron & $4 / 7$ & $25-62$ & 38 & 17 \\
\hline Lead & $6 / 7$ & $0.6-1.2$ & 0.9 & 0.2 \\
\hline Magnesium & $7 / 7$ & $3900-4400$ & 4157 & 162 \\
\hline Manganese & $4 / 7$ & $1.2-1.6$ & 1.3 & 0.2 \\
\hline Mercury & $2 / 7$ & $0.14-0.15$ & 0.15 & - \\
\hline Potassium & $3 / 7$ & $990-1200$ & 1097 & 105 \\
\hline Silver & $1 / 7$ & - & 5 & - \\
\hline Sodium & $7 / 7$ & $2500-3200$ & 2843 & 230 \\
\hline Tin & $2 / 7$ & $24-66$ & 45 & - \\
\hline Zinc & $7 / 7$ & $16-61$ & 35 & 16 \\
\hline
\end{tabular}

(a) Number of samples with detectable concentrations/total number of samples analyzed. 
Table F.12. Building 320: Volatile Organic Compounds Detected in Routine Samples

\begin{tabular}{|c|c|c|c|c|}
\hline \multirow[b]{2}{*}{ Constituent } & \multirow[b]{2}{*}{ Frequency ${ }^{(a)}$} & \multicolumn{3}{|c|}{ Concentration $(\mu \mathrm{g} / \mathrm{L})$} \\
\hline & & Range & Average & $\begin{array}{l}\text { Standard } \\
\text { Deviation }\end{array}$ \\
\hline Acetone & $5 / 53$ & $8.8-43$ & 26.0 & 12.5 \\
\hline Acetonitrile & $1 / 27$ & - & 170.0 & - \\
\hline Bromodichloromethane & $22 / 33$ & $1.1-3.3$ & 1.7 & 0.6 \\
\hline Bromoform & $1 / 33$ & - & 0.5 & - \\
\hline 2-Butanone & $1 / 53$ & - & 26.0 & - \\
\hline Chloroform & $53 / 53$ & $6.9-32$ & 19.2 & 6.4 \\
\hline Dibromochloromethane & $3 / 33$ & $1.4-2$ & 1.8 & 0.3 \\
\hline Ethylbenzene & $4 / 33$ & $0.5-4.9$ & 1.7 & 2.1 \\
\hline Hexone & $4 / 53$ & $24-110$ & 54.8 & 39.7 \\
\hline Methylene chloride & $39 / 53$ & $0.4-1.6$ & 1.1 & 0.4 \\
\hline Tetrahydrofuran & $1 / 53$ & - & 36.0 & - \\
\hline Toluene & $2 / 53$ & $0.14-0.18$ & 0.16 & - \\
\hline 1,1,1-Trichloroethane & $3 / 53$ & $1.2-2.6$ & 1.77 & 0.7 \\
\hline Xylenes (total) & $7 / 53$ & $0.5-12.0$ & 5.4 & 4.6 \\
\hline
\end{tabular}

(a) Number of samples with detectable concentrations/total number of samples analyzed.

Table F.13. Building 320: Volatile Organic Compounds Detected in Nonbusiness Day Samples

\begin{tabular}{||l|c|c|r|c||}
\hline \multirow{2}{*}{ Constituent } & \multirow{2}{*}{ Frequency } & \multicolumn{2}{c|}{ Concentration $(\mu \mathrm{g} / \mathrm{L})$} \\
\cline { 3 - 5 } & & Range & Average & $\begin{array}{c}\text { Standard } \\
\text { Deviation }\end{array}$ \\
\hline Acetone & $1 / 13$ & - & 25.0 & - \\
\hline Bromodichloromethane & $6 / 8$ & $1.1-2.1$ & 1.6 & 0.3 \\
\hline Chloroform & $13 / 13$ & $7.4-30.0$ & 20.4 & 6.6 \\
\hline Ethylbenzene & $1 / 8$ & - & 0.8 & - \\
\hline Hexone & $1 / 13$ & - & 26.0 & - \\
\hline Methylene chloride & $13 / 13$ & $0.4-1.4$ & 0.8 & 0.4 \\
\hline Toluene & $1 / 13$ & - & 0.2 & - \\
\hline Xylenes (total) & $3 / 13$ & $0.5-4.4$ & 2.0 & 2.1 \\
\hline \hline
\end{tabular}

(a) Number of samples with detectable concentrations/total number of samples analyzed. 
Table F.14. Building 320: Semivolatile Organic Compounds

\begin{tabular}{|c|c|c|c|c|}
\hline \multirow[b]{2}{*}{ Constituent } & \multirow[b]{2}{*}{ Frequency $^{(a)}$} & \multicolumn{3}{|c|}{ Concentration $(\mu \mathrm{g} / \mathrm{L})$} \\
\hline & & Range & Average & $\begin{array}{l}\text { Standard } \\
\text { Deviation }\end{array}$ \\
\hline \multicolumn{5}{|c|}{ Acids/Bases/Neutrals (ABNs) } \\
\hline Di-n-butylphthalate & $2 / 14$ & $2.5-2.6$ & 2.6 & - \\
\hline
\end{tabular}

Table F.15. Building 320: Radiological Parameters Detected in Routine Samples

\begin{tabular}{||l|c|c|c|c||}
\hline \multirow{2}{*}{ Parameter } & \multirow{2}{*}{ Frequency $^{(\mathrm{a})}$} & \multicolumn{3}{c|}{ Concentration (pCi/L) } \\
\cline { 3 - 5 } & & Range & Average & 2SEM $^{(\mathrm{b})}$ \\
\hline Gross alpha & $8 / 32$ & $0.9-2.9$ & 1.7 & 0.5 \\
\hline Gross beta & $10 / 32$ & $2.1-4.3$ & 3.1 & 0.4 \\
\hline
\end{tabular}

(a) Number of samples with detectable concentrations/total number of samples analyzed.

(b) Two times the standard error of the calculated mean.

Table F.16. Building 324 Process Sewer: General Chemical Parameters

\begin{tabular}{||l|c|c|c|c||}
\hline \multirow{2}{*}{\multicolumn{1}{|c|}{ Parameter }} & \multirow{2}{*}{ Frequency ${ }^{(\mathrm{a})}$} & \multicolumn{2}{c|}{ Concentration $(\mu \mathrm{gg} / \mathrm{L})$} \\
\cline { 3 - 5 } & & Range & Average & $\begin{array}{c}\text { Standard } \\
\text { Deviation }\end{array}$ \\
\hline Alkalinity & $2 / 2$ & - & 50000 & - \\
\hline Chemical Oxygen Demand & $2 / 2$ & $4200-6400$ & 5300 & - \\
\hline Total carbon & $2 / 2$ & $14000-15000$ & 14500 & - \\
\hline Total dissolved solids & $2 / 2$ & $80000-100000$ & 90000 & - \\
\hline Total organic carbon & $2 / 2$ & - & 1000 & - \\
\hline \hline
\end{tabular}

(a) Number of samples with detectable concentrations/total number of samples analyzed. 
Table F.17. Building 324 Process Sewer: Ammonia and Anions

\begin{tabular}{||l|c|c|c|c|}
\hline \multirow{2}{*}{\multicolumn{1}{c|}{ Constituent }} & \multirow{2}{*}{ Frequency $^{(\mathrm{a})}$} & \multicolumn{2}{c|}{ Concentration $(\mu \mathrm{g} / \mathrm{L})$} \\
\cline { 3 - 5 } & & Range & Average & $\begin{array}{c}\text { Standard } \\
\text { Deviation }\end{array}$ \\
\hline Chloride & $2 / 2$ & $3170-3430$ & 3300.0 & - \\
\hline Fluoride & $2 / 2$ & $319-434$ & 377 & - \\
\hline Nitrate & $2 / 2$ & $729-982$ & 856 & - \\
\hline Sulfate & $2 / 2$ & $12900-15400$ & 14150 & - \\
\hline Sulfides & $1 / 2$ & - & 300 & - \\
\hline \hline
\end{tabular}

(a) Number of samples with detectable concentrations/total number of samples analyzed.

Table F.18. Building 324 Process Sewer: Metals

\begin{tabular}{|c|c|c|c|c|}
\hline \multirow[b]{2}{*}{ Constituent } & \multirow[b]{2}{*}{ Frequency $^{\text {(a) }}$} & \multicolumn{3}{|c|}{ Concentration $(\mu \mathrm{g} / \mathrm{L})$} \\
\hline & & Range & Average & $\begin{array}{l}\text { Standard } \\
\text { Deviation }\end{array}$ \\
\hline Aluminum & $2 / 2$ & $49-66$ & 58 & 一 \\
\hline Barium & $2 / 2$ & $25-28$ & 27 & - \\
\hline Calcium & $2 / 2$ & $19000-20000$ & 19500 & - \\
\hline Chromium & $2 / 2$ & $5.7-8.1$ & 6.9 & - \\
\hline Copper & $2 / 2$ & $7.4-8.0$ & 7.7 & - \\
\hline Iron & $2 / 2$ & $23-47$ & 35 & - \\
\hline Magnesium & $2 / 2$ & $4400-4600$ & 4500 & - \\
\hline Manganese & $2 / 2$ & $0.9-1.3$ & 1.1 & - \\
\hline Mercury & $1 / 2$ & - & 0.1 & - \\
\hline Potassium & $2 / 2$ & $980-1500$ & 1240 & - \\
\hline Sodium & $2 / 2$ & $2400-2900$ & 2650 & - \\
\hline Thallium & $1 / 2$ & - & 1.1 & - \\
\hline Zinc & $2 / 2$ & - & 11 & - \\
\hline
\end{tabular}

(a) Number of samples with detectable concentrations/total number of samples analyzed. 
Table F.19. Building 324 Process Sewer: Volatile Organic Compounds

\begin{tabular}{||l|c|c|c|c|}
\hline \multirow{2}{*}{\multicolumn{1}{c|}{ Constituent }} & \multirow{2}{*}{ Frequency $^{(\mathrm{a})}$} & \multicolumn{2}{c|}{ Concentration $(\mu \mathrm{g} / \mathrm{L})$} \\
\cline { 3 - 5 } & & Range & Average & $\begin{array}{c}\text { Standard } \\
\text { Deviation }\end{array}$ \\
\hline Bromodichloromethane & $3 / 3$ & $0.8-1.6$ & 1.2 & 0.4 \\
\hline Chloroform & $3 / 3$ & $4.9-8.9$ & 7.4 & 2.2 \\
\hline Dibromochloromethane & $2 / 3$ & $0.6-1.4$ & 1.0 & - \\
\hline
\end{tabular}

(a) Number of samples with detectable concentrations/total number of samples analyzed.

Table F.20. Building 324 Process Sewer: Radiological Parameters

\begin{tabular}{|c|c|c|c|c|}
\hline \multirow{2}{*}{ Parameter } & \multirow{2}{*}{ Frequency ${ }^{(a)}$} & \multicolumn{3}{|c|}{ Concentration (pCi/L) } \\
\hline & & Range & Average & 2 SEM $^{(b)}$ \\
\hline Gross alpha & $2 / 3$ & $1.1-1.8$ & 1.5 & - \\
\hline Gross beta & $2 / 3$ & $3.0-9.7$ & 6.4 & - \\
\hline Tritium & $2 / 2$ & $172.0-545.0$ & 358.5 & 一 \\
\hline
\end{tabular}

(a) Number of samples with detectable concentrations/total number of samples analyzed.

(b) Two times the standard error of the calculated mean.

Table F.21. Building 324 Retention Process Sewer: General Chemical Parameters

\begin{tabular}{||l|c|c|c|c|}
\hline \multirow{2}{*}{ Parameter } & \multirow{2}{*}{ Frequency $^{(a)}$} & \multicolumn{3}{c|}{ Concentration $(\mu \mathrm{g} / \mathrm{L})$} \\
\cline { 3 - 5 } & & Range & Average & $\begin{array}{c}\text { Standard } \\
\text { Deviation }\end{array}$ \\
\cline { 3 - 5 } & $3 / 3$ & $48000-120000$ & 72667 & 41004 \\
\hline Alkalinity & $3 / 3$ & $2800-8800$ & 6800 & 3464 \\
\hline Chemical Oxygen Demand & $3 / 3$ & $14000-30000$ & 19667 & 8963 \\
\hline Total carbon & $3 / 3$ & $90000-200000$ & 126667 & 63509 \\
\hline Total dissolved solids & $3 / 3$ & $600-1000$ & 767 & 208 \\
\hline Total organic carbon & & & & \\
\hline \hline
\end{tabular}

(a) Number of samples with detectable concentrations/total number of samples analyzed. 
Table F.22. Building 324 Retention Process Sewer: Ammonia and Anions

\begin{tabular}{|c|c|c|c|c|}
\hline \multirow[b]{2}{*}{ Constituent } & \multirow[b]{2}{*}{ Frequency ${ }^{(a)}$} & \multicolumn{3}{|c|}{ Concentration $(\mu \mathrm{g} / \mathrm{L})$} \\
\hline & & Range & Average & $\begin{array}{l}\text { Standard } \\
\text { Deviation }\end{array}$ \\
\hline Ammonia & $1 / 3$ & - & 50 & - \\
\hline Chloride & $3 / 3$ & $3590-12000$ & 6427 & 4827 \\
\hline Fluoride & $3 / 3$ & $322-379$ & 341 & 33 \\
\hline Nitrate & $3 / 3$ & $685-15400$ & 5748 & 8362 \\
\hline Sulfate & $3 / 3$ & $12600-23800$ & 17467 & 5742 \\
\hline Sulfides & $2 / 3$ & $300-400$ & 350 & - \\
\hline
\end{tabular}

(a) Number of samples with detectable concentrations/total number of samples analyzed.

Table F.23. Building 324 Retention Process Sewer: Metals

\begin{tabular}{|c|c|c|c|c|}
\hline \multirow[b]{2}{*}{ Constituent } & \multirow[b]{2}{*}{ Frequency $^{(a)}$} & \multicolumn{3}{|c|}{ Concentration $(\mu \mathrm{g} / \mathrm{L})$} \\
\hline & & Range & Average & $\begin{array}{l}\text { Standard } \\
\text { Deviation }\end{array}$ \\
\hline Aluminum & $2 / 3$ & $56-58$ & 57 & - \\
\hline Barium & $3 / 3$ & $25-48$ & 34 & 13 \\
\hline Calcium & $3 / 3$ & $19000-45000$ & 28000 & 14731 \\
\hline Copper & $2 / 3$ & - & 5.3 & - \\
\hline Iron & $3 / 3$ & $32-43$ & 36 & 6 \\
\hline Magnesium & $3 / 3$ & $4400-9600$ & 6233 & 2919 \\
\hline Manganese & $3 / 3$ & $1.7-2.1$ & 2 & 0 \\
\hline Mercury & $2 / 3$ & $0.05-0.10$ & 0.07 & - \\
\hline Potassium & $2 / 3$ & $1400-2900$ & 2150 & - \\
\hline Sodium & $3 / 3$ & $2400-11000$ & 5433 & 4827 \\
\hline Thallium & $1 / 3$ & - & 2 & - \\
\hline Zinc & $2 / 3$ & $7-9$ & 8 & - \\
\hline
\end{tabular}

(a) Number of samples with detectable concentrations/total number of samples analyzed. 
Table F.24. Building 324 Retention Process Sewer: Volatile Organic Compounds

\begin{tabular}{||l|c|c|c|c|}
\hline \multirow{2}{*}{\multicolumn{1}{|c|}{ Constituent }} & \multirow{2}{*}{ Frequency $^{(\mathrm{a})}$} & \multicolumn{2}{c|}{ Concentration $(\boldsymbol{\mu g} / \mathrm{L})$} \\
\cline { 3 - 5 } & & Range & Average & $\begin{array}{c}\text { Standard } \\
\text { Deviation }\end{array}$ \\
\hline Bromodichloromethane & $2 / 3$ & $0.5-1.1$ & 0.8 & - \\
\hline Chloroform & $3 / 3$ & $4.4-6.3$ & 5.2 & 1.0 \\
\hline Dibromochloromethane & $1 / 3$ & - & 0.7 & - \\
\hline \hline
\end{tabular}

(a) Number of samples with detectable concentrations/total number of samples analyzed.

Table F.25. Building 324 Retention Process Sewer: Radiological Parameters

\begin{tabular}{||l|c|c|c|c||}
\hline \multirow{2}{*}{ Parameter } & \multirow{2}{*}{ Frequency $^{\text {(a) }}$} & \multicolumn{3}{c||}{ Concentration (pCi/L) } \\
\cline { 3 - 5 } & & Range & Average & 2 SEM $^{\text {(b) }}$ \\
\hline Gross alpha & $1 / 3$ & - & 1.9 & - \\
\hline Gross beta & $3 / 3$ & $3.2-4.2$ & 3.6 & 0.6 \\
\hline Tritium & $3 / 3$ & $136.0-627.0$ & 421.7 & 294.6 \\
\hline \hline \begin{tabular}{l} 
(a) Number of samples with detectable concentrations/total number of samples analyzed. \\
(b) Two times the standard error of the calculated mean. \\
\hline
\end{tabular}
\end{tabular}

Table F.26. Building 326: General Chemical Parameters

\begin{tabular}{|c|c|c|c|c|}
\hline \multirow[b]{2}{*}{ Parameter } & \multirow[b]{2}{*}{ Frequency $^{(a)}$} & \multicolumn{3}{|c|}{ Concentration $(\mu \mathrm{g} / \mathrm{L})$} \\
\hline & & Range & Average & $\begin{array}{l}\text { Standard } \\
\text { Deviation }\end{array}$ \\
\hline Alkalinity & $7 / 7$ & $48000-130000$ & 92571 & 29205 \\
\hline Chemical Oxygen Demand & $6 / 7$ & $9000-89000$ & 33167 & 31288 \\
\hline Total carbon & $7 / 7$ & $14000-44000$ & 29857 & 11082 \\
\hline Total dissolved solids & $7 / 7$ & $80000-210000$ & 151429 & 50143 \\
\hline Total organic carbon & $7 / 7$ & $2000-24000$ & 8286 & 7910 \\
\hline
\end{tabular}


Table F.27. Building 326: Ammonia and Anions

\begin{tabular}{||l|c|c|r|c||}
\hline \multirow{2}{*}{\multicolumn{1}{c|}{ Constituent }} & \multirow{2}{*}{ Frequency $^{(\mathrm{a})}$} & \multicolumn{2}{c|}{ Concentration $(\boldsymbol{\mu g} / \mathrm{L})$} \\
\cline { 3 - 5 } & & Range & Average & $\begin{array}{c}\text { Standard } \\
\text { Deviation }\end{array}$ \\
\hline Ammonia & $2 / 7$ & $150-300$ & 225 & - \\
\hline Chloride & $7 / 7$ & $5600-12000$ & 8686 & 2432.5 \\
\hline Fluoride & $7 / 7$ & $265-544$ & 404 & 102 \\
\hline Nitrate & $7 / 7$ & $1200-12400$ & 7286 & 3830 \\
\hline Phosphate & $1 / 7$ & - & 1060 & - \\
\hline Sulfate & $7 / 7$ & $18200-53000$ & 29771 & 14316 \\
\hline Sulfides & $3 / 7$ & $220-400$ & 307 & 90 \\
\hline
\end{tabular}

(a) Number of samples with detectable concentrations/total number of samples analyzed.

Table F.28. Building 326: Metals

\begin{tabular}{|c|c|c|c|c|}
\hline \multirow[b]{2}{*}{ Constituent } & \multirow[b]{2}{*}{ Frequency $^{(a)}$} & \multicolumn{3}{|c|}{ Concentration $(\mu \mathrm{g} / \mathrm{L})$} \\
\hline & & Range & Average & $\begin{array}{l}\text { Standard } \\
\text { Deviation }\end{array}$ \\
\hline Aluminum & $7 / 7$ & $29-100$ & 58 & 26 \\
\hline Barium & $7 / 7$ & $26-42$ & 34 & 6 \\
\hline Beryilium & $1 / 7$ & - & 0 & - \\
\hline Calcium & $7 / 7$ & $21000-43000$ & 32286 & 7868 \\
\hline Chromium & $3 / 7$ & $5.0-6.6$ & 5.8 & 0.8 \\
\hline Copper & $7 / 7$ & $35-140$ & 80 & 46 \\
\hline Iron & $7 / 7$ & $23-350$ & 198 & 125 \\
\hline Lead & $5 / 7$ & $1.9-8.6$ & 4.0 & 2.7 \\
\hline Magnesium & $7 / 7$ & $4600-9100$ & 6857 & 1722 \\
\hline Manganese & $7 / 7$ & $2-60$ & 22 & 22 \\
\hline Mercury & $2 / 7$ & $0.11-0.23$ & 0.17 & - \\
\hline Nickel & $2 / 7$ & $24-27$ & 26 & - \\
\hline Potassium & $7 / 7$ & $1200-3400$ & 2500 & 757 \\
\hline Selenium & $1 / 7$ & - & 1.2 & - \\
\hline Sodium & $7 / 7$ & $5500-24000$ & 11071 & 6595 \\
\hline Thallium & $2 / 7$ & $0.9-1.2$ & 1.1 & - \\
\hline Zinc & $7 / 7$ & $48-520$ & 156 & 171 \\
\hline
\end{tabular}

(a) Number of samples with detectable concentrations/total number of samples analyzed. 
Table F.29. Building 326: Volatile Organic Compounds

\begin{tabular}{|c|c|c|c|c|}
\hline \multirow[b]{2}{*}{ Constituent } & \multirow[b]{2}{*}{ Frequency $^{(\mathrm{a})}$} & \multicolumn{3}{|c|}{ Concentration ( $\mu \mathrm{g} / \mathrm{L})$} \\
\hline & & Range & Average & $\begin{array}{l}\text { Standard } \\
\text { Deviation }\end{array}$ \\
\hline Acetone & $7 / 8$ & $45-2535$ & 505 & 908 \\
\hline Chloroform & $6 / 8$ & $0.6-1.9$ & 1.2 & 0.5 \\
\hline Isopropyl alcohol & $1 / 8$ & - & 40798 & - \\
\hline Methylene chloride & $2 / 8$ & - & 1.2 & - \\
\hline Tetrahydrofuran & $5 / 8$ & $3.7-9.0$ & 6.8 & 2.2 \\
\hline
\end{tabular}

(a) Number of samples with detectable concentrations/total number of samples analyzed.

Table F.30. Building 326: Semivolatile Organic Compounds

\begin{tabular}{|c|c|c|c|c|}
\hline \multirow[b]{2}{*}{ Constituent } & \multirow[b]{2}{*}{ Frequency $^{(a)}$} & \multicolumn{3}{|c|}{ Concentration ( $\mu \mathrm{g} / \mathrm{L})$} \\
\hline & & Range & Average & $\begin{array}{l}\text { Standard } \\
\text { Deviation }\end{array}$ \\
\hline \multicolumn{5}{|c|}{ Acids/Bases/Neutrals (ABNs) } \\
\hline Di-n-octylphthalate & $1 / 6$ & - & 1.3 & - \\
\hline Diethylphthalate & $1 / 6$ & - & 6.6 & - \\
\hline \multicolumn{5}{|c|}{ Pesticides } \\
\hline Aldrin & $1 / 7$ & - & 0.004 & - \\
\hline Alpha-BHC & $2 / 7$ & $0.001-0.002$ & 0.002 & - \\
\hline Delta-BHC & $1 / 7$ & - & 0.004 & - \\
\hline
\end{tabular}

(a) Number of samples with detectable concentrations/total number of samples analyzed.

Table F.31. Building 326: Radiological Parameters

\begin{tabular}{||l|c|c|c|c|}
\hline \multirow{2}{*}{ Parameter } & \multirow{2}{*}{ Frequency $^{(\mathrm{a})}$} & \multicolumn{3}{c|}{ Concentration (pCi/L) } \\
\cline { 3 - 5 } & & Range & Average & 2SEM $^{(\mathrm{b})}$ \\
\hline Gross alpha & $2 / 7$ & $1.3-1.7$ & 1.5 & - \\
\hline Gross beta & $6 / 7$ & $2.5-7.8$ & 5.0 & 1.4 \\
\hline Tritium & $4 / 7$ & $118.0-420.0$ & 275.3 & 137.3 \\
\hline \hline
\end{tabular}

(a) Number of samples with detectable concentrations/total number of samples analyzed.

(b) Two times the standard error of the calculated mean. 
Table F.32. Building 331: General Chemical Parameters Detected in Routine Samples

\begin{tabular}{||l|c|c|c|c||}
\hline \multirow{2}{*}{\multicolumn{1}{|c|}{ Parameter }} & \multirow{2}{*}{ Frequency $^{(\mathrm{a})}$} & \multicolumn{2}{c|}{ Concentration $(\mu \mathrm{g} / \mathrm{L})$} \\
\cline { 3 - 5 } & & Range & Average & $\begin{array}{c}\text { Standard } \\
\text { Deviation }\end{array}$ \\
\hline Alkalinity & $34 / 34$ & $40000-130000$ & 69250 & 21379 \\
\hline Chemical Oxygen Demand & $27 / 33$ & $6000-140000$ & 20593 & 25755 \\
\hline Total carbon & $33 / 33$ & $14000-76000$ & 22364 & 10591 \\
\hline Total dissolved solids & $32 / 32$ & $90000-480000$ & 142188 & 69083 \\
\hline Total organic carbon & $33 / 33$ & $2000-61000$ & 6394 & 10176 \\
\hline \hline
\end{tabular}

(a) Number of samples with detectable concentrations/total number of samples analyzed.

Table F.33. Building 331: General Chemical Parameters Detected in Nonbusiness Day Samples

\begin{tabular}{||l|c|c|c|c||}
\hline \multirow{2}{*}{\multicolumn{1}{|c|}{ Parameter }} & \multirow{2}{*}{ Frequency $^{(a)}$} & \multicolumn{2}{c|}{ Concentration $(\mu \mathrm{g} / \mathrm{L})$} \\
\cline { 3 - 5 } & & Range & Average & $\begin{array}{c}\text { Standard } \\
\text { Deviation }\end{array}$ \\
\hline Alkalinity & $5 / 5$ & $45000-50000$ & 48200 & 2050 \\
\hline Chemical Oxygen Demand & $2 / 5$ & $7000-8000$ & 7500 & 710 \\
\hline Total carbon & $5 / 5$ & $13000-15000$ & 13800 & 837 \\
\hline Total dissolved solids & $5 / 5$ & $90000-120000$ & 102000 & 10950 \\
\hline Total organic carbon & $5 / 5$ & $2000-3000$ & 2400 & 548 \\
\hline
\end{tabular}

(a) Number of samples with detectable concentrations/total number of samples analyzed. 
Table F.34. Building 331: Ammonia and Anions Detected in Routine Samples

\begin{tabular}{||l|c|c|r|c||}
\hline \multirow{2}{*}{ Constituent } & \multirow{2}{*}{ Frequency $^{\text {(a) }}$} & \multicolumn{3}{c|}{ Concentration (ug/L) } \\
\cline { 3 - 5 } & & Range & Average & $\begin{array}{c}\text { Standard } \\
\text { Deviation }\end{array}$ \\
\hline Ammonia & $23 / 34$ & $30-1000$ & 169 & 270 \\
\hline Bromide & $2 / 35$ & $140-200$ & 170 & - \\
\hline Chloride & $35 / 35$ & $3600-167000$ & 12031 & 27068 \\
\hline Cyanide & $25 / 32$ & $1-70$ & 19 & 22 \\
\hline Fluoride & $35 / 35$ & $400-900$ & 643 & 126 \\
\hline Nitrate & $35 / 35$ & $300-33000$ & 5803 & 7885 \\
\hline Nitrite & $2 / 29$ & $110-130$ & 120 & - \\
\hline Phosphate & $24 / 35$ & $212-19800$ & 3626 & 4083 \\
\hline Sulfate & $35 / 35$ & $10000-47900$ & 19631 & 6332 \\
\hline Sulfides & $12 / 33$ & $200-400$ & 235 & 64 \\
\hline \hline (a) Number of samples with detectable concentrations/total number of samples analyzed. \\
\hline
\end{tabular}

Table F.35. Building 331: Ammonia and Anions Detected in Nonbusiness Day Samples

\begin{tabular}{||l|c|c|r|c||}
\hline \multirow{2}{*}{ Constituent } & \multirow{2}{*}{ Frequency $^{(\mathrm{a})}$} & \multicolumn{2}{c|}{ Concentration $(\mu \mathrm{g} / \mathrm{L})$} \\
\cline { 3 - 5 } & & Range & Average & $\begin{array}{c}\text { Standard } \\
\text { Deviation }\end{array}$ \\
\hline Ammonia & & $23-30$ & 28 & 4 \\
\hline Bromide & $1 / 5$ & - & 110 & - \\
\hline Chloride & $5 / 5$ & $4700-6800$ & 6060 & 847 \\
\hline Cyanide & $2 / 5$ & $2-8$ & 5 & - \\
\hline Fluoride & $5 / 5$ & $600-800$ & 700 & 71 \\
\hline Nitrate & $5 / 5$ & $300-2700$ & 1200 & 1005 \\
\hline Phosphate & $1 / 5$ & - & 2200 & - \\
\hline Sulfate & $5 / 5$ & $17000-21000$ & 19000 & 1871 \\
\hline Sulfides & $1 / 5$ & - & 300 & - \\
\hline \hline
\end{tabular}
(a) Number of samples with detectable concentrations/total number of samples analyzed. 
Table F.36. Building 331: Metals Detected in Routine Samples

\begin{tabular}{||l|c|c|c|c||}
\hline \multirow{2}{*}{ Constituent } & \multirow{2}{*}{ Frequency } & \multicolumn{3}{c|}{ Concentration $(\mu \mathrm{g} / \mathrm{L})$} \\
\cline { 3 - 5 } & & Range & Average & $\begin{array}{c}\text { Standard } \\
\text { Deviation }\end{array}$ \\
\hline Aluminum & $32 / 33$ & $22-630$ & 168 & 178 \\
\hline Arsenic & $5 / 33$ & $2-3$ & 2 & 1 \\
\hline Barium & $33 / 33$ & $17-41$ & 29 & 5 \\
\hline Beryllium & $1 / 33$ & - & 0 & - \\
\hline Cadmium & $2 / 33$ & - & 3 & - \\
\hline Calcium & $33 / 33$ & $18000-43000$ & 24424 & 6888 \\
\hline Chromium & $4 / 33$ & $7-22$ & 17 & 7 \\
\hline Copper & $33 / 33$ & $10-110$ & 30 & 22 \\
\hline Iron & $31 / 33$ & $18-460$ & 81 & 85 \\
\hline Lead & $27 / 33$ & $0.6-17.0$ & 2.6 & 3.1 \\
\hline Magnesium & $33 / 33$ & $4000-18000$ & 5755 & 2439 \\
\hline Manganese & $24 / 33$ & $1-15$ & 3 & 3 \\
\hline Mercury & $7 / 33$ & $0.06-0.17$ & 0.11 & 0.04 \\
\hline Nickel & $2 / 33$ & $16-17$ & 17 & - \\
\hline Potassium & $32 / 33$ & $940-7700$ & 2670 & 1723 \\
\hline Selenium & $1 / 33$ & - & 2.0 & - \\
\hline Silver & $1 / 33$ & - & 3.6 & - \\
\hline Sodium & $1 / 33$ & $3300-110000$ & 11958 & 18299 \\
\hline Thallium & $33 / 33$ & $0.8-1.1$ & 1.0 & - \\
\hline Tin & $5 / 33$ & $24-110$ & 71 & 31 \\
\hline Vanadium & $1 / 33$ & - & 7 & - \\
\hline Zinc & $33 / 33$ & $22-140$ & 59 & 27 \\
\hline \hline a) Number of samples with & detectable concentrations/total number of samples analyzed.| \\
\hline \hline & & & & \\
\hline
\end{tabular}


Table F.37. Building 331: Metals Detected in Nonbusiness Day Samples

\begin{tabular}{|c|c|c|c|c|}
\hline \multirow[b]{2}{*}{ Constituent } & \multirow[b]{2}{*}{ Frequency $^{(\mathbf{a})}$} & \multicolumn{3}{|c|}{ Concentration $(\mu \mathrm{g} / \mathrm{L})$} \\
\hline & & Range & Average & $\begin{array}{l}\text { Standard } \\
\text { Deviation }\end{array}$ \\
\hline Aluminum & $5 / 5$ & $56-81$ & 70 & 11 \\
\hline Antimony & $1 / 5$ & - & 42 & - \\
\hline Barium & $5 / 5$ & $28-33$ & 30 & 2 \\
\hline Calcium & $5 / 5$ & $19000-21000$ & 20000 & 1000 \\
\hline Copper & $5 / 5$ & $10-36$ & 20 & 13 \\
\hline Iron & $4 / 5$ & $23-65$ & 39 & 19 \\
\hline Lead & $3 / 5$ & $0.7-1.5$ & 1.1 & 0.4 \\
\hline Magnesium & $5 / 5$ & $4300-5000$ & 4700 & 292 \\
\hline Manganese & $1 / 5$ & - & 3 & - \\
\hline Potassium & $4 / 5$ & $1000-2000$ & 1400 & 432 \\
\hline Selenium & $1 / 5$ & - & 2 & - \\
\hline Silver & $2 / 5$ & $3.4-4.2$ & 3.8 & - \\
\hline Sodium & $5 / 5$ & $3200-7200$ & 4140 & 1714 \\
\hline Tin & $1 / 5$ & - & 33 & - \\
\hline Zinc & $5 / 5$ & $42-79$ & 58 & 15 \\
\hline
\end{tabular}

(a) Number of samples with detectable concentrations/total number of samples analyzed. 
Table F.38. Building 331: Volatile Organic Compounds Detected in Routine Samples

\begin{tabular}{|c|c|c|c|c|}
\hline \multirow[b]{2}{*}{ Constituent } & \multirow[b]{2}{*}{ Frequency ${ }^{(a)}$} & \multicolumn{3}{|c|}{ Concentration $(\mu \mathrm{g} / \mathrm{L})$} \\
\hline & & Range & Average & $\begin{array}{l}\text { Standard } \\
\text { Deviation }\end{array}$ \\
\hline Acetone & $7 / 55$ & $7.4-1800.0$ & 284.9 & 668.2 \\
\hline Acetonitrile & $1 / 26$ & - & 430.0 & - \\
\hline Bromodichloromethane & $16 / 32$ & $0.5-9.8$ & 2.3 & 2.3 \\
\hline Bromoform & $1 / 32$ & - & 26.0 & - \\
\hline 2-Butanone & $3 / 55$ & $51-170$ & 103.3 & 60.8 \\
\hline Chlorobenzene & $1 / 26$ & - & 0.4 & - \\
\hline Chloroform & $55 / 55$ & $3.1-33.0$ & 11.4 & 6.5 \\
\hline Dibromochloromethane & $6 / 32$ & $0.7-11.0$ & 2.7 & 4.1 \\
\hline Hexone & $2 / 55$ & - & 19.0 & - \\
\hline Methylene chloride & $41 / 55$ & $0.4-2.0$ & 1.0 & 0.4 \\
\hline Tetrahydrofuran & $1 / 55$ & - & 3.0 & - \\
\hline Toluene & $4 / 55$ & $0.22-0.86$ & 0.53 & 0.26 \\
\hline 1,1,1-Trichloroethane & $1 / 55$ & - & 2.1 & - \\
\hline Trichloroethene & $2 / 55$ & $0.5-0.9$ & 0.7 & - \\
\hline Xylenes (total) & $3 / 55$ & $1.4-2.4$ & 1.8 & 0.5 \\
\hline
\end{tabular}


Table F.39. Building 331: Volatile Organic Compounds Detected in Nonbusiness Day Samples

\begin{tabular}{|c|c|c|c|c|}
\hline \multirow[b]{2}{*}{ Constituent } & \multirow[b]{2}{*}{ Frequency ${ }^{(a)}$} & \multicolumn{3}{|c|}{ Concentration $(\mu \mathrm{g} / \mathrm{L})$} \\
\hline & & Range & Average & $\begin{array}{l}\text { Standard } \\
\text { Deviation }\end{array}$ \\
\hline Acetone & $1 / 10$ & - & 67.0 & - \\
\hline Bromodichloromethane & $6 / 8$ & $1.2-9.5$ & 3.2 & 3.2 \\
\hline Bromoform & $1 / 8$ & - & 15.0 & - \\
\hline Chloroform & $10 / 10$ & $8.6-26.0$ & 16.9 & 5.3 \\
\hline Dibromochloromethane & $2 / 8$ & $1.7-11.0$ & 6.4 & - \\
\hline Hexone & $1 / 10$ & - & 38.0 & - \\
\hline Methylene chloride & $10 / 10$ & $0.4=1.1$ & 0.8 & 0.3 \\
\hline Toluene & $2 / 10$ & $0.4-0.5$ & 0.5 & - \\
\hline Xylenes (total) & $2 / 10$ & $0.3-1.9$ & 1.1 & - \\
\hline
\end{tabular}


Table F.40. Building 331: Semivolatile Organic Compounds Detected in Routine Samples

\begin{tabular}{|c|c|c|c|c|}
\hline \multirow[b]{2}{*}{ Constituent } & \multirow[b]{2}{*}{ Frequency ${ }^{(a)}$} & \multicolumn{3}{|c|}{ Concentration $(\mu \mathrm{g} / \mathrm{L})$} \\
\hline & & Range & Average & $\begin{array}{l}\text { Standard } \\
\text { Deviation }\end{array}$ \\
\hline \multicolumn{5}{|c|}{ Acids/Bases/Neutrals (ABNs) } \\
\hline Benzyl alcohol & $2 / 14$ & $4.1-28.0$ & 16.1 & - \\
\hline Bis(2-ethylhexyl)phthalate & $6 / 35$ & $1.7-6.4$ & 3.7 & 2.1 \\
\hline Decane & $1 / 21$ & $\overline{-}$ & 37.0 & - \\
\hline $\mid \begin{array}{l}\text { Di-n-butylphthalate } \\
\end{array}$ & $4 / 14$ & $2.0-3.6$ & 2.5 & 0.8 \\
\hline \multicolumn{5}{|c|}{ Pesticides } \\
\hline $4,4^{\prime}-\mathrm{DDE}$ & $3 / 34$ & $0.002-0.720$ & 0.242 & 0.414 \\
\hline Aldrin & $1 / 34$ & $\overline{-}$ & 0.011 & $\overline{-}$ \\
\hline Alpha-BHC & $3 / 34$ & $0.004-0.007$ & 0.006 & 0.002 \\
\hline Beta-BHC & $3 / 34$ & $0.010-0.026$ & 0.015 & 0.009 \\
\hline Delta-BHC & $9 / 34$ & $0.005-0.033$ & 0.012 & 0.009 \\
\hline Dieldrin & $1 / 34$ & - & 0.003 & - \\
\hline Endosulfan I & $5 / 34$ & $0.002-0.005$ & 0.003 & 0.001 \\
\hline Endrin & $1 / 34$ & - & 0.007 & - \\
\hline Endrin aldehyde & $1 / 34$ & - & 0.012 & - \\
\hline Gamma-BHC (Lindane) & $5 / 34$ & $0.002-0.004$ & 0.003 & 0.001 \\
\hline Methoxychlor & $1 / 34$ & - & 0.019 & - \\
\hline
\end{tabular}


Table F.41. Building 331: Semivolatile Organic Compounds Detected in Nonbusiness Day Samples

\begin{tabular}{|c|c|c|c|c|}
\hline \multirow[b]{2}{*}{ Constituent } & \multirow[b]{2}{*}{ Frequency $^{(a)}$} & \multicolumn{3}{|c|}{ Concentration $(\mu \mathrm{g} / \mathrm{L})$} \\
\hline & & Range & Average & $\begin{array}{l}\text { Standard } \\
\text { Deviation }\end{array}$ \\
\hline \multicolumn{5}{|c|}{ Acids/Bases/Neutrals (ABNs) } \\
\hline Bis(2-ethylhexyl)phthalate & $1 / 5$ & - & 3.6 & - \\
\hline \multicolumn{5}{|c|}{ Pesticides } \\
\hline Aldrin & $1 / 5$ & - & 0.004 & - \\
\hline Delta-BHC & $1 / 5$ & - & 0.017 & - \\
\hline Endosulfan I & $1 / 5$ & - & 0.006 & - \\
\hline Gamma-BHC (Lindane) & $1 / 5$ & - & 0.005 & - \\
\hline
\end{tabular}

(a) Number of samples with detectable concentrations/total number of samples analyzed.

Table F.42. Building 331: Radiological Parameters Detected in Routine Samples

\begin{tabular}{||l|c|c|c|c||}
\hline \multirow{2}{*}{\multicolumn{1}{|c|}{ Parameter }} & \multirow{2}{*}{ Frequency $^{(a)}$} & \multicolumn{3}{c|}{ Concentration (pCi/L) } \\
\cline { 3 - 5 } & & Range & Average & 2SEM \\
\cline { 3 - 5 } & & $0.8-8.3$ & 3.0 & 1.0 \\
\hline Gross alpha & $17 / 33$ & $2.1-9.5$ & 4.4 & 0.9 \\
\hline Gross beta & $23 / 33$ & $280.0-330.0$ & 305.0 & - \\
\hline Tritium & $2 / 2$ & & - \\
\hline \hline
\end{tabular}

(a) Number of samples with detectable concentrations/total number of samples analyzed.

(b) Two times the standard error of the calculated mean.

Table F.43. Building 331: Radiological Parameters Detected in Nonbusiness Day Samples

\begin{tabular}{|l|c|c|c|c||}
\hline \multirow{2}{*}{ Parameter } & \multirow{2}{*}{ Frequency } & \multicolumn{3}{c|}{ Concentration (pCi/L) } \\
\cline { 3 - 5 } & & Range & Average & 2SEM \\
\hline Gross alpha & $3 / 5$ & $0.9-12.8$ & 4.9 & 7.9 \\
\hline Gross beta & $1 / 5$ & - & 2.7 & - \\
\hline \hline (a) Number of samples with detectable concentrations/total number of samples analyzed. \\
(b) Two times the standard error of the calculated mean. \\
\hline
\end{tabular}


Table F.44. Building 3720: General Chemical Parameters Detected in Routine Samples

\begin{tabular}{||l|c|c|c|c||}
\hline \multirow{2}{*}{\multicolumn{1}{|c|}{ Parameter }} & \multirow{2}{*}{ Frequency ${ }^{(a)}$} & \multicolumn{2}{c|}{ Concentration $(\mu \mathrm{g} / \mathrm{L})$} \\
\cline { 3 - 5 } & & Range & Average & $\begin{array}{c}\text { Standard } \\
\text { Deviation }\end{array}$ \\
\hline Alkalinity & $29 / 29$ & $40000-120000$ & 58862 & 15887 \\
\hline Chemical Oxygen Demand & $21 / 29$ & $3000-51000$ & 12900 & 11550 \\
\hline Total carbon & $28 / 28$ & $12000-30000$ & 18036 & 4501 \\
\hline Total dissolved solids & $27 / 27$ & $80000-190000$ & 105556 & 23751 \\
\hline Total organic carbon & $28 / 28$ & $1000-16000$ & 3214 & 3011 \\
\hline \hline
\end{tabular}

(a) Number of samples with detectable concentrations/total number of samples analyzed.

Table F.45. Building 3720: General Chemical Parameters Detected in Nonbusiness Day Samples

\begin{tabular}{||l|c|c|c|c||}
\hline \multirow{2}{*}{\multicolumn{1}{|c|}{ Parameter }} & \multirow{2}{*}{ Frequency $^{(\mathrm{a})}$} & \multicolumn{3}{c|}{ Concentration $(\mu \mathrm{g} / \mathrm{L})$} \\
\cline { 3 - 5 } & & Range & Average & $\begin{array}{c}\text { Standard } \\
\text { Deviation }\end{array}$ \\
\hline Alkalinity & $6 / 6$ & $40000-70000$ & 52670 & 10630 \\
\hline Chemical Oxygen Demand & $1 / 6$ & - & 14000 & - \\
\hline Total carbon & $6 / 6$ & $11000-23000$ & 15333 & 4227 \\
\hline Total dissolved solids & $6 / 6$ & $90000-100000$ & 95000 & 5480 \\
\hline Total organic carbon & $6 / 6$ & $1000-5000$ & 2333 & 1506 \\
\hline \hline
\end{tabular}

(a) Number of samples with detectable concentrations/total number of samples analyzed. 
Table F.46. Building 3720: Ammonia and Anions Detected in Routine Samples

\begin{tabular}{|c|c|c|c|c|}
\hline \multirow[b]{2}{*}{ Constituent } & \multirow[b]{2}{*}{ Frequency $^{(a)}$} & \multicolumn{3}{|c|}{ Concentration $(\mu \mathrm{g} / \mathrm{L})$} \\
\hline & & Range & Average & $\begin{array}{l}\text { Standard } \\
\text { Deviation }\end{array}$ \\
\hline Ammonia & $5 / 29$ & $30-100$ & 74 & 36 \\
\hline Chloride & $29 / 29$ & $2200-11600$ & 5658 & 1774 \\
\hline Cyanide & $4 / 26$ & $2-10$ & 5 & 3 \\
\hline Fluoride & $29 / 29$ & $200-1000$ & 554 & 162 \\
\hline Nitrate & $29 / 29$ & $600-16000$ & 3234 & 3606 \\
\hline Sulfate & $29 / 29$ & $8500-28000$ & 15879 & 3523 \\
\hline Sulfides & $10 / 27$ & $200-300$ & 232 & 39 \\
\hline
\end{tabular}

(a) Number of samples with detectable concentrations/total number of samples analyzed.

Table F.47. Building 3720: Ammonia and Anions Detected in Nonbusiness Day Samples

\begin{tabular}{|c|c|c|c|c|}
\hline \multirow[b]{2}{*}{ Constituent } & \multirow[b]{2}{*}{ Frequency ${ }^{(a)}$} & \multicolumn{3}{|c|}{ Concentration $(\mu \mathrm{g} / \mathrm{L})$} \\
\hline & & Range & Average & $\begin{array}{l}\text { Standard } \\
\text { Deviation }\end{array}$ \\
\hline Ammonia & $1 / 6$ & - & 23 & - \\
\hline Chloride & $6 / 6$ & $1900-5800$ & 4167 & 1271 \\
\hline Fluoride & $6 / 6$ & $200-800$ & 517 & 223 \\
\hline Nitrate & $6 / 6$ & $500-1600$ & 867 & 398 \\
\hline Sulfate & $6 / 6$ & $15000-40000$ & 19833 & 9908 \\
\hline Sulfides & $3 / 6$ & $200-300$ & 267 & 58 \\
\hline
\end{tabular}

(a) Number of samples with detectable concentrations/total number of samples analyzed. 
Table F.48. Building 3720: Metals Detected in Routine Samples

\begin{tabular}{||l|c|c|c|c||}
\hline \multirow{2}{*}{ Constituent } & \multirow{2}{*}{ Frequency } & \multicolumn{2}{c|}{ Concentration $(\mu \mathrm{g} / \mathrm{L})$} \\
\cline { 3 - 5 } & & Range & Average & $\begin{array}{c}\text { Standard } \\
\text { Deviation }\end{array}$ \\
\hline Aluminum & $28 / 29$ & $21-140$ & 69 & 29 \\
\hline Antimony & $1 / 29$ & - & 33 & - \\
\hline Arsenic & $1 / 29$ & - & 2 & - \\
\hline Barium & $29 / 29$ & $14-66$ & 29 & 9 \\
\hline Cadmium & $3 / 29$ & - & 4 & 0 \\
\hline Calcium & $29 / 29$ & $19000-43000$ & 21897 & 4723 \\
\hline Chromium & $5 / 29$ & $4.7-27.0$ & 14 & 9 \\
\hline Copper & $29 / 29$ & $4-130$ & 19 & 24 \\
\hline Iron & $29 / 29$ & $27-230$ & 89 & 41 \\
\hline Lead & $24 / 29$ & $1.1-7.1$ & 3.0 & 1.7 \\
\hline Magnesium & $29 / 29$ & $4000-9100$ & 4803 & 1012 \\
\hline Manganese & $27 / 29$ & $1.0-13.0$ & 4.2 & 2.8 \\
\hline Mercury & $19 / 27$ & $0.06-0.87$ & 0.24 & 0.19 \\
\hline Nickel & $4 / 29$ & $15-18$ & 17 & 1 \\
\hline Potassium & $23 / 29$ & $910-2800$ & 1537 & 507 \\
\hline Selenium & $3 / 29$ & $0.6-2.0$ & 1.1 & 0.8 \\
\hline Sodium & $29 / 29$ & $3000-13000$ & 5766 & 2309 \\
\hline Thallium & $5 / 29$ & $0.6-2.0$ & 1.1 & 0.5 \\
\hline Tin & $6 / 29$ & $34-65$ & 47 & 14 \\
\hline Zinc & $29 / 29$ & $16-280$ & 60 & 52 \\
\hline \hline na) Num & & & & \\
\hline
\end{tabular}

(a) Number of samples with detectable concentrations/total number of samples analyzed. 
Table F.49. Building 3720: Metals Detected in Nonbusiness Day Samples

\begin{tabular}{||l|c|c|c|c||}
\hline \multirow{2}{*}{ Constituent } & \multirow{2}{*}{ Frequency } & \multicolumn{3}{c|}{ Concentration $(\mu \mathrm{g} / \mathrm{L})$} \\
\cline { 3 - 5 } & & Range & Average & $\begin{array}{c}\text { Standard } \\
\text { Deviation }\end{array}$ \\
\hline Aluminum & $6 / 6$ & $42-190$ & 77 & 57 \\
\hline Barium & $6 / 6$ & $15-29$ & 25 & 5 \\
\hline Cadmium & $1 / 6$ & - & 3 & - \\
\hline Calcium & $6 / 6$ & $19000-21000$ & 19833 & 983 \\
\hline Cobalt & $1 / 6$ & - & 7 & - \\
\hline Copper & $6 / 6$ & $6.6-14.0$ & 10.2 & 3.4 \\
\hline Iron & $6 / 6$ & $44-84$ & 65 & 14 \\
\hline Lead & $5 / 6$ & $1.0-4.1$ & 2.4 & 1.3 \\
\hline Magnesium & $6 / 6$ & $4100-4700$ & 4283 & 223 \\
\hline Manganese & $4 / 6$ & $1.5-3.3$ & 2.1 & 0.9 \\
\hline Mercury & $5 / 6$ & $0.11-0.26$ & 0.18 & 0.06 \\
\hline Potassium & $3 / 6$ & $1000-1300$ & 1100 & 173 \\
\hline Silver & $1 / 6$ & - & 4.7 & - \\
\hline Sodium & $6 / 6$ & $2700-3600$ & 2983 & 407 \\
\hline Thallium & $1 / 6$ & - & 2 & - \\
\hline Tin & $1 / 6$ & - & 24 & - \\
\hline Zinc & $6 / 6$ & $15-49$ & 34 & 12 \\
\hline \hline (a) Number of samples with detectable concentrations/total number of samples analyzed. \\
\hline \hline
\end{tabular}


Table F.50. Building 3720: Volatile Organic Compounds Detected in Routine Samples

\begin{tabular}{|c|c|c|c|c|}
\hline \multirow[b]{2}{*}{ Constituent } & \multirow[b]{2}{*}{ Frequency ${ }^{(a)}$} & \multicolumn{3}{|c|}{ Concentration $(\mu \mathrm{g} / \mathrm{L})$} \\
\hline & & Range & Average & $\begin{array}{l}\text { Standard } \\
\text { Deviation }\end{array}$ \\
\hline Acetone & $23 / 48$ & $7.7-530.0$ & 88.8 & 142.9 \\
\hline Acetonitrile & $2 / 56$ & $7.1-820.0$ & 413.6 & - \\
\hline Bromodichloromethane & $10 / 31$ & $0.85-2.0$ & 1.3 & 0.4 \\
\hline Carbon disulfide & $1 / 44$ & - & 2.5 & - \\
\hline Chloroform & $47 / 48$ & $2.5-32.0$ & 12.4 & 5.4 \\
\hline Dibromochloromethane & $1 / 31$ & - & 1.7 & - \\
\hline 1,2-Dichloroethylene & $6 / 44$ & $0.4-1.0$ & 0.6 & 0.2 \\
\hline Ethanol & $6 / 44$ & $5.5-26.0$ & 14.1 & 8.7 \\
\hline Diethyl ether & $2 / 44$ & $5.0-38.0$ & 21.5 & - \\
\hline Ethylbenzene & $3 / 31$ & $0.4-0.9$ & 0.6 & 0.2 \\
\hline Hexone & $3 / 48$ & $5.8-37.0$ & 21.9 & 15.6 \\
\hline Isopropyl alcohol & $11 / 44$ & $5.2-34.0$ & 13.1 & 8.6 \\
\hline Methylene chloride & $39 / 48$ & $0.4-9.7$ & 1.4 & 1.5 \\
\hline Tetrahydrofuran & $8 / 48$ & $3.4-406.0$ & 63.4 & 138.8 \\
\hline Toluene & $7 / 48$ & $0.1-410$ & 69.4 & 150.8 \\
\hline 1,1,2-Trichloroethane & $1 / 44$ & - & 0.8 & - \\
\hline Trichloroethene & $47 / 48$ & $0.7-2.1$ & 1.3 & 0.4 \\
\hline Xylenes (total) & $3 / 48$ & $2.1-2.9$ & 2.4 & 0.4 \\
\hline
\end{tabular}


Table F.51. Building 3720: Volatile Organic Compounds Detected in Nonbusiness Day Samples

\begin{tabular}{|c|c|c|c|c|}
\hline \multirow[b]{2}{*}{ Constituent } & \multirow[b]{2}{*}{ Frequency ${ }^{(\mathbf{a})}$} & \multicolumn{3}{|c|}{ Concentration $(\mu \mathrm{g} / \mathrm{L})$} \\
\hline & & Range & Average & $\begin{array}{l}\text { Standard } \\
\text { Deviation }\end{array}$ \\
\hline Acetone & $2 / 11$ & $25.0-37.0$ & 31.0 & - \\
\hline Bromodichloromethane & $1 / 6$ & - & 2.0 & - \\
\hline Chlorobenzene & $1 / 6$ & - & 0.7 & - \\
\hline Chloroform & $11 / 11$ & $5.8-40.0$ & 14.7 & 9.7 \\
\hline 1,2-Dichloroethylene & $4 / 11$ & $0.4-1.1$ & 0.7 & 0.3 \\
\hline Isopropyl alcohol & $1 / 11$ & - & 7.5 & - \\
\hline Methylene chloride & $11 / 11$ & $0.3-1.5$ & 0.9 & 0.4 \\
\hline Tetrahydrofuran & $1 / 11$ & - & 7.0 & - \\
\hline Toluene & $2 / 11$ & $0.2-0.6$ & 0.4 & - \\
\hline Trichloroethene & $11 / 11$ & $0.8-1.6$ & 1.2 & 0.3 \\
\hline
\end{tabular}

(a) Number of samples with detectable concentrations/total number of samples analyzed.

Table F.52. Building 3720: Semivolatile Organic Compounds Detected in Routine Samples

\begin{tabular}{||l|c|c|c|c|}
\hline \multirow{2}{*}{ Constituent } & \multirow{2}{*}{ Frequency ${ }^{(a)}$} & \multicolumn{2}{c|}{ Concentration $(\mu \mathrm{g} / \mathrm{L}$ ) } \\
\cline { 3 - 5 } & & Range & Average & $\begin{array}{c}\text { Standard } \\
\text { Deviation }\end{array}$ \\
\hline & & Acids/Bases/Neutrals (ABNs) & \\
\hline Bis(2-ethylhexyl)phthalate & $10 / 28$ & $1.2-8.6$ & 3.4 & 2.2 \\
\hline Di-n-butylphthalate & $4 / 13$ & $1.9-3.6$ & 2.5 & 0.8 \\
\hline Diethylphthalate & $3 / 14$ & $35.0-170.0$ & 81.3 & 76.8 \\
\hline Tributyl phosphate & $2 / 28$ & $5.6-9.8$ & 7.7 & - \\
\hline \hline
\end{tabular}

(a) Number of samples with detectable concentrations/total number of samples analyzed. 
Table F.53. Building 3720: Semivolatile Organic Compounds Detected in Nonbusiness Day Samples

\begin{tabular}{||l|c|c|c|c||}
\hline \multirow{2}{*}{$\begin{array}{c}\text { Constituent } \\
\text { Frequency }\end{array}$} & \multicolumn{3}{|c|}{ Concentration $(\mu \mathrm{g} / \mathrm{L})$} \\
\cline { 3 - 5 } & & Range & Average & $\begin{array}{c}\text { Standard } \\
\text { Deviation }\end{array}$ \\
\hline Bis(2-ethylhexyl)phthalate & $2 / 6$ & $1.5-7.6$ & 4.6 & - \\
\hline \hline (a) Number of samples with detectable concentrations/total number of samples analyzed. \\
\hline
\end{tabular}

Table F.54. Building 3720: Radiological Parameters Detected in Routine Samples

\begin{tabular}{||l|c|c|c|c||}
\hline \multirow{2}{*}{ Parameter } & \multirow{2}{*}{ Frequency $^{(\mathrm{a})}$} & \multicolumn{3}{c|}{ Concentration (pCi/L) } \\
\cline { 3 - 5 } & & Range & Average & 2SEM \\
\hline Gross alpha & $28 / 28$ & $4.1-44.6$ & 13.7 & 3.0 \\
\hline Gross beta & $25 / 28$ & $2.6-17.6$ & 5.2 & 1.2 \\
\hline Uranium-234 & $1 / 1$ & - & 8.0 & - \\
\hline Uranium-235 & $1 / 1$ & - & 0.4 & - \\
\hline Uranium-238 & $1 / 1$ & - & 6.5 & - \\
\hline \hline
\end{tabular}

(a) Number of samples with detectable concentrations/total number of samples analyzed.

(b) Two times the standard error of the calculated mean.

Table F.55. Building 3720: Radiological Parameters Detected in Nonbusiness Day Samples

\begin{tabular}{||l|c|c|c|c||}
\hline \multirow{2}{*}{\multicolumn{1}{|c|}{ Parameter }} & \multirow{2}{*}{ Frequency ${ }^{(\mathrm{a})}$} & \multicolumn{3}{c|}{ Concentration (pCi/L) } \\
\cline { 3 - 5 } & & Range & Average & 2SEM \\
\cline { 3 - 5 } & & $7.4-28.0$ & 17.3 & 5.8 \\
\hline Gross alpha & $6 / 6$ & $4.0-10.6$ & 6.1 & 2.3 \\
\hline Gross beta & $5 / 6$ & & \\
\hline \hline
\end{tabular}

(a) Number of samples with detectable concentrations/total number of samples analyzed. (b) Two times the standard error of the calculated mean. 
Table F.56. End-of-Pipe: General Chemical Parameters Detected in Routine Samples

\begin{tabular}{|c|c|c|c|c|}
\hline \multirow[b]{2}{*}{ Parameter } & \multirow[b]{2}{*}{ Frequency ${ }^{(\mathbf{a})}$} & \multicolumn{3}{|c|}{ Concentration $(\mu \mathrm{g} / \mathrm{L})$} \\
\hline & & Range & Average & $\begin{array}{l}\text { Standard } \\
\text { Deviation }\end{array}$ \\
\hline Alkalinity & $28 / 28$ & $40000-140000$ & 59536 & 21852 \\
\hline Chemical Oxygen Demand & $19 / 28$ & $4700-84000$ & 12953 & 17600 \\
\hline Total carbon & $28 / 28$ & $13000-42000$ & 17929 & 5850 \\
\hline Total dissolved solids & $27 / 27$ & $80000-240000$ & 109630 & 36319 \\
\hline Total organic carbon & $29 / 29$ & $1000-36000$ & 3793 & 6315 \\
\hline
\end{tabular}

(a) Number of samples with detectable concentrations/total number of samples analyzed.

Table F.57. End-of-Pipe: General Chemical Parameters Detected in Nonbusiness Day Samples

\begin{tabular}{||l|c|c|c|c||}
\hline \multirow{2}{*}{\multicolumn{1}{|c|}{ Parameter }} & \multirow{2}{*}{ Frequency ${ }^{(\mathrm{a})}$} & \multicolumn{3}{c|}{ Concentration $(\mu \mathrm{g} / \mathrm{L})$} \\
\cline { 3 - 5 } & & Range & Average & $\begin{array}{c}\text { Standard } \\
\text { Deviation }\end{array}$ \\
\hline Alkalinity & $7 / 7$ & $40000-70000$ & 53860 & 11580 \\
\hline Chemical Oxygen Demand & $1 / 7$ & - & 9000 & - \\
\hline Total carbon & $6 / 6$ & $12000-17000$ & 14167 & 1941 \\
\hline Total dissolved solids & $6 / 6$ & $80000-100000$ & 90000 & 6320 \\
\hline Total organic carbon & $7 / 7$ & $2000-3000$ & 2143 & 378 \\
\hline \hline
\end{tabular}

(a) Number of samples with detectable concentrations/total number of samples analyzed. 
Table F.58. End-of-Pipe: Ammonia and Anions Detected in Routine Samples

\begin{tabular}{|l|c|c|c|c||}
\hline \multirow{2}{*}{ Constituent } & \multirow{2}{*}{ Frequency $^{(\mathrm{a})}$} & \multicolumn{2}{c|}{ Concentration $(\mathrm{\mu g} / \mathrm{L})$} \\
\cline { 3 - 5 } & & Range & Average & $\begin{array}{c}\text { Standard } \\
\text { Deviation }\end{array}$ \\
\hline Ammonia & $8 / 26$ & $23-100$ & 48 & 28 \\
\hline Bromide & $1 / 27$ & - & 200 & - \\
\hline Chloride & $27 / 27$ & $2500-190000$ & 14024 & 35457 \\
\hline Cyanide & $4 / 28$ & $1-5$ & 3 & 2 \\
\hline Fluoride & $26 / 27$ & $200-800$ & 565 & 158 \\
\hline Nitrate & $27 / 27$ & $200-20000$ & 2988 & 4495 \\
\hline Phosphate & $5 / 27$ & $383-800$ & 522 & 166 \\
\hline Sulfate & $27 / 27$ & $10000-36900$ & 17756 & 4467 \\
\hline Sulfides & $8 / 26$ & $200-400$ & 283 & 63 \\
\hline \hline
\end{tabular}

(a) Number of samples with detectable concentrations/total number of samples analyzed.

Table F.59. End-of-Pipe: Ammonia and Anions Detected in Nonbusiness Day Samples

\begin{tabular}{|c|c|c|c|c|}
\hline \multirow[b]{2}{*}{ Constituent } & \multirow[b]{2}{*}{ Frequency ${ }^{(a)}$} & \multicolumn{3}{|c|}{ Concentration $(\mu \mathrm{g} / \mathrm{L})$} \\
\hline & & Range & Average & $\begin{array}{l}\text { Standard } \\
\text { Deviation }\end{array}$ \\
\hline Ammonia & $1 / 7$ & - & 60 & - \\
\hline Chloride & $7 / 7$ & $2200-6100$ & 4629 & 1743 \\
\hline Fluoride & $7 / 7$ & $200-800$ & 486 & 248 \\
\hline Nitrate & $7 / 7$ & $500-900$ & 714 & 177 \\
\hline Sulfate & $7 / 7$ & $10000-20000$ & 15857 & 3848 \\
\hline Sulfides & $2 / 6$ & - & 200 & - \\
\hline
\end{tabular}

(a) Number of samples with detectable concentrations/total number of samples analyzed. 
Table F.60. End-of-Pipe: Metals Detected in Routine Samples

\begin{tabular}{|c|c|c|c|c|}
\hline \multirow[b]{2}{*}{ Constituent } & \multirow[b]{2}{*}{ Frequency $^{(a)}$} & \multicolumn{3}{|c|}{ Concentration ( $\mu \mathrm{g} / \mathrm{L})$} \\
\hline & & Range & Average & $\begin{array}{l}\text { Standard } \\
\text { Deviation }\end{array}$ \\
\hline Aluminum & $29 / 29$ & $40-410$ & 89 & 68 \\
\hline Arsenic & $2 / 28$ & $2-3$ & 3 & - \\
\hline Barium & $29 / 29$ & $15-64$ & 29 & 9 \\
\hline Beryllium & $1 / 29$ & - & 1 & - \\
\hline Calcium & $29 / 29$ & $18000-45000$ & 23241 & 6828 \\
\hline Chromium & $3 / 29$ & $15-20$ & 17 & 3 \\
\hline Copper & $29 / 29$ & $8-30$ & 14 & 6 \\
\hline Iron & $29 / 29$ & $23-250$ & 92 & 45 \\
\hline Lead & $24 / 28$ & $0.7-5.9$ & 2.4 & 1.2 \\
\hline Magnesium & $29 / 29$ & $4200-10000$ & 5221 & 1409 \\
\hline Manganese & $29 / 29$ & $1.5-9.3$ & 3.0 & 1.7 \\
\hline Mercury & $12 / 26$ & $0.08-0.41$ & 0.15 & 0.09 \\
\hline Nickel & $2 / 29$ & $16-18$ & 17 & - \\
\hline Potassium & $26 / 29$ & $950-3100$ & 1533 & 567 \\
\hline Selenium & $2 / 28$ & $1.1-2.0$ & 1.6 & - \\
\hline Sodium & $29 / 29$ & $3200-95000$ & 9969 & 17937 \\
\hline Thallium & $2 / 28$ & $1.4-2.0$ & 1.7 & - \\
\hline Tin & $7 / 29$ & $26-68$ & 42 & 17 \\
\hline Zinc & $29 / 29$ & $20-84$ & 39 & 14 \\
\hline
\end{tabular}


Table F.61. End-of-Pipe: Metals Detected in Nonbusiness Day Samples

\begin{tabular}{||l|c|c|c|c||}
\hline \multirow{2}{*}{ Constituent } & \multirow{2}{*}{ Frequency $^{(\mathrm{a})}$} & \multicolumn{2}{c|}{ Concentration $(\mu \mathrm{g} / \mathrm{L})$} \\
\cline { 3 - 5 } & & Range & Average & $\begin{array}{c}\text { Standard } \\
\text { Deviation }\end{array}$ \\
\hline Aluminum & $7 / 7$ & $36-150$ & 75 & 38 \\
\hline Arsenic & $1 / 7$ & - & 2 & - \\
\hline Barium & $7 / 7$ & $16-31$ & 26 & 7 \\
\hline Cadmium & $1 / 7$ & - & 3 & - \\
\hline Calcium & $7 / 7$ & $19000-22000$ & 20286 & 1254 \\
\hline Copper & $7 / 7$ & $9-15$ & 11 & 2.1 \\
\hline Iron & $7 / 7$ & $55-90$ & 75 & 12 \\
\hline Lead & $6 / 7$ & $1.3-3.0$ & 2.3 & 0.8 \\
\hline Magnesium & $7 / 7$ & $4300-4800$ & 4543 & 162 \\
\hline Manganese & $6 / 7$ & $1.4-3.5$ & 2.2 & 0.7 \\
\hline Nickel & $1 / 7$ & - & 24 & - \\
\hline Potassium & $7 / 7$ & $940-1700$ & 1304 & 325 \\
\hline Sodium & $7 / 7$ & $3200-4100$ & 3514 & 372 \\
\hline Tin & $1 / 7$ & - & 100 & - \\
\hline Zinc & $7 / 7$ & $18-52$ & 32 & 14 \\
\hline \hline
\end{tabular}

(a) Number of samples with detectable concentrations/total number of samples analyzed. 
Table F.62. End-of-Pipe: Volatile Organic Compounds Detected in Routine Samples

\begin{tabular}{|c|c|c|c|c|}
\hline \multirow[b]{2}{*}{ Constituent } & \multirow[b]{2}{*}{ Frequency ${ }^{(a)}$} & \multicolumn{3}{|c|}{ Concentration $(\mu \mathrm{g} / \mathrm{L})$} \\
\hline & & Range & Average & $\begin{array}{l}\text { Standard } \\
\text { Deviation }\end{array}$ \\
\hline Acetone & $10 / 47$ & $13-63$ & $\overline{33.6}$ & 16.7 \\
\hline Acetonitrile & $1 / 24$ & - & 76.0 & - \\
\hline Bromodichloromethane & $15 / 29$ & $0.9-3.2$ & 2.0 & 0.7 \\
\hline Bromoform & $2 / 29$ & $0.5-0.9$ & 0.7 & - \\
\hline Chloroform & $47 / 47$ & $3.4-20.0$ & 11.2 & 4.1 \\
\hline Dibromochloromethane & $7 / 29$ & $1.0-2.2$ & 1.6 & 0.4 \\
\hline Ethylbenzene & $1 / 29$ & - & 0.2 & - \\
\hline Hexone & $1 / 47$ & - & 10.0 & - \\
\hline Isopropyl alcohol & $1 / 47$ & - & 575.0 & - \\
\hline Methylene chloride & $38 / 47$ & $0.2-1.6$ & 0.9 & $\overline{0.4}$ \\
\hline Tetrachloroethene & $1 / 47$ & - & 2.0 & - \\
\hline Tetrahydrofuran & $2 / 47$ & $7.4-9.4$ & 8.4 & - \\
\hline Toluene & $1 / 47$ & - & 1.4 & - \\
\hline 1,1,1-Trichloroethane & $1 / 47$ & - & 1.4 & - \\
\hline Trichloroethene & $5 / 47$ & $0.3-0.7$ & 0.5 & 0.1 \\
\hline Trichlorofluoromethane & $3 / 24$ & $1.4-4.4$ & 2.4 & 1.7 \\
\hline Xylenes (total) & $5 / 47$ & $0.5-1.6$ & 1.1 & 0.4 \\
\hline
\end{tabular}

(a) Number of samples with detectable concentrations/total number of samples analyzed. 
Table F.63. End-of-Pipe: Volatile Organic Compounds Detected in Nonbusiness Day Samples

\begin{tabular}{||l|c|c|c|c||}
\hline \multirow{2}{*}{ Constituent } & \multirow{2}{*}{ Frequency ${ }^{(\mathrm{a})}$} & \multicolumn{2}{c|}{ Concentration $(\mu \mathrm{g} / \mathrm{L})$} \\
\cline { 3 - 5 } & & Range & Average & $\begin{array}{c}\text { Standard } \\
\text { Deviation }\end{array}$ \\
\hline Acetone & $1 / 13$ & - & 33.0 & - \\
\hline Bromodichloromethane & $3 / 6$ & $1.8-3.3$ & 2.4 & 0.8 \\
\hline Bromoform & $1 / 6$ & - & 1.7 & - \\
\hline Chloroform & $13 / 13$ & $3.1-18.0$ & 9.2 & 4.6 \\
\hline Dibromochloromethane & $2 / 6$ & $1.0-2.7$ & 1.9 & - \\
\hline Hexone & $2 / 13$ & $20.0-33.0$ & 26.5 & - \\
\hline Methylene chloride & $13 / 13$ & $0.3-1.4$ & 0.7 & 0.5 \\
\hline Tetrachloroethene & $1 / 13$ & - & 0.5 & - \\
\hline Trichloroethene & $1 / 7$ & - & 0.8 & - \\
\hline Trichlorofluoromethane & $2 / 6$ & $1.7-4.2$ & 3.0 & 1.8 \\
\hline Xylenes (total) & $1 / 13$ & - & 2.0 & - \\
\hline \hline Ta) Number of samples & & - & -1.0 & - \\
\hline
\end{tabular}

(a) Number of samples with detectable concentrations/total number of samples analyzed. 
Table F.64. End-of-Pipe: Semivolatile Organic Compounds Detected in Routine Samples

\begin{tabular}{|c|c|c|c|c|}
\hline \multirow[b]{2}{*}{ Constituent } & \multirow[b]{2}{*}{ Frequency ${ }^{(\mathbf{a})}$} & \multicolumn{3}{|c|}{ Concentration ( $\mu \mathrm{g} / \mathrm{L})$} \\
\hline & & Range & Average & $\begin{array}{l}\text { Standard } \\
\text { Deviation }\end{array}$ \\
\hline \multicolumn{5}{|c|}{ Acids/Bases/Neutrals (ABNs) } \\
\hline Bis(2-ethylhexyl)phthalate & $11 / 28$ & $2.0-38.0$ & 21.9 & 10.5 \\
\hline Butylbenzylphthalate & $1 / 12$ & - & 7.6 & - \\
\hline Di-n-butylphthalate & $4 / 12$ & $2.6-5.7$ & 3.9 & 1.3 \\
\hline Tributyl phosphate & $1 / 28$ & - & 6.4 & - \\
\hline \multicolumn{5}{|c|}{ Pesticides } \\
\hline $4,4^{\prime}-\mathrm{DDE}$ & $2 / 26$ & $0.004-0.024$ & 0.014 & - \\
\hline Beta-BHC & $1 / 26$ & - & 0.002 & - \\
\hline Delta-BHC & $6 / 26$ & $0.002-0.014$ & 0.006 & 0.005 \\
\hline Endosulfan I & $2 / 26$ & $0.004-0.005$ & 0.005 & - \\
\hline Endosulfan sulfate & $1 / 26$ & - & 0.036 & - \\
\hline Gamma-BHC (Lindane) & $1 / 26$ & - & 0.003 & - \\
\hline Heptachlor & $2 / 26$ & $0.008-0.010$ & 0.009 & - \\
\hline
\end{tabular}

Table F.65. End-of-Pipe: Semivolatile Organic Compounds Detected in Nonbusiness Day Samples

\begin{tabular}{||l|c|c|c|c||}
\hline \multirow{2}{*}{ Constituent } & \multirow{2}{*}{ Frequency ${ }^{\text {(a) }}$} & \multicolumn{3}{c|}{ Concentration $(\mu \mathrm{g} / \mathrm{L}$ ) } \\
\cline { 3 - 5 } & & Range & Average & $\begin{array}{c}\text { Standard } \\
\text { Deviation }\end{array}$ \\
\hline & & Acids/Bases/Neutrals (ABNs) \\
\hline Bis(2-ethylhexyl)phthalate & $3 / 7$ & $16.0-31.0$ & 22.7 & 7.6 \\
\hline Delta-BHC & $1 / 6$ & - & 0.013 & - \\
\hline Heptachlor & $2 / 6$ & $0.008-0.013$ & 0.011 & - \\
\hline \hline
\end{tabular}

(a) Number of samples with detectable concentrations/total number of samples analyzed. 
Table F.66. End-of-Pipe: Radiological Parameters Detected in Routine Samples

\begin{tabular}{||l|c|c|c|c||}
\hline \multirow{2}{*}{\multicolumn{1}{|c|}{ Parameter }} & \multirow{2}{*}{ Frequency $^{(\mathrm{a})}$} & \multicolumn{2}{c|}{ Concentration (pCi/L) } \\
\cline { 3 - 5 } & & Range & Average & 2SEM $^{\text {(b) }}$ \\
\hline Gross alpha & $26 / 27$ & $1.4-9.2$ & 3.3 & 0.8 \\
\hline Gross beta & $16 / 27$ & $2.1-12.5$ & 3.8 & 1.2 \\
\hline Tritium & $1 / 10$ & - & 227.0 & - \\
\hline
\end{tabular}

(a) Number of samples with detectable concentrations/total number of samples analyzed. (b) Two times the standard error of the calculated mean.

Table F.67. End-of-Pipe: Radiological Parameters Detected in Nonbusiness Day Samples

\begin{tabular}{||l|c|c|c|c||}
\hline \multirow{2}{*}{\multicolumn{1}{|c|}{ Parameter }} & \multirow{2}{*}{ Frequency $^{(\mathrm{a})}$} & \multicolumn{2}{c|}{ Concentration (pCi/L) } \\
\cline { 3 - 5 } & & Range & Average & 2SEM \\
\hline Gross alpha & $7 / 7$ & $1.3-4.4$ & 2.4 & 0.9 \\
\hline Gross beta & $3 / 7$ & $2.2-2.7$ & 2.4 & 0.3 \\
\hline Tritium & $1 / 3$ & - & 423.0 & - \\
\hline
\end{tabular}

(a) Number of samples with detectable concentrations/total number of samples analyzed.

(b) Two times the standard error of the calculated mean. 
Appendix G

Glossary 


\section{Appendix G}

\section{Glossary}

alkalinity

alternate influent

bottle blank

building

Chemical Oxygen Demand

composite sample

constituent

daily-trip blank

diverter station a property of water which indicates its capacity to neutralize a strong acid to a designated $\mathrm{pH}$.

water from the city of Richland that has undergone chlorination and filtration. Alternate influent is supplied to the Hanford Site at Building 382B.

a blank sample which is prepared by filling a sample bottle with reagent water and any preservatives used with actual field samples. Bottle blanks are not transported to the field. Bottle blanks are used to assess sample contamination from bottles and sample preservatives.

a structure with a roof and walls on the Hanford Site (also called a facility).

a measure of the oxygen required to oxidize all organic and inorganic compounds in water.

sample collected over time in small increments.

a chemical or radiological component of a mixture or solution (for example, chloroform is a chemical constituent in the treated influent).

a bottle blank which is transported out to the field (unopened at all times). Daily-trip blanks are used to check for contamination from bottles, sample preparation, and handling. Unlike full-trip blanks which may be analyzed for all constituent classes, daily-trip blanks are exclusively prepared and analyzed for volatile organic compounds.

when retention process sewer water leaves a building it goes through a retention process sewer electric valve. This valve diverts the water to the radioactive liquid waste system if the radiation monitor detects radiation.

\section{G. 1}


effluent

end-of-pipe

equipment blank

field-transfer blank

flow-proportional composite sample

grab sample

full-trip blank

laboratory reagent blank
If the water is not radioactive, it is sent to the 307 Basins.

treated or untreated water that flows out of a building, treatment plant, sewer, or industrial outfall. Generally, this refers to wastes that are discharged into surface waters (such as the Columbia River) and are regulated under the Clean Water Act.

a location south of the Treated Effluent Disposal Facility Collection Sump where all of the 300 Area process and retention process sewer streams meet.

a blank sample which consists of preservatives and reagent water which has been passed through and collected by a sampler. Equipment blanks provide a check on sampler cleanliness and potential contamination from sampler components, such as tubing.

a blank sample which is prepared at the sampling site by pouring reagent water into a sample bottle and adding any preservatives used with effluent samples. Field-transfer blanks are used to quantify sample contamination which arises from conditions at the sampling location.

a composite sample in which an increment is collected every time a specified volume of water has flowed past the sampling point (for example, a system might be set to collect $1 \mathrm{~L}$ every time 500 have passed the system).

a sample collected by rapidly filling a sample container with sample solution (i.e., effluent). Unlike composite samples, grab samples represent only a "snapshot" of the waste stream.

a bottle blank which is transported out to the field (unopened at all times). Full-trip blanks are used to check for contamination from bottles, sample preparation, and handling.

a blank sample that consists of reagent water which is carried through an entire analysis procedure, including the addition of any required chemicals. Laboratory reagent blanks provide an indication of contamination during analysis. 
maximum contaminant levels

method detection limit

National Pollutant Discharge Elimination System (NPDES)

nonbusiness day sample

nonregulated constituent

quality control

regulated constituent

relative percent difference

routine sample

semivolatile organic compound the highest permissible amount of a chemical or radiological constituent in water delivered to any user of a public water system. Maximum contaminant levels are enforceable standards.

the minimum concentration of a compound that can be measured and reported with a $99 \%$ probability that the value is above zero.

a provision of the Clean Water Act that prohibits discharge of pollutants into waters within the U.S. unless a special permit is issued by the U.S. Environmental Protection Agency, a state (where delegated), or a tribal government on an Indian reservation.

a sample collected on a weekend (Saturday or Sunday) or a holiday (e.g., Memorial Day).

chemical or radiological compounds which do not have specified concentration limits set by the U.S. Environmental Protection Agency

the planned and systematic actions that provide a way to control and measure the characteristics of equipment and processes to meet established requirements.

chemical or radiological compounds which have specified concentration limits set by the U.S. Environmental Protection Agency.

a measure of how similar two numbers are to each other. The RPD is calculated using

$$
R P D=\frac{\left|x_{1}-x_{2}\right|}{\bar{x}} \times 100
$$

where $x_{1}$ and $x_{2}$ are the numbers being compared, and $\bar{x}$ is their average.

a sample of effluent or influent taken on a regularly scheduled workday (Monday through Friday).

an organic compound with a relatively high boiling point and a low vapor pressure at room temperature. 
standard error of the mean (SEM)

statement of work

time-proportional composite sample

total carbon

total organic carbon

total dissolved solids

treated influent

trihalomethane

untreated influent a measure of the variability of an estimated mean, which is calculated using the formula

$$
\operatorname{SEM}=\sigma / \sqrt{n}
$$

where $n$ is the number of measurements, and $\sigma$ is the standard deviation of the measurements. If the data follows a normal distribution, there is a $95 \%$ probability that the true mean falls within the estimated mean plus or minus two times the standard error of the mean (2SEM).

a work document that provides the technical and quality assurance requirements applicable to a specific work activity.

a composite sample in which an increment is collected at uniformly spaced time intervals (for example, a sampling system might be set to collect $1 \mathrm{~L}$ every 2 hours)

a measure of the total carbon content of water, which arises from both organic and inorganic constituents.

a measure of the organic chemical content of water.

a measure of dissolved and suspended solids in a wastewater sample. Generally, total dissolved solids are determined by drying the sample and weighing the remaining residue.

water taken from the Columbia River at the 312 Intake Pumphouse that has undergone chlorination and filtration at Building 315.

an organic compound similar to methane which contains a carbon atom, a hydrogen atom, and three halogen atoms such as chlorine or bromine. Trihalomethanes are common byproducts of water chlorination.

water taken from the Columbia River at the 312 Intake Pumphouse that has not undergone chlorination and filtration. 
volatile organic compound

waste acceptance criteria an organic compound with a low boiling point and a high vapor pressure at room temperature.

the criteria that the liquid waste stream to the Treated Effluent Disposal Facility (TEDF) must meet to ensure that the TEDF can meet regulatory requirements. 
